\title{
Activating the edge
}

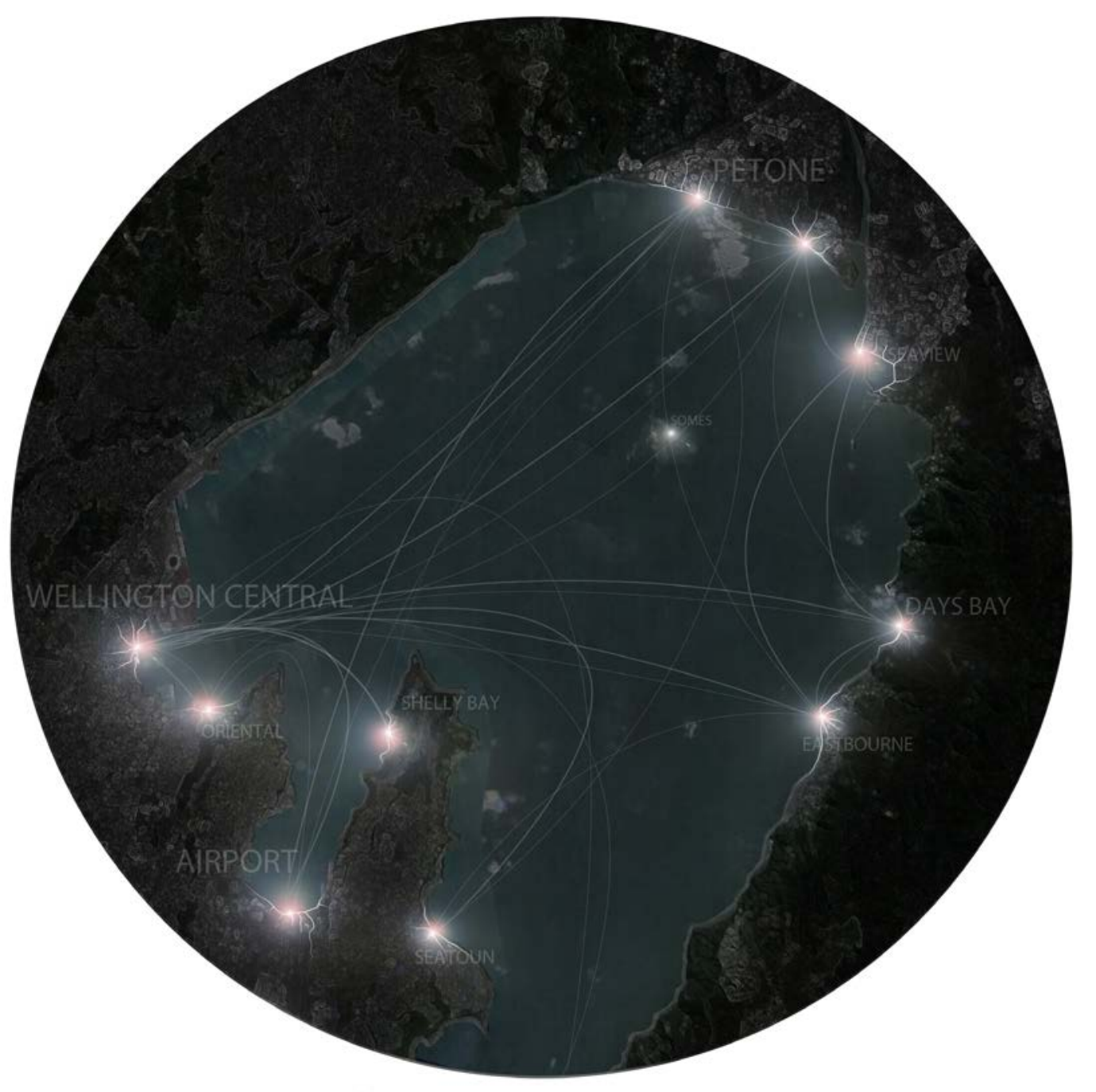

Investigating landscape architectures potential

to utilise transport

infrastructures public life generating ability

By Jordan Kuiti 



\title{
Activating the edge
}

\section{Investigating landscape architectures potential to utilise transport infrastructures public life generating ability}

\author{
By Jordan Kuiti
}

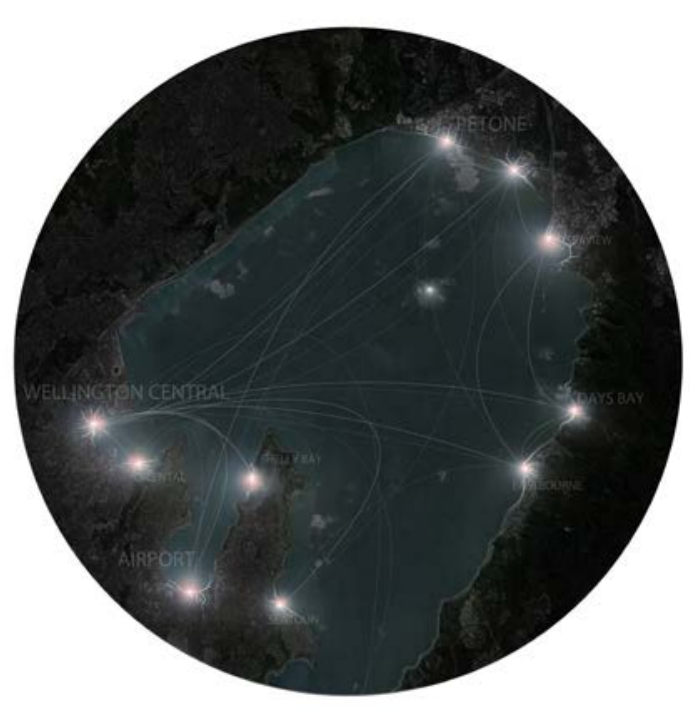

A 120-POINT THESIS SUBMITTED TO THE VICTORIA UNIVERSITY OF WELLINGTON IN PARTIAL FULFILMENT OF THE REQUIREMENTS FOR THE DEGREE OF MASTER OF LANDSCAPE ARCHITECTURE BY JORDAN KUITI 2014.

NO MATERIAL WITHIN THIS THESIS MAY BE USED WITHOUT THE PERMISSION OF THE COPYRIGHT OWNER 



\section{Acknowledgments}

This thesis would not have been possible without the help and support of several individuals. I would like to take a moment to thank the people that have contributed to my work for the last five years of study.

Firstly thank you to my supervisors Penny Allan and Peter Connolly for all the support and guidance over the last twelve months. They have managed to direct my thoughts and push me when I needed encouragement.

Thank you to my classmates in the landscape architecture discipline for going through the last five years with me. Late nights completing projects have been made much more enjoyable with their energy and enthusiasm and I have been pushed by their work to become a better designer.

Finally I would like to say a huge thank you to my family. To my brother Brad, sister Chelsey, aunties, uncles, nana, and granddad, thank you for your support and patience. A special thank you to my parents, Mike and Sue. I will be forever grateful for the love and support they have given me over the years that has helped me to achieve to the best of my ability. Last but not least thank you to my partner Chelsea, who made this journey a lot easier and more enjoyable with her love and support. 


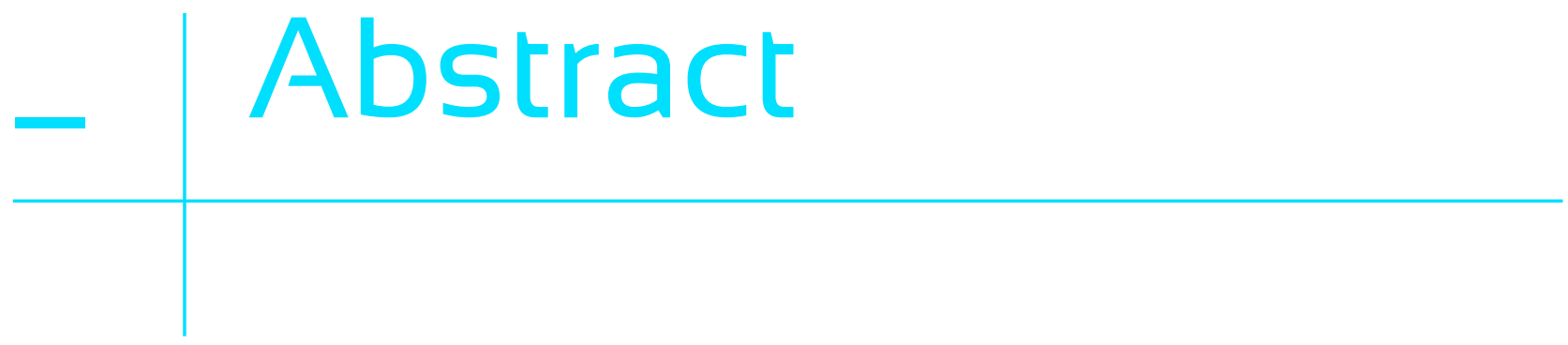


Transport infrastructure is a key aspect of any city. The ability to move large groups of people into and through the city can positively or negatively affect the public life associated with that city. With this in mind transport infrastructure is often designed in a very technical manner, which seeks to move maximum numbers of people around the system as fast as possible for the least amount of money. There seems to be a lack of embrace of other aspects associated with transport infrastructure. These other aspects include public life, place making, enjoyment, and what is the transport adding to the city?

With the population of New Zealand's cities increasing, more money is being allocated to transport infrastructure projects. With a change in approach these projects could work functionally but also offer other benefits, such as public life, new development, enhanced identity, and importantly a more liveable city for the inhabitants. Instead of the functional aspects of transport infrastructure being the only driver, a more holistic approach should be utilised which takes into account the social and public life generating potential. Wellington City has been chosen as a test site as it is an example of a city currently going through transport infrastructure upgrades whilst also struggling with future transport issues. Situated in a unique harbour setting the waterfront is split from the CBD with a traffic heavy six-lane road. The harbour offers a transport resource that is not being utilised. Ferry transport offers a new approach to transport in Wellington that offers greater benefits than just moving people around the system.

This thesis proposes a fresh look at transport infrastructure in Wellington with the development of a ferry network designed to service the entire Wellington Harbour. Through researching the development potentials offered by transport networks this thesis argues that a holistic approach to transport infrastructure can have wider reaching benefits that just moving people around the system efficiently. 


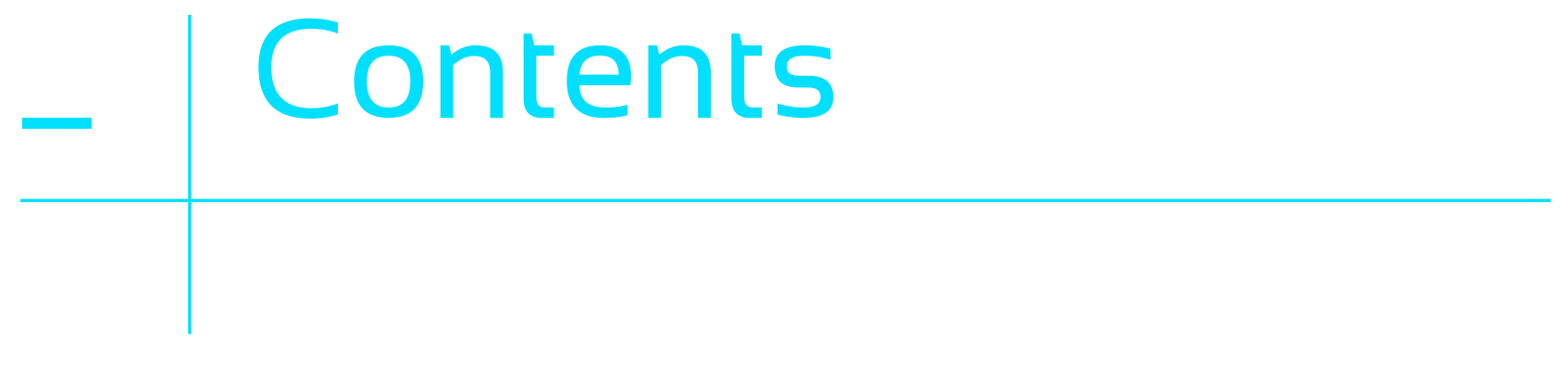

1_ Introduction

1.1_ Theoretical approach 2

1.2_ Research intentions 2

1.3_ Thesis format 4

1.4_ Scope of research 6

2_ Background 7

2.1_ Project inspiration 8

2.2_ Preoccupations 9

2.3_ Transport infrastructure 9

2.4_ Connection to the waterfront 10

2.5_ Site 11

2.6_ Methodology 12

2.7_ Conclusion 14

3_ Positioning Chapter 15

3.1_ Theoretical bases 17

3.2_ Field Work 21

3.3_ Case studies 37

3.4_ Conclusion 49

4_ Site Assessment 51

4.1_ Wellington Regional Analysis 53

4.2_ Wellington Harbour Analysis 57

5_ System Design 65

5.1_ Selected sites 67

5.2_ Ferry logistics 75

5.3_ Implementation 85

5.4_ Typologies 89 
6.1_ Site Analysis 95

6.2_ Design Testing 103

6.3_ Design Detail 109

7_ Airport 121

7.1_ Site Analysis $\quad 123$

7.2_ Design Testing 129

7.3_ Design Detail 143

8_ Oriental Bay 153

8.1_ Site Analysis 155

8.2_ Design Testing 159

8.3_ Design Detail 167

9_ Seaview 177

9.1_ Site Analysis 179

9.2_ Design Testing 185

9.3_ Design Detail 191

10_ Discussion 199

10.1_ Introduction 200

10.2_ What happens on the ground 201

10.3_ Ferry service and associated public life 202

10.4_ Functionality increases Viability 203

10.5_ Harbour relationship 204

10.6_ Further research 204

11_ Conclusion 205

12_ Bibliography 207 
\begin{tabular}{l|l}
-1 & Introduction \\
\hline &
\end{tabular} 
Transport infrastructure moves large numbers of people around cities everyday, yet traditionally has only been designed in a technical manner. With that significant pulse of people there are other, less tangible opportunities that transport infrastructure can offer the city. If a fresh approach to the design of transport infrastructure is utilised, it can be used as a catalyst to create hubs of activity in the city. This potential is increased in the multimodal transport nodes that represent some of the most vibrant and interesting areas in contemporary cities'.

As city populations grow the need for a successful public transport network becomes increasingly important. The discipline tendency is to move maximum numbers of people around the system as fast as possible in the most economical way. With landscape architects having an ever increasing role in the design of transport infrastructure there is an opportunity to change the way that infrastructure is designed. Wellington City Council is currently debating public transport options. Most of the options are based around new roads and other land based systems. Wellington city sits adjacent to a harbour, around the edge of which are other settlements. The topography of Wellington means that the city centre is separated from the rest of the harbours edge by roads and tunnels. In peak hour times these roads become very congested and waiting times are increasing as populations grow. This is restricting the growth of the other centres around Wellington City as people are reluctant to live outside the city when they have to travel in peak hour times for work. This thesis argues that the integration of a ferry system into the public transport network can have a far-reaching effect beyond that of easing transport issues. A ferry network could encourage development on the harbours edge that has the potential to generate diversity and public life to connect the city to its unique context. 


\section{1_ Theoretical approach}

Transport infrastructure provides the framework in which the city operates. The movement of people to, through, and from the city allows the city to function. The public life generating abilities of that infrastructure aren't always utilised, as other things are attributed greater significance. As populations grow the liveability of a city is heavily influenced by transport infrastructure. Through the process of researching for this thesis it was established that the theoretical basis for designing transport infrastructure to generate public life is limited. This led to finding other ways of understanding how and why public life is generated through transport infrastructure. Theory was used as a starting point to see what current approaches to transport infrastructure exist. The theories investigated are urban acupuncture, landscape urbanism, and functional design. These theories lead into fieldwork on current Wellington ferry sites to understand what public life is associated with ferry transport. Case studies were then used to further position within the discipline. This approach is one way of using transport infrastructure to generate public life.

\section{2_ Research intentions}

Public transport infrastructure is a global issue as designers try to allow for movement around cities with an ever-increasing population. This thesis argues that a fresh look at transport infrastructure projects can allow for that functional movement but also provide the city with other, less tangible benefits. The concept is to use the pulse of people from transport infrastructure as a catalyst to create centres of public life.

The design of ferry infrastructure often becomes the design of a piece of architecture that can be attached to the land to allow people to move back and forth. The thesis argues that this approach misses an opportunity to enhance public life in the unique setting of the waterfront. By designing both at the scale of the system and the human scale, this thesis argues that transport infrastructure has the potential to generate public life that will change the identity of the city. It is about more than designing space and designing a functioning system but rather designing a catalyst that will influence how the city is perceived. 


\title{
1.3_ Thesis format
}

\author{
Chapter 2__Background
}

This chapter explains background issues that influenced this project. Design is a personal process that will affect any design project. This chapter allows the reader to understand how and why this project was chosen. Issues surrounding transport infrastructure and waterfront design are introduced here. The test site of Wellington is also introduced with a methodology of how this thesis was approached.

\section{Chapter 3__ Positioning}

The positioning chapter includes theoretical bases, fieldwork, and case studies. The thesis is in response to current discipline tendencies and this chapter explains what they are. Theoretical bases provide a positioning within discipline theory. Fieldwork investigates where the gap in the discipline is and generates a series of design strategies that are related to ferry infrastructure. Case studies are then used to further investigate discipline tendencies through the lens of the fieldwork. Each case study was picked specifically for this research problem; the case studies are as follows:

Caracas cable car - Provides an example of urban acupuncture.

Parramatta Road Concept - Provides an example of landscape urbanism.

Transmission Gully Concept - Provides an example of functional based transport infrastructure.

Brisbane ferry terminal design competition - This design competition shows the positives and negatives of the current discipline tendencies when it comes to the design of ferry terminals.

Circular Quay - This multimodal transport hub combines several forms of transport seamlessly to move people around a city sitting on the harbour edge. The design also shows how the pulse of people from transport infrastructure can generate public life. 


\section{Chapter 4__ Site Assessment}

An analysis at two scales investigates Wellington's suitability as a testing site for the research question. The regional scale analysis investigates Wellington region, where the harbour fits into the region, and how a ferry service would affect the region.

The harbour analysis investigates the edge between Wellington harbour and the surrounding context. This includes the history of the harbour edge and analysis of the surrounding city. The two existing ferry wharves are examined to understand what other areas would be suitable for a wharf.

\section{Chapter 5__System Design}

The system design chapter investigates what functional requirements would be necessary to create a working ferry system. Additional ferry sites are established which allows for waiting times, numbers of ferries, and ferry phasing to be generated. The functional aspects of the design are important as it boosts the viability of the system, which will lead to an increased volume of people utilising the network.

\section{Chapter 6 S_ Site Specific Design}

With the functional requirements of the system understood this chapter begins to answer the research question and push past the current discipline tendency. The transport infrastructure is used as a catalyst to generate and support the design of hubs along the waterfront. They are designed to generate public life and re-establish a connection between the harbour and the people of Wellington. Four test sites have been chosen from the system to experiment with what could be generated from the transport infrastructure. A site from each of the four typologies has been chosen to show what scale of development each typology could sustain.

\section{Chapter 7___ Discussion}

Having completed the research into discipline tendencies when it comes to designing transport infrastructure and undertaken the design process to test the research question, this chapter reveals the findings. What has been learnt? What has been added to the discipline knowledge because of this research? This chapter also reflects on the importance of public life and infrastructure before suggesting how this research could advance beyond the limitations of this document in future. 


\section{4_ Scope of research}

Wellington is the testing ground for this research, yet the process undertaken to use ferry infrastructure to generate public life could be used in other harbour side cities. This research works specifically with ferry infrastructure yet similar conclusions could be reached with other forms of public transport infrastructure. Although designed to be feasible a limitation of this research is that no build costs were generated, meaning that the design is not heavily influenced by economic restraints. 
_2 Background 


\section{1_ Project inspiration}

Having travelled to Sydney I was impressed with the way large populations of people were moved to and from the city each day. The public transport system is extremely effective and one pass allows people to travel on the bus, train, light rail, and ferry. This made moving around the system very easy and enhanced the experience I had in the city. Not only did the public transport run well but it also became part of the culture. Ferries in particular were very impressive as they service the whole harbour edge and become part of the identity of Sydney. Circular Quay becomes a central part of the system where transport meets, creating a constant pulse of people which support retail, business, apartments, and public space. The water becomes another surface for inhabitation and a unique form of public life is generated.

I became interested in how transport infrastructure could be implemented in a way that enhanced the identity of a city. How could that pulse of people using public transport be harnessed to create nodes of public life that affects the city? In harbour side cities in particular ferry transport is a way of inhabiting the harbour to create a public surface for the city. The series of nodes along the edge create a connected network that encompasses the whole harbour. By linking into other forms of transport on the land this network can then spread back into the city from the waterfront to create one continuous public realm. 


\section{2_ Preoccupations}

There are two major preoccupations that can be seen as a common theme running through my previous projects. These preoccupations are waterfront design, and designing through multiple scales. These preoccupations have culminated in this research project. Having grown up in New Zealand I have always felt a pull towards the waterfront as a place to spend time with friends and family. This has influenced this project and the decision to choose ferry transport as the mode of transport to test the research question. Understanding how a project works at multiple scales has also been a reoccurring theme, one that works well with the landscape architecture discipline. The design section of this research shows the design of the ferry system, right down to the design of individual ferry terminals.

\section{3_ Transport infrastructure}

Developed cities almost always have some form of transport infrastructure project in progress. Public transport in particular has the potential to have wide reaching effects on the city. Moving large volumes of people around the city creates a pulse of movement and life that can be utilised in design. This is an influential part of the design of our cities and is a significant part of landscape architecture as a discipline.

One of the issues regarding transport infrastructure is how to balance all of the different variables to generate the best outcome. Often functional and economical drivers become the biggest influence whereas less tangible things such as place making, public life, and experience have less weighting. This thesis explores how a transport infrastructure project could develop and evolve to change the city, whilst also meeting all of the functional and economic requirements. 


\section{4_ Connection to the waterfront}

Historically New Zealand has a close association with the ocean and the waterfront. Maori have used the water as a resource for many hundreds of years. Water has provided safety, food, and transport to New Zealand's ancestors. This is not restricted to Maori though as the first European travellers that arrived on these shores also arrived by sea, finding similar benefits in terms of food and travel. In the modern context the beachside batch is seen as a New Zealand icon and a waterfront within thirty minutes of driving is a commodity that most New Zealanders have access to.

The line between water and land isn't a clear point but rather a moving threshold that provides a transition from water to land. The love of this transitional space has led to waterfronts being an area of conflict when it comes to waterfront development. Waterfronts are typically some of the most valuable land in the city which has led to pressure from developers for large scale developments that allow people to live right on the water's edge. Access to the water and views associated with the waterfront mean that a lot of money is to be made in these areas. When this is coupled with expanding urban centres in New Zealand's waterfront cities then this pressure is intensified.

The movement in the threshold between land and sea is reflected in the boundary and function of the waterfront. It is a place of growth and change, being influenced by the characteristics and needs of the city ${ }^{2}$. Traditionally waterfronts have been set aside for port activity and have been split from the public. In those times port industry provided the bulk of work, money, and trade for the inhabitants of the city. As other sectors grew and the city became less reliant on port activity pressure was generated to claim back the waterfront for the cities inhabitants. The regeneration of the waterfront as a public space allowed people to reconnect to the water. Population growth in central city locations has resulted in new pressure on the waterfront, as there is a need for the city to expand. As port industry was often adjacent to CBD's there is a common trend to develop this high value land to cater for the expanding city. This creates a tension between developers and a large portion of the population that wants to see the waterfront retained as a public amenity.

This tension between large-scale development and recreational space makes it seem as if they are the only two options available to the waterfront. Using transport to bring a pulse of people could please both parties. Nodes of amplified activity where development occurs, in conjunction with transport infrastructure, could allow for the city centre to expand in a way that doesn't affect the recreational nature of the waterfront. This concept of trying to stop change is in conflict with the history of the waterfront and against the good of the city argues Raymond Gastil, "Open-minded societies design waterfronts that accept change, recognizing, in a deeply pragmatic way, that all cities and all societies can be improved and thrive on continuous reinvention in their physical and cultural expression"3. 


\section{5_ Site}

Wellington City is situated in a unique location. The natural harbour setting with hills rising up on either side creates the effect of the city surrounding, protecting, and looking down upon the water. The CBD is so close to the waterside there could be a very strong relationship to the natural setting Wellington finds itself in. The historic layout of transport infrastructure along the waterfront means the city is separated from the waterfront. This doesn't stop large numbers of people flooding the waterfront at lunch times or on the weekend, but with the development of other transport infrastructure projects there is an opportunity to strengthen that connection between city and sea. The city is one area whilst the waterfront is a distinctly different area.

Wellington City has been chosen as the test site because it is dealing with several of the issues this thesis is investigating. The location means that it is close to the water and there are limitations on its connection to the rest of the harbour edge because of its steep topography. The water is currently underutilised as a resource and the waterfront is disconnected from the CBD because of transport infrastructure. The issue of transport also has a lot of publicity at the moment because of proposed transport projects and the discussion of the future of the public transport network. This thesis seeks to use Wellington as a testing ground for these issues to see if transport infrastructure can serve a larger purpose than just moving people around the system.

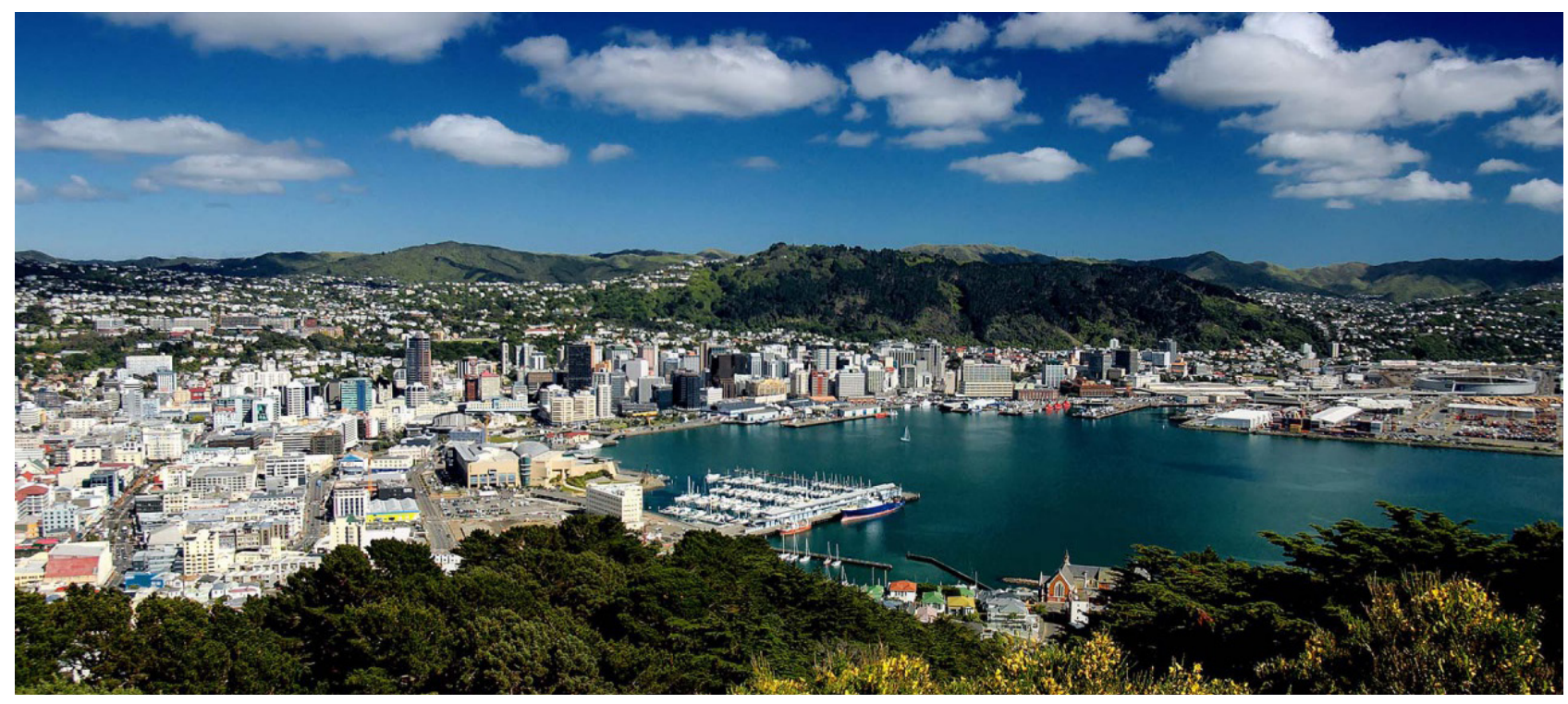

Figure 2.5.1 (Above)__ Image of Wellington Harbour looking towards Wellington City.

Sourced: http://www.newzealandfishinglodges.co.nz/wp-content/uploads/Wellington.jpg 


\section{6_ Methodology}

A research through design approach was implemented for this research project. This seemed the most appropriate way to approach research in a design-based profession. The two processes should not be separate but rather intertwined to generate the best outcome. As the discipline tendency for transport infrastructure is to use a quantitative method, this thesis uses a qualitative approach. The quantitative data has traditionally been used because it is easy to measure numbers of people, travel times, and project costs. The gap in discipline knowledge seems to be in what other less quantifiable things can be produced by changing the approach to designing transport infrastructure. Instead of the transport being the final product, how can it be used as a catalyst to enable other development?

The method followed to generate knowledge for this thesis is unique and specifically relates to the research question. To claim any authority over how transport infrastructure can generate public life through design it was important to understand how this could happen. The ferry service on Wellington Harbour that runs from Wellington Central to Eastbourne provided a case study that showed what could be produced by ferry transport. A period of detailed mapping of public life at these two ferry sites revealed that there is a specific form of public life associated with ferry transport.

Once there was an understanding of ferry associated public life, ten design strategies that would allow for the manipulation of that public life were generated. These strategies allowed for the understanding of public life to be utilised in a design sense. Analysis of the ferry case studies was undertaken through the lens of this fieldwork. This allowed the analysis to focus on how the design of the ferry terminal affects public life.

The ten strategies also influenced the way the design process was undertaken after positioning the thesis in the discipline. Although the four ferry terminal designs vary in detail they are all driven by the analysis of how ferries can generate public life. This helps to drive the design process and push the outcome beyond the design of a single public space.

Developing methods for dealing with complicated issues is a key job for landscape architects. There are large numbers of issues that a landscape architect is confronted with when undertaking a project. These issues are varied and there is more than one way of dealing with them. This thesis proposes one way of dealing with public life associated with ferry transport systems. 
The research problem developed and changed with the project through the process of designing

Fieldwork provided a breakthrough here. The discoveries helped push the design forward.

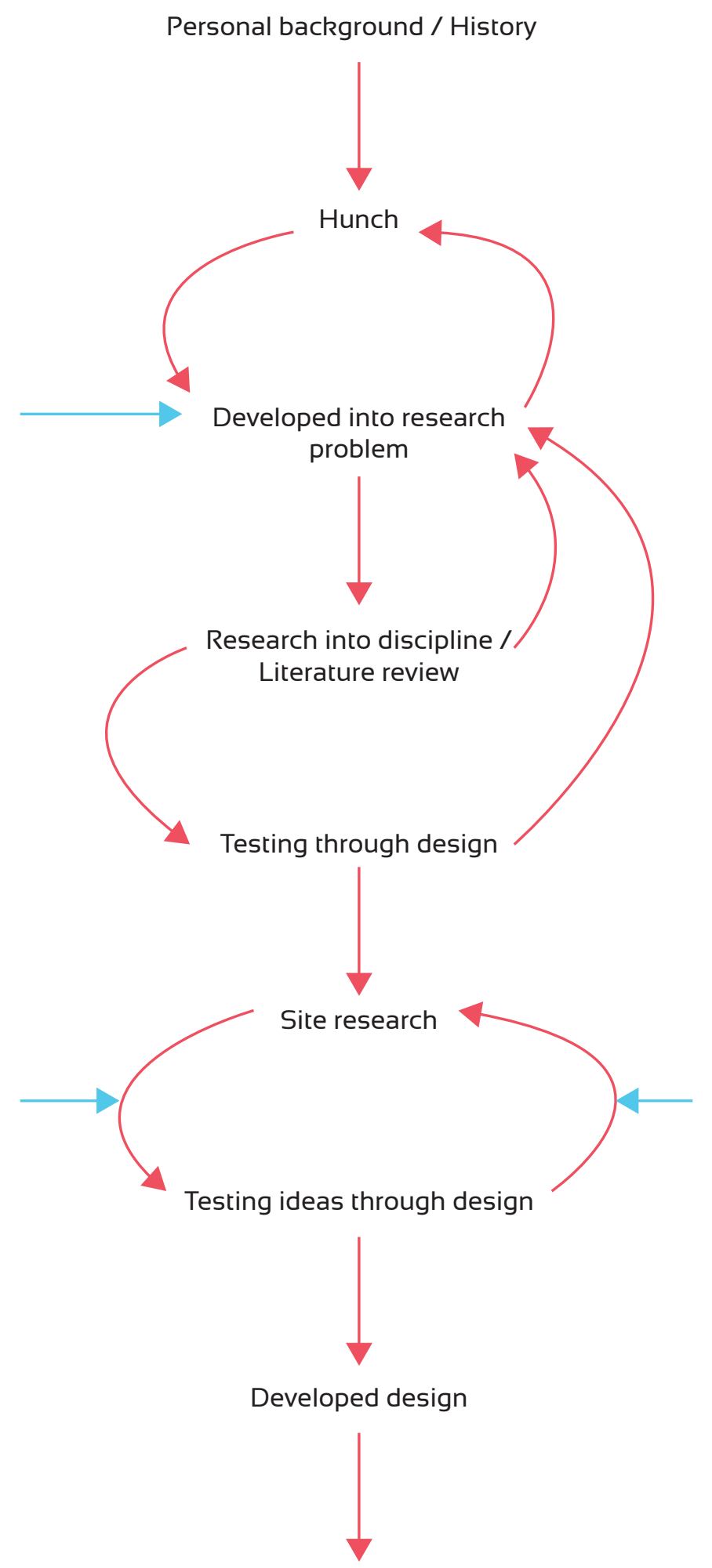

Reflection on the final design, the research process, and the way in which the design met the research problem
Spoke with owner of ferry company which provided an insight into technical issues and helped to gain some authority over the project.

Figure 2.5.2 (Above)_ Diagram of the project method and methodology. It is specific to this design research. (Authors own image). 


\section{7_ Conclusion}

Wellington provides a testing ground to understand how public transport infrastructure can generate public life. The city's location means that it is restricted in terms of growth and also restricted in terms of access to the rest of the harbour edge. A growing population means that roads already working at capacity are getting more congested and there is limited room to expand. The unique harbour setting is split from the CBD and is underutilised for the resources that it could provide to the city. The generation of a ferry network can alleviate all of these issues, so not only does the transport system work better but also public life and identity is generated down on the water's edge. 
_3 $\mid$ Positioning Chapter 
The positioning chapter uses landscape theory, fieldwork, and case studies to develop an understanding of the current discipline tendencies. The theoretical basis section provides an overview of current theories related to the design of transport infrastructure. There seems to be three key approaches to the design of transport infrastructure. These are designing from a purely functional point of view, landscape urbanism, and urban acupuncture.

Once positioned within relevant theory, fieldwork on the current ferry sites in Wellington provides an understanding of public life associated with transport infrastructure. From this fieldwork ten design strategies allow the understanding of public life to have a real physical implication in the design of space.

Case studies are then investigated through the lens of the theory and the design strategies. This further positions the research in the discipline and provides some physical examples of current theory. 


\section{1_ Theoretical bases}

There are three reoccurring approaches to the design of transport infrastructure that form the base of this theoretical review. These approaches are landscape urbanism, urban acupuncture, and taking a functional approach to design. Each approach has positive and negative tendencies that affect the performance of that theory in practice. This thesis argues that the gap in these theories is the fieldwork that allows an in-depth understanding of a particular transport system. This fieldwork allows theoretical approaches to become physical interventions that work on the ground.

\subsection{1_ Landscape Urbanism}

The term 'Landscape Urbanism' typically refers to the significance, and emergence of landscape architecture as a profession in the formulation of cities. Traditionally the different professions have designed transport infrastructure individually with no discussion on objectives and goals for the infrastructure ${ }^{4}$. Landscape urbanism suggests that where architecture has a tendency to be static, landscape architecture is a medium that understands systems, temporal change, and complex relationships that are related to a project $\mathrm{t}^{5}$. This has resulted in landscape architecture having an increasing role in the design of cities.

James Corner, Charles Waldheim, and Mario Schjetnan are just a few renowned landscape theorists that advocate landscape urbanism as the approach to designing cities. James Corner argues that landscape urbanism is the result of several design professions merging together to create a 'hybrid practice' that is better equip to positively affect the city $^{6}$. He suggests that landscape architecture is the profession that is central to the hybrid practice and that is reflected in the name 'landscape urbanism'6. This concept is supported by Charles Waldheim and pushed further when he suggests that landscape urbanism is the lens through which we interpret the city?. This way of viewing the city is a strong concept in landscape urbanism as it allows the designer to view the city as a complex system. "Landscape first existed as a genre of painting, a way of seeing, before it became actively engaged in either designing built environments or recording natural ones" 7 . This theory is based heavily on the approach to designing, where architects, urban designers, and landscape architects work together on a project to generate the best outcome. The splitting up of the disciplines is seen as detrimental to project outcome.

Landscape urbanism is currently one of the leading theories in landscape architecture. Landscape architectures core principles of understanding sites and systems means that it is a good discipline for leading largescale urban projects. The theory talks specifically about how a project is approached; how it is a way of viewing the city, yet how that theory transfers into physical space isn't as clear. This theory proposes fieldwork as the tool that allows theoretical views to become designed spaces. It allows an understanding of what is being produced and how that can be manipulated. This is relevant to this research as the project is about understanding ferry infrastructure and how it can generate public life. 


\subsection{2_ Urban Acupuncture}

Although viewed in western culture as a new way of treating the body, Chinese acupuncture is actually centuries old ${ }^{8}$. The concept argues that the body is a complex system that has an energy force that travels through $\mathrm{it}^{8}$. This energy has the power to influence persons mental, emotional, and physical health ${ }^{8}$. Urban acupuncture transfers these views of the body and relates it to the city in a design sense. The theory suggests that the city is also a complex system that is influenced by dynamic forces, and that with precise interventions there can be a large effect on the city. It is about more than just a single project and more about inserting a catalyst that will change and affect the city in a significant way. Urban acupuncture is a way of approaching urban renewal "which uses the smallest effort in the critical point to get maximum results"'.

Mario Casagrande explains urban acupuncture as being "characterised by punctual interventions through the official surface of the city which aim to establish contact between the urban collective conscious and the life providing systems of nature, including human nature "IO . The two key concepts of urban acupuncture are characterised in this statement. The first is that urban acupuncture is a way of looking at the city. It is about understanding the flows of energy that exist in the city and realising that by altering part of the system there can be a change to the system as a whole. The second concept is that these interventions are designed as 'punctual interventions' that will change when they interact with the system. The projects associated with urban acupuncture are not designed as a static project but rather an intervention that can evolve and grow to meet the needs of the city.

Urban Think Tank is one design studio producing physical examples of how this theory can be realised on the ground. Their Caracas Metro Cable project is often held up as one of the best examples of urban acupuncture. The project shows how this theory can be applied to the design of transport infrastructure to change people's lives. As explained by two architects from the studio "We may not be able to stop drug usage and violent crimes, but we can offer alternative activities, such as football leagues organized in an environment where the concepts of fair play and tolerance are communicated"II. This studio isn't viewing the design of infrastructure as a single design intervention but rather something that will act as a catalyst and have a profound effect on the city. The urban acupuncture approach typically places the infrastructure and through the interaction with the local community the design grows and changes. This thesis argues that an understanding of how a particular infrastructure generates public life allows the design of that infrastructure to be strengthened. This way the public life affects the infrastructure and the infrastructure affects the public life. 


\subsection{3_ Functional Design}

The traditional method for the design of transport infrastructure is the functional approach. Although not a theory as such it is an approach to designing that is currently being used in the transport industry. This approach looks at the design of infrastructure from a functional point of view. The question this way of designing is trying to solve is how can large numbers of people be moved around the system quickly and efficiently? The approach is often used in the design of large transport systems, highways, and roads of significance.

This approach to designing is very transport engineer orientated. The projects seem to be analysed on the numbers associated with out-puts and travel times. There seems to be little importance given to other aspects of design, as functionality is the main concern. This quantitive way of designing has been used because it provides measureable outcomes that can justify the project. This is relevant in the study area of Wellington as there are several transport projects currently under analysis. The Basin Flyover project is coming under a lot of scrutiny, as there are legitimate concerns over the quality of space that the flyover will create. These concerns include dark unsafe areas created by the flyover and also impact on the iconic Basin Reserve cricket ground. As the flyover works in terms of cutting down congestion at peak times it is highly likely it will go ahead, despite the concerns over the qualitive side of the project. This is because quantitive results are much easier to prove than qualitive results, especially in the analysis stage before the project is completed.

The public does seem to be becoming more aware of transport concerns when it comes to environment deterioration ${ }^{12}$. Bryan Richards argues in 'Transport in Cities' that there are more systems and techniques now with the potential to alleviate transport issues as ever before and that "All that is lacking in many cities is the courage to try them out ${ }^{\prime \prime \prime}$. He goes on to say that "as far as road-building is concerned, more consideration must be given to finding how the community will benefit"13.

This thesis argues that whilst functionality and efficiency is important, it shouldn't be the only driving factor in a transport infrastructure project. It is true that functionality in a transport system means that the system runs on time, with minimum waiting times and delays. This can encourage people to use this form of transport. The issue is when this becomes the only concern. When this quantitive approach is of equal importance as other less tangible aspects of the project the design outcome can really enhance the quality of the city. 


\subsection{4_ Conclusion}

There is an increasing population of people living in urban areas that has led to transport infrastructure becoming an important aspect to the design of cities. As populations continue to grow this issue will become even more significant. Landscape urbanism, urban acupuncture, and purely functional are all ways of approaching the design of transport infrastructure. All of these theories are related, yet have different core principles that affect the design outcome. They provide an overview of the current discipline tendencies when it comes to the design of transport infrastructure. The gap in the theory is how this actually translates into physical space. Transport infrastructure is a complex issue and the way in which public life can be generated is even more complex. One way in which this can be understood is through in-depth fieldwork. Fieldwork allows for an understanding of how things work on the ground. It shows what and how things are being produced. 


\section{2_ Field Work}

There are four ferry sites currently in Wellington. Two of these are regular stops, with the other two just occasional stops. This section is a study of these sites to understand what is being produced by ferry transport in its current state. This thesis argues that understanding how ferry transport generates public life allows for that public life to be manipulated in a design sense. This fieldwork analyses each of the two sites to understand what the ferry is producing. Mapping and tracing areas of activity and interest do this. Once there is an understanding of things being produced by the infrastructure we can begin to understand how this can be manipulated to intensify the public life.

\subsection{1_ Introduction to sites}

There are four ferry terminals operating in Wellington. These are Wellington Central, Matiu Somes Island, Eastbourne, and Seatoun. Of these four sites the most frequent journey is between Wellington Central and Eastbourne. Matiu Somes doesn't service a large population and is more there as a tourist route whilst Seatoun is stopped at once in peak hour time on the route between Wellington Central and Eastbourne.

The design and location of the terminals mean that they are integrated into the urban fabric to varying degrees. Eastbourne's topography means that the ferry wharf has become an integral part of 'Eastbourne life'. It provides quick travel into the city centre and acts as a marker for the residents of Eastbourne. People that don't use the ferry for transport are aware of where the terminal is and often gather at the wharf and beach during summer time. Wellington Centrals terminal isn't as iconic as Eastbourne's which is due partly to the design of the terminal. A platform is attached to the side of the waterfront in Wellington and that is the extent of the design. The two varying degrees of design can show how different physical interventions generate different forms of public life.

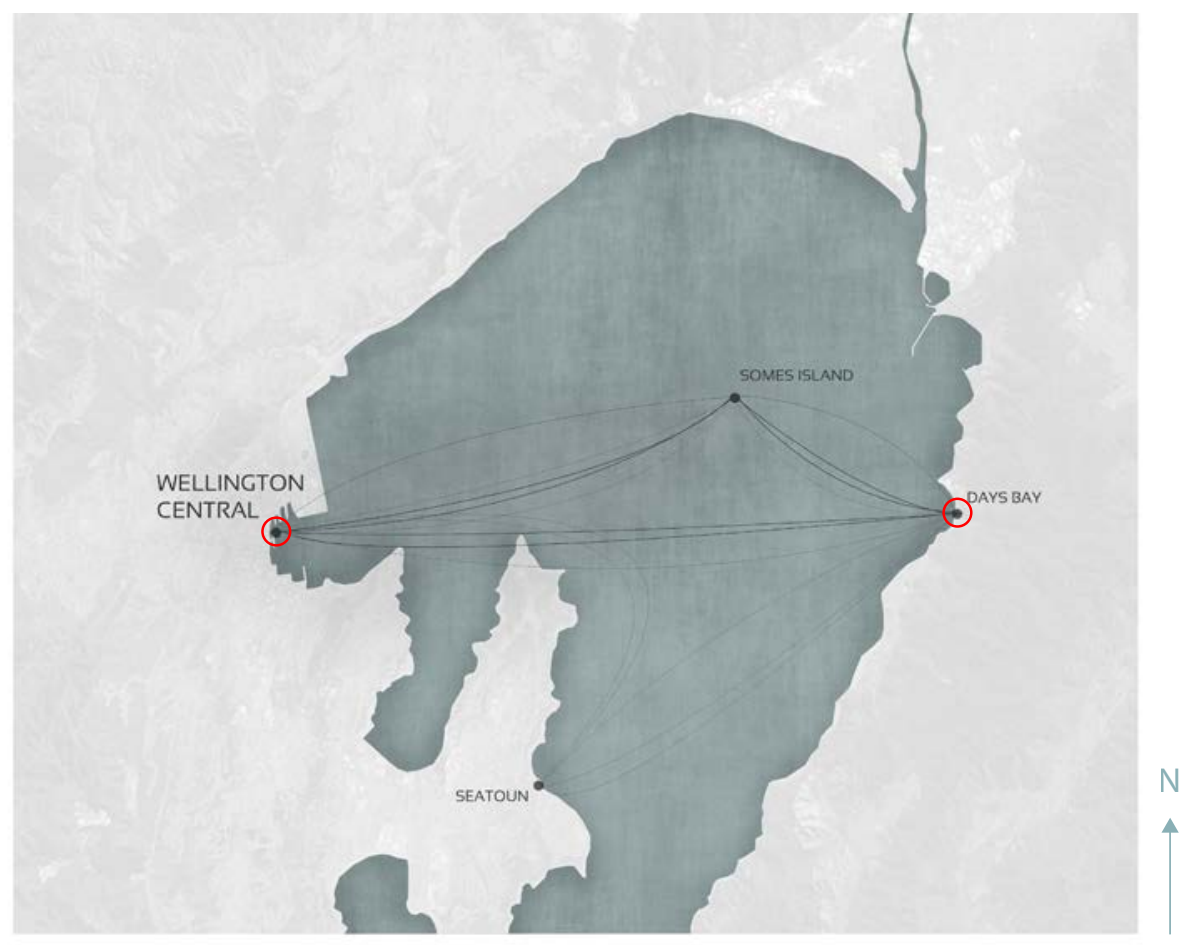

Figure 3.2.1 (Left)_ Existing ferry network in Wellington, showing the two selected fieldwork areas. (Authors own image) 


\subsection{3_ Eastbourne terminal}

The ferry terminal in Eastbourne affects the public life at two different scales. At a large scale it has become part of what it means to live in Eastbourne. The steep topography, distance to Wellington, and Eastbourne's connection to the water influence this. At a more intimate scale the ferry infrastructure influences the public life directly around the landing point.

Eastbourne consists of a thin area of flat land that then rises up into the steep hillside. The steep terrain means that Eastbourne looks down upon the water, which allows the area to see the ferry coming from a distance. This allows people to see when the transport is coming and rush down to catch it as it arrives.

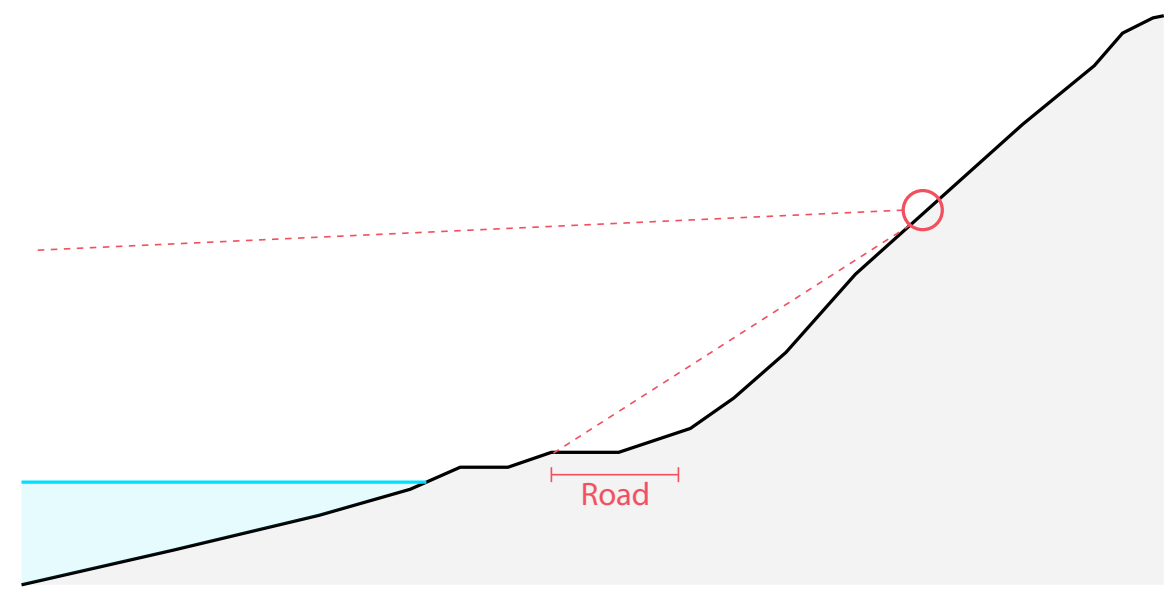

Figure 3.2.2 (Above)_ Section through hill showing topography and views down to the

Figure 3.2.3 (Right) Diagram of route between Eastbourne and Wellington Central. (Authors own image).

\section{water. (Authors own image).}

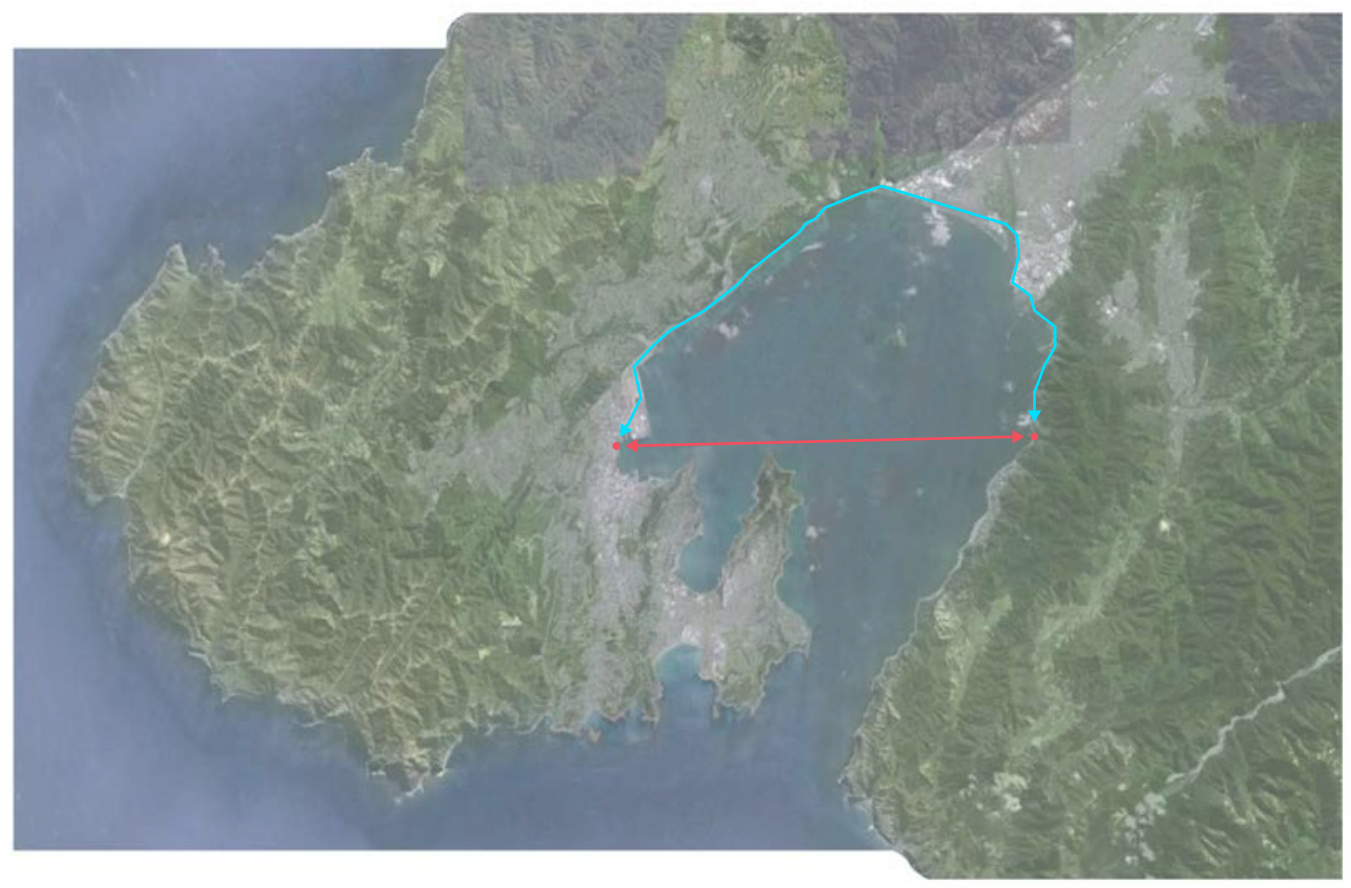

The distance to Wellington means that it is quicker to catch the ferry to Wellington at peak hour times. Eastbourne is viewed as a harbour side village. The ferry wharf is like a gateway into the city centre and has become closely associated with Eastbourne as a place. 
The ferry terminal provides an entrance into Eastbourne. Anyone travelling to Eastbourne has to go past the terminal and beach, which leads to it becoming part of what Eastbourne is known for. The ferry can be seen coming in to pick people up and activates the end of the wharf.

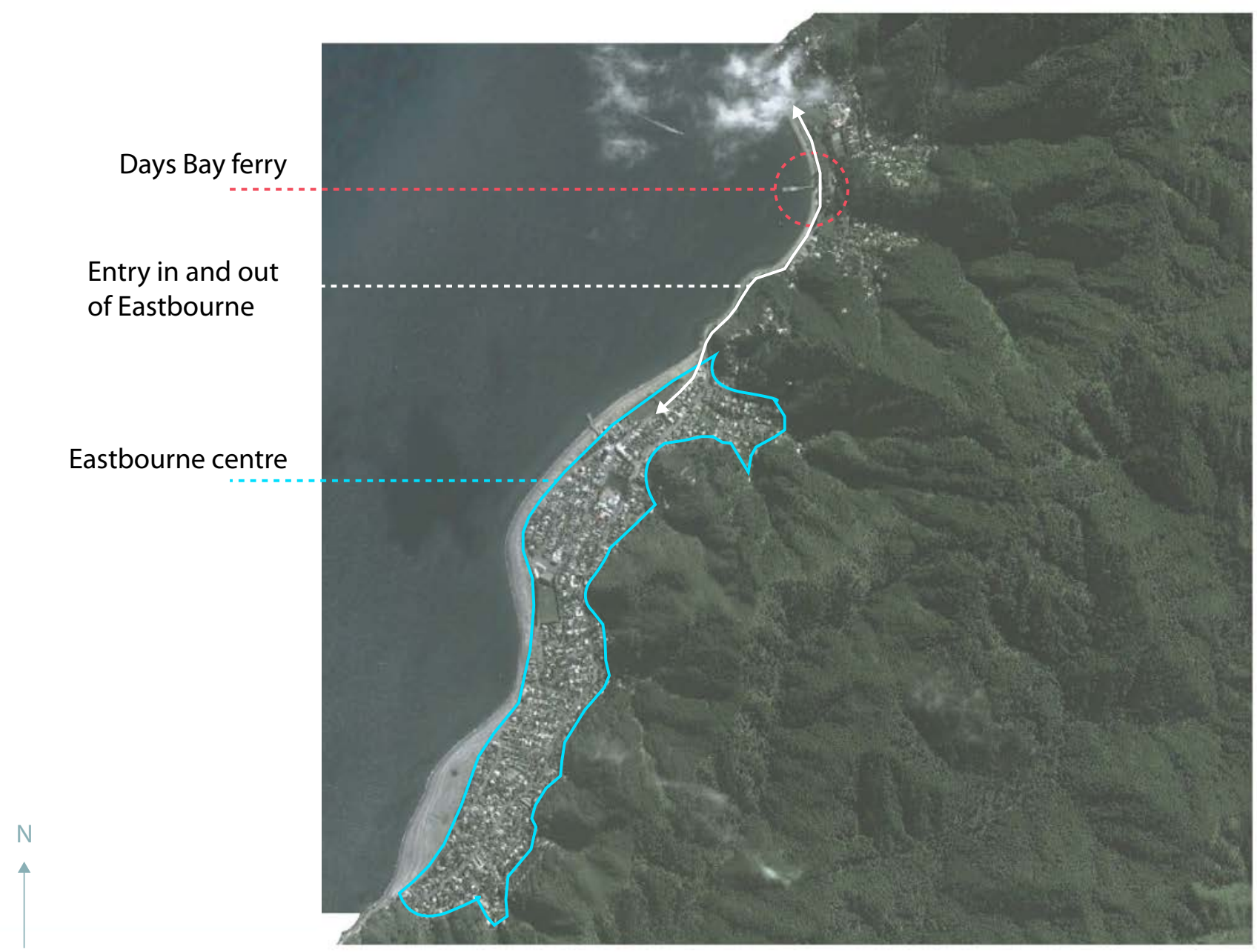

Figure 3.2.4 (Above)_ Mapping the location of the terminal in relation to the transport routes and Eastbourne centre. (Authors own image).

At a more intimate scale the wharf has an influence on the public life associated with the area directly around it. Spending time at the site and studying how people acted in the space generated these maps. 
The way the design is laid out creates a series of spaces and thresholds that people using the ferry service move through. There is also a series of associated spaces that support the ferry terminal in terms of allowing people to spend time in the site.

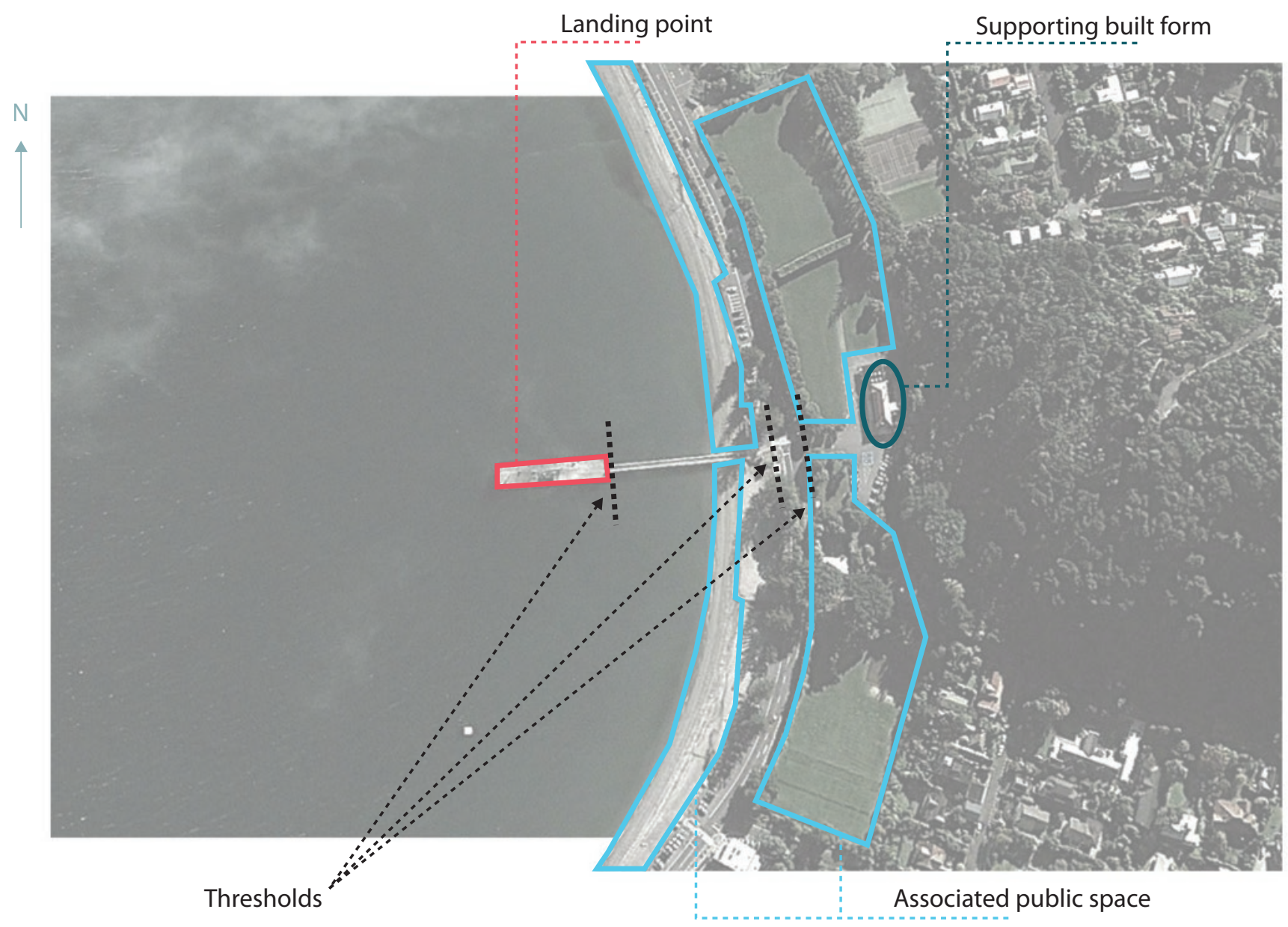

Figure 3.2.5 (Above)_ Mapping of the thresholds and spaces associated with the ferry. (Authors own image). 


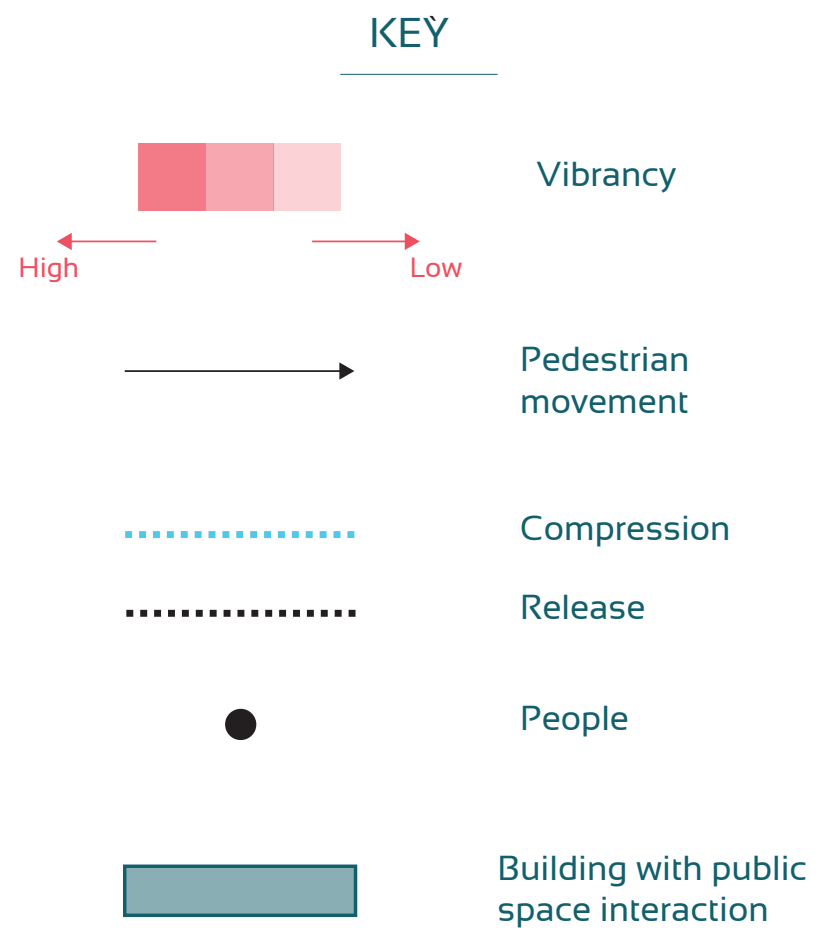

Figure 3.2.6 (Above)_ Map

The areas of most activity tend to be around the ferry wharf and the axis between the wharf and the restaurant. The beach is very uniform all the way along so this area of activity seems to be influenced by the wharf placement. The public space associated with the beach allows for more people to spend time by the infrastructure.

The built form is important for activating the site and allowing the site to become a destination as well as part of the journey. 


\subsection{3_ Wellington City Terminal}

Wellington City's terminal doesn't influence the space around it the same way as in Eastbourne. The ferry terminal is located along the waterfront a short five-minute walk to the CBD. The public space around the terminal isn't associated with the transport infrastructure. This results in the feeling that if the ferry wharf were taken away, the space would still operate relatively the same. The design of the ferry infrastructure is much different than that at Eastbourne.

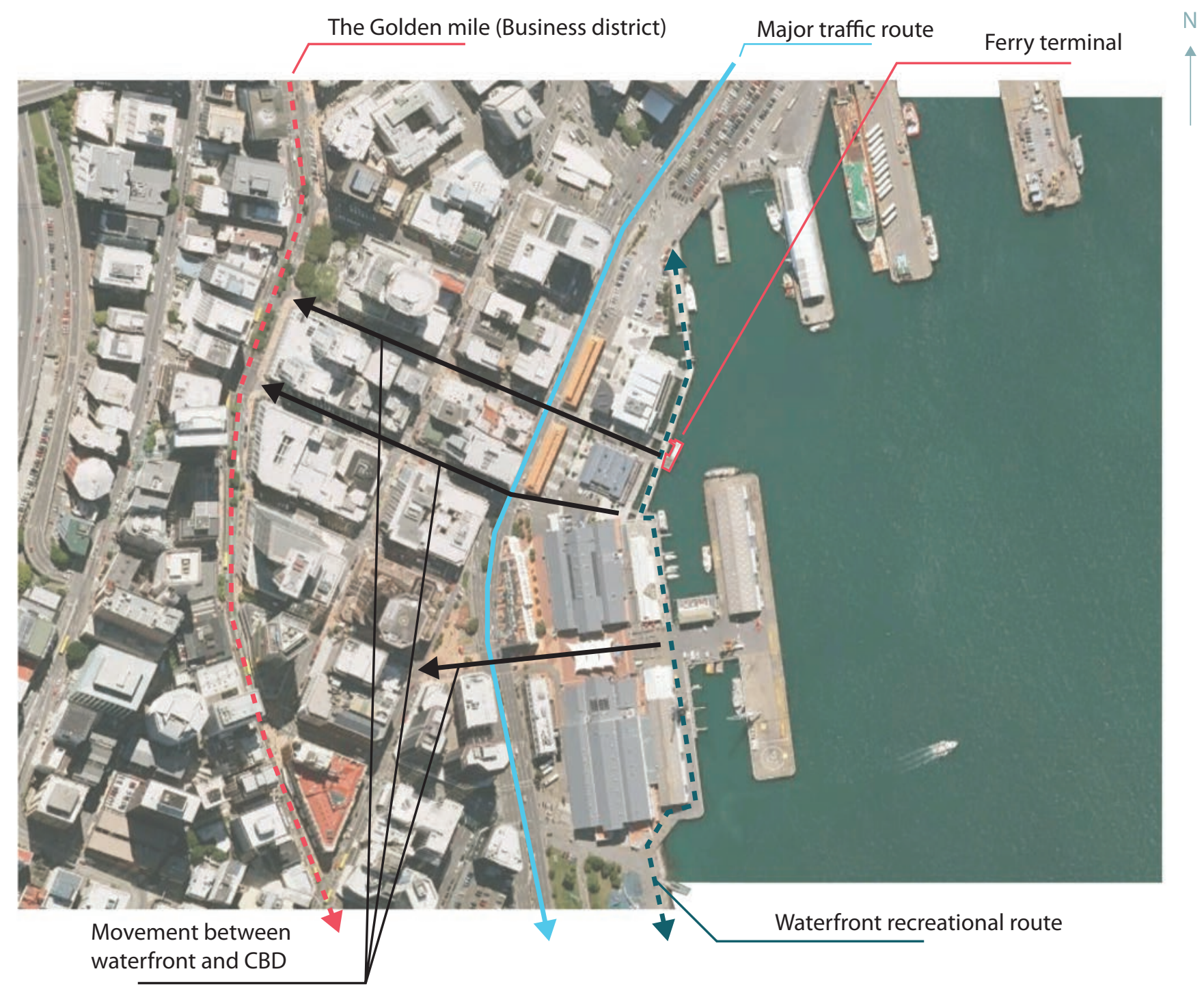

Figure 3.2.7 (Above)_ Mapping how the current ferry terminal links in with other major movement routes through Wellington. (Authors own image).

The ferry site is a short distance away from the CBD and Lambton Quay. The movement through here could be quick and easy allowing people safe travel to work; yet Jervois Quay creates a barrier that restricts movement.

The ferry links into the pedestrian movement along the waterfront well and could collect people moving through to the train station to go out to Hutt City. 
There is public space in the area, yet most of it relates to the built form. The seating that is provided right on the waterfront is to the north away from where the ferry stops. The ferry is on the side of a pedestrian heavy movement channel with minimal resting space. There is the opportunity to create a real event of the ferry here but it the design of the space doesn't do this.

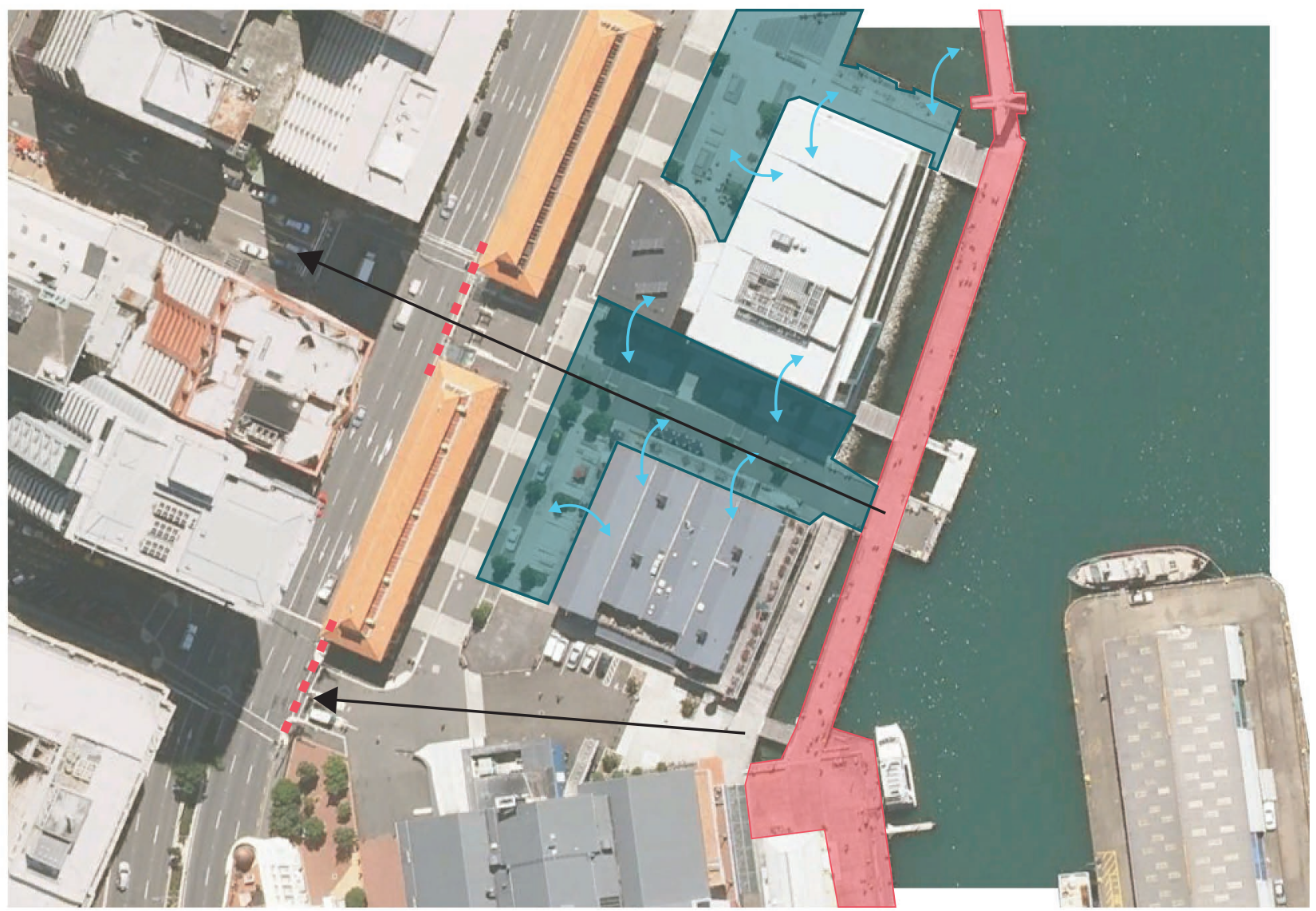

Figure 3.2.8 (Above)_ Investigation of current public space associated with the ferry terminal. (Authors own image).

Public space

Movement channel

Public space relationship

Links into the CBD

Barriers to pedestrian

movement 


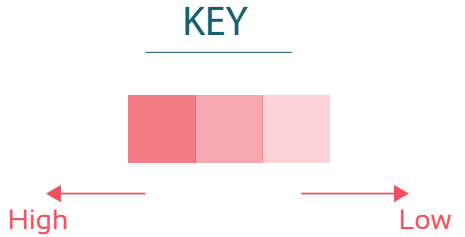

Vibrancy

People

Pedestrian movement

As this site is located close to the CBD there is the potential for it to become a real hub of vibrancy as people take a break from work. There is currently some vibrancy here as people come down at lunchtimes and in the evening to spend time on the waterfront. The activity tends to happen at level changes, where people can sit or lean. This could be used to create a spectacle of the ferry coming in and out, yet because of the terminal configuration the ferry is just tacked onto the side of this activity.

There is a large amount of public space connecting the ferry through to Lambton Quay, yet lack of public seating means that people don't spend much time here. The seats that are provided tend to be associated with the built form, which means the seating relates to that more than the ferry.

You get the sense here that if the ferry were removed the space would function in the same way. This is different to the Days Bay where the ferry is an integral part of the public life.

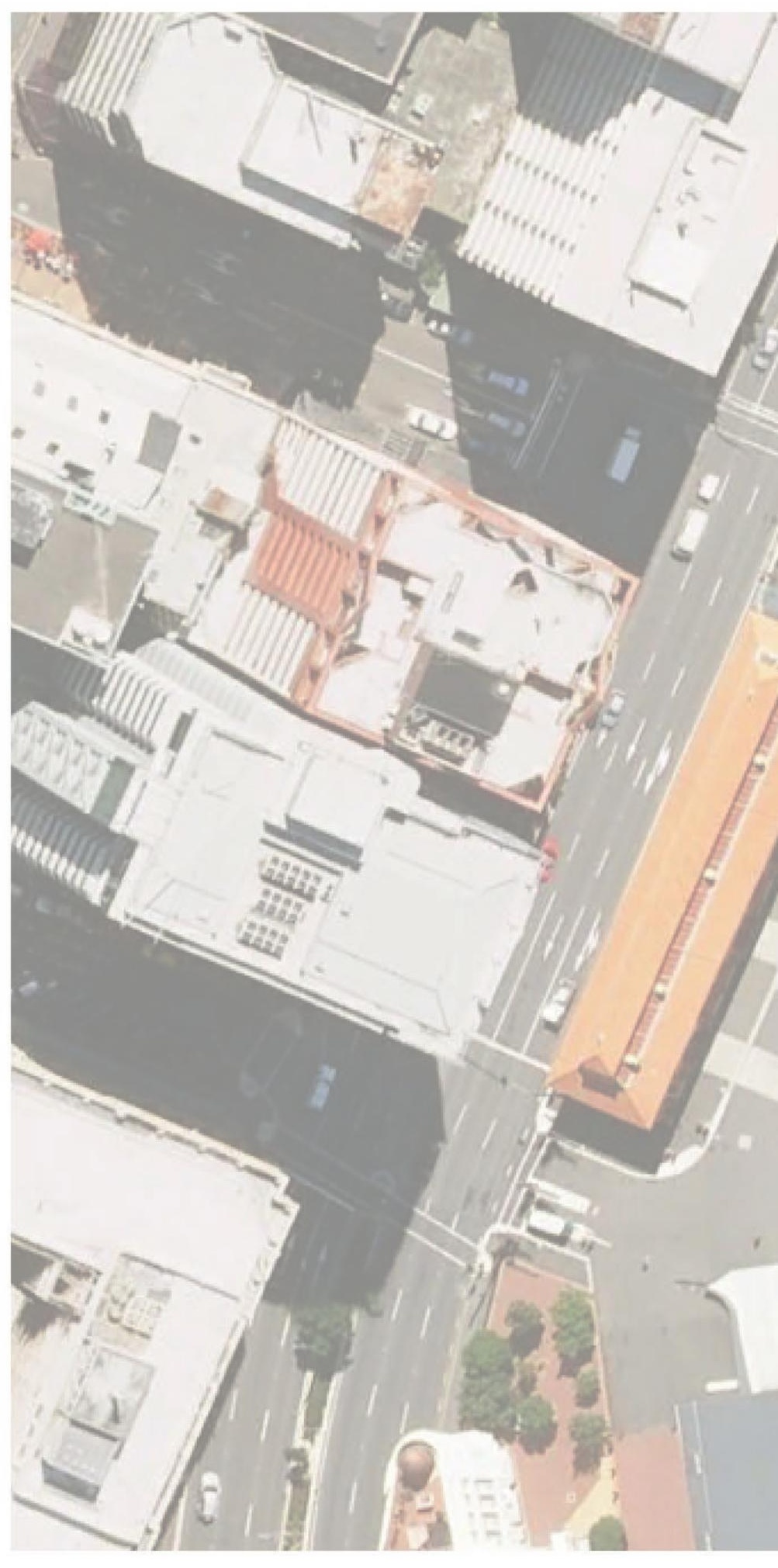

Figure 3.2.9 (Abo 


\subsection{4_ Design Strategies}

The fieldwork at the two existing ferry sites shows that transport infrastructure associated with ferry transport does affect the public life around it. Through developing and analysing the field work ten design strategies have been established which allow for the design of space that is specifically related to the ferry service. These strategies relate to the event of using the ferry and its public life affects. From spending time at the site and recording what happened, these were the things that seemed to be affecting the public space. They are the design tools derived from seeing things happen at existing ferry sites.

\section{Anticipation - manipulation of the arrival event}

There is a transformative moment as people move from the ferry onto the land. Pulling, pushing, stretching and compressing the arrival event can manipulate this moment. By adding moments along this path the designer can make people pause and stop.
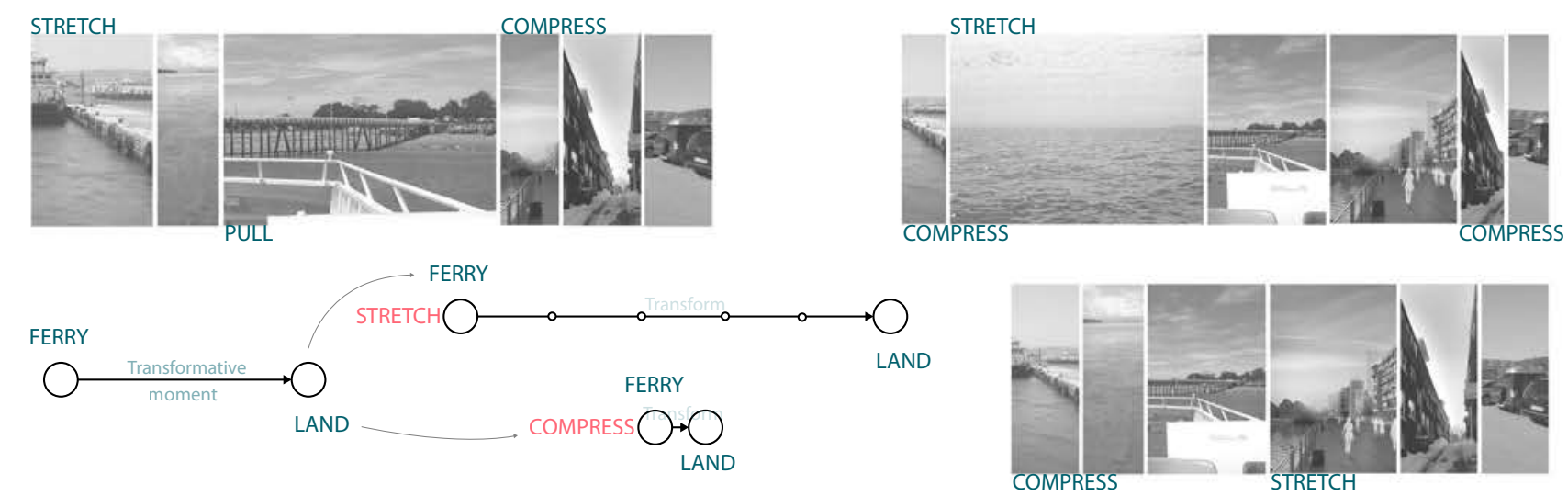

\section{Discovery - unfolding visual structure}

By hiding some areas of the design and revealing others there is a sense of discovery in the journey. This is related to the way the landform emerges on the horizon line, and as the passenger nears the destination more detail is revealed. For some ferry stops hiding areas of the design heightens the experience. In others the whole visual structure should be revealed at once to create a sense of movement and energy.

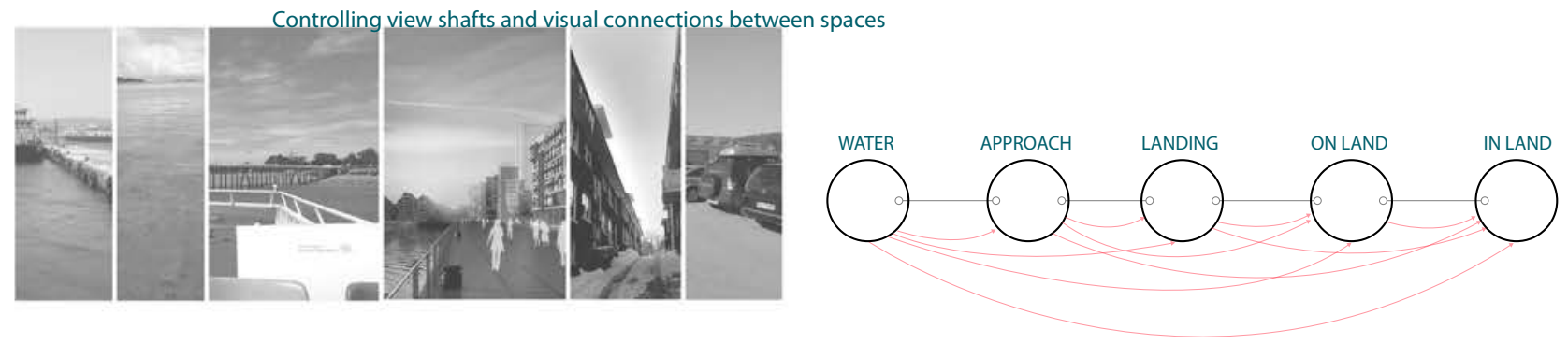




\section{Connectivity - plug into existing transport network}

The ferry terminal needs to relate to other forms of transport in order to encourage the use of the ferry and associated public space. This includes both car parking for personal cars and the existing public transport network.
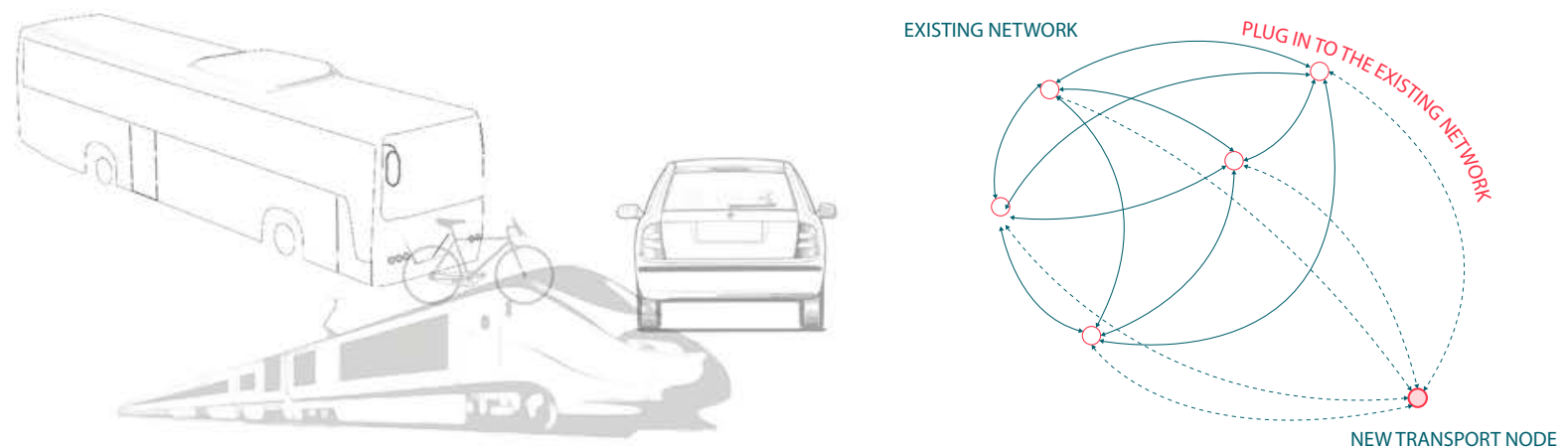

Viability - increase population to boost ferry viability and other opportunities

An increase in residential development around a ferry site increases the viability of the ferry service. This population rise also increases the opportunities for other development including retail and entertainment.

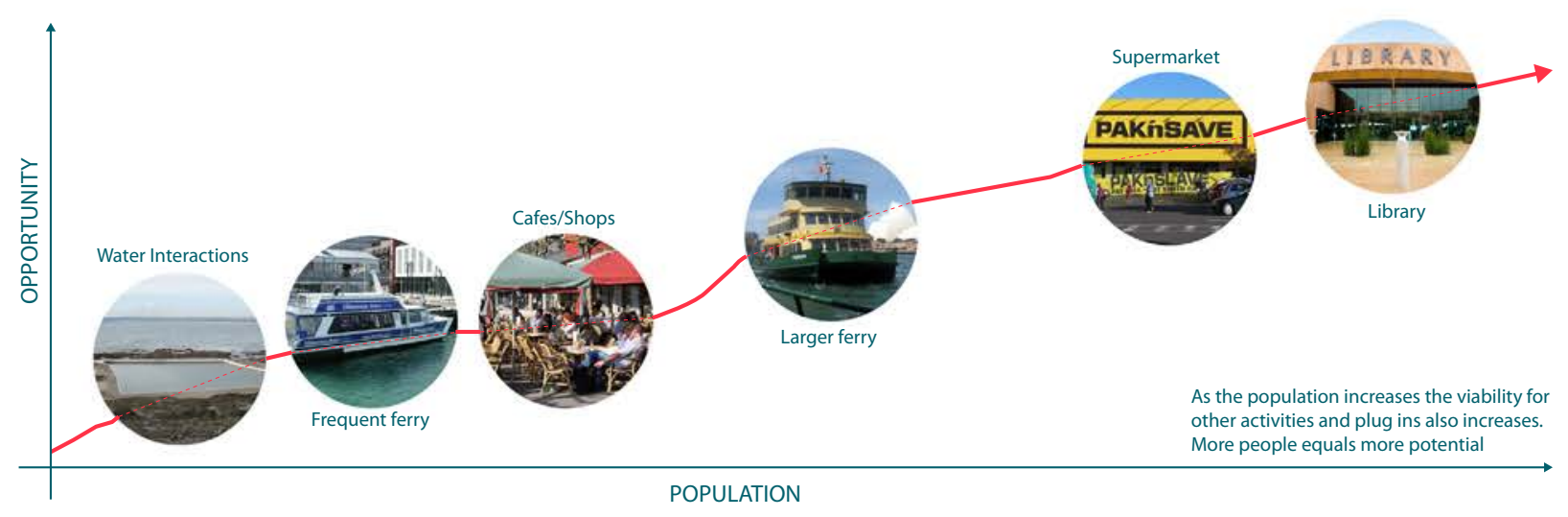


Flow redirection - rearranging relationships to focus on the waterfront

New development of residential, retail, and public space should focus on enhancing the waterfront. This has the power to create hubs of social activity and public life on the waterfront to strengthen the cities connection to the edge.
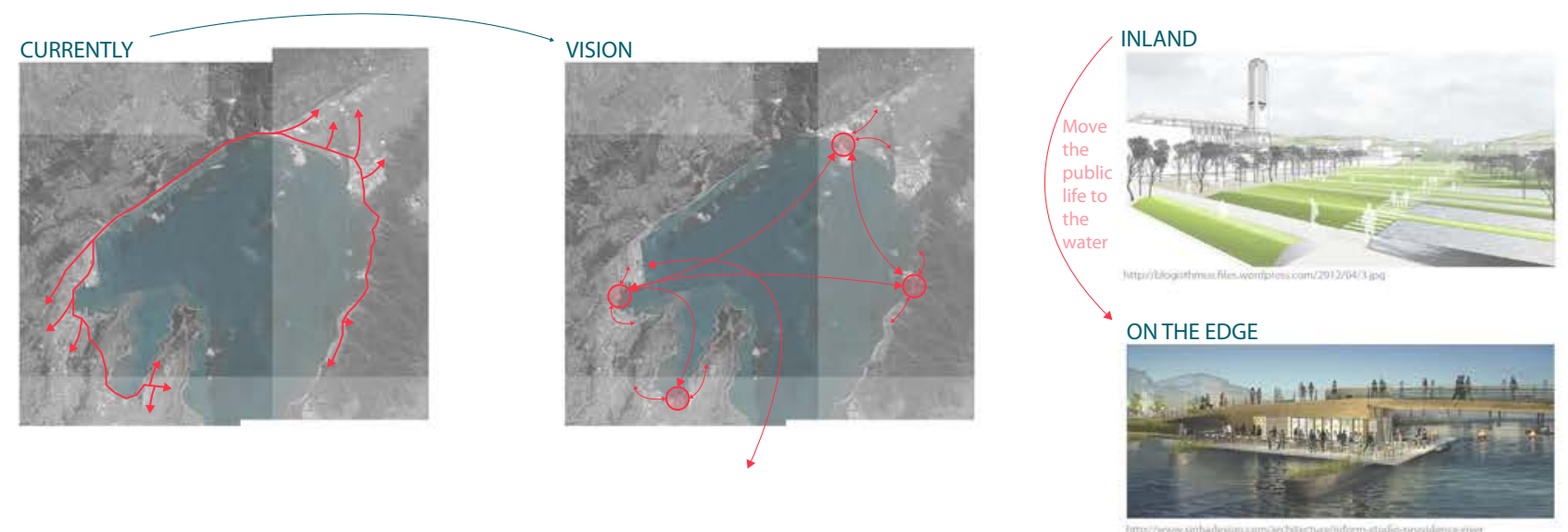

Immersion - level change to enhance connection to site and water

The inter tidal zone is a constantly moving area. The design of the surrounding public space should reflect this. Level change can create connection with the water at a large scale or in an intimate moment.

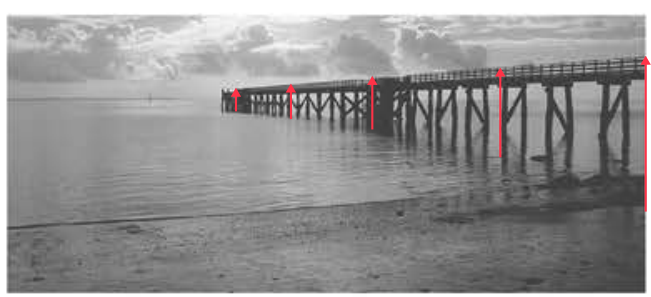

TOPOGRAPHY

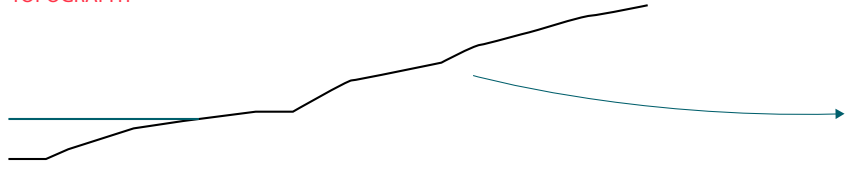

A strong moment is created when the land

drops down to the water

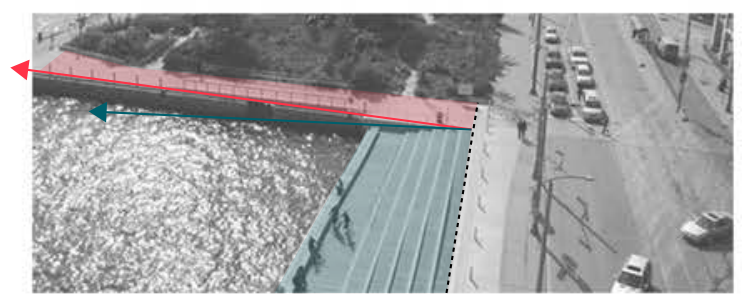

Raise up

Create stage effect
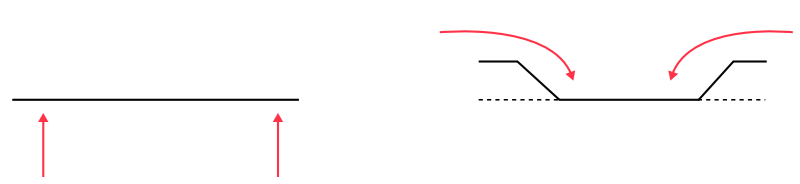


\section{Compression - manipulation of movement channels}

The compression of movement channels has the potential to make pauses and create moments along the journey. As people jump off the ferry there is a compression that is then released as they move onto the land. A designer can manipulate where people stop and pause by using this strategy.
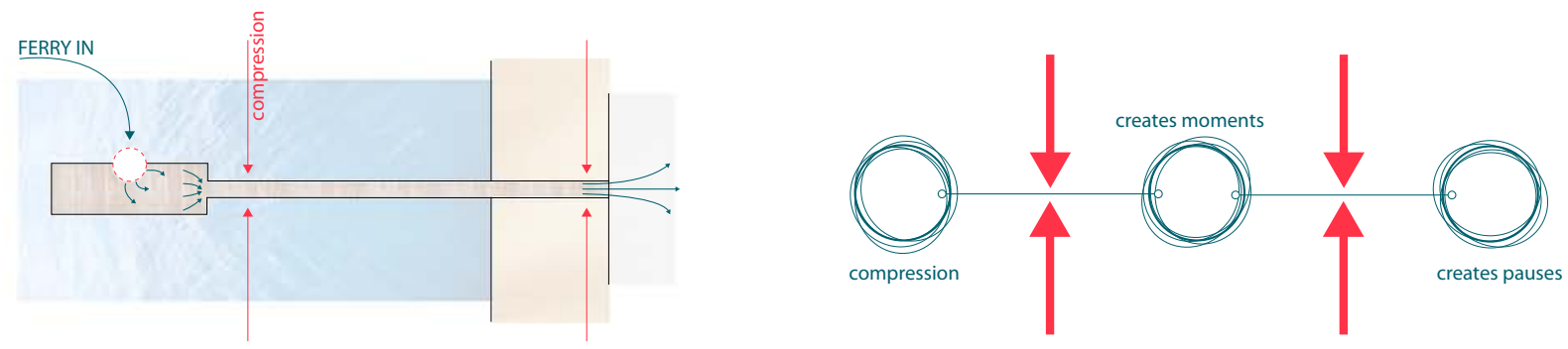

Flow over - hierarchy of interaction with associated public space

The terminal itself shouldn't be the only space related to the ferry infrastructure. Associated public spaces allow people to spend time in the area. This public space can take the form of green space, boardwalks, beaches, or hardscape. The design of these spaces should encourage interaction with the water and ferry.

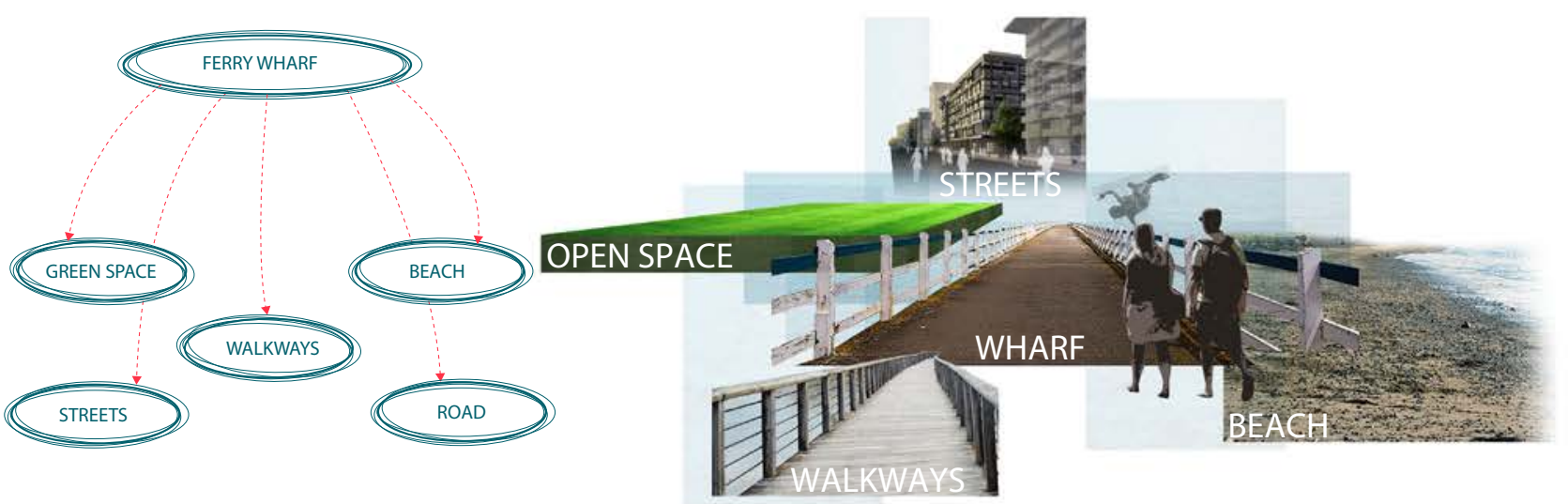




\section{Waiting - manipulation of departure event}

The event of waiting for the ferry can be manipulated to affect the users experience of the infrastructure. A sense of community is often created with the ferry service, as people arrive together in the morning and travel home together at night. Manipulating the departure point can affect this. Pushing people out to the end of a jetty can enhance the feeling of isolation or community. Bringing the ferry terminal in close to land can remove that feeling of isolation.
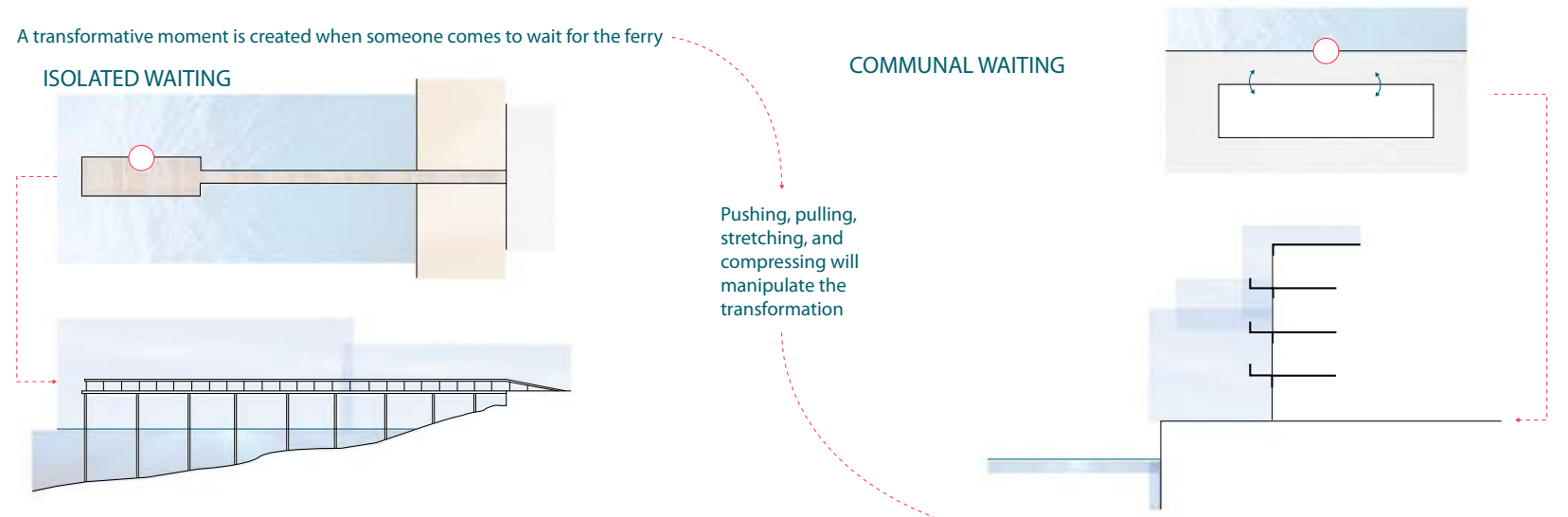

It has the potential to create community

Plug ins - plug ins with public space interaction

The ferry infrastructure offers the opportunity for other functions to plug into the site to activate the public space. Bars and restaurants are frequently used, though larger sites can sustain larger functions such as libraries or gallery space.
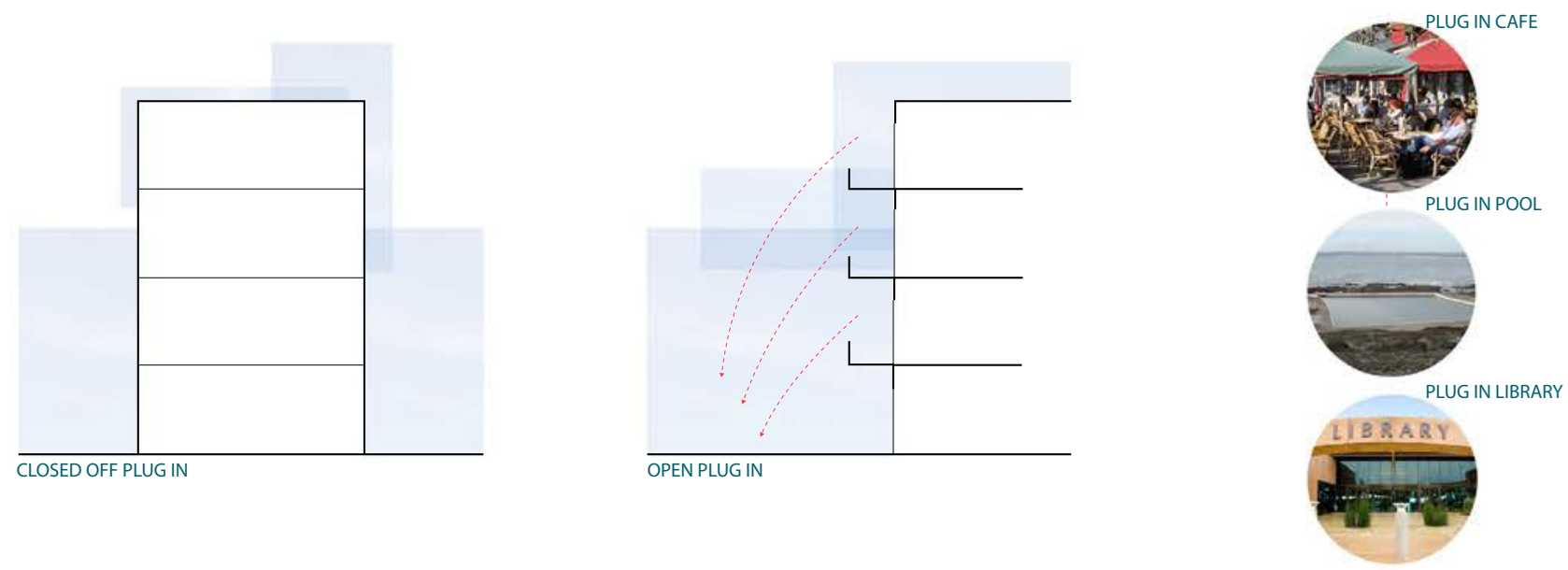


\subsection{5_ Conclusion}

This fieldwork analysis has helped to understand the relationship between public life and ferry infrastructure. Eastbourne ferry and Wellington ferry both produce different kinds of public life. By analysing these two sites this thesis was able to generate design strategies that will enable manipulation of the associated public life. This thesis argues that this is the gap in knowledge from landscape theory that allows for the design of transport infrastructure that will generate public life. 


\section{3_ Case studies}

A mix of transport infrastructure case studies, both from New Zealand and internationally, has been selected to investigate issues surrounding the thesis research question. The studies show different approaches that designers have used in the design of transport infrastructure. There is a relatively even split between ferry infrastructure and other forms of transport infrastructure.

The selected case studies are:

3.3.1_ Caracas cable car

3.3.2_ Parramatta road concept

3.3.3_ Transmission Gully

3.3.4_ Brisbane ferry design competition

3.3.5_ Circular Quay

The first three case studies show examples of the three theoretical approaches to the design of transport infrastructure. The next two examples show current discipline tendencies that specifically relate to ferry infrastructure. The research focuses on key issues related to transport infrastructure and how it can generate public life.

The case studies provide a way of understanding how other designers have approached the design of transport infrastructure, ferry transport infrastructure in particular. There are positives and negatives associated with each case study. When viewed with theoretical bases and fieldwork these studies provide an understanding of the discipline knowledge surrounding this issue. It generates a lens through which designing can take place and grounds the project within current practice. 

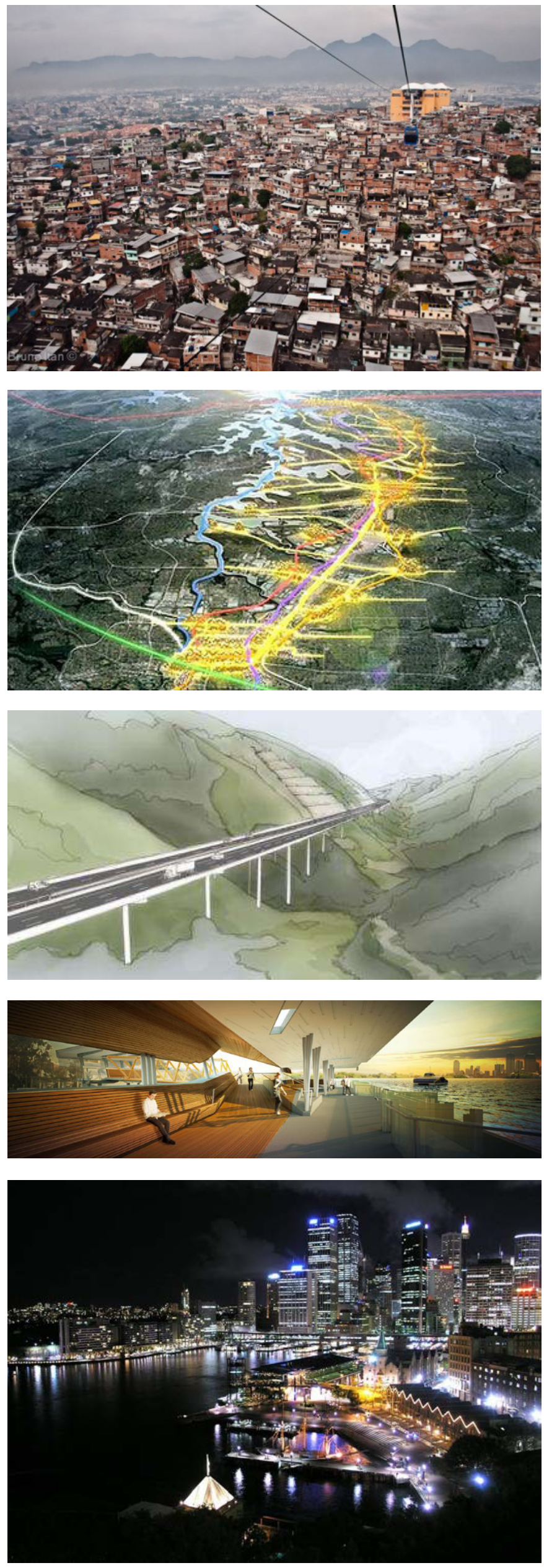

Figure 3.3.0 (Above)_Images of the five case studies. Sources from top to bottom:

1_ http://inhabitat.com/ cable-car-system-crownsurban-revitalization-projectin-rio-de-janeiros-alemaofavela-complex/ 2_ http:// news.domain.com. real-estate-news/disputeover-parramatta-road-plan20120613-2Oals.html http://www.opus.co.nz/index. php?id=2302 4_ http://www. premiers.qld.gov.au/assets/ ferry-design3-lge.jpg 5_ http:// static.panoramio.com/photos/ large/15134512.jpg 


\subsection{1_ Caracas cable car}

\section{Where: San Agustin, Caracas, Venezuela}

What: The gondola system is part of a larger network of small-scale interventions that fit into the fabric of Caracas. It provides travel from the barrios in San Agustin down into the city. Five stations will make up at 2.1 kilometre route that links into other forms of transport ${ }^{14}$.

Theoretical base: This project, designed by the Urban Think Tank studio, is one of the most frequently used examples of urban acupuncture. It utilises key principles relating to urban acupuncture when designing the infrastructure. These principles include understanding the city has an energy force that can be tapped into, small scale interventions that act as a catalyst, and interacting local community needs and wants. Each of the five stations has similar components, yet the additional functions differ to allow site-specific interaction with the surrounding context ${ }^{15}$.

Compliance with design strategies: The design of this transport infrastructure utilises 9 of the design strategies used to generate public life. The only one that doesn't seem to be here is the waiting manipulation of the departure event.

Transport Efficiency: The cable car provides a very efficient form of travel without any extensive demolition work. The unique topography of San Agustin would have needed serious ground works to facilitate any other forms of transport. By raising the transport above the ground plane a quicker form of transport has been generated that needs minimal infrastructure compared to other options.

Public life: This project adds to the already vibrant life of Caracas. The terminals where people can get on and off the system are designed to evolve into community centres. This starts to include the transport system in all parts of life in Caracas. Not only for transport to the city but also as a leisure area.

The structure is highly visible in much of the neighbourhood so can become a way finding tool. With the structure so visible at all times of the day it becomes part of the city. This encourages use of the transport system and of the terminals that house other activities, such as community centres. 


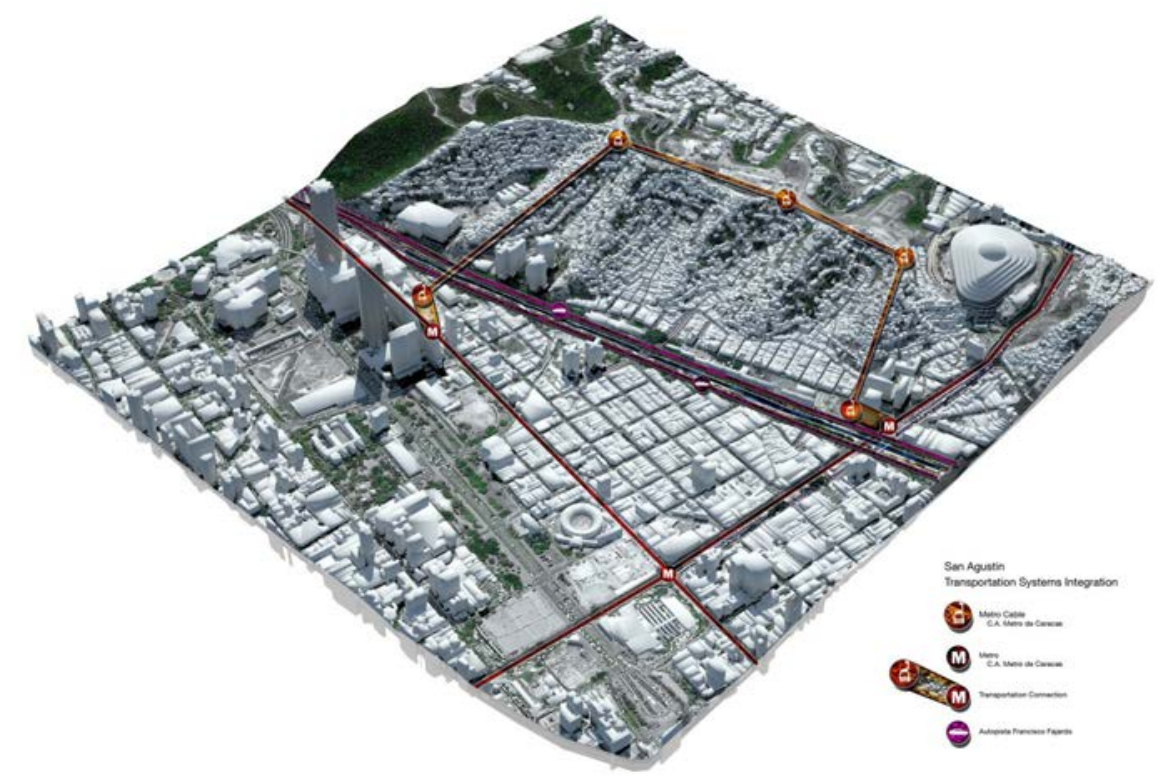

Figure 3.3.1 (Above)_ Image showing the route of the cable car and where it links into other forms of transport. Sourced: http://www.thepolisblog.org/2010/10/interview-life-linefor-caracas.html

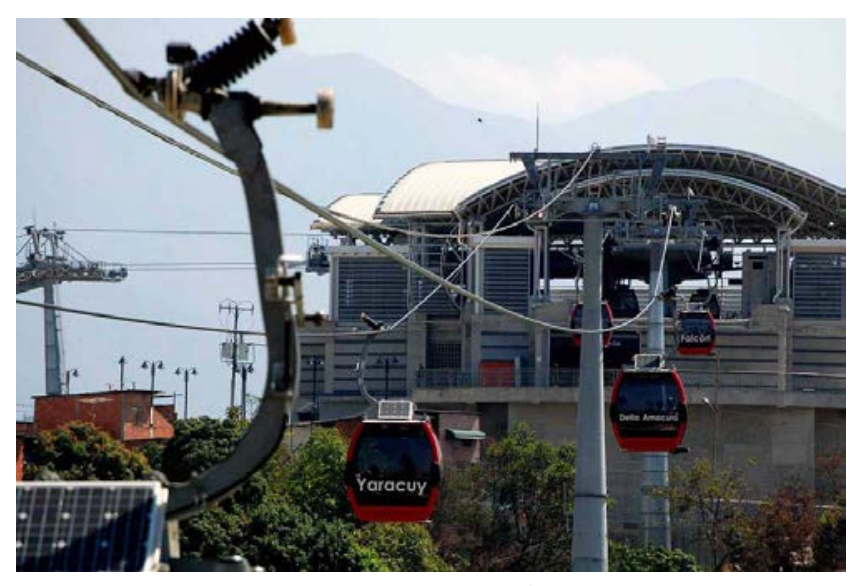

Figure 3.3.2 (Above)_ Large numbers of cable cars lower waiting times and increase system viability. Sourced: http://gondolaproject.com/2010/03/

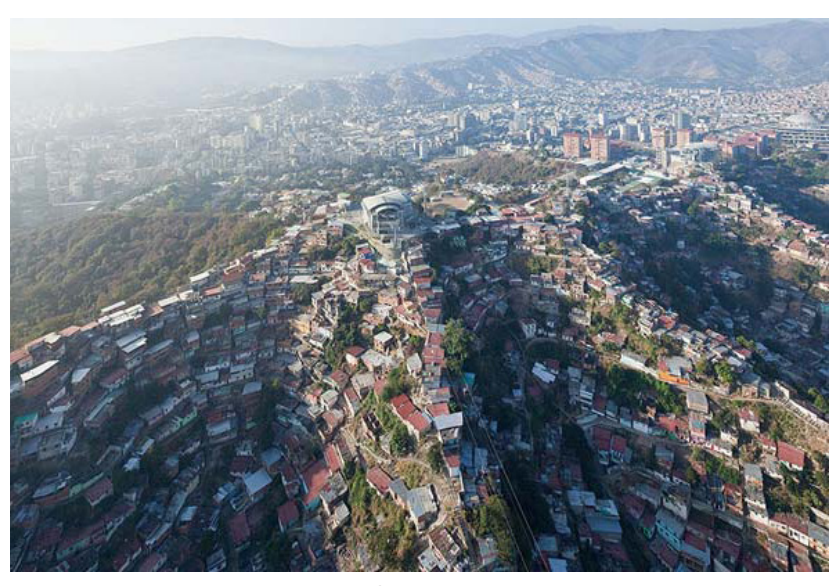

Figure 3.3.3 (Above)_ View of the unique topography in Caracas. Sourced: http://u-tt.com/projects_Metrocable.html

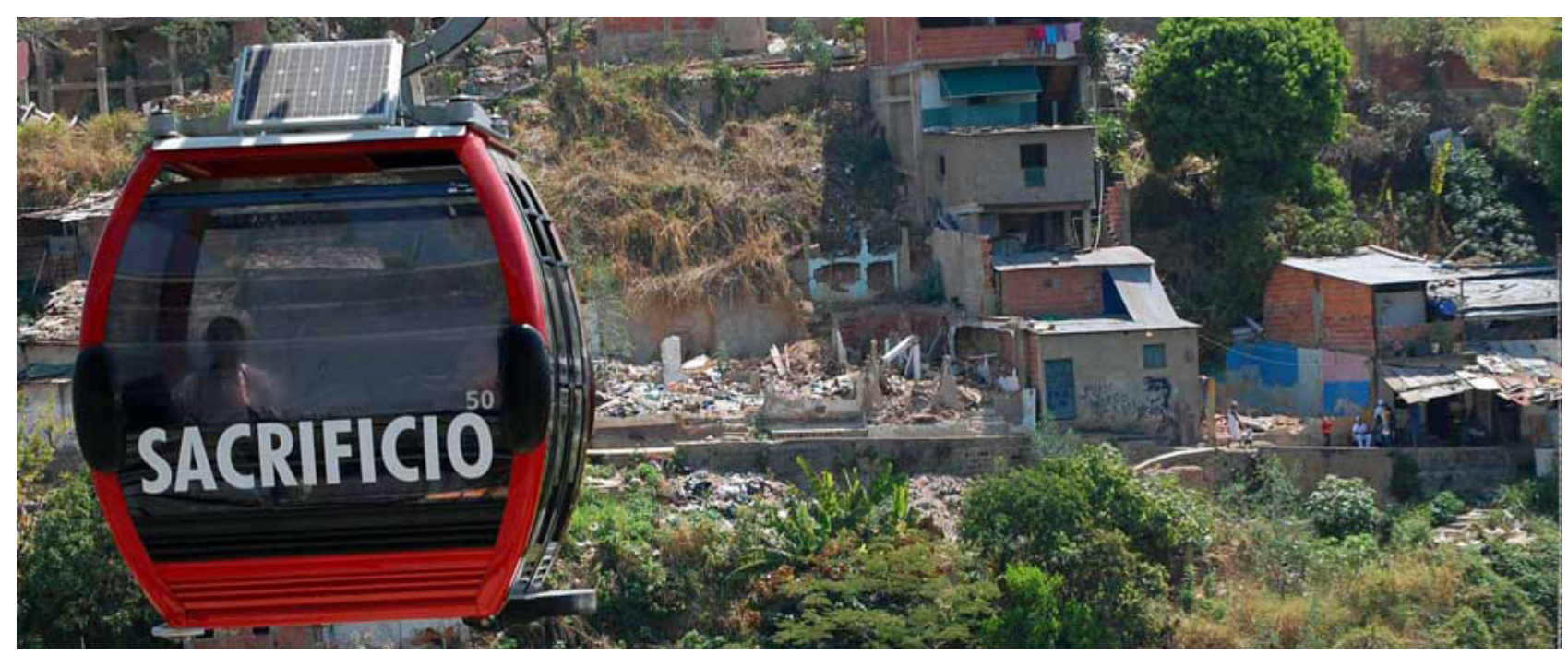

Figure 3.3.4 (Above)_ The highly visible transport infrastructure becomes part of life in Caracas. It has been designed to reinvigorate and make life easier for the people living around it. Sourced: http://gondolaproject.com/wp-content/uploads/2010/03/Sacrificiocopy.jpg 


\subsection{2_ Parramatta road concept}

Where: Sydney, NSW, Australia

What: This project is the proposal for the redesign of Parramatta Road as a liveability corridor. The design includes residential, commercial, and retail space along the 23 kilometres that is currently a congested sixlane highway with depreciated buildings and monotonous car yards ${ }^{16}$.

Theoretical base: This project is an example of landscape urbanism. This large-scale urban development that is driven by landscape architectural principles, shows what kind of large-scale master plan projects are being produced. The team working on this project are a mix of design professionals that all seem to be contributing to the design of certain areas. This project seems to be using the design of transport infrastructure as a way of fixing current transport issues but also addressing other issues such as population growth ${ }^{17}$.

Compliance with design strategies: The design of this infrastructure is at a scale that makes it difficult to understand the intricacies of the design. At a large scale it increase population for viability and connects into existing transport systems. The other design strategies can only be understood through the design of the smaller spaces.

Transport Efficiency: This project seems to have fixed congestion and waiting time issues along Parramatta Road. They have done this by using a range of different transport methods, both private and public. Ferries, trains, light rail, and roads have been implemented as a means of connecting Parramatta and Sydney Central.

Public life: This project seems to programme new public life into the site. The master plan concept incorporates retail, residential, commercial, and public space into the design of the space. This will allow for different types of people to inhabit the space at all times, creating a vibrant corridor of activity.

This design has a different approach and theoretical base than the Caracas project. The urban acupuncture theory is to put interventions into the existing fabric to see what could develop. This project has designed a whole new fabric that has its own public life. Although the project does pick up on existing characteristics of the site the designers do seem to be trying to manufacture a different form of public life. 


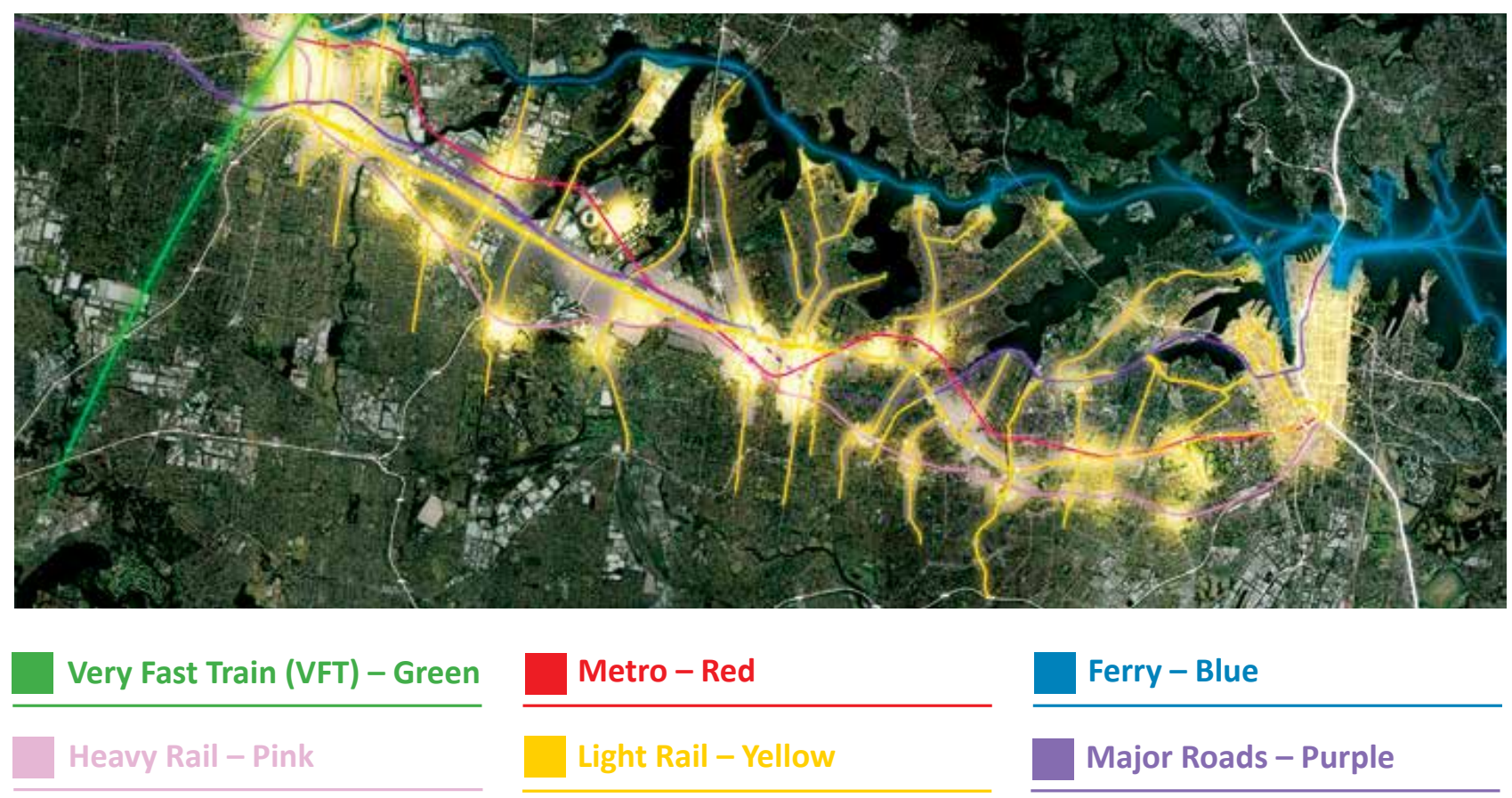

Figure 3.3.5 (Above)_ Map showing the different modes of transport that power the development of this site. Sourced: http://www. urbantaskforce.com.au/urbanideas/june2012/

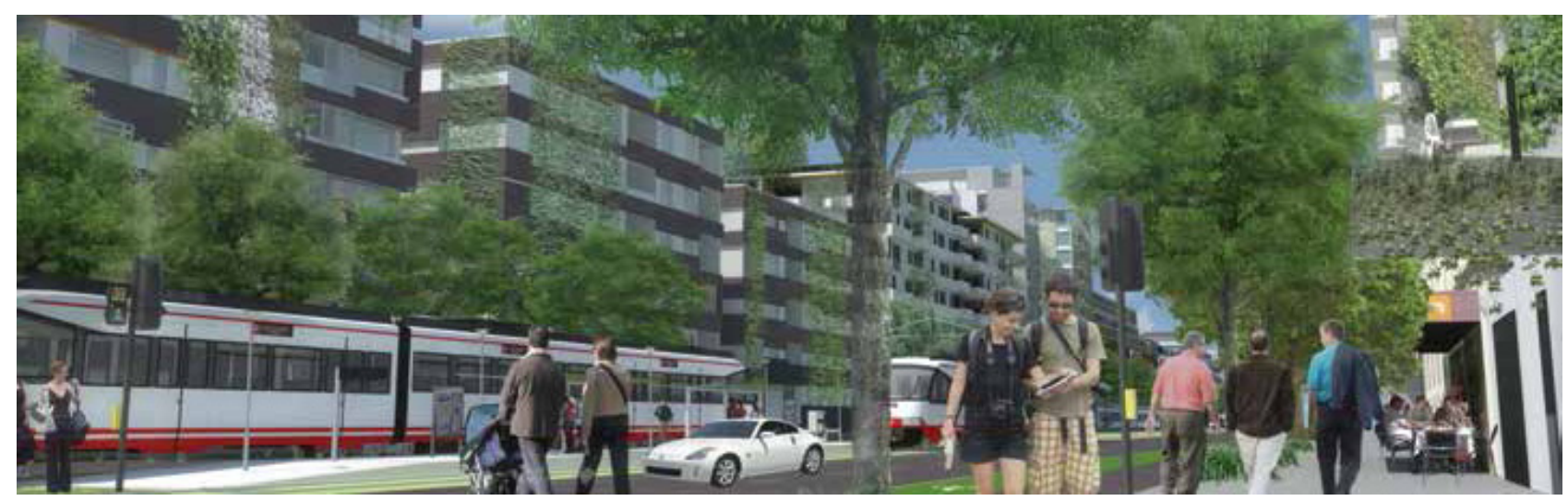

Figure 3.3.6 (Above)_ This is a large scale project that has a long time frame. Often landscape urbanism projects are master plan type projects that are set to be completed 30-40 years in the future. Sourced: http://www.urbantaskforce.com.au/urbanideas/june2012/
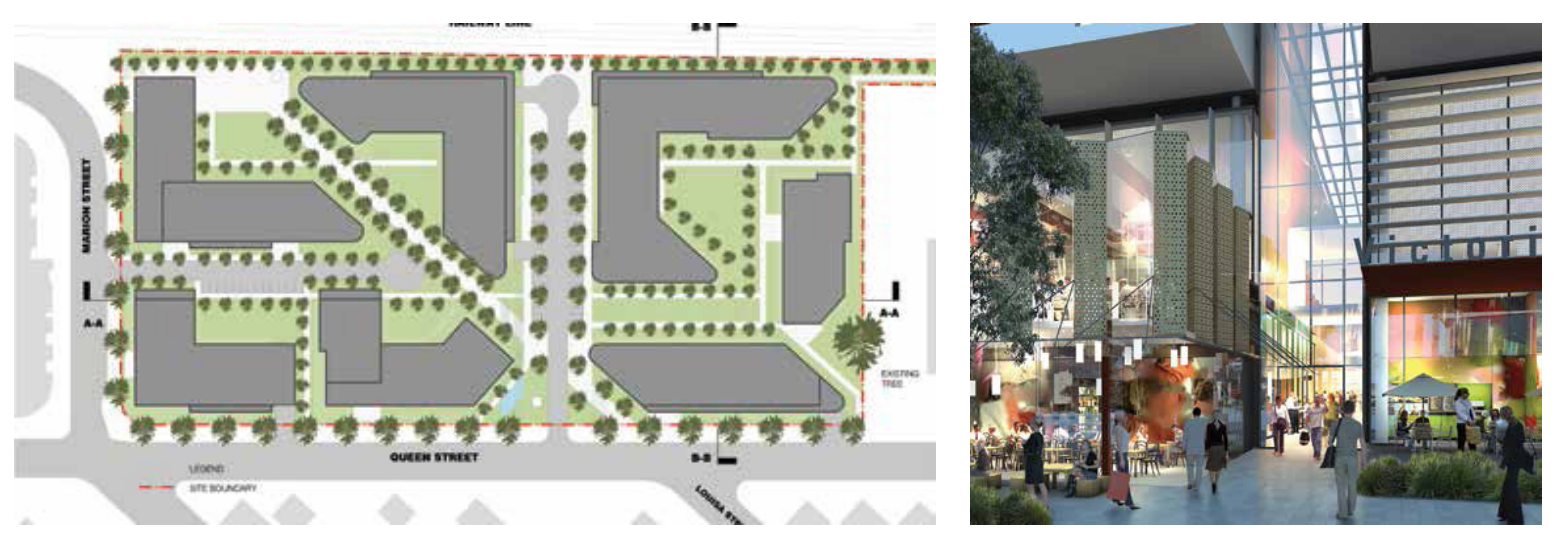

Figure 3.3.7 (Above)_ Several different designers worked on concepts for different parts of the road. These images show different levels of design. Sourced: http://www.urbantaskforce.com.au/urbanideas/june2O12/ 


\subsection{3_ Transmission Gully}

Where: Wellington Region, New Zealand

What: A 27 kilometre highway that will connect Wellington City to Kapiti. This project loops around the back of Cannons Creek, Whitby, Pukerua Bay, and Paekakariki to provide another link out of Wellington to increase resilience of the regional network ${ }^{18}$.

Theoretical base: This project is an example of the functional approach to designing transport infrastructure. These large-scale highway/ connection projects are often the ones that utilise the functional approach to design. These projects are about moving large numbers of people from one point to another as quick as possible. Transmission Gully is a prime example of that, connecting Wellington to the rest of the region.

Compliance with design strategies: This project doesn't seem to use the design strategies as it is designed from a purely functional point of view.

Transport Efficiency: The project provides a much quicker transport option to the existing alternative routes. It will also have more resilience, as it doesn't face the same disaster issues the current coastal road does.

Public life: The functional approach taken by this project means that it doesn't focus on public life. This project is about connecting Wellington City with the rest of the North Island in the fastest possible manner. 


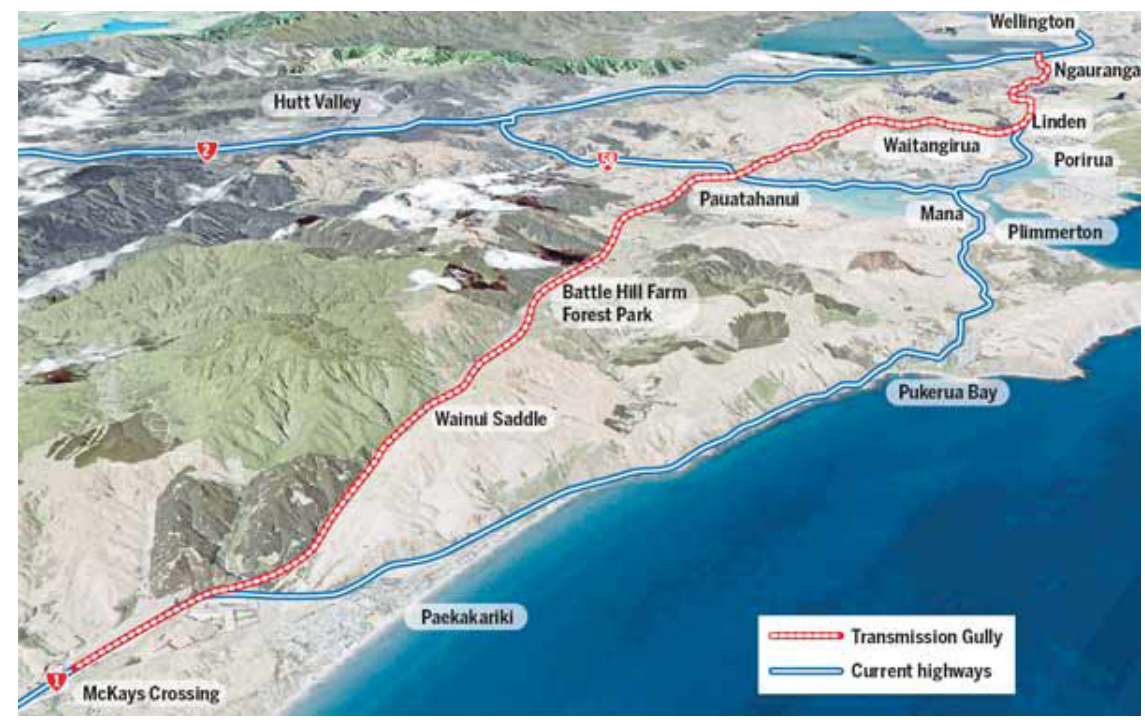

Figure 3.3.8 (Above)_ Map showing the proposed route vs. the old route. Sourced: http://static2.stuff.co.nz/1260903515/474/3165474.jpg

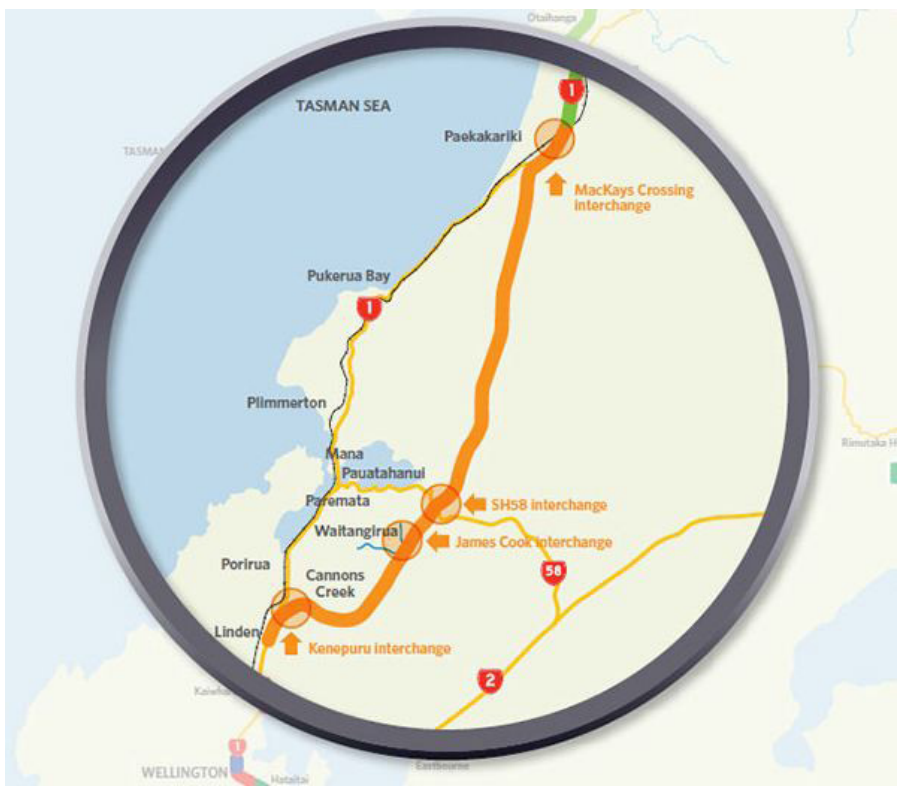

Figure 3.3.9 (Above)_ Image looking at the interchanges along Transmission Gully. Sourced transmission-gully/

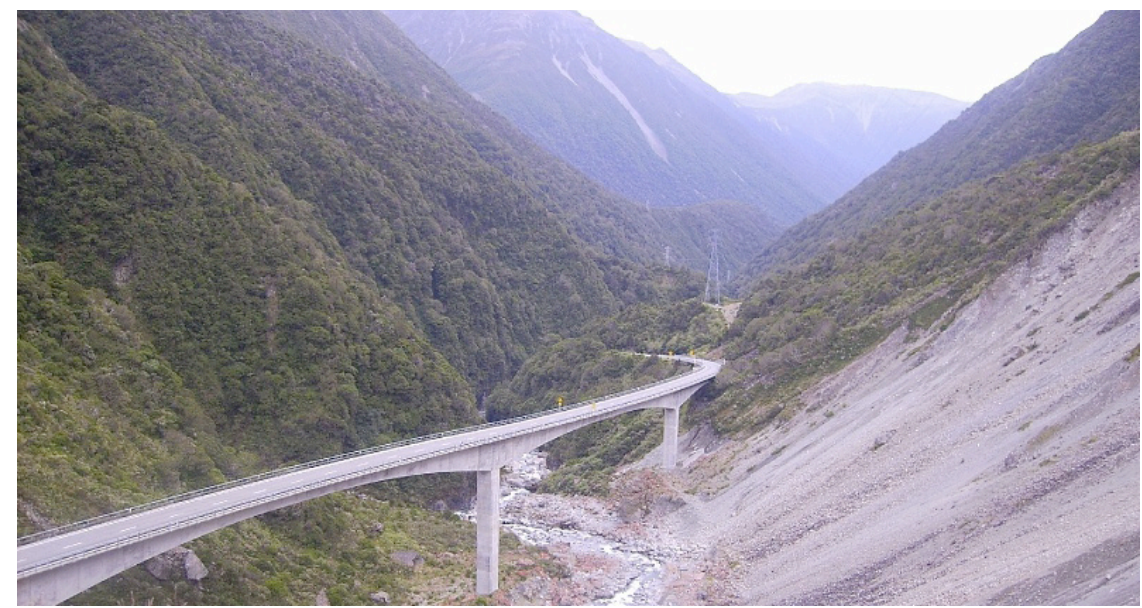

Figure 3.3.10 (Above)_ Potential look of the proposed highway. Sourced: http:// eyeofthefish.org/wp-content/uploads/2008/07/otiragorge.jpg 


\subsection{4_ Brisbane ferry terminal design competition}

Where: Brisbane, Australia

What: After a series of floods this design competition asked for submissions for the design of a ferry terminal that can replace destroyed terminals. These three entries are the three finalists.

Theoretical base: This case study has been chosen as it provides an example of the current discipline tendencies when it comes to the design of ferry transport. The projects all treat the design of the terminal as a piece of architecture. Although it looks impressive on paper, there seems to be little consideration given to how it relates back to the current urban fabric, or how it can generate public life.

Compliance with design strategies: Strategies such as level change that relate specifically to the design of the terminal itself seem to be evident in these three projects. Larger scale strategies such as the associated public space that connect the design into the surrounding context do not seem to be considered in the design of this infrastructure.

Transport Efficiency: The terminals work functionally in terms of getting people from the ferry to the land. There is little indication given to how these terminals relate to existing transport infrastructure.

Public life: It is hard to analyse the public life associated with these projects as there is a minimal understanding of how it would connect back into existing urban fabric. The terminals themselves are functioning platforms that allow people to move from the ferry onto the land. The design of these terminals do look interesting from a design perspective and would provide an interesting transition between the water and the land, yet how this project effects the surrounding city is under developed.

The images to the right are taken from the competition documents and show examples of well-designed pieces of architecture that lack connection to the surrounding context. 

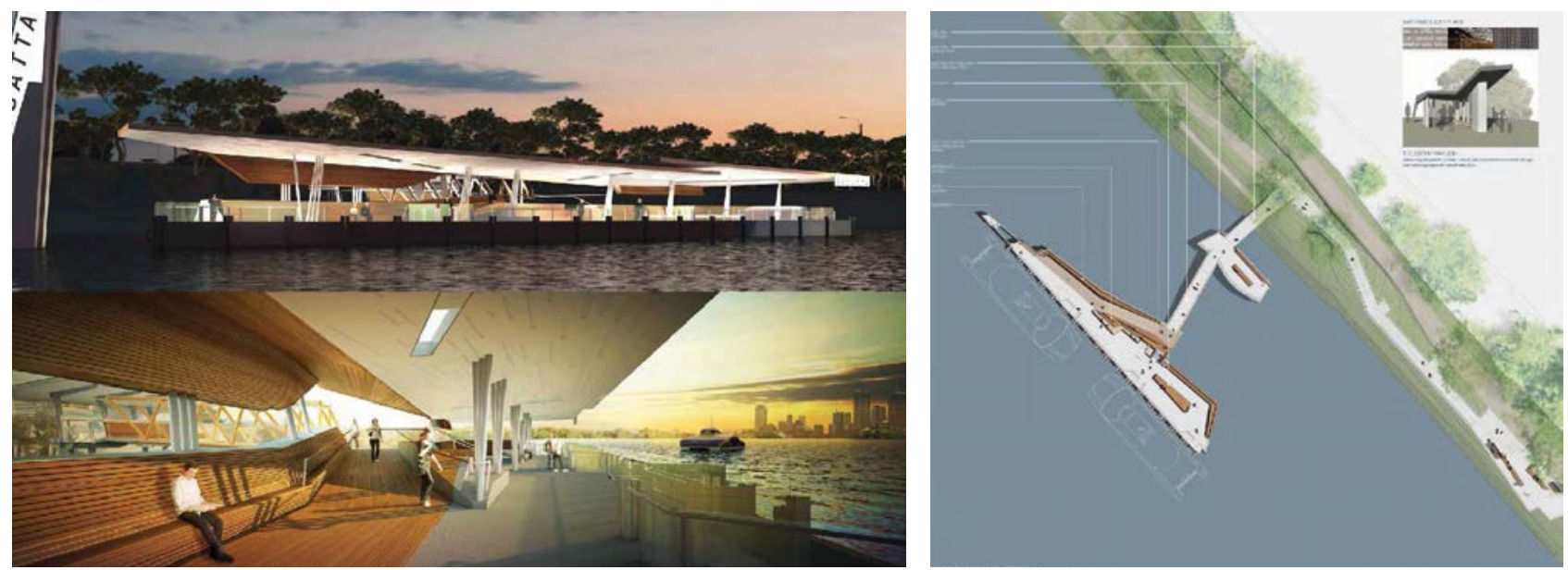

Figure 3.3.11 (Above) These images show how ferry infrastructure is designed. Often the plan deals with the design of the terminal itself but not the surrounding context. The terminal itself is designed to a high level, with perspectives showing it as an object that isn't connected to surrounding context. Sourced: http://www.premiers.qld.gov.au/ferry-terminal-competition.aspx

Second Nature Collaborative
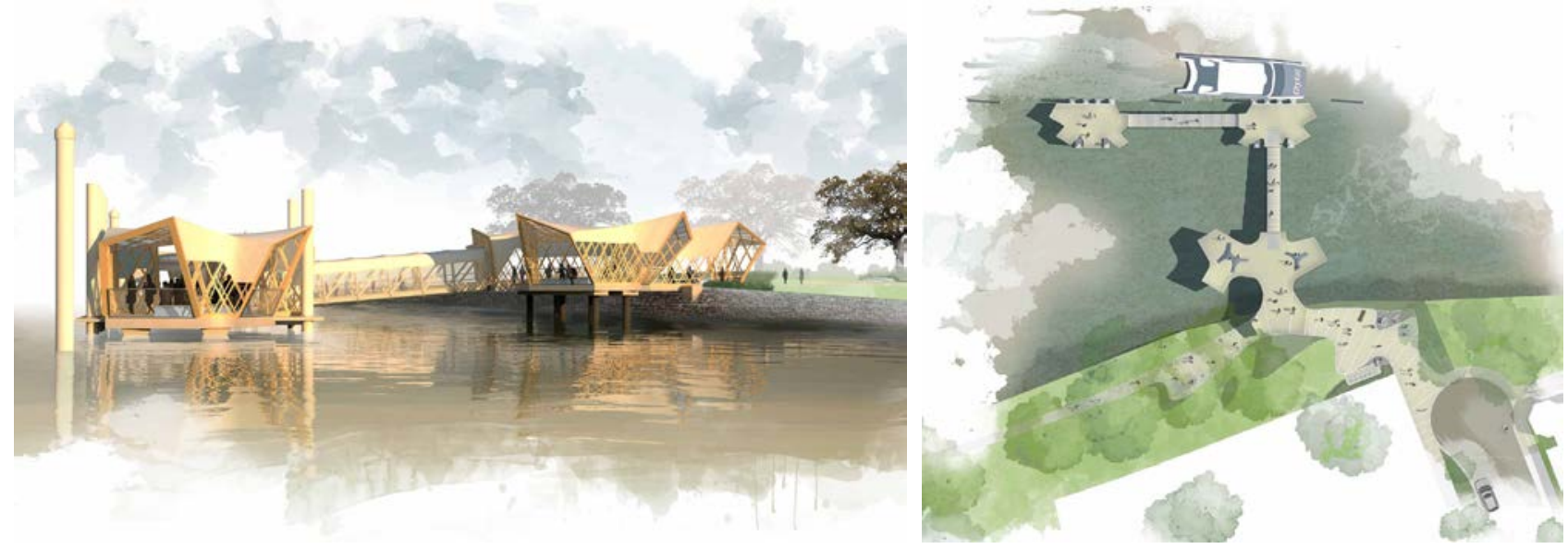

Figure 3.3.12 (Above)_Detailed perspective of ferry terminal. Sourced: http://www.premiers.qld.gov.au/ferry-terminal-competition.aspx

Figure 3.3.13 (Above)_ Plan showing the design with minimal interaction with context. Sourced: http:// www.premiers.qld.gov.au/ferry-terminal-competition. aspx

Shane Thompson Architects \& Lat27

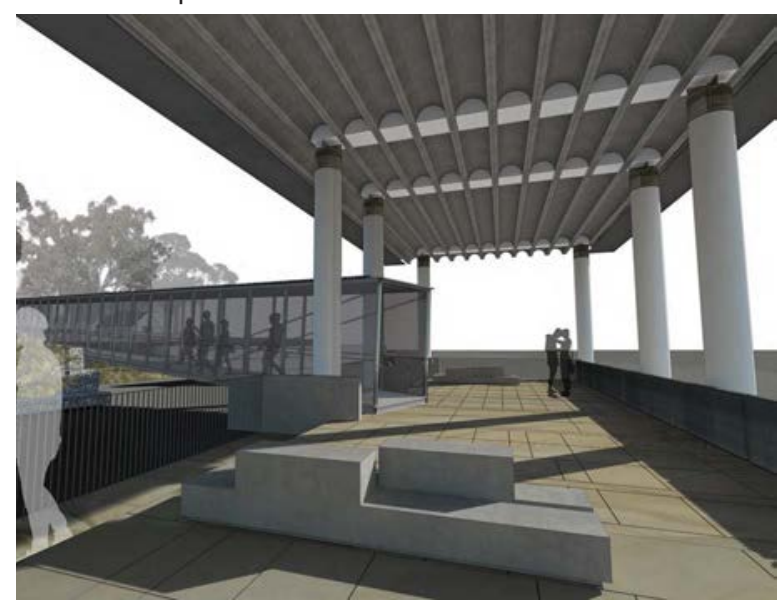

Figure 3.3.14 (Above)_ Detailed perspective of ferry terminal. Sourced: http://www.premiers.qld.gov.au/ferry-terminalcompetition.aspx

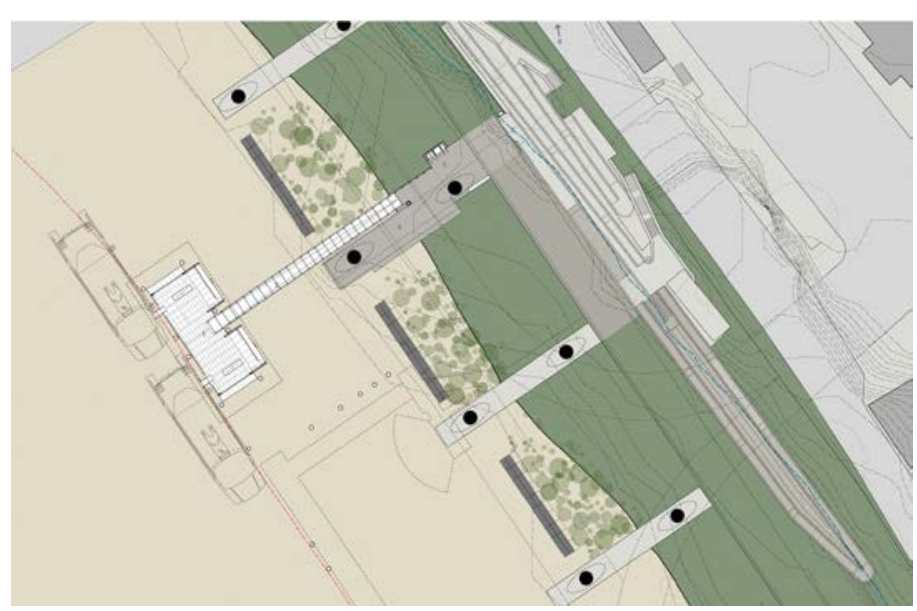

Figure 3.3.15 (Above)_Plan showing the design with minimal interaction with context. Sourced: http://www.premiers. qld.gov.au/ferry-terminal-competition.aspx 


\subsection{5_Circular Quay}

\section{Where:Sydney, Australia}

What: A multi modal transport hub that combines transport, public space, apartments, retail, and leisure in one area.

Theoretical base: Circular Quay is an example of how transport infrastructure can generate public life. The ferry infrastructure is an integral part of the site and without it the area wouldn't function the same. The constant pulse of people using the public transport system brings life and movement to the area. This pulse of energy is used to support retail and restaurant space, which in turn attracts more visitors to the area. Circular Quay often feels like the entrance to Sydney with the constant flow of public transport linking the rest of Sydney to the CBD.

Unlike the Wellington Central ferry terminal, the Circular Quay ferries aren't clipped onto the side of a walkway. They become the focal point that everything else faces in on. If the ferry terminals were removed this site would lose a significant pulse of people that generates the public life associated with Circular Quay.

Compliance with design strategies: Circular Quay hasn't been designed specifically to generate public life, and parts of the design were added over time to create the composition of space that can be seen today. Yet the design strategies can be seen through the case study. This is an extremely well connected transport system, there is a hierarchy of public space, compression of movement channels, and there are several different plug ins that activate the public space. Even though these things are not done in a purposeful manner they still show ways that design can influence the public life.

Transport Efficiency: This multimodal transport hub is very efficient in terms of moving large numbers of people around the transport system. Frequent trains, buses, and ferries mean waiting times are low. With public transport being given priority it becomes the easiest way of moving around the city. The ferries provide commuter routes and also tourist routes as part of a network of thirty wharves ${ }^{19}$.

The transport system pass also helps with the efficiency of the system. One pass can get passengers onto ferries, buses, light rail, and trains that makes moving between transport modes easy.

Public life: There is a pulse of life in Circular Quay that is there at all times of the day and night. Different building use means that a mix of people frequent the site at all times. The transport system supports this, as it is easy to get here and then home. For some people Circular Quay is just a part of their day as they move to and from work. For others Circular Quay acts as a destination point where they can relax and spend time. The public space and transport infrastructure supports this. 
Figure 3.3.16 (Right)_ Image of one of the entrances to the train station. The multi modal nature of Circular Quay ensures that there is a pulse of energy at all times.

Sourced:http://upload. wikimedia.org/wikipedia/ commons/1/15/Circular_ Quay_station_entrance.jpg
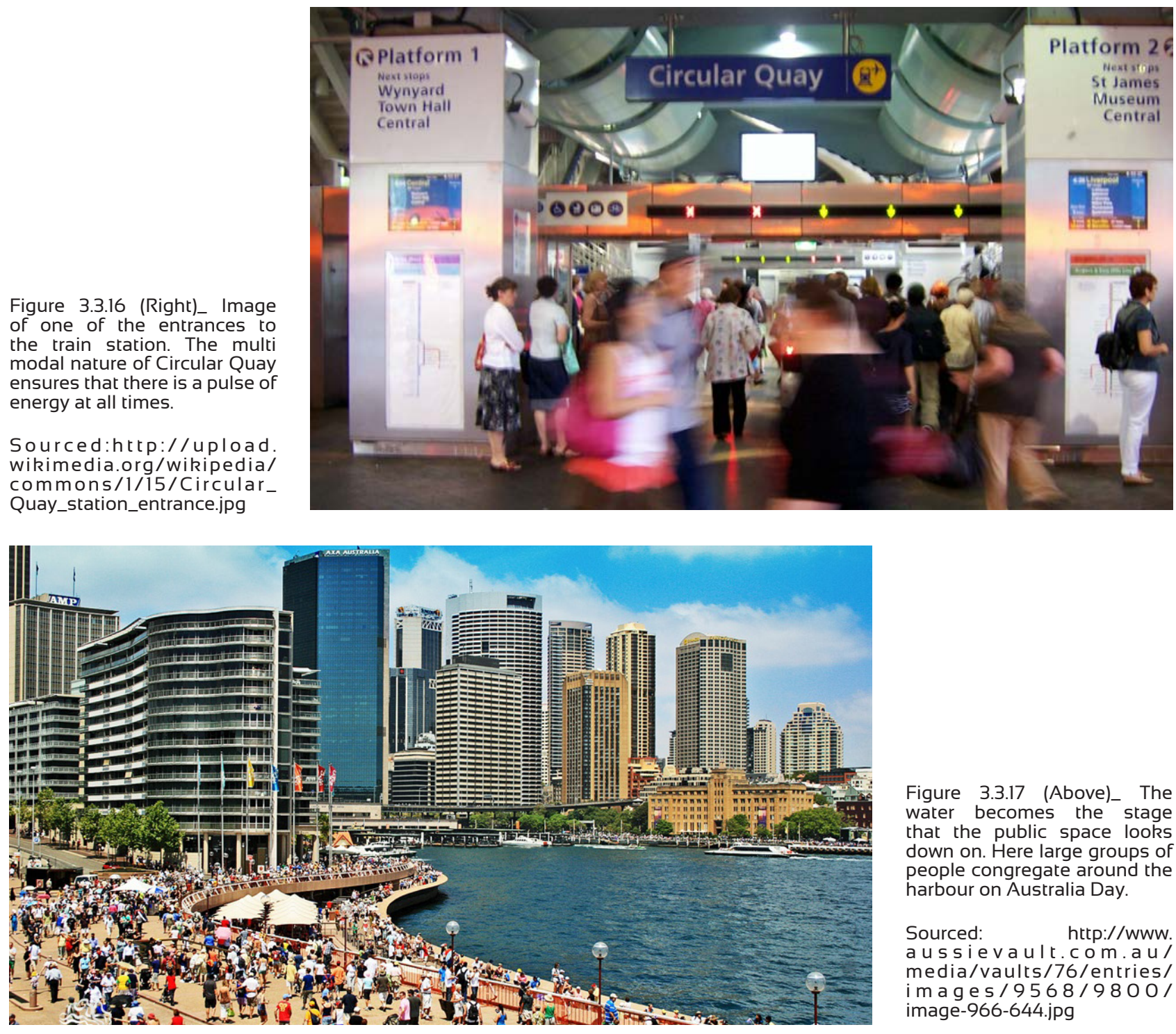

Figure 3.3.17 (Above)_ The water becomes the stage that the public space looks that the public space looks
down on. Here large groups of people congregate around the harbour on Australia Day.

\section{Sourced:}

hetp://www

aussievault.com.au media/vaults/76/entries/ i mages/9568/9800/ image-966-644.jpg

Figure 3.3.18 (Above)_ This image shows Circular Quay still active at night. The mix of uses and pulse of people from the transport network allows the space to be occupied during the day and at night.

Sourced: hetp://upload. wikimedia.org/wikipedia/ commons/O/Of/Across_ Circular_Quay.jpg

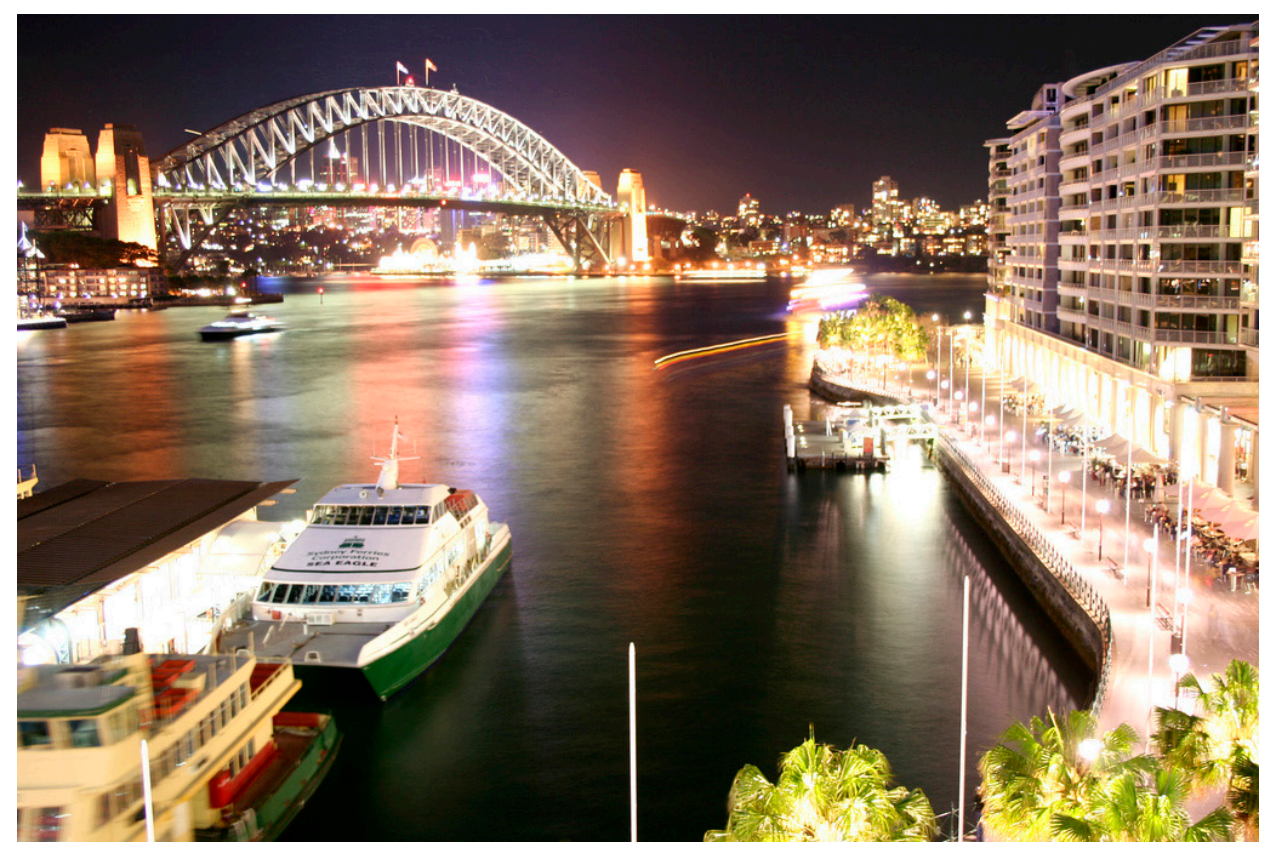




\section{4_ Conclusion}

The purpose of this positioning chapter was to understand what the current discipline tendencies are, and to position the research within landscape architectures knowledge of transport infrastructure.

Landscape urbanism, urban acupuncture, and functional design are all ways of approaching the design of transport infrastructure. Each theory has strengths and weaknesses that will affect the design outcome, yet one area that seems to be a gap in all landscape theory is how these concepts can be translated into physical design. This thesis argues that fieldwork allows for an in-depth knowledge of transport infrastructure that has physical implications for the design of space. The fieldwork undertaken for this thesis generated an understanding of ferry infrastructure and what is produced by the ferry system. This understanding culminated in ten design strategies that helped to direct the design of additional ferry development. The five case studies selected show the discipline tendencies when it comes to designing infrastructure. It was important to have an understanding about what previous designers had produced when dealing with a similar issue.

In conclusion the research shows that landscape architecture is having an ever increasing effect on the design of transport infrastructure, which in turn is having an effect on the way a city functions. By changing the way we view transport infrastructure a new approach can be used that uses transport as a catalyst for public life. 
_4 Site Assessment 
This section introduces Wellington City as the site chosen to test the research question. The site assessment ranges in scale from the analysis of the region as a whole and analysis of Wellington Harbour. This analysis through a range of scales provides an understanding of how the city currently operates at all relevant levels and shows where opportunities for change are. 


\section{1_ Wellington Regional Analysis}

Wellington Regional Analysis: provides an insight into what role Wellington harbour plays in the context of the region as a whole. Current transport options are also analysed to see how they can work with a functioning ferry system.

\subsection{1_ Location within New Zealand}

The Wellington region is located at the bottom of the North Island and covers an area of 813,005 hectares. It is home to Wellington City, the capital of New Zealand.

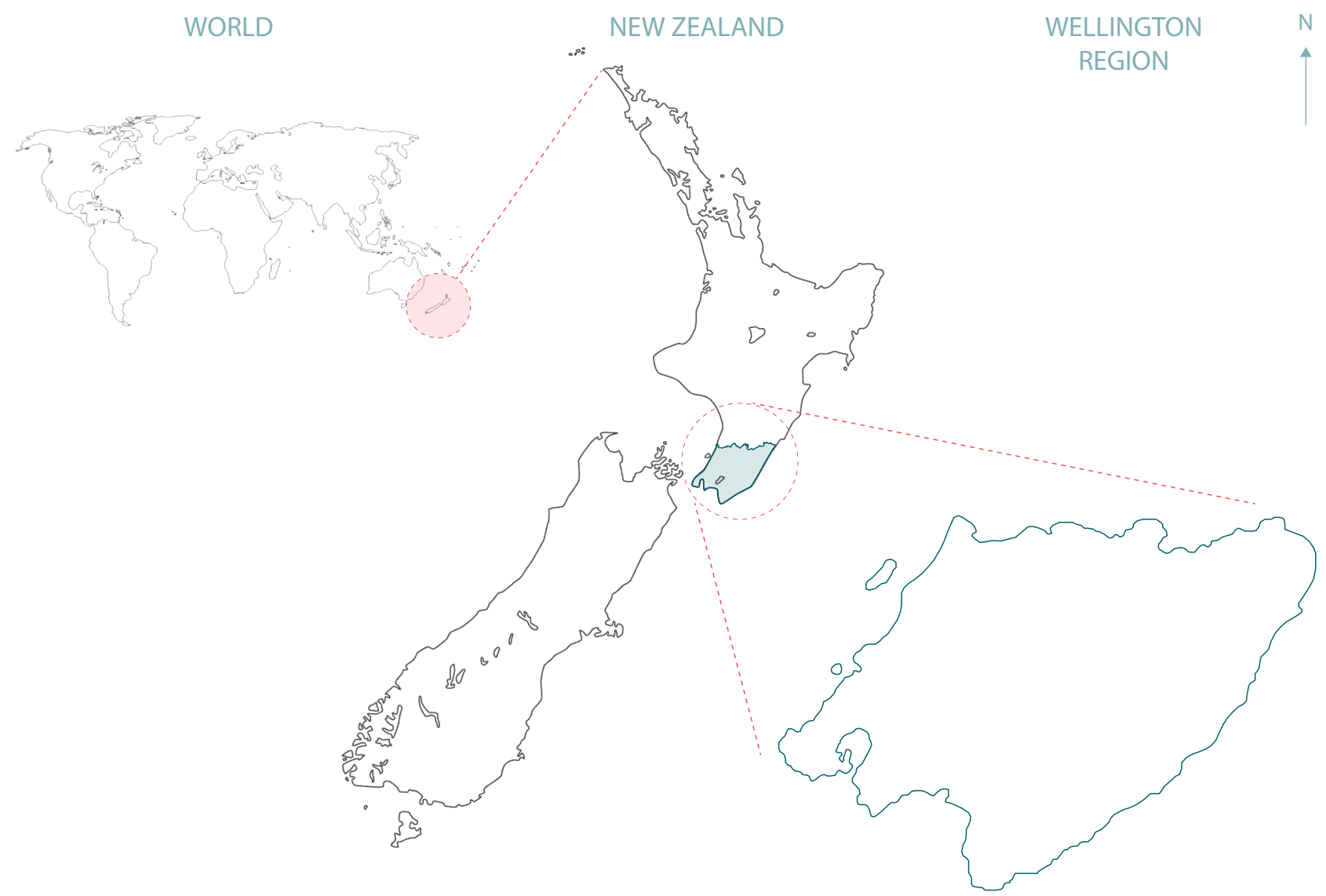

Figure 4.1.1 (Above)_ Welling region in relation to New Zealand and the world. (Authors own image). 


\subsection{2_ Cities within Region}

Wellington City, Lower Hutt City, Upper Hutt City, and Porirua City are the four cities located in the Wellington region with Wellington being the most significant as it is the capital of the country. The cities most affected by this research are Wellington City and Lower Hutt City as they border Wellington Harbour.

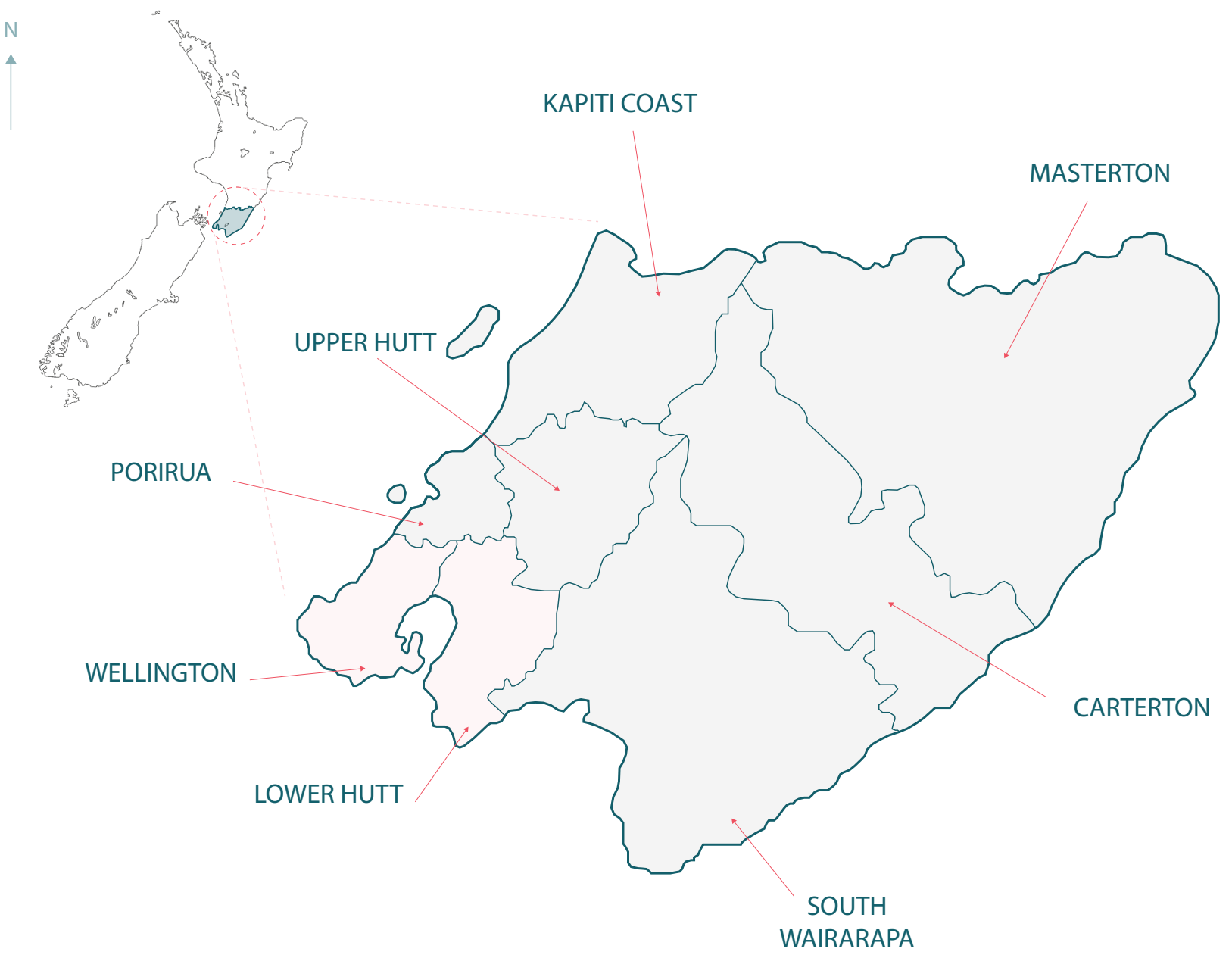

Figure 4.1.2 (Above)_ Cities within Wellington Region. Wellington City and Hutt city have been highlighted as they are the most affected by this research. (Authors own image). 


\subsection{3_ Harbours Role in Region}

Wellington Harbour plays a significant role in both the region and New Zealand as a whole. The depth and sheltered nature of Wellington Harbour means that it is the ideal location for Centreport, the third largest port in New Zealand ${ }^{20}$. Although privately owned, Wellington City Council and Horizon Regional Council both own shares in the company ${ }^{21}$. This brings large amounts of money into the region and provides jobs to the area.

Cruise ships dock in Centreport from October to May. This brings an influx of overseas passengers that financially supports the region. The natural depth of the harbour supports the large ships that are needed for these activities.

The harbour also provides a connection between the Wellington region and the South Island. Aside from the airport this is the main connection between the two islands. For many South Islanders the harbour is the first impression they get of Wellington.

Boats and ships play an important role for the Wellington Region, and the country as a whole. At a smaller scale the current ferry service is underutilised given the extent and connection of the harbour to residential areas.

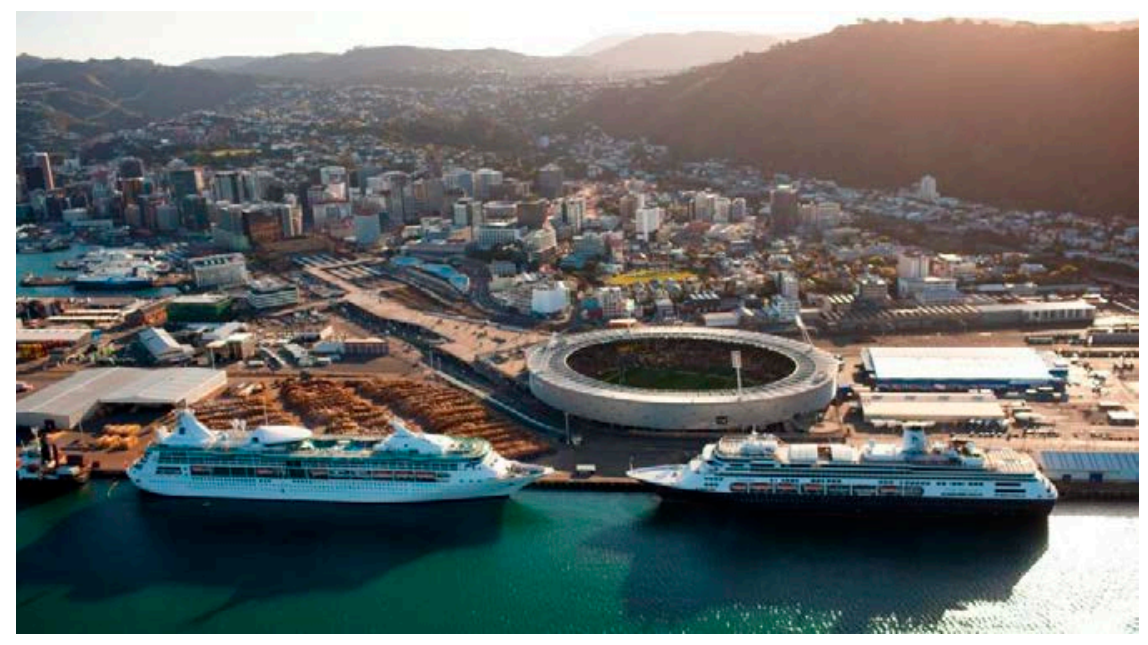

Figure 4.1.3 (Above)_ Cruise ships docking in Wellington harbour which brings money into the region. Sourced: http://positivelyinformed.com/category/marketing/cruise/ 


\subsection{4_ Regional Transport Systems}

The two longest running highways, state highway one and two, run through the Wellington region culminating in Wellington City. These highways move large numbers of people up and down the country and make the region a well-connected area.

InterCity buses and Newmans Coach lines both provide long distance bus routes up and down the country to connect the Wellington region with other regions throughout New Zealand.

As well as the buses Wellington City is also connected to the rest of the North Island by train lines, which stretch up to Auckland. This provides for movement of people and also cargo to Centreport for export.

The Inter Islander ferry crosses the Cook Strait to connect Wellington City with Picton in the South Island. Aside from air travel this is the quickest way of moving between both islands. The ferry can handle vehicles to allow people to drive themselves around the islands.

Wellington Airport connects the Wellington region with the rest of the country and the world. The airport is located on the edge of the harbour and provides international visitors with their first impression of the Wellington region.

The Wellington region is a well-connected region with several different public transport options. Multiple forms of transport provide different ways of moving around not only the region but the country as well.

Wellington Airport

State Highway 1

State Highway 2

North Island Train Line

Interislander Cook Strait Ferry

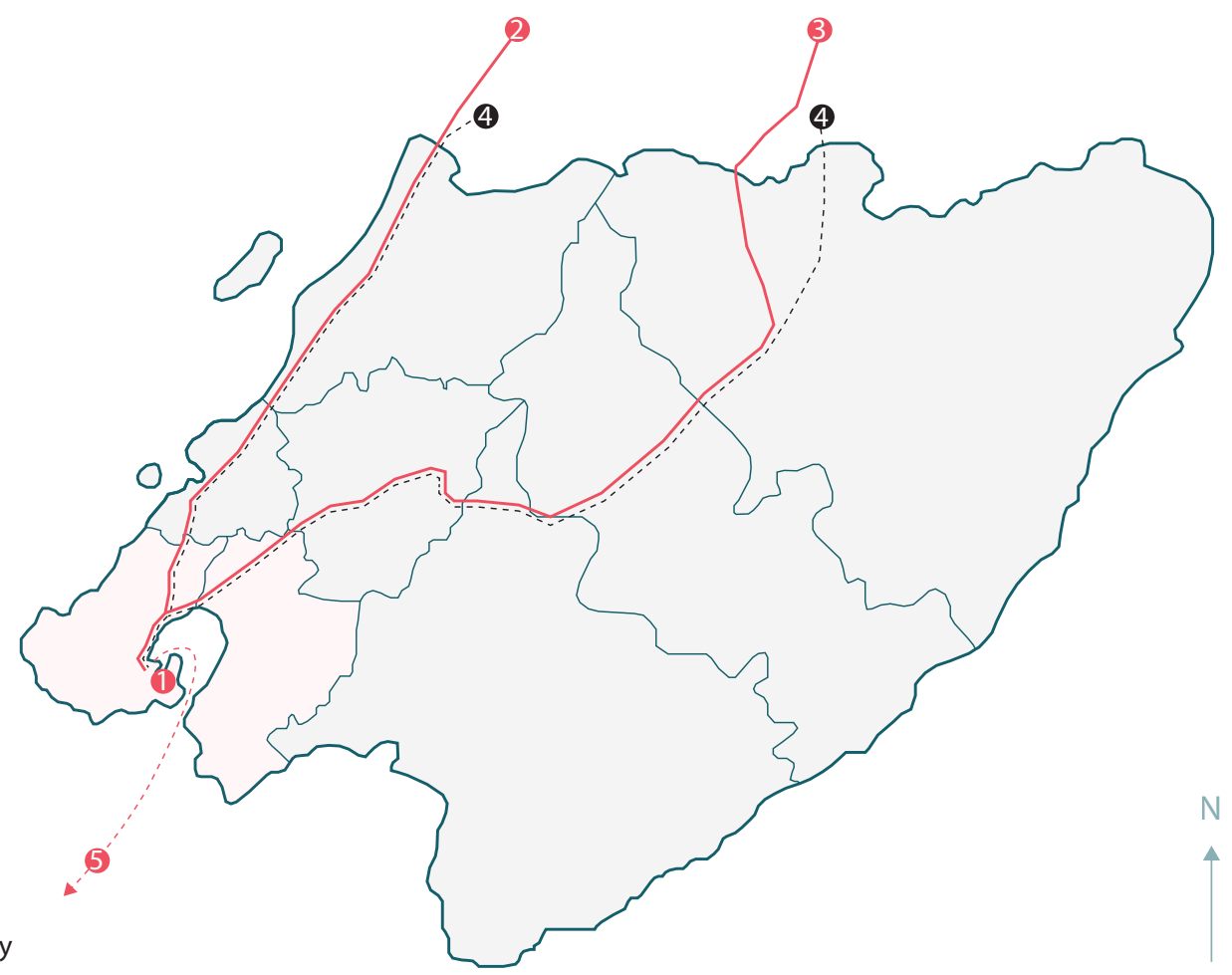

Figure 4.1.4 (Above)_ Regional transport systems currently operating. (Authors own image). 


\section{2_ Wellington Harbour Analysis}

Wellington Harbour Analysis: details the existing edge condition of the Wellington Harbour. The cities immediately adjacent to the harbour are Wellington City and Hutt City. The harbour analysis looks at how these cities are currently connected and what opportunities are offered by the harbour.

\subsection{1_ Cities surrounding harbour}

There are two cities located on the harbour edge. Wellington City is the larger of the two and is located on the southern side of the harbour, next to the harbour mouth. Hutt City occupies the northern and eastern boundaries of the harbour. The two cities are connected by a motorway and train line that runs along the western side of the harbour as well as a ferry service that currently moves between the central city in Wellington and Eastbourne, a small suburb on the eastern side of Hutt City.

The current population estimation for 2013 was 203,332, significantly more than the 100,847 people residing in the Hutt City catchment ${ }^{22}$.

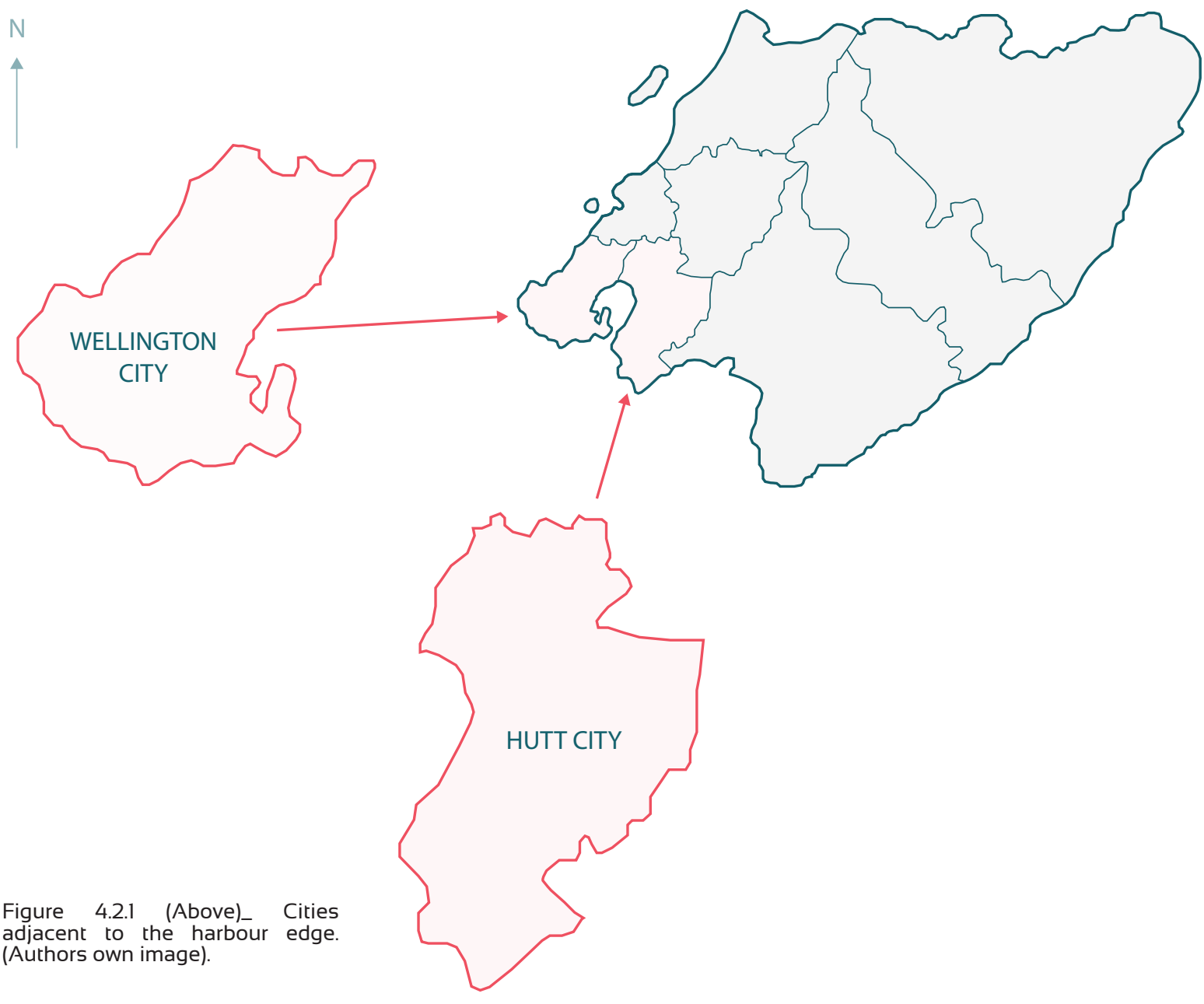




\subsection{2_ History of the waterfront}

Wellington was discovered early in the 12th century when the Ngai Tara tribe moved down from the Hawkes Bay ${ }^{23}$. Since then other tribes have also migrated to Wellington, and merged tribes.

In 1840 the New Zealand Company's settler ship landed in Petone ${ }^{24}$. Originally the city was supposed to be located in Petone but due to swampy land the plans were moved south to the current location of Wellington City ${ }^{23}$.

Wellington City waterfront has a history of growing and changing to suit the needs of the city. The original shoreline sits roughly 200 metres in land at some points from the current waterfront. Since 1852 there have been gradual additions, which have seen the city grow beyond its natural boundaries. Waterfronts are vibrant dynamic places, a concept that is reflected in its moving edge.

As the city continues to grow and more pressure is placed on the current transport infrastructure there is the opportunity for the waterfront to change again.
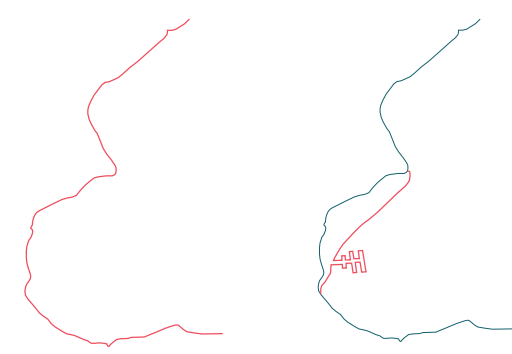

Original Coastline

$1852-1879$
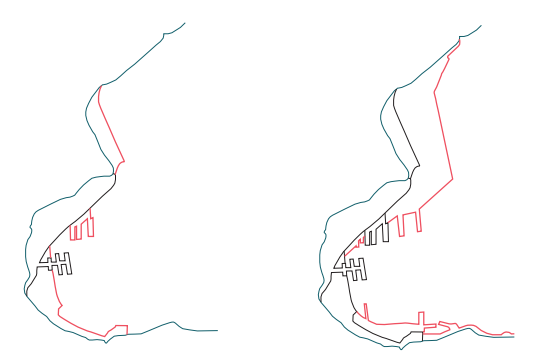

$1880-1900$

$1901-1930$

Figure 4.2.2 (Right)_ The development and growth of Wellington City coastline over 150 years. The harbour has always changed to meet the needs of the city and it will continue to with this transport project. (Authors own image).
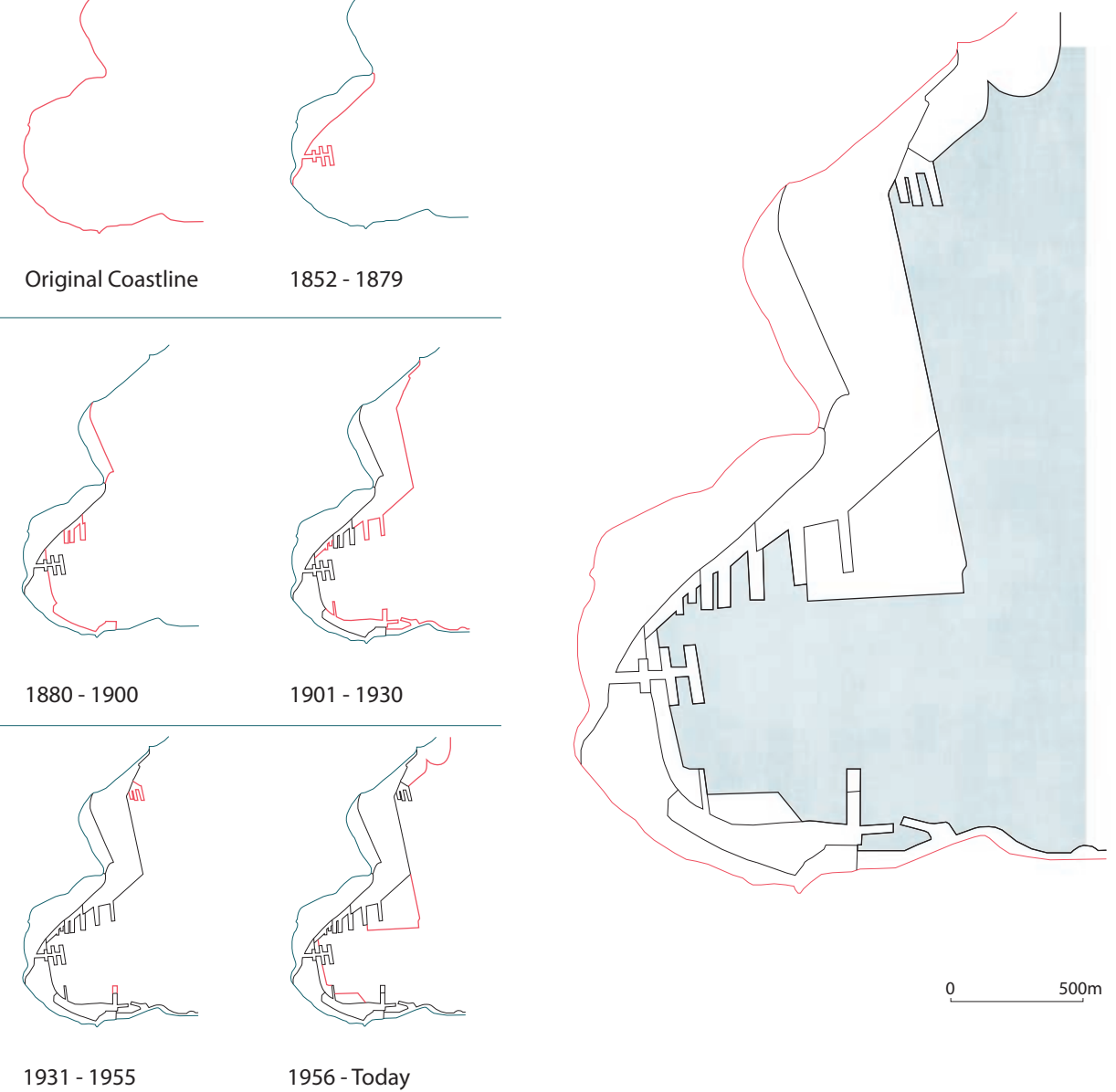


\subsection{3_ Street grid system}

The street system in Wellington and Hutt City is very grid like and the sense of directionality moves people down to the harbour side. Straight lines that run down to the water create sight lines that enhance the connection to the water. Although the city grid enhances directionality to the water, traffic heavy roads often run parallel to the harbour edge. This creates pedestrian movement to the harbour that is blocked by vehicular orientated movement.

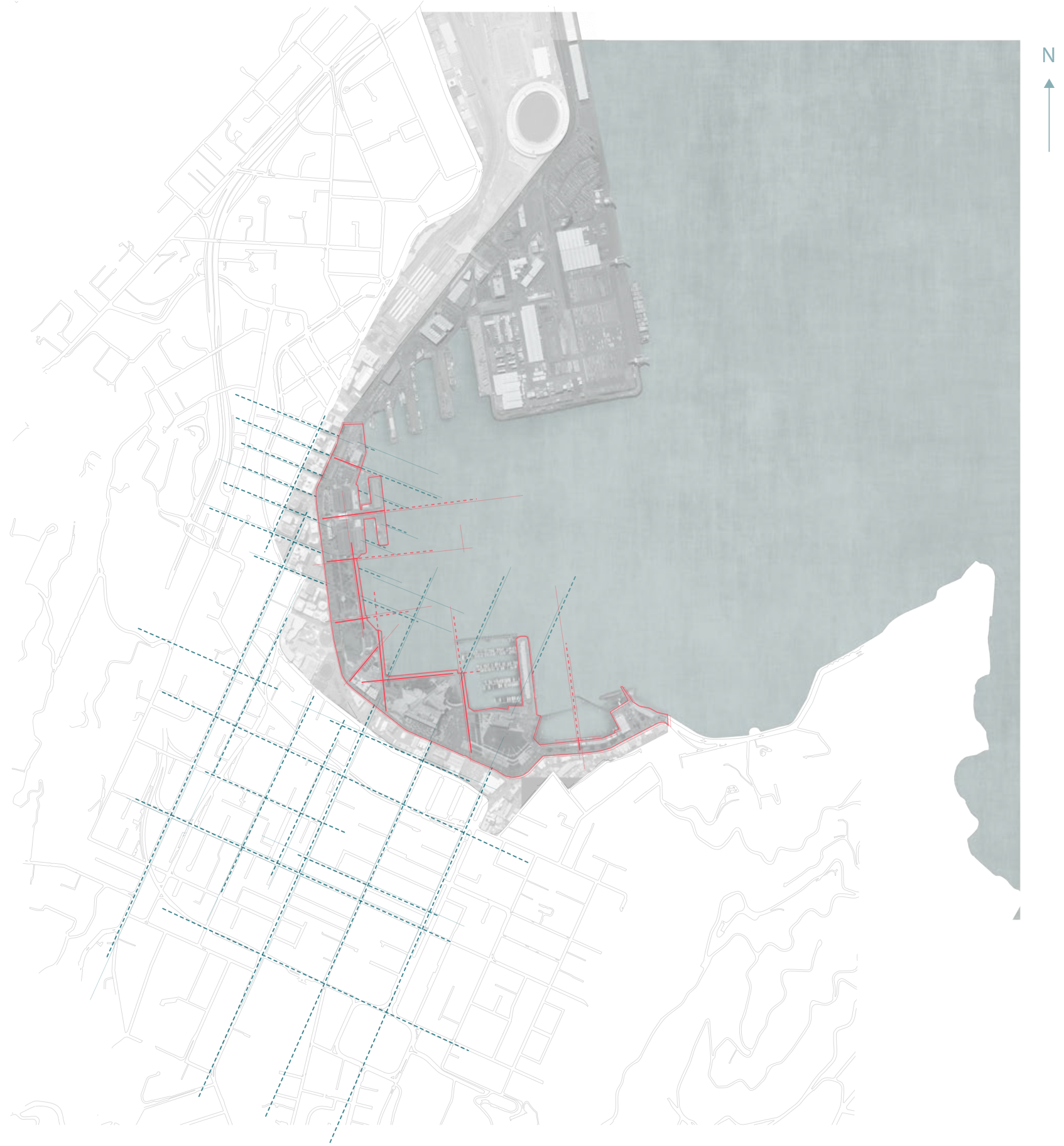

Figure 4.2 .3 (Above)_ The grid shifts on the reclaimed land, which gives the sense of entering a new area. (Authors own image). 


\section{Currently}

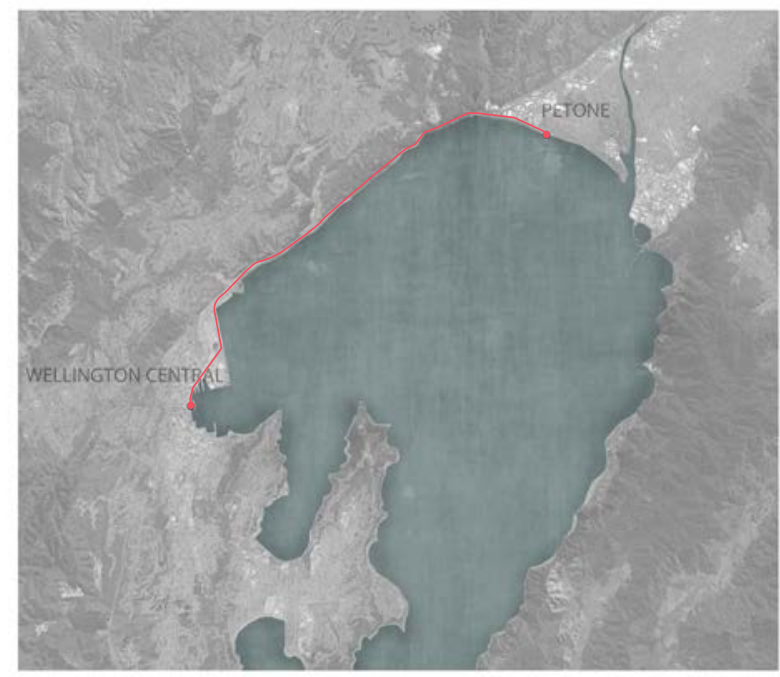

\section{Post Earthquake}

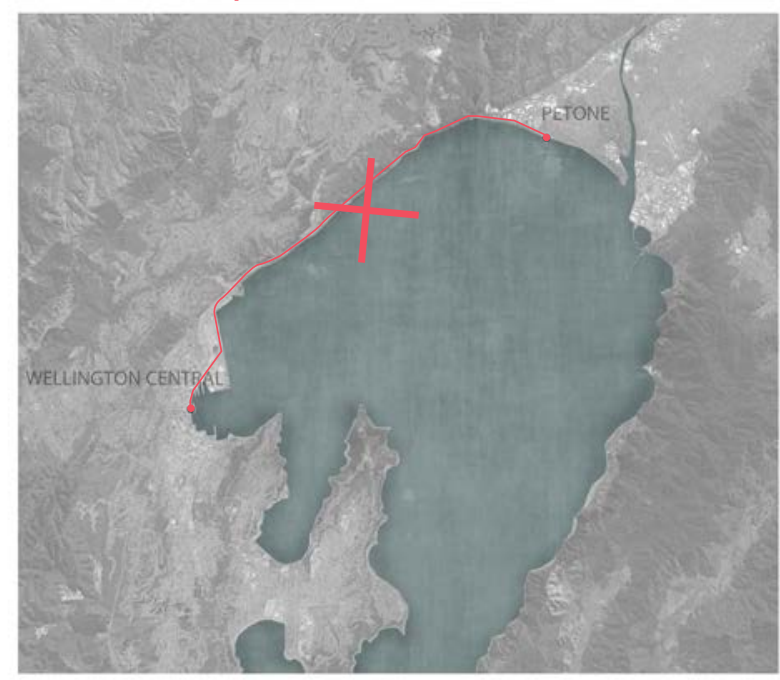

Post Ferry

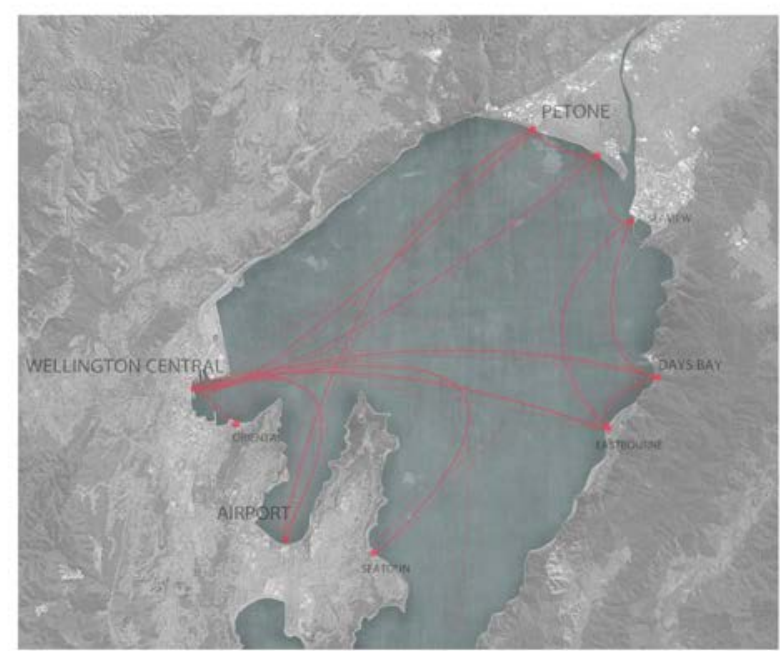

Figure 4.2 .4 (Above)_ Image showing how a ferry service can increase the resilience of Wellington City. (Authors own image).

\subsection{4_ Connection between Wellington City and Hutt City}

The current connection between Wellington City and Hutt City consists of a four-lane motorway and two sets of train tracks. This infrastructure sits on the thin strip of flat land between the harbour and a steep hillside.

There is a limited opportunity to widen this area as the earthworks needed to remove some of the hillside would be extensive. With growing traffic demands and a limited area to expand, this connection will struggle to meet the demands of the future traffic increases.

The other issue with this area is the fact that Wellington Region is located directly on a fault line. Several earthquakes have recently hit the region and the connection out of the CBD has been damaged. Large quantities of traffic clog the roads and train lines have been damaged. This thesis proposes a harbour connection that would better suit the topography and geographic location of Wellington harbour. 


\subsection{5_ Projected population growth}

Extrapolating the data in the 2006 census can generate population estimates. Figure 4.2 .5 shows the increase in population from 2001 to 2006 and then makes predictions on how that population may grow through to 2031.

The population in Wellington City is forecast to grow significantly over the next 17 years whilst growth in Hutt City is relatively low. One reason for this may be the connection between Wellington City and Hutt City doesn't function very efficiently. As discussed previously the motorway is already working at capacity during peak times and is a weak point in the system during a disaster. This can deter people that work in the CBD from living on the other side of the harbour. This may also contribute to the aging population in Hutt City as it is hard to access work and university in the $\mathrm{CBD}^{25}$. A ferry service could provide the catalyst for development along this harbour edge as travel into the city centre becomes a lot easier. This development could be increased by linking into the existing public transport network to strengthen the connection between the CBD and the rest of the population around the harbour.

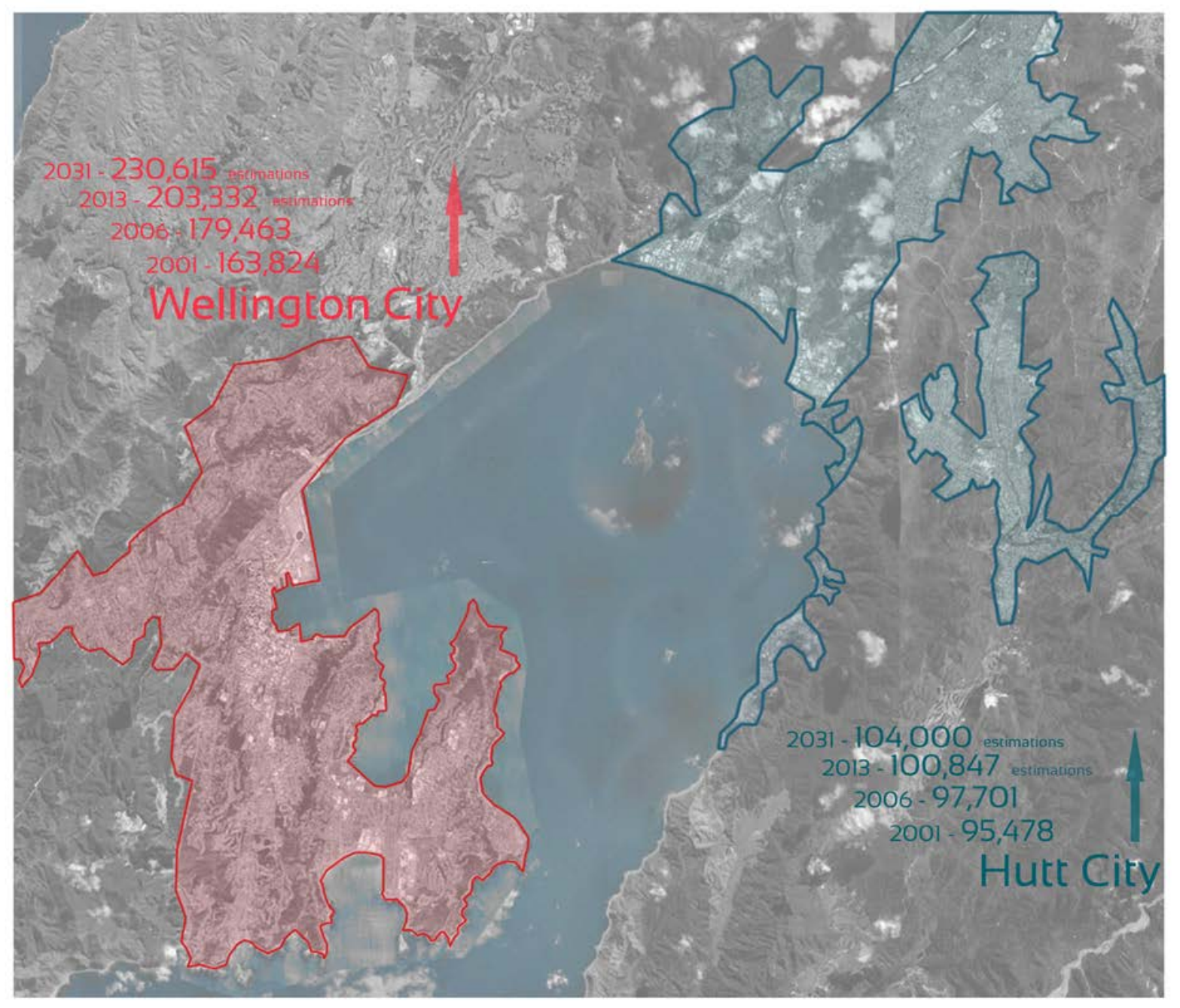

Figure 4.2.5 (Above)_ Mapping of current populations, and forecasts for further growth. (Authors own image). 


\subsection{6_ Existing ferry network}

There is an existing ferry service that operates between four stops. The main flow of movement is between Wellington Central and Days Bay. Figure 4.2.6 shows where the current ferry network exists in Wellington. The ferry doesn't service much of the coastline, which may be effecting its ability to become a key part of the transport system. It is hoped that by amplifying the existing service it will become a more viable way of moving around the harbour.

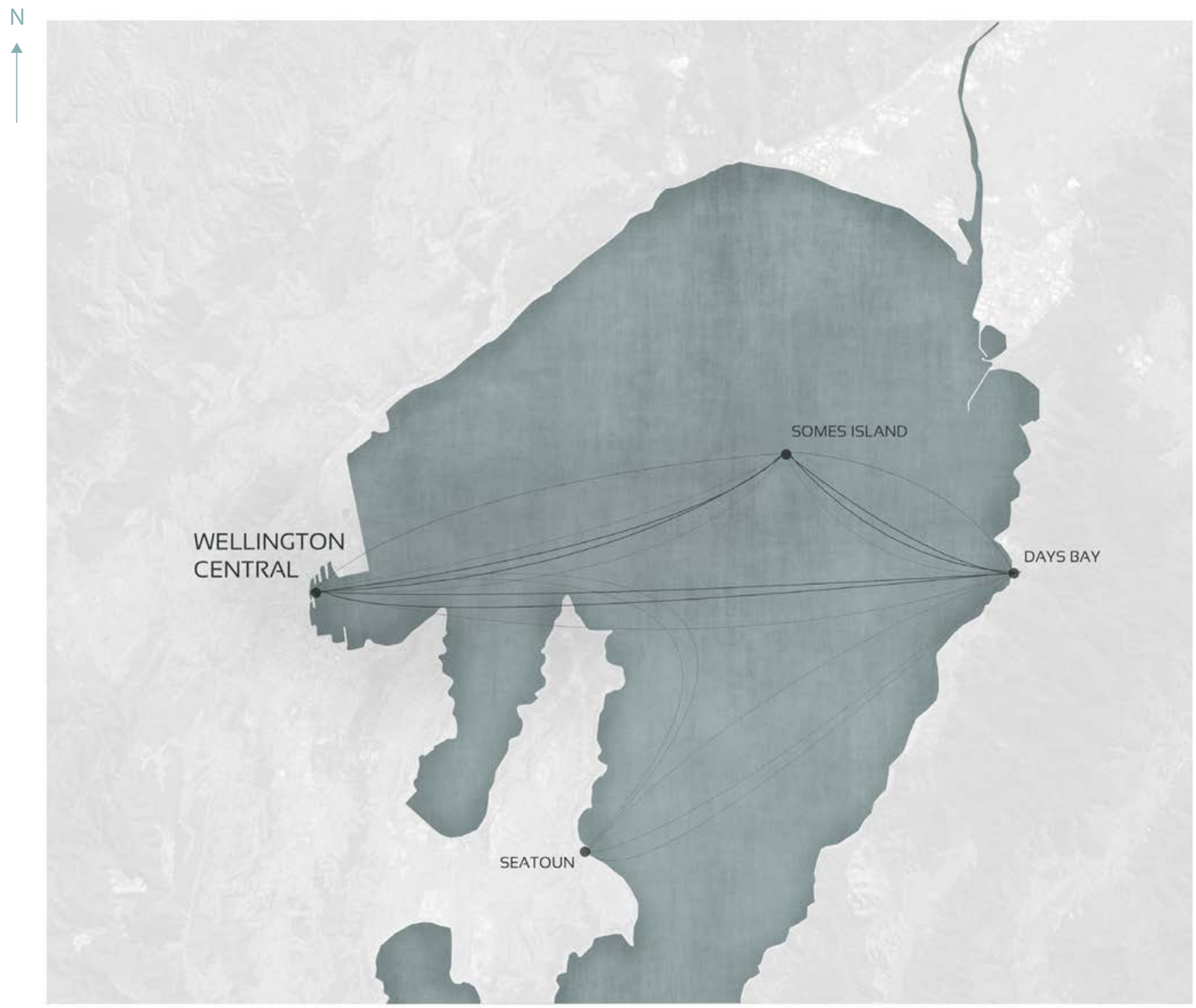

Figure 4.2.6 (Above)_ Mapping of existing ferry service on Wellington harbour. (Authors own image). 
There are multiple spots around the harbours edge that could sustain a ferry terminal. Figure 4.2.7 shows selected centres that could benefit from the ferry service. Some of these spots have existing wharves, whilst some just have a beach.

\section{WELLINGTON CENTRAL}




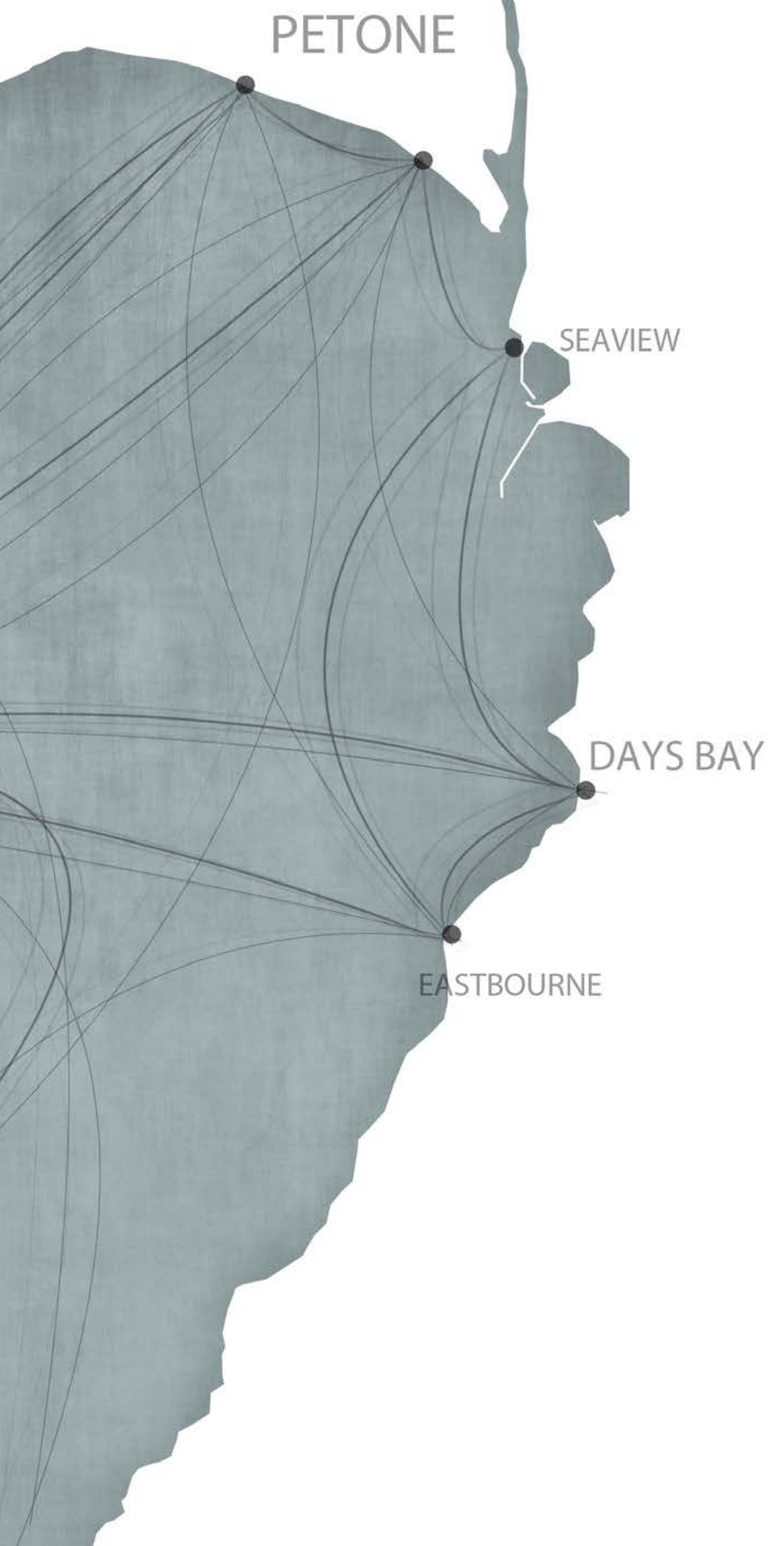

Figure 4.2.7 (Above)_Mapping of the potential ferry system. (Authors own image). 
_5 $\mid$ System Design 
The design section is split into two scales, that of the system and that of the landing site. With transport infrastructure it is important that the system works functionally, as that is what gets people to use that mode of transport. The system has been designed first to make sure that it is viable and then this allows the designer to design the terminal sites in a way that generates public life. This chapter uses information gathered in the positioning and site assessment chapters to design the ferry system. 
5.1_ Selected sites

Figure 5.1.1 (Above) The image shows the network of ferries that will established on Wellington harbour. (Authors own image).

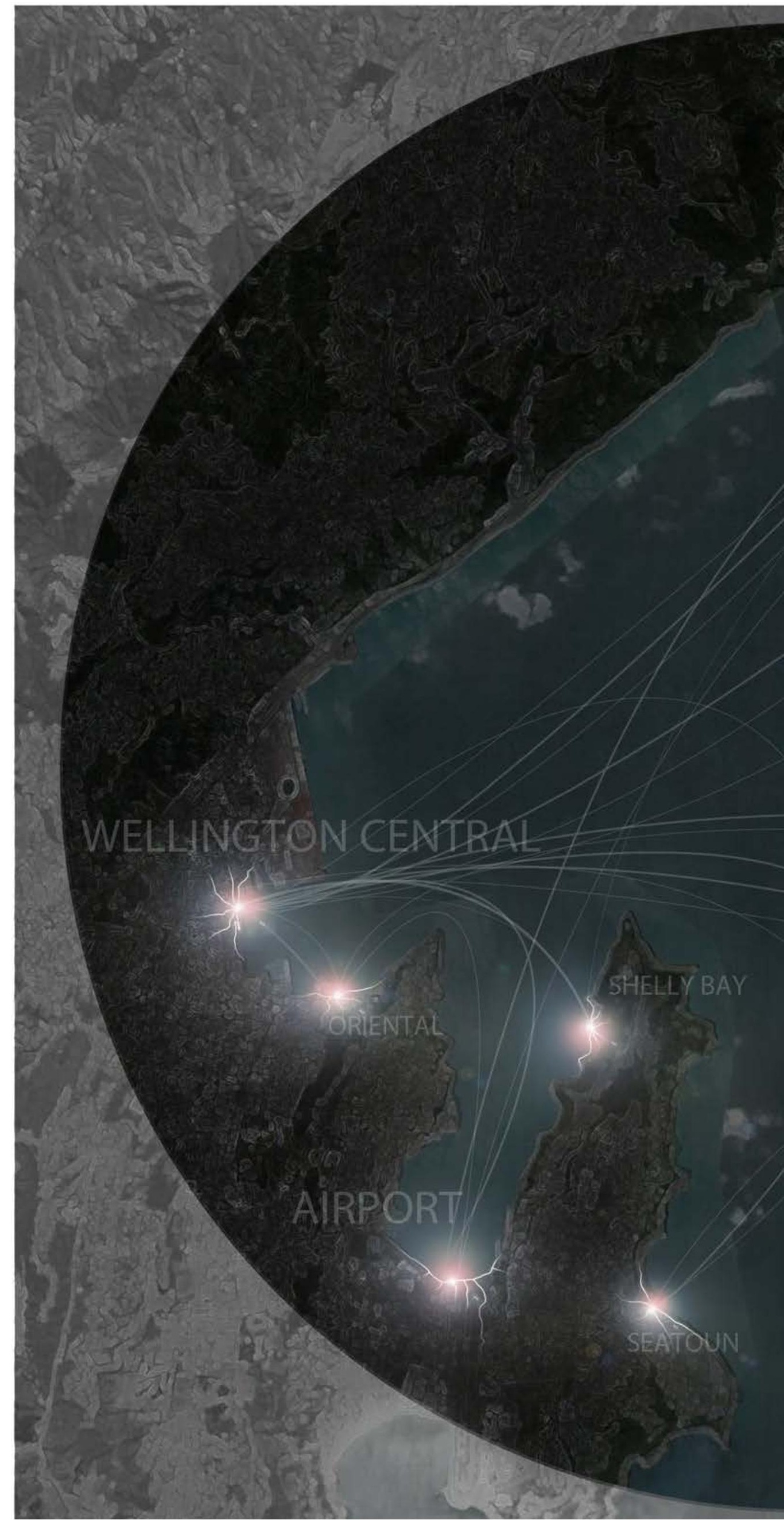




\subsection{1_ Development zones}

The purpose of these ferry sites are to act as catalysts for development and public life on the waterfront. Transit orientated development uses 800 metres as the distance someone will walk to utilise public transport ${ }^{26}$. This distance is an arguable number as other factors such as terrain and quality of public space must also influence the limit in which a pedestrian will travel. Although the exact distances are debatable 800 metres is a good starting point to indicate where development associated with the ferry service may occur. These maps are indications of the 800-metre radius on each ferry site.

\section{Wellington Central}

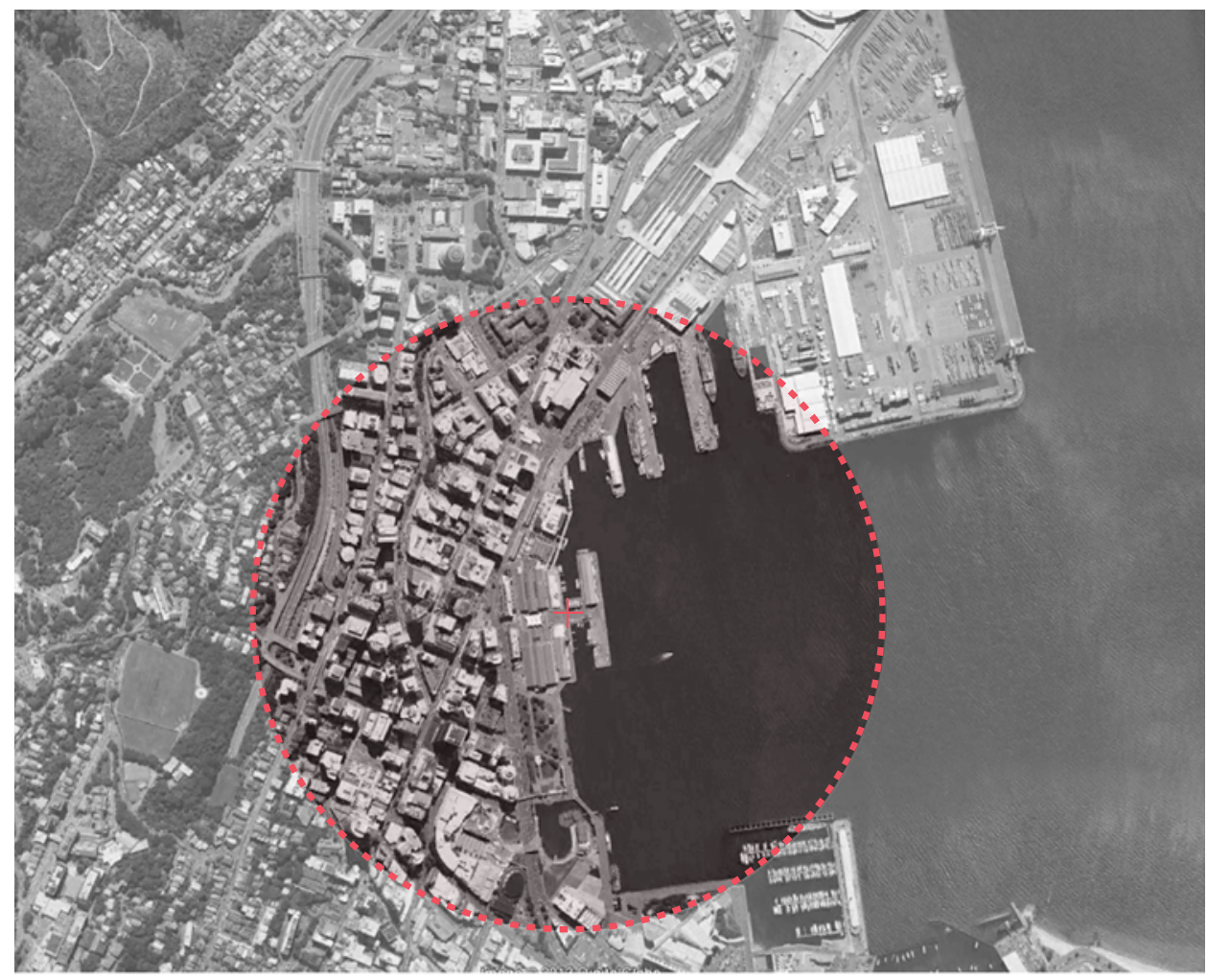

Figure 5.1 .2 (Above)_ 800 metre radius for transit orientated development in Wellington Central. (Authors own image). 


\section{Airport}

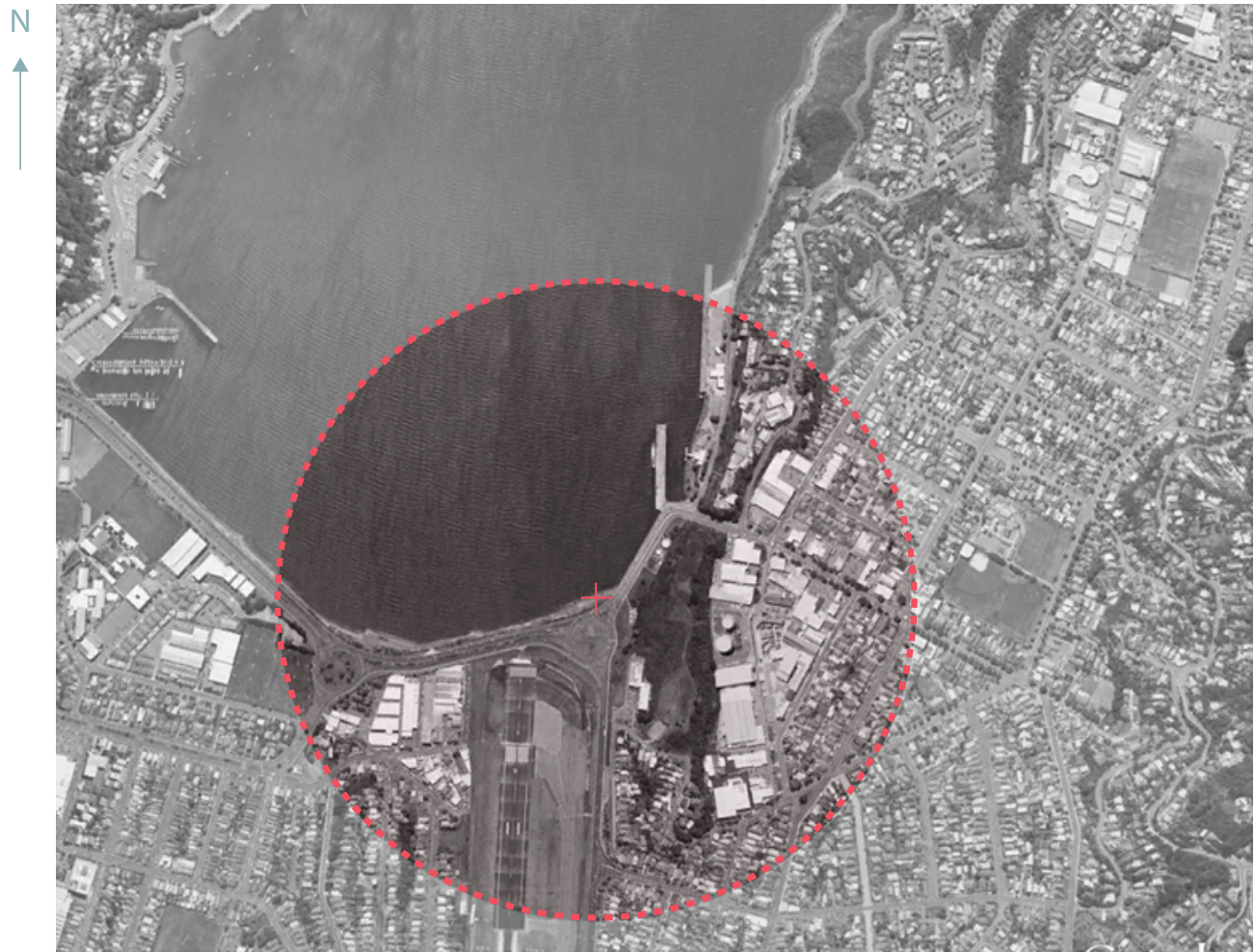

Figure 5.1.3 (Above) 800 metre radius for transit orientated development at the airport. (Authors own image).

Seaview

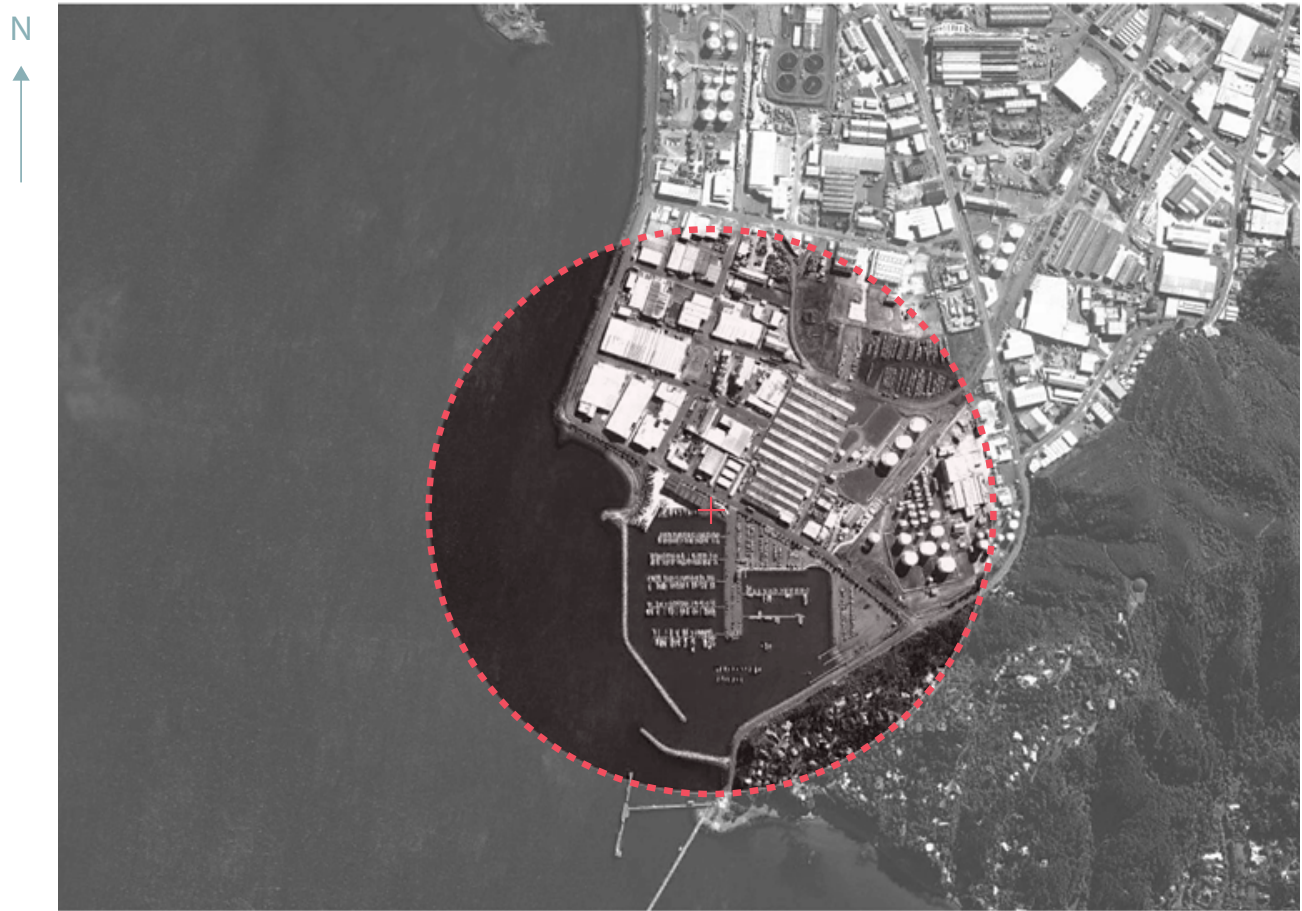

Figure 5.1.4 (Above) 800-metre radius for transit orientated development in Seaview. (Authors own image). 


\section{Eastbourne}

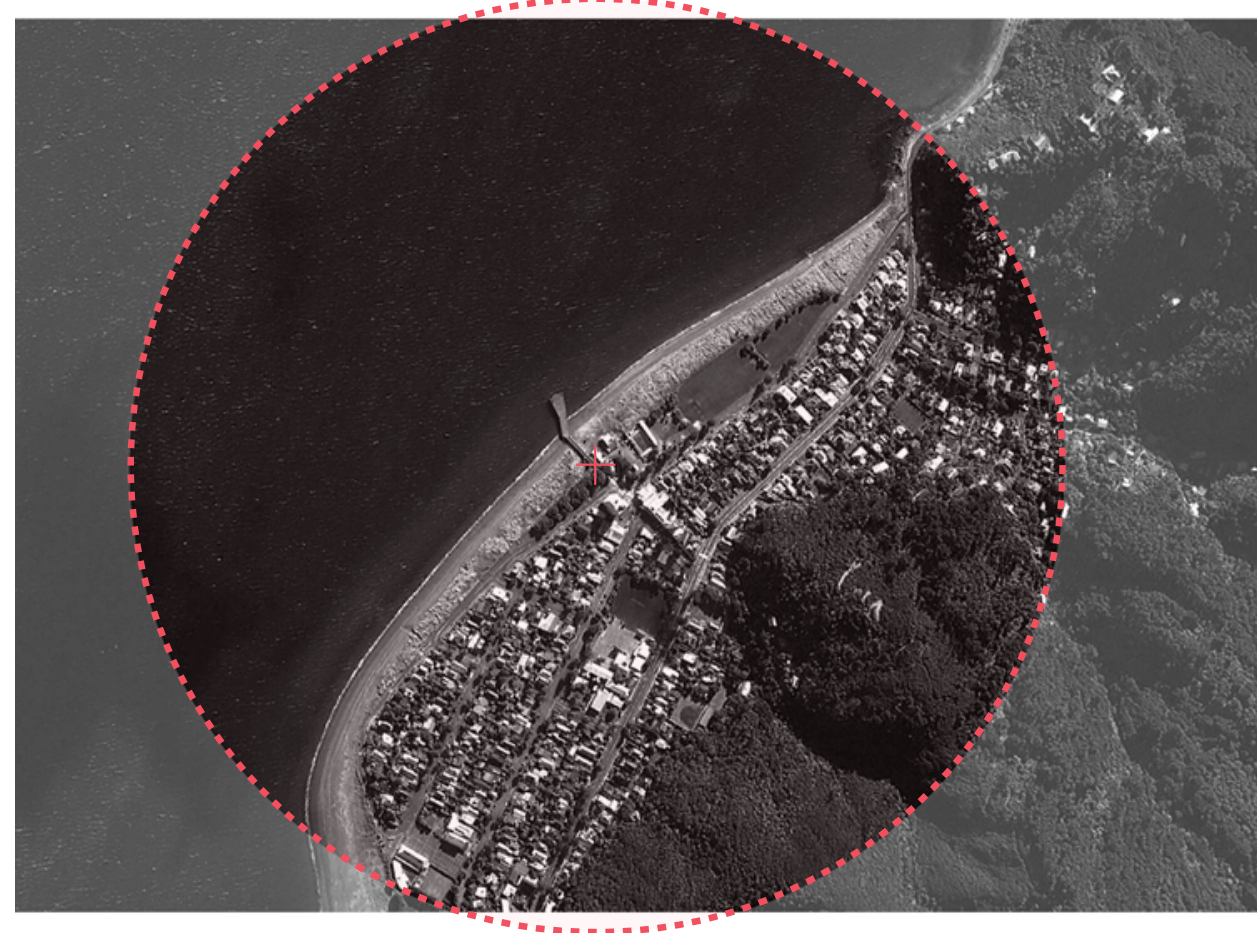

Figure 5.1.5 (Above)_ 800-metre radius for transit orientated development in Eastbourne. (Authors own image).

\section{Petone 1}

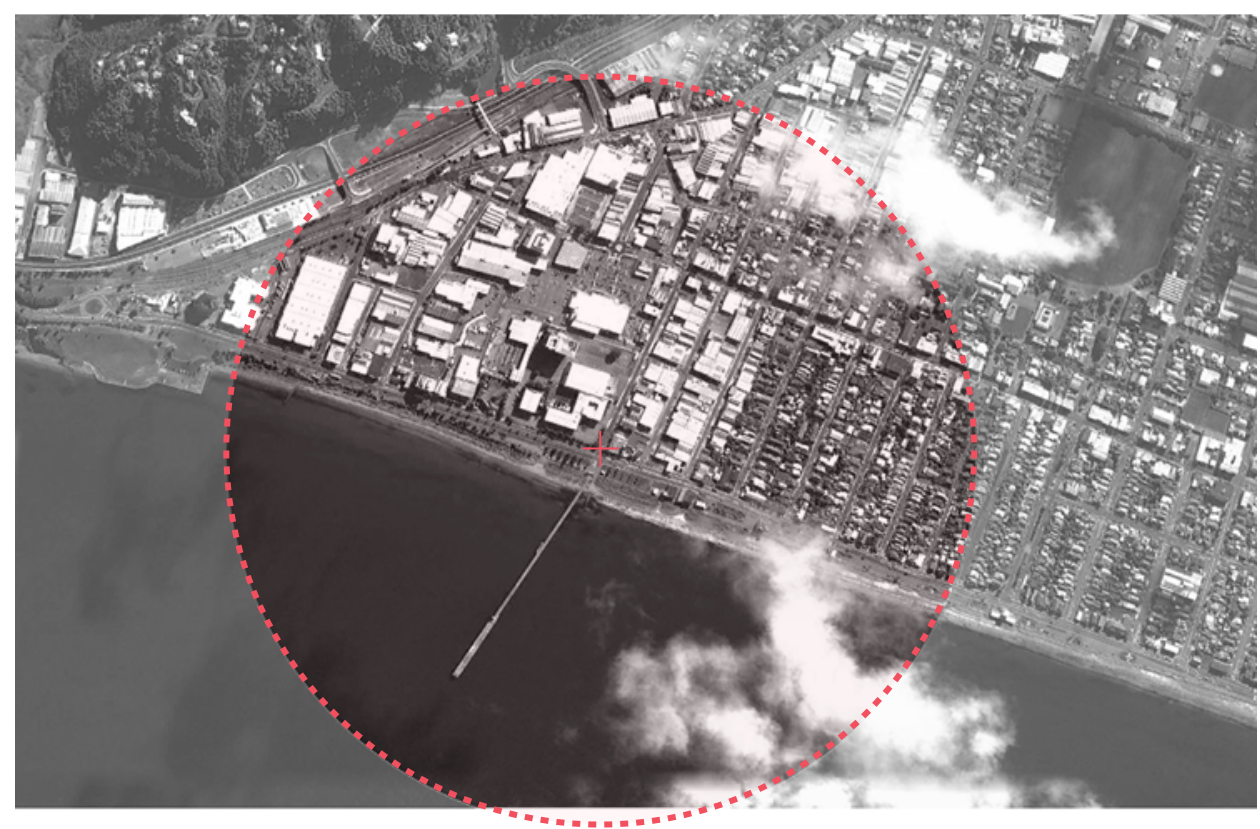

Figure 5.1.6 (Above)_ 800-metre radius for transit orientated development at the Petone, site one. (Authors own image). 
Petone 2

N

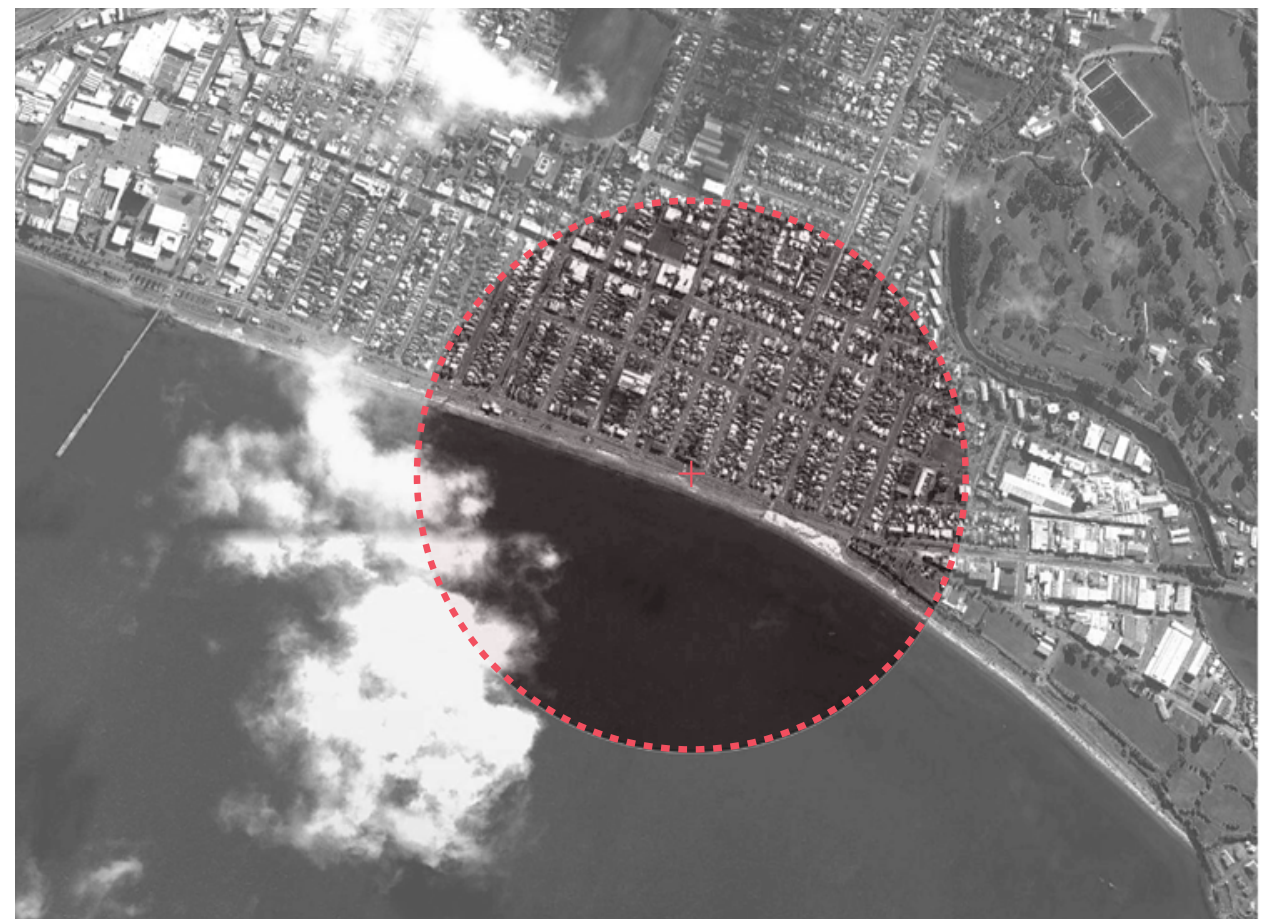

Figure 5.1 .7 (Above)_ 800-metre radius for transit orientated development in Petone, site two. (Authors own image).

\section{Seatoun}

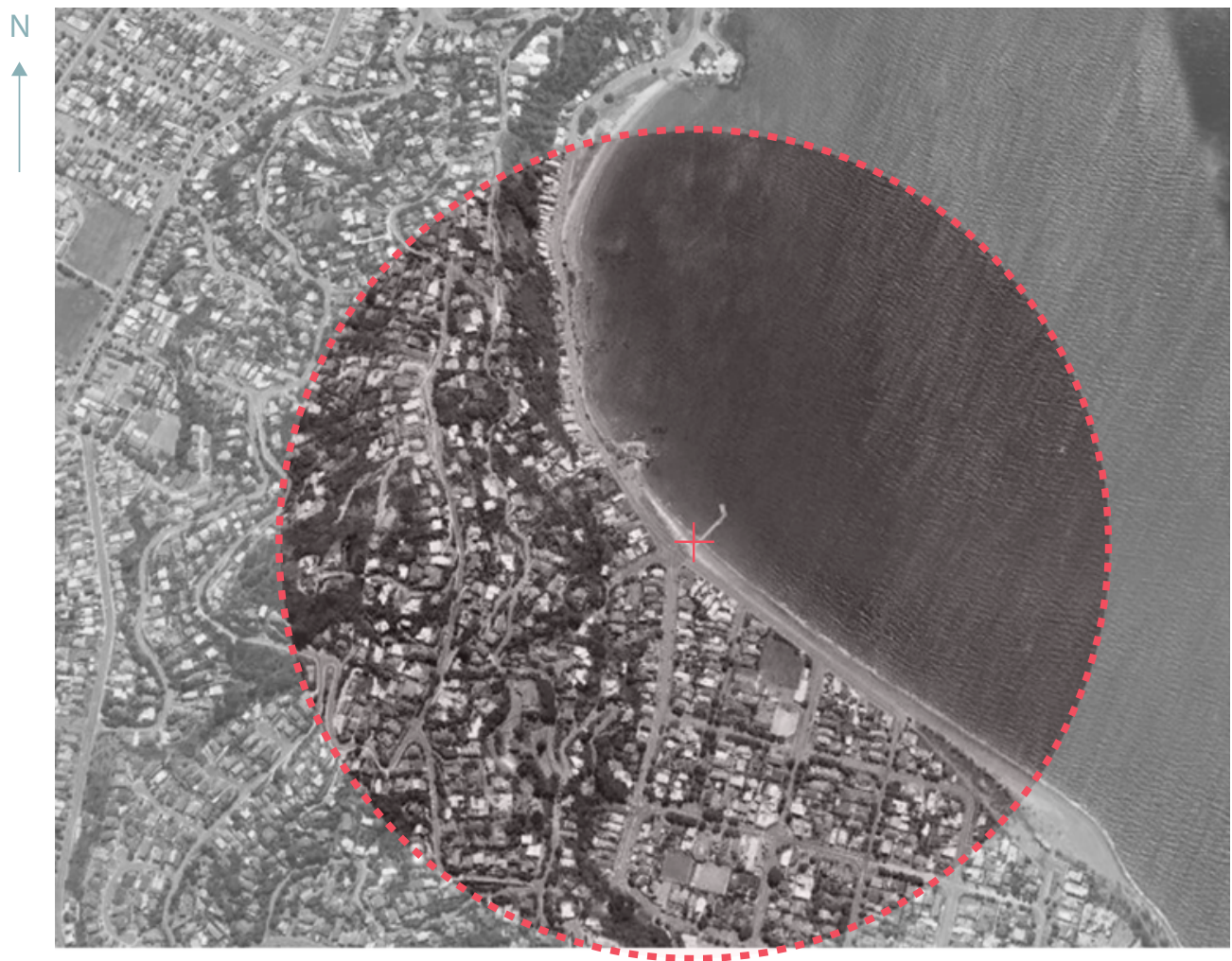

Figure 5.1 .8 (Above)_ 800-metre radius for transit orientated development in Seatoun. (Authors own image). 
Oriental Bay

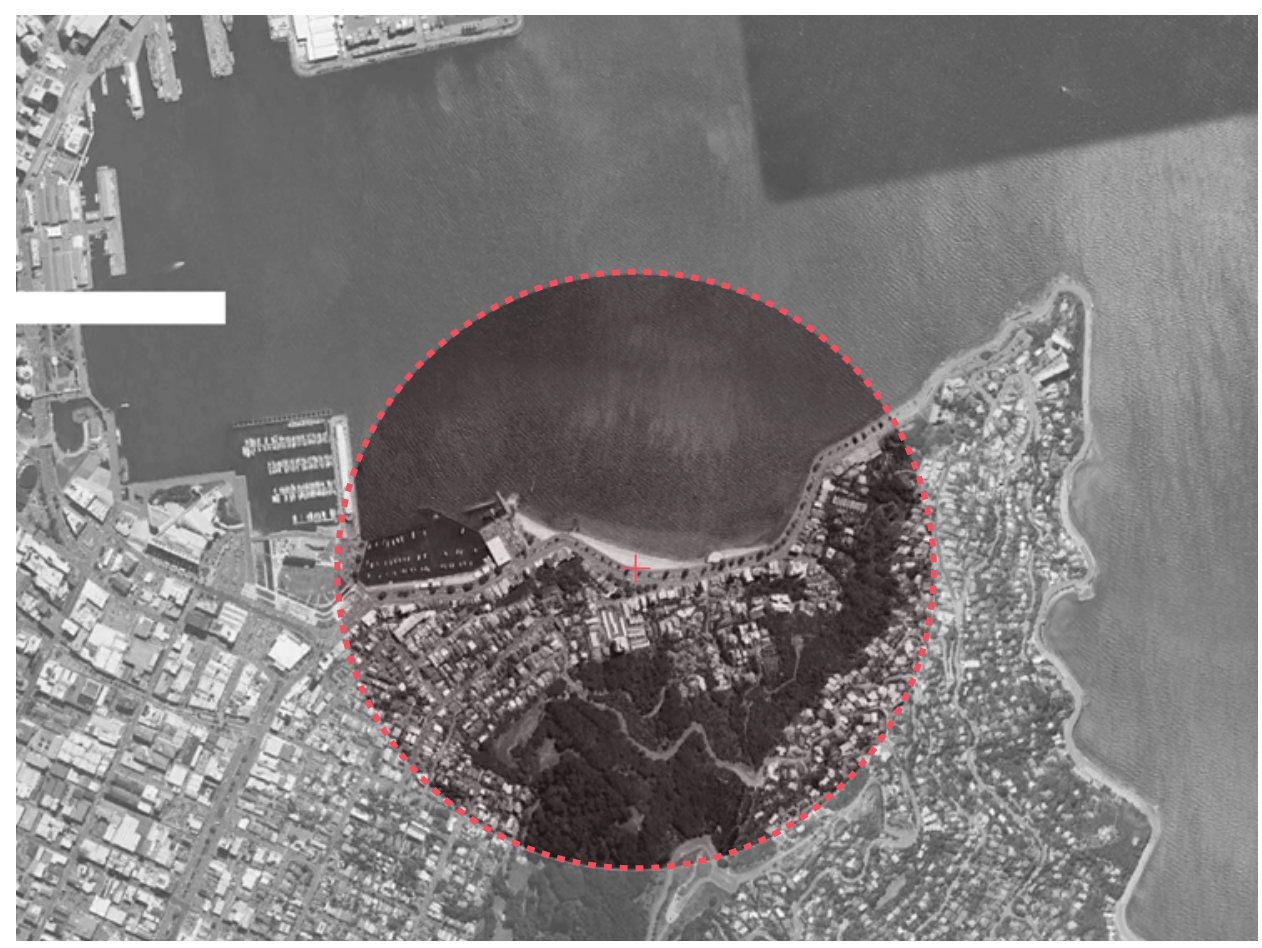

Figure 5.1.9 (Above)_ 800-metre radius for transit orientated development in Oriental Bay. (Authors own image).

Shelly Bay

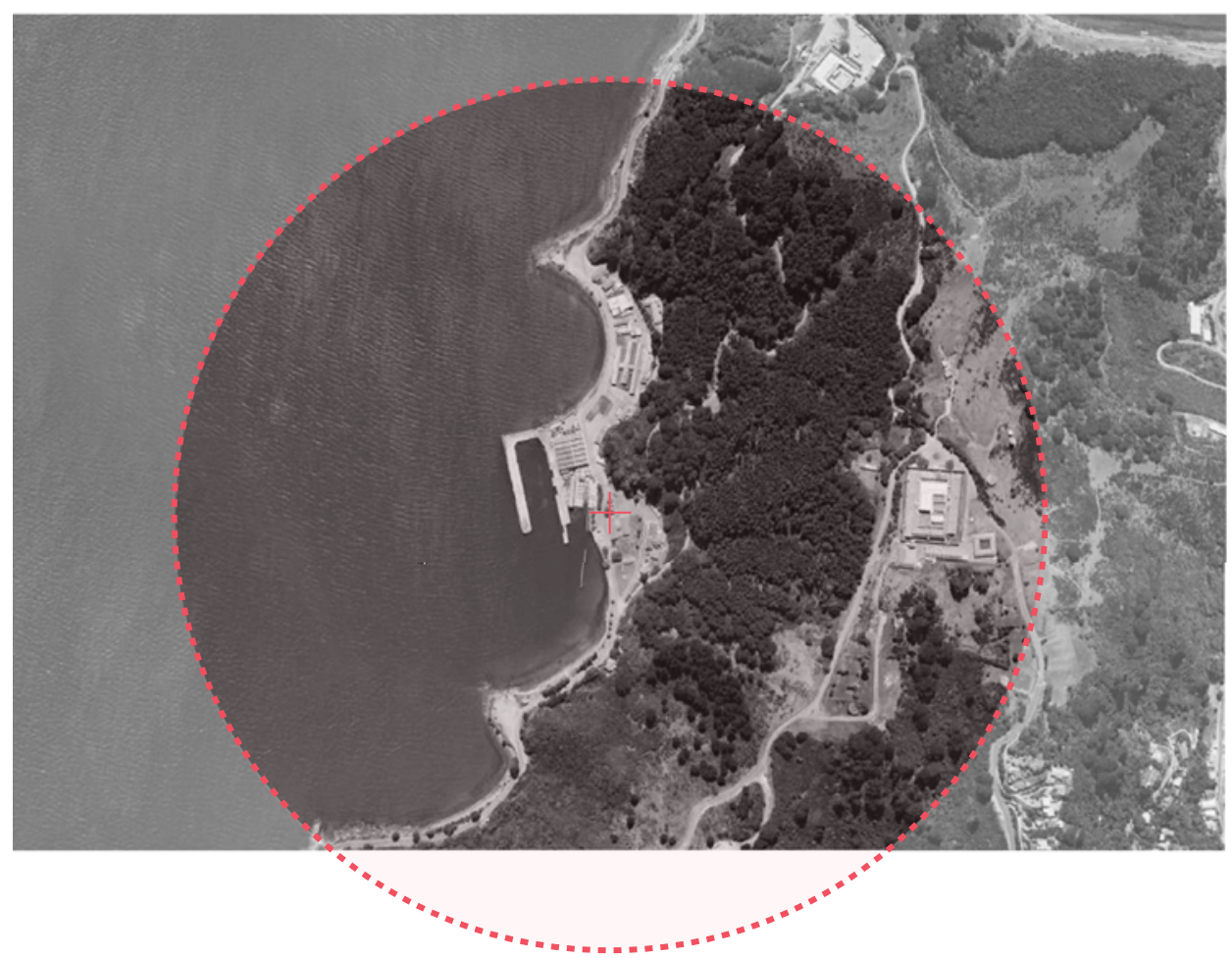

Figure 5.1.10 (Above)_ 800-metre radius for transit orientated development at the Shelly Bay. (Authors own image). 
Days Bay

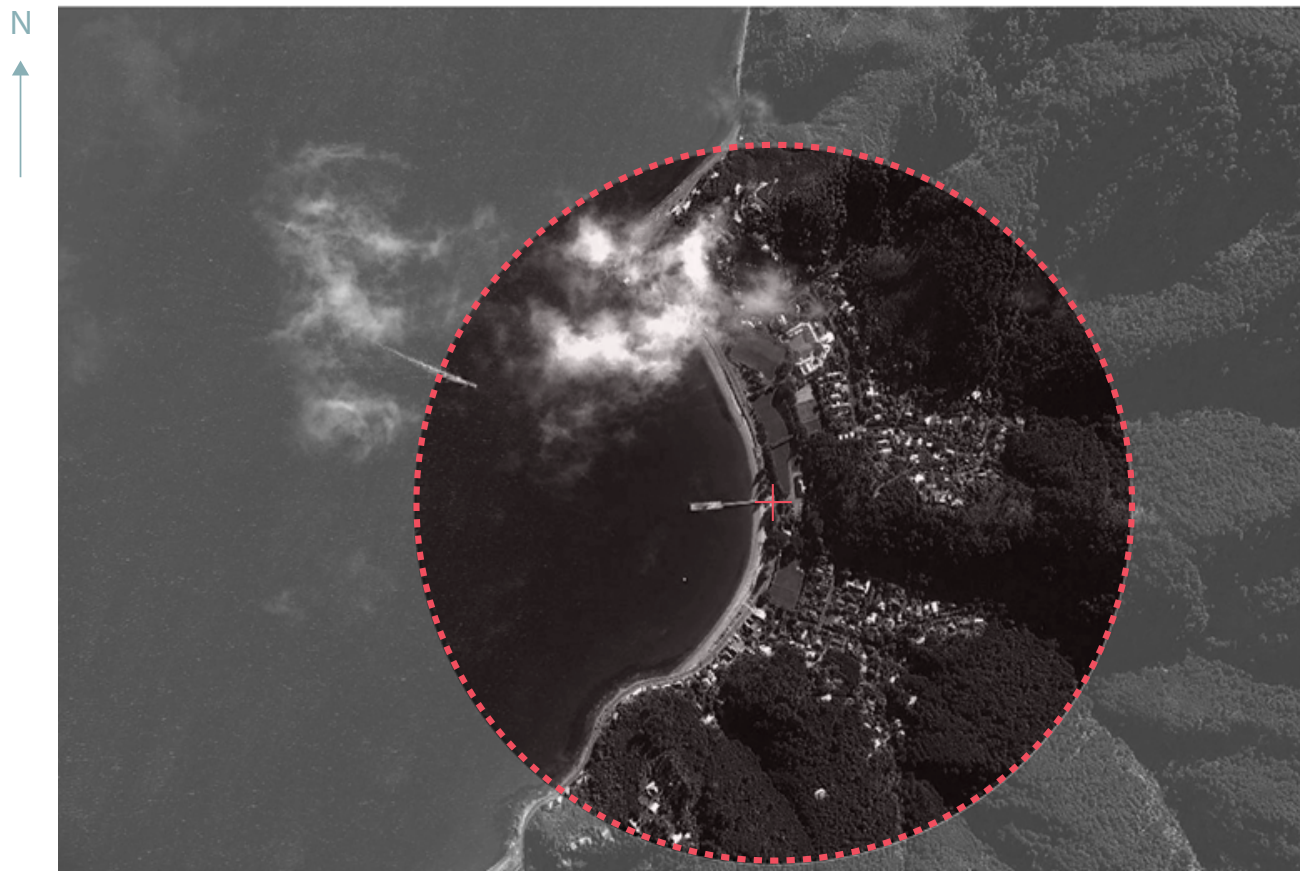

Figure 5.1.11 (Above)_ 800-metre radius for transit orientated development in Days Bay. (Authors own image). 


\section{2_ Ferry logistics}

Through consulting with ferry owners it became evident that the functional side of the ferry system needs to be working well before any public life will be generated. If the system doesn't work efficiently the ferry infrastructure is likely to fail. Waiting times, distances, peak hour travel, and boat numbers all need to be thought of to encourage people to use the system.

\subsection{1_ Peak hour express travel}

The ferry will operate differently at peak hour travel than it will during the rest of the day. During the peak times the ferry system must run quickly and efficiently as this is when people are moving to and from. The scenic nature of the ferry isn't as important as getting to the destination quickly. This has lead to one ferry in each route running an express service. This service moves between Wellington Central and some of the large ferry stops and some of the small terminals are removed. The other ferry on that route runs as normal. The speed of the system is increased and it becomes a viable way of moving round the system. Car parking and other transport modes may be increased at these larger centres to accommodate the large flow of people.

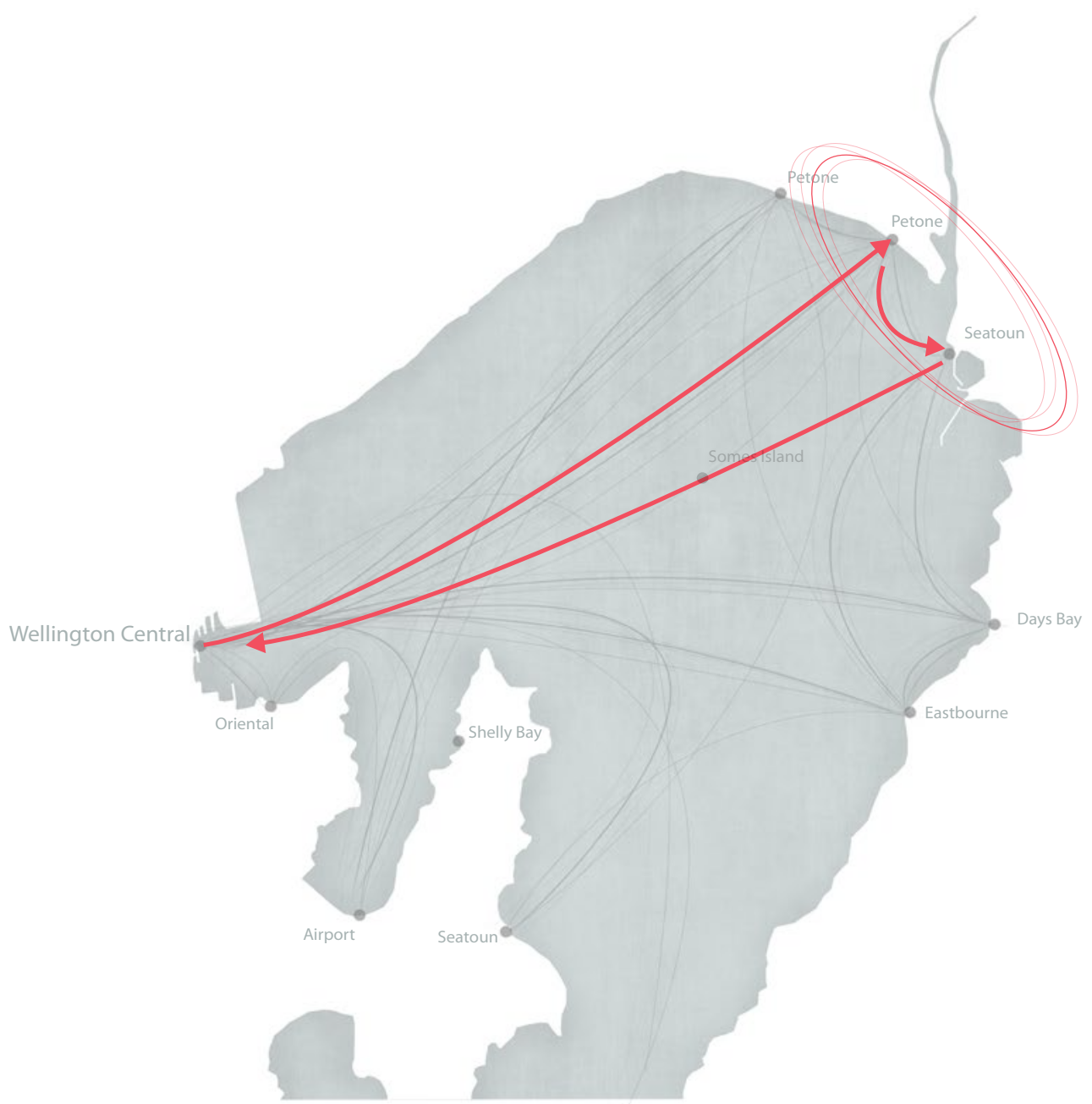

Petone Route

Specifications_

- Two boats

- As one

boat leaves

Wellington the

other returns

from Petone

$-20-25$

minute journey

Figure 5.2.1 (Above)_ Mapping of the express service to Petone. (Authors own image) 


\section{Eastbourne Route}

Specifications_

_ Two boats

_ As one

boat leaves

Wellington the

other returns

from Eastbourne

_-20 - 25 minute journey

Miramar Route

\section{Specifications_}

_ Two boats

_ As one boat leaves Wellington the other is half way between Shelly Bay

_ 15-20 minute journey

_ Allows for the Shelly Bay development to connect back to Wellington Central

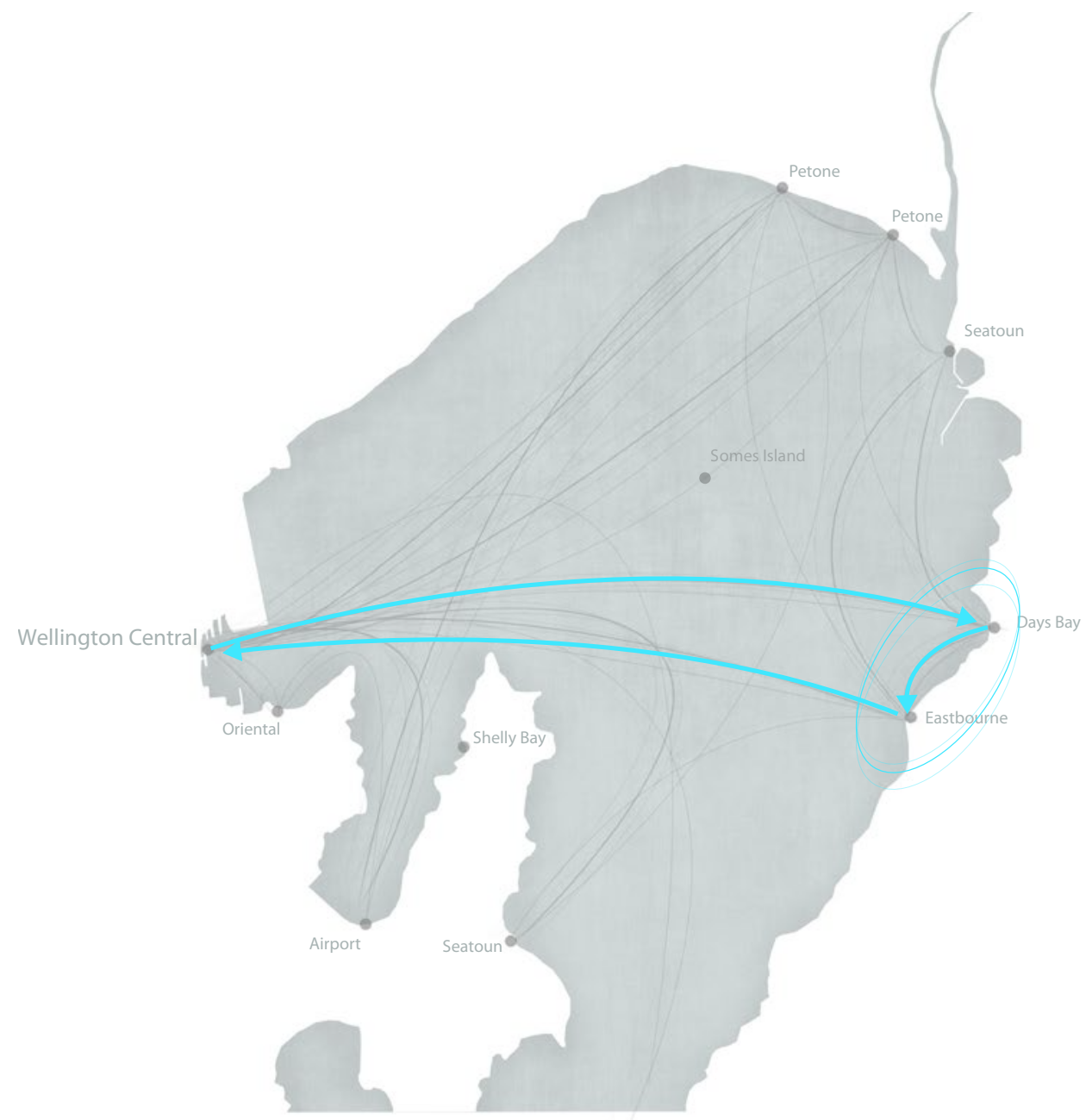

Figure 5.2.2 (Above)_ Mapping of the express service to Eastbourne. (Authors own image).

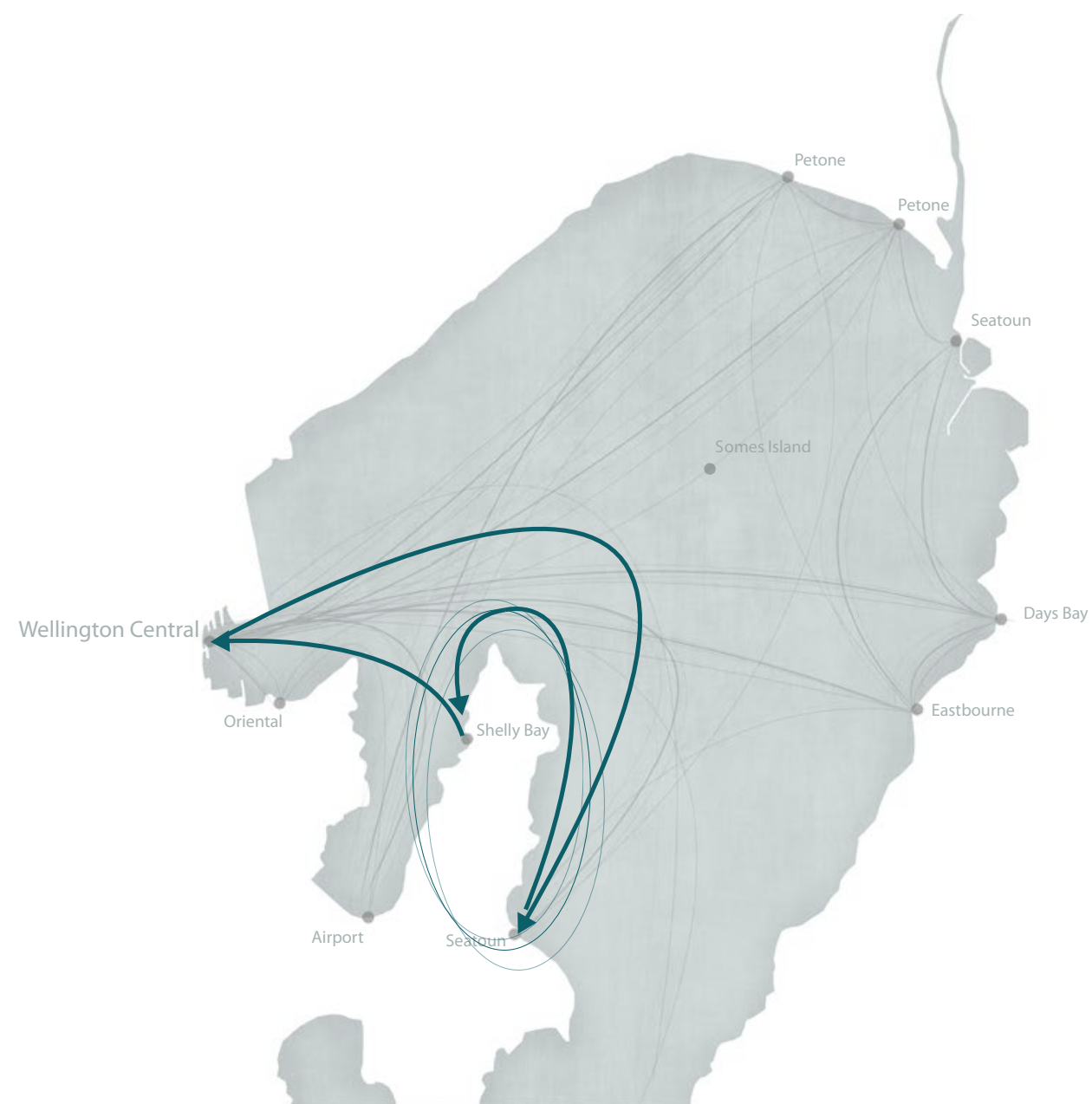

Figure 5.2.3 (Above)_ Mapping of the express service to Miramar. (Authors own image). 


\subsection{2_ Off Peak/Weekend travel}

At off peak times and on the weekend the waiting times can be slightly longer as people tend not to be in as much of a rush. Small recreational ferry terminals such as Oriental Bay are added into the system and most of the harbours edge is activated.

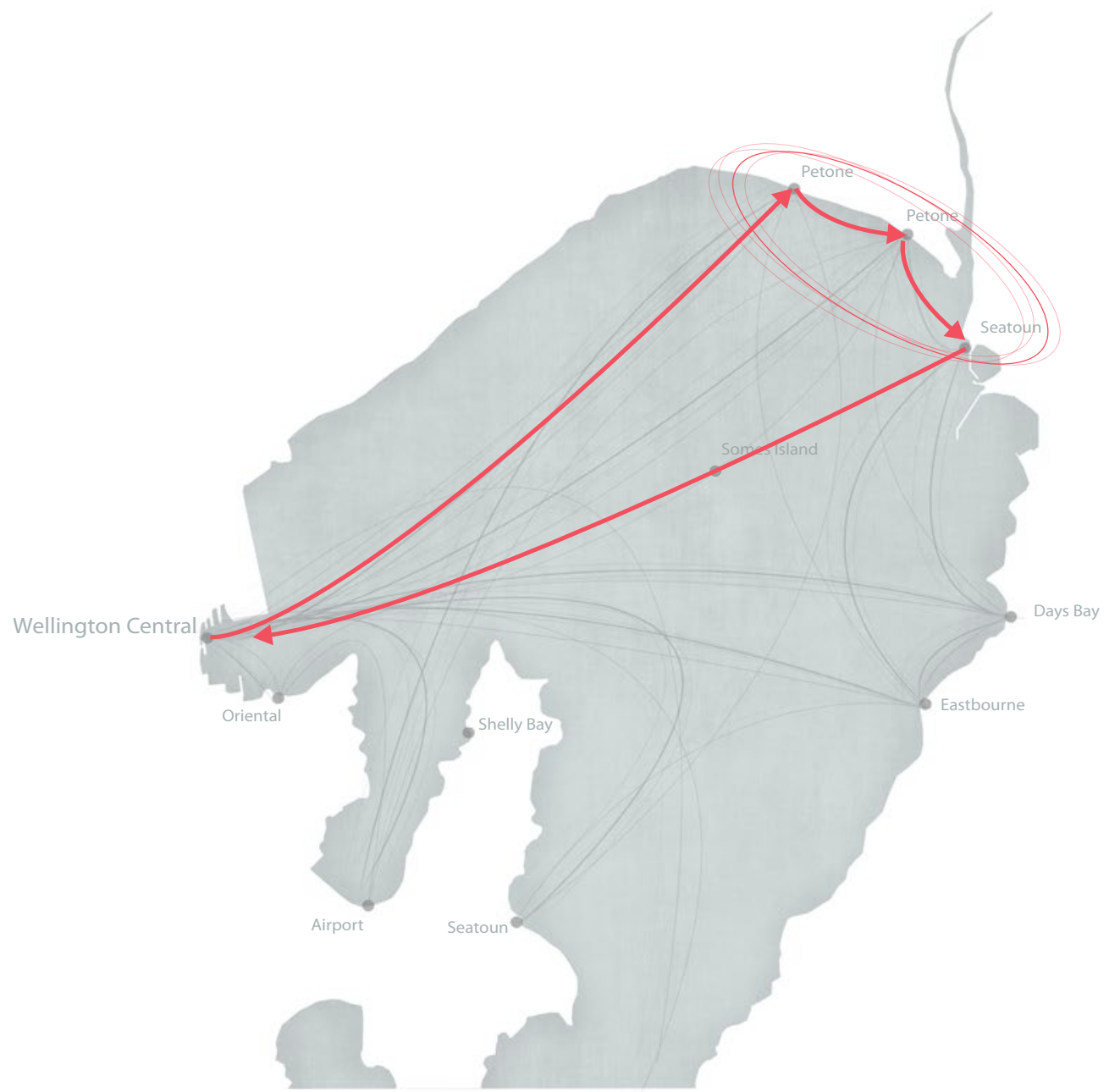

Petone Route

Specifications_

_ Two boats

_ Extra Petone terminal added into the system to increase connectivity

Figure 5.2.4 (Above)_ Mapping of the off peak service to Petone. (Authors own image). 


\section{Eastbourne Route}

\section{Specifications_}

_ Two boats

Somes Island

terminal added to the system.

This is more of a tourist stop rather than an area with large development.

\section{Miramar Route}

\section{Specifications_}

_Two boats

_ Allows for the Shelly Bay development to connect back to Wellington Central

\section{_ Oriental Bay} included in the system to connect people to the beach.

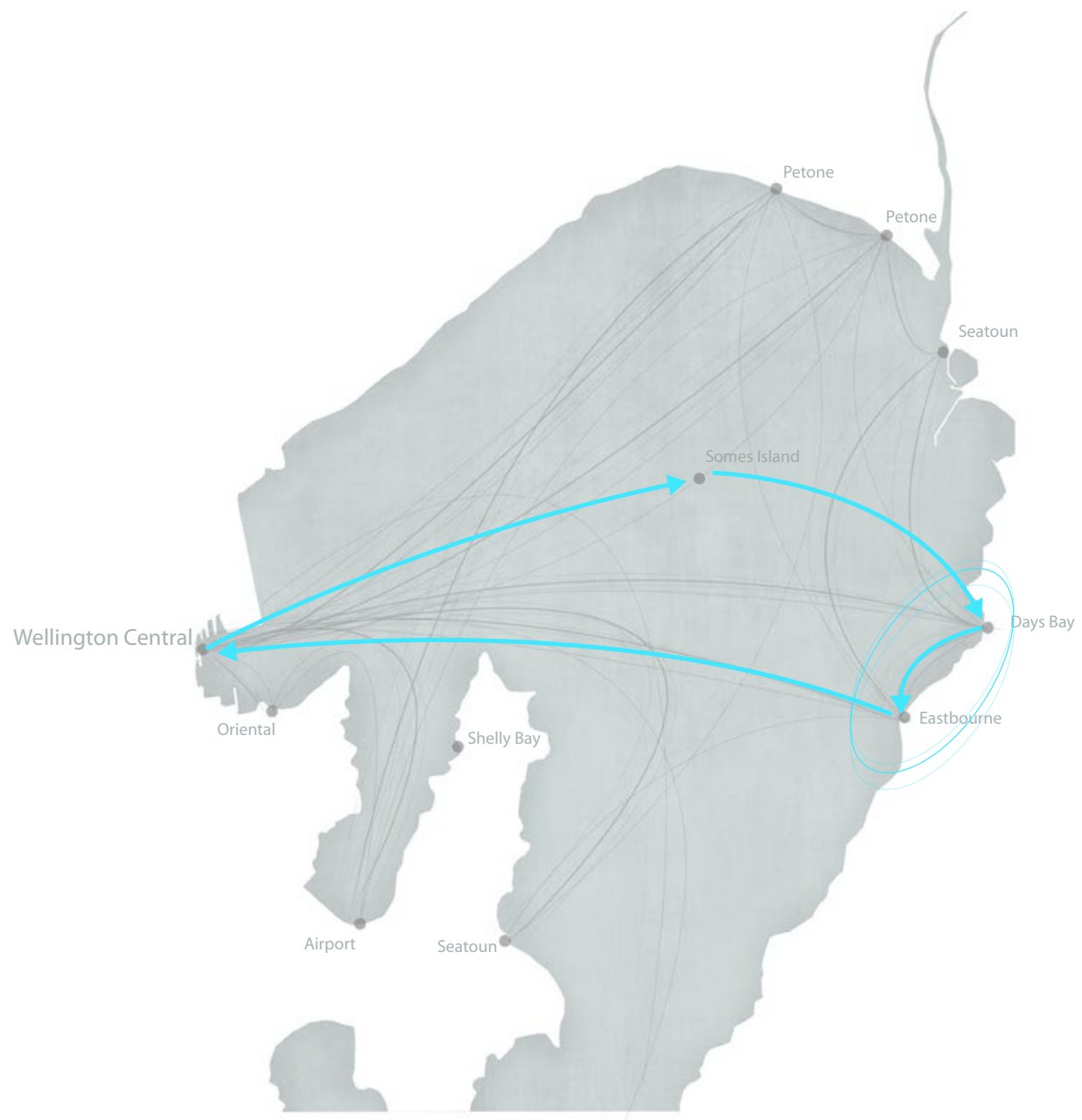

Figure 5.2.5 (Above)_ Mapping of the off peak service to Eastbourne. (Authors own image).

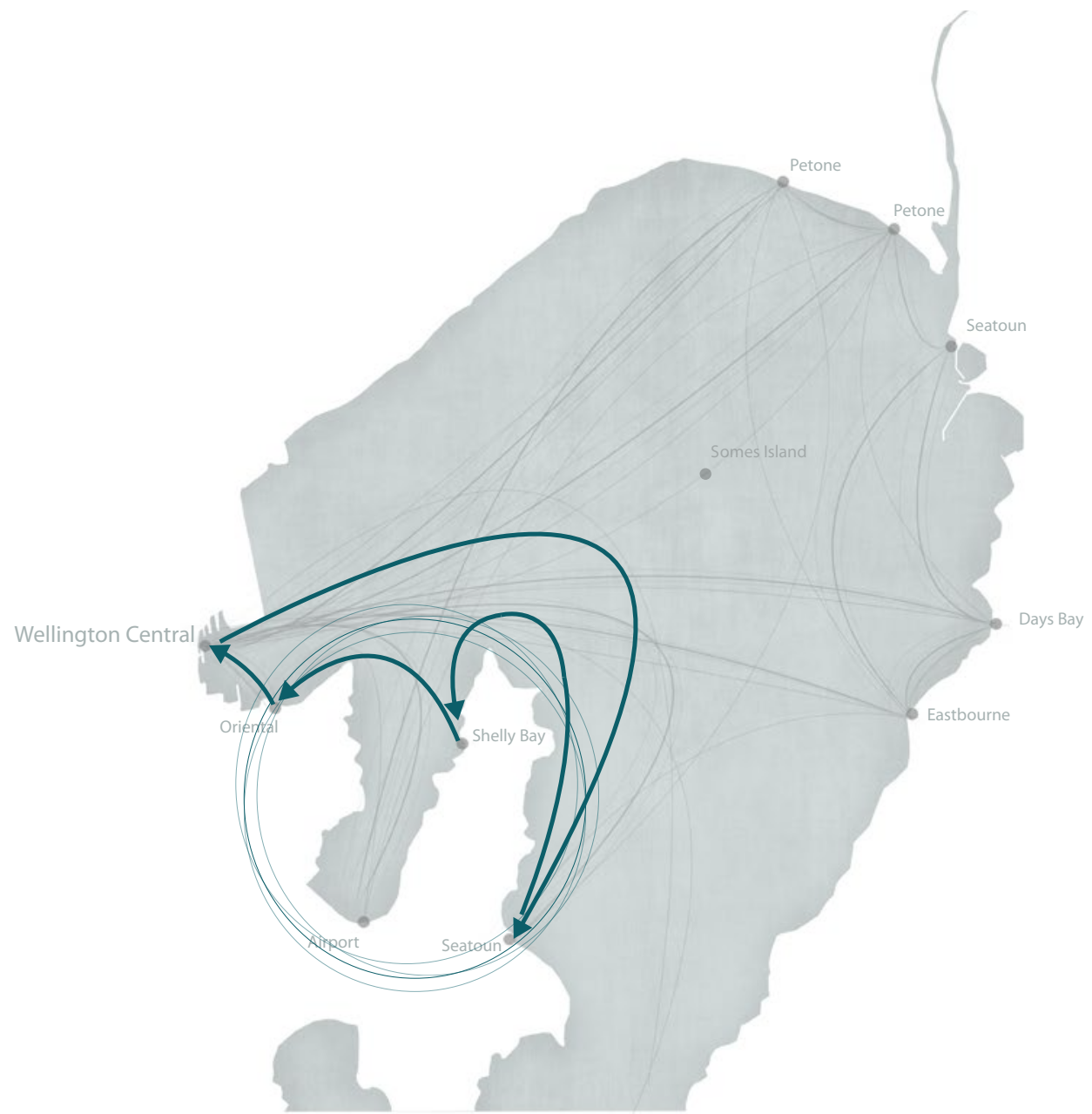

Figure 5.2.6 (Above)_ Mapping of the off peak service to Miramar. 


\subsection{3_ Airport System}

There are two ways in which the airport ferry could function. The first is shown in figure 5.2.7 and involves people getting into Wellington City via any mode of transport. Their bags are handed over at the ferry terminal and are moved through the system so people don't need to handle them until they reach check in. People then get onto the ferry which travels to the ferry wharf to the north of the airport, they move into a shuttle which brings them the short distance to the airport doors.

The second option is shown in figure 5.2.8 and involves the ferry being able to move right up to terminal itself, removing the need for the shuttle. This would require the terminal to move north, or some form of channel that would connect the airport to the harbour.
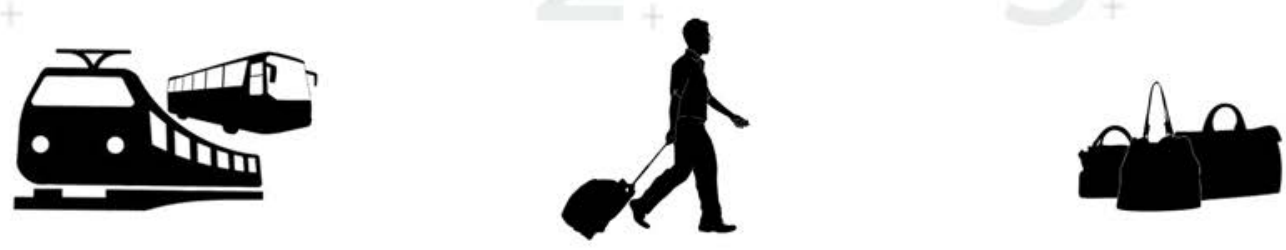

Get off the train/bus/car

in Wellington city
Walk to the ferry

terminal
Drop off bags/suitcases.

These will then go

straight through the

system to the airport. No

more carrying needed

by passenger

Get on to fel 


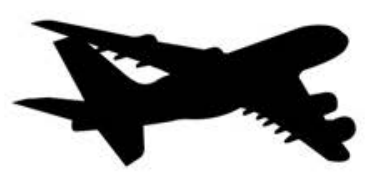

Travel across to the airport on the ferry -

bypassing all the traffic
Hop onto a shuttle that is waiting for the ferry to carry the passengers

down to the airport
Jump straight onto the plane to reach your destination

Figure 5.2.7 (Above)_ Option one for the airport ferry service. Requires a wharf in Evans Bay. (Authors own image). 

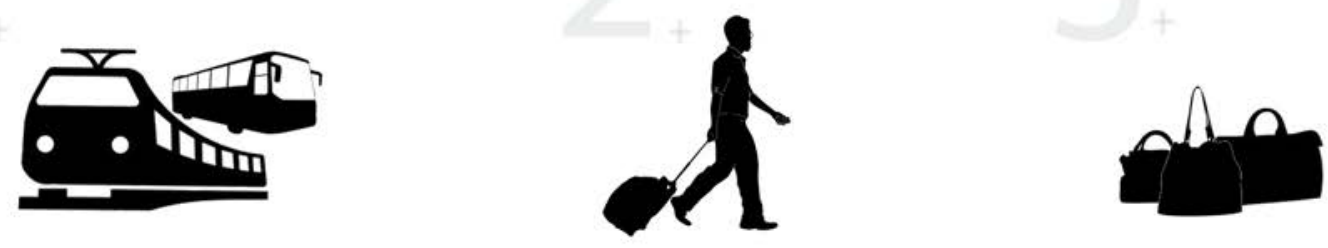

Get off the train/bus/car

in Wellington city
Walk to the ferry

terminal
Drop off bags/suitcases.

These will then go

straight through the system to the airport. No more carrying needed

by passenger

Figure 5.2.8 (Above)_ Option two for the airport ferry service. Requires a canal from Evans Bay to the airport terminal. (Authors own image). 


\subsection{4_ Number of ferries}

There are four groups of ferries that make up the ferry network. The Petone group, Eastbourne group, Miramar group, and the airport connection. Each of these routes will need two ferries initially to start operating effectively. Any less and the waiting times will be too long and people may not use the network. The system will need eight ferries to operate successfully once all ferry locations are realised.

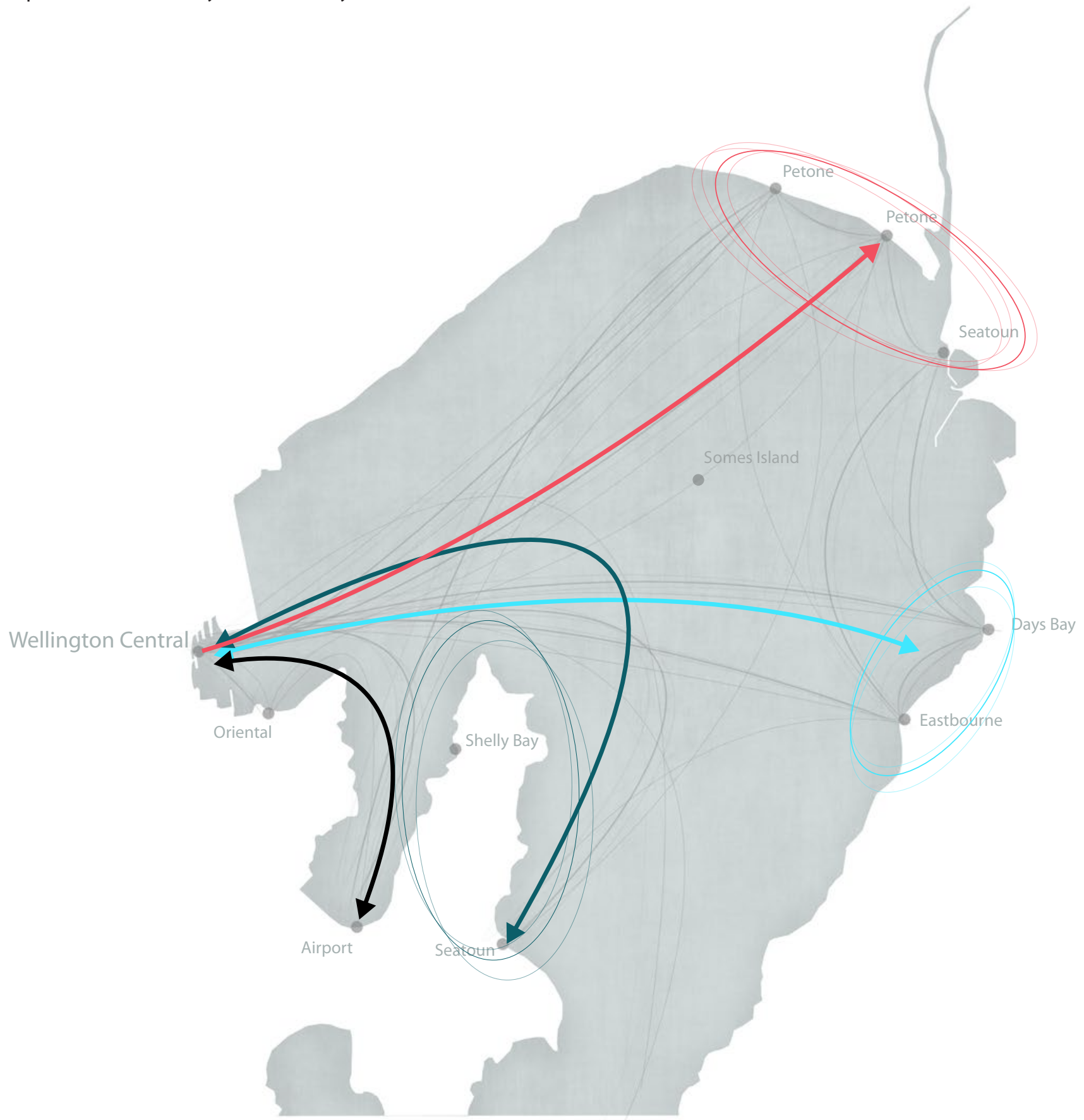

Figure 5.2.9 (Above)_ Map showing the different ferry routes. Each route needs two ferries. (Authors own image). 


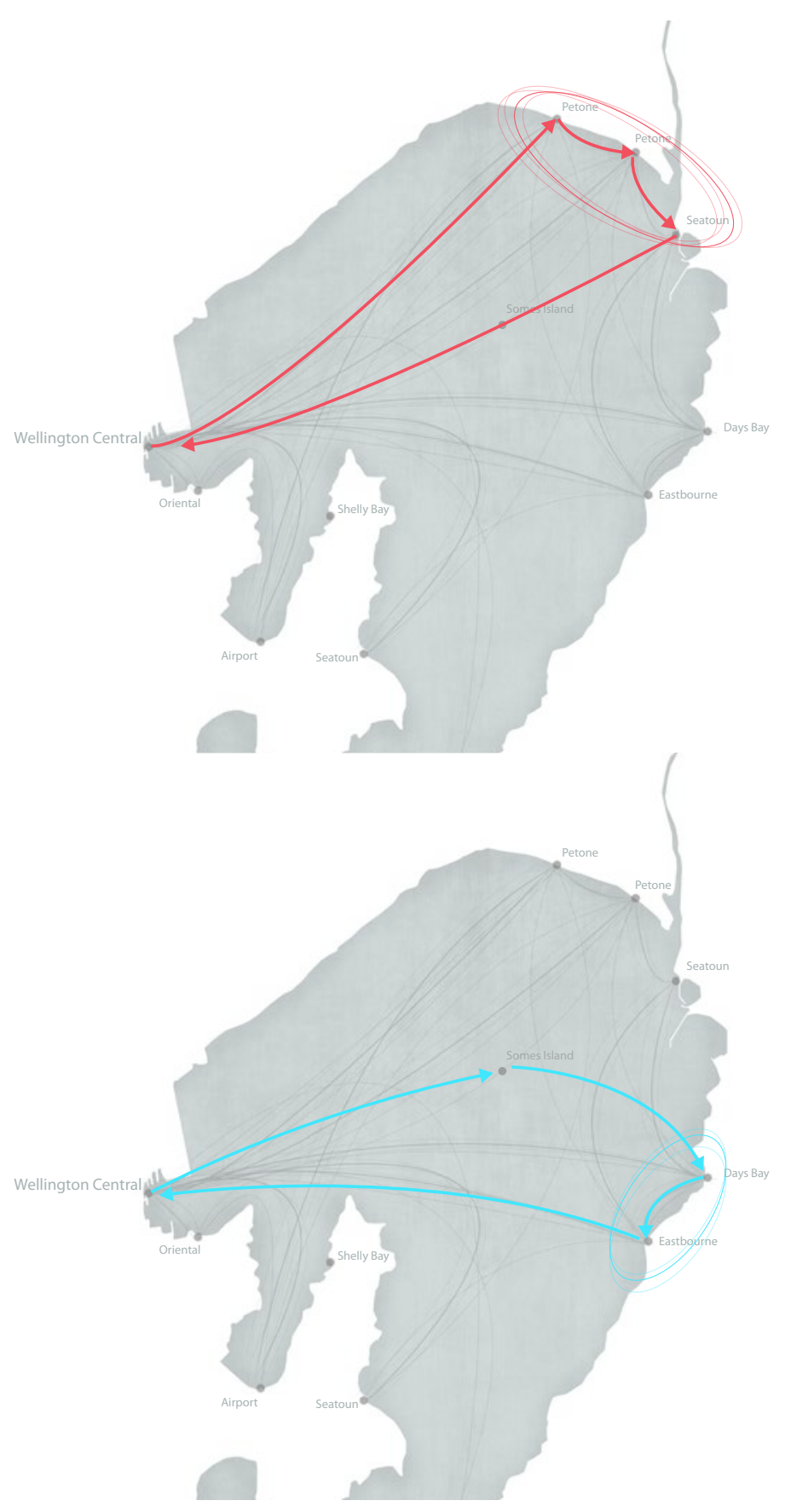

\subsection{5_ Waiting times}

Petone Route

Specifications_

_ Runs every 30

minutes

_ 25 - 30 minute journey

\section{Eastbourne Route}

Specifications_ _ Runs every 30 minutes

_ 20 - 25 minute journey

\section{Miramar Route}

Specifications_

_ Runs every 30 mins

_ 15-20 minute journey 


\section{3_ Implementation}

\subsection{1_ Connection to rest of transport network}

It is important that the ferry system plugs into the existing transport system. Figure 5.3.1 shows the current model in Wellington where most of the transport systems are separate and they all have a different payment method. This thesis argues that a transport model in which the different modes of transport are interlinked provides a better system for the people using the transport network. Circular Quay in Sydney shows that a unified transport system increases viability and results in more people using the network.

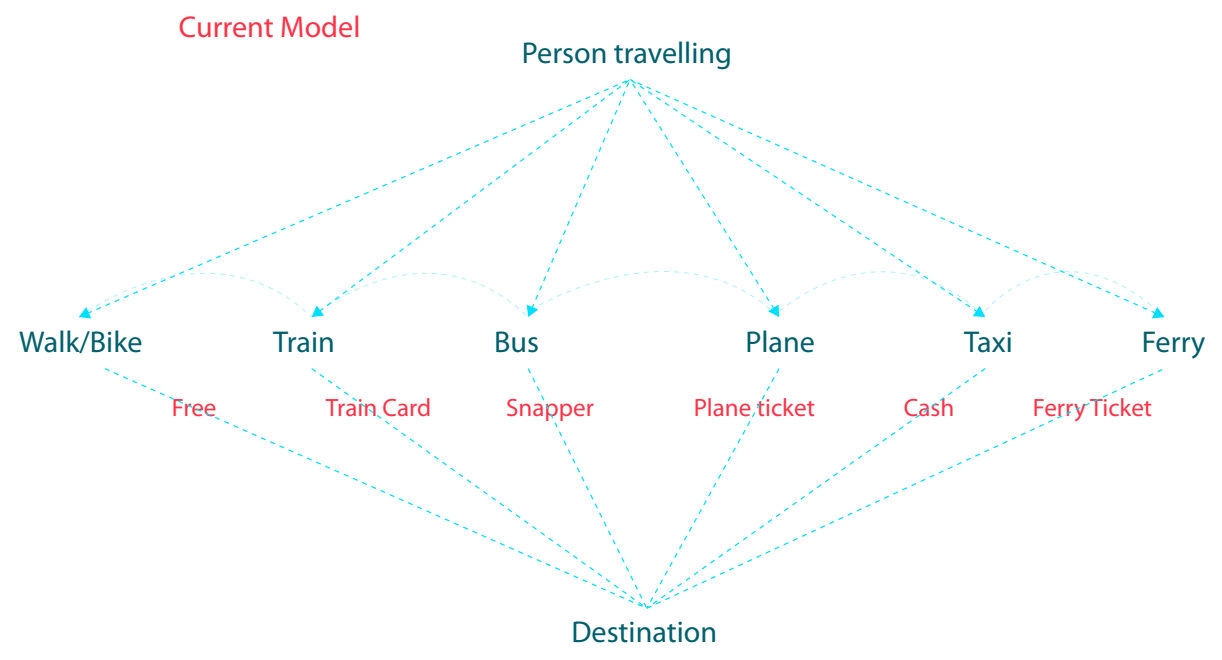

Proposed Model

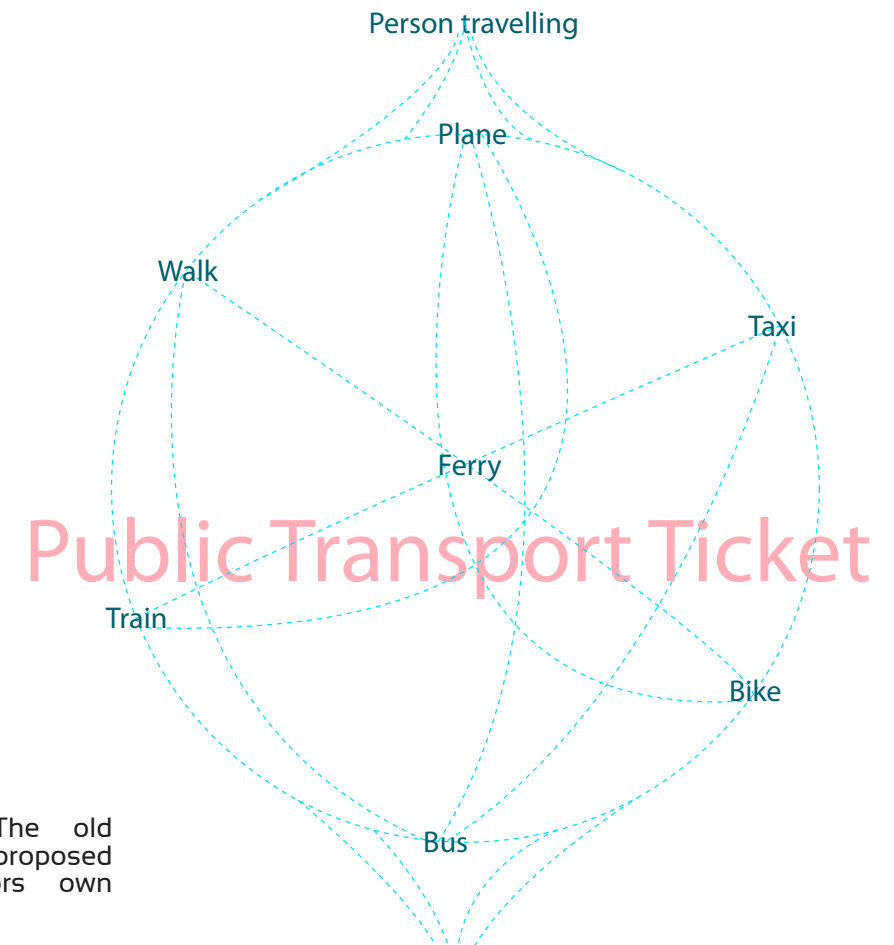

Destination 
By combining the different payments into one ticket it becomes much easier to use the public transport network. Figure 5.3 .3 shows a concept of a ticket that could be purchased that would allow people to get onto all forms of transport. This pre paid card could create a seamless transition for people and change the way transport operates in Wellington.
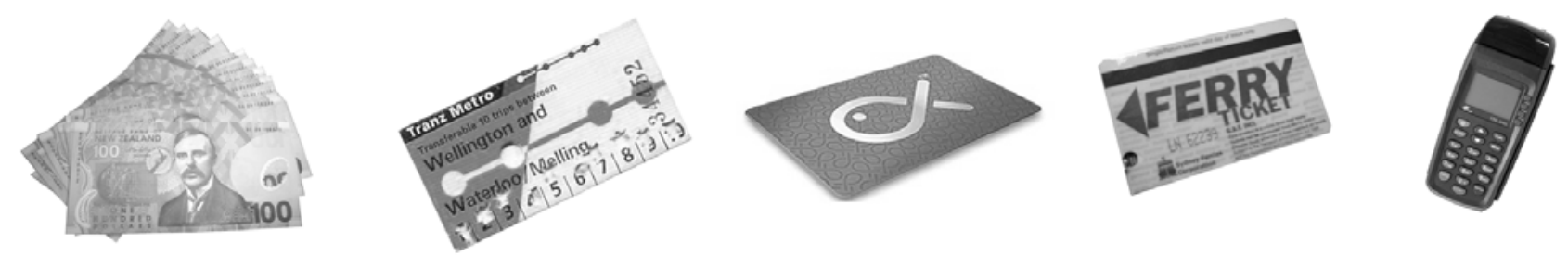

Figure 5.3.2 (Above)_ Existing payment methods for Wellingtons different transport systems. (Authors own image).

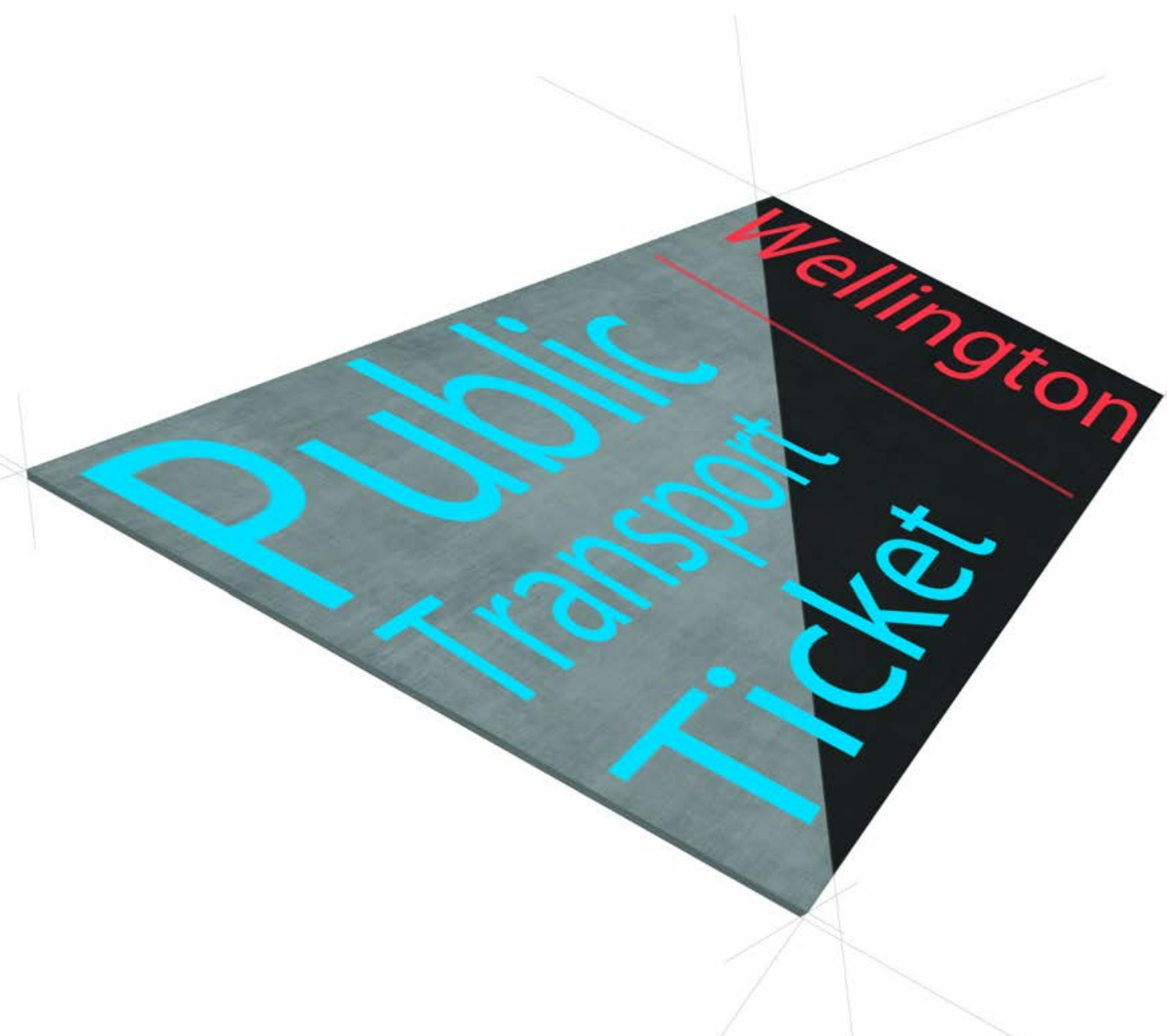

Figure 5.3.3 (Above)_ Proposed payment method for all forms of public transport. (Authors own image). 


\subsection{2_ Phasing of terminals}

The phasing of the ferry terminals became a key part of getting the system to work. A ferry terminal can't be placed on site and be expected to attract large numbers of people to use the system. The standard approach is to place a small wharf that allows the ferry to come into the new site. The ferry runs to the new wharf on the weekends and at particular times during off peak hours. As interest builds in the infrastructure the ferry travels there more frequently. Public space and other development can begin to utilise the increasing flow of people, at the same time generating more interest in the ferry.

It has been established that some of the selected ferry sites are ready for a frequent ferry service right away. Other sites will need to be developed over a longer period of time. Figure 5.3.4 establishes a timeline for when selected ferry sites will be developed.

\section{5 years}

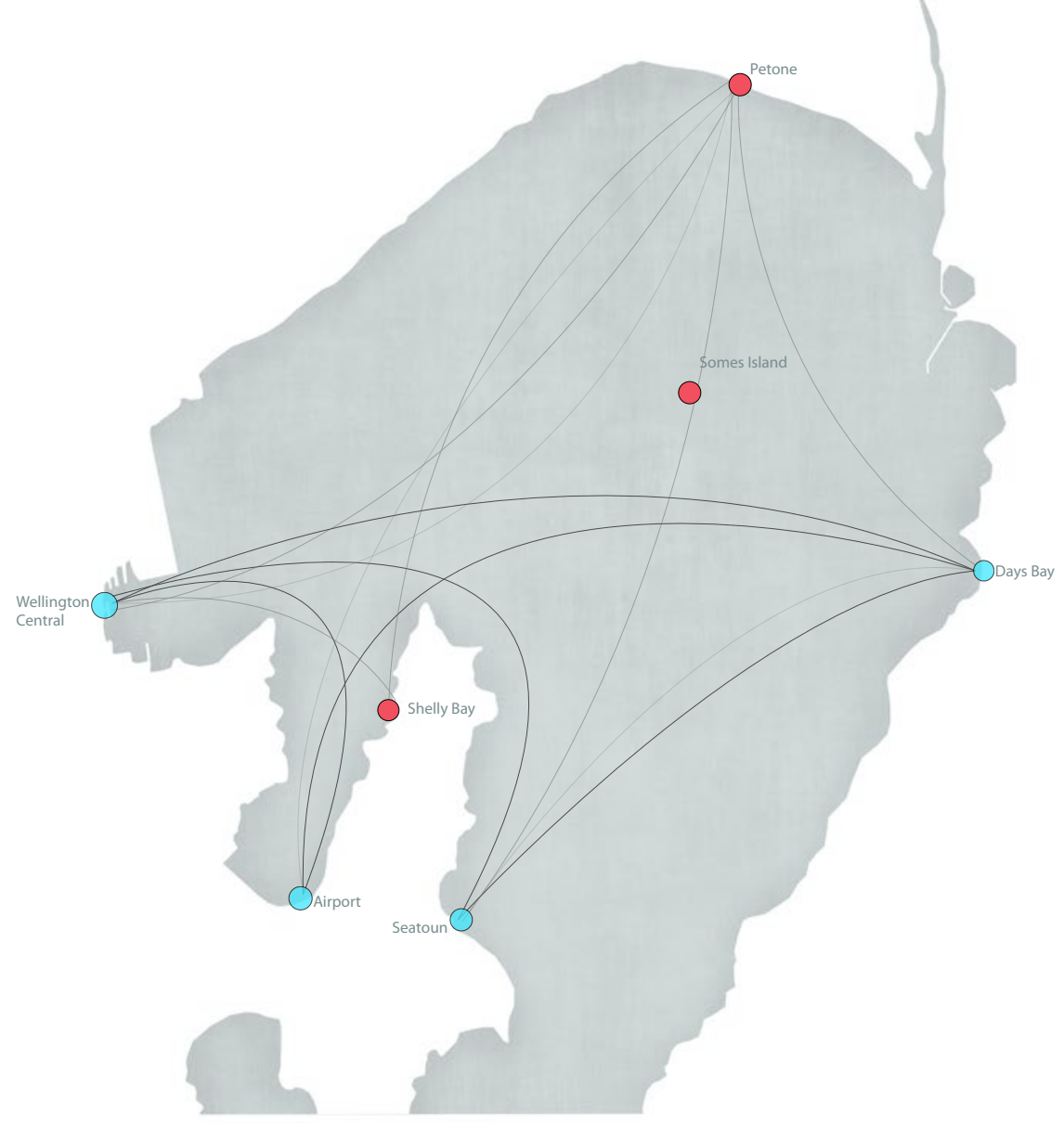


Large intervention_Established service that runs every day and is a larger scale development

Small wharf intervention_Placed to generate interest in the ferry service. Will only run on weekends.

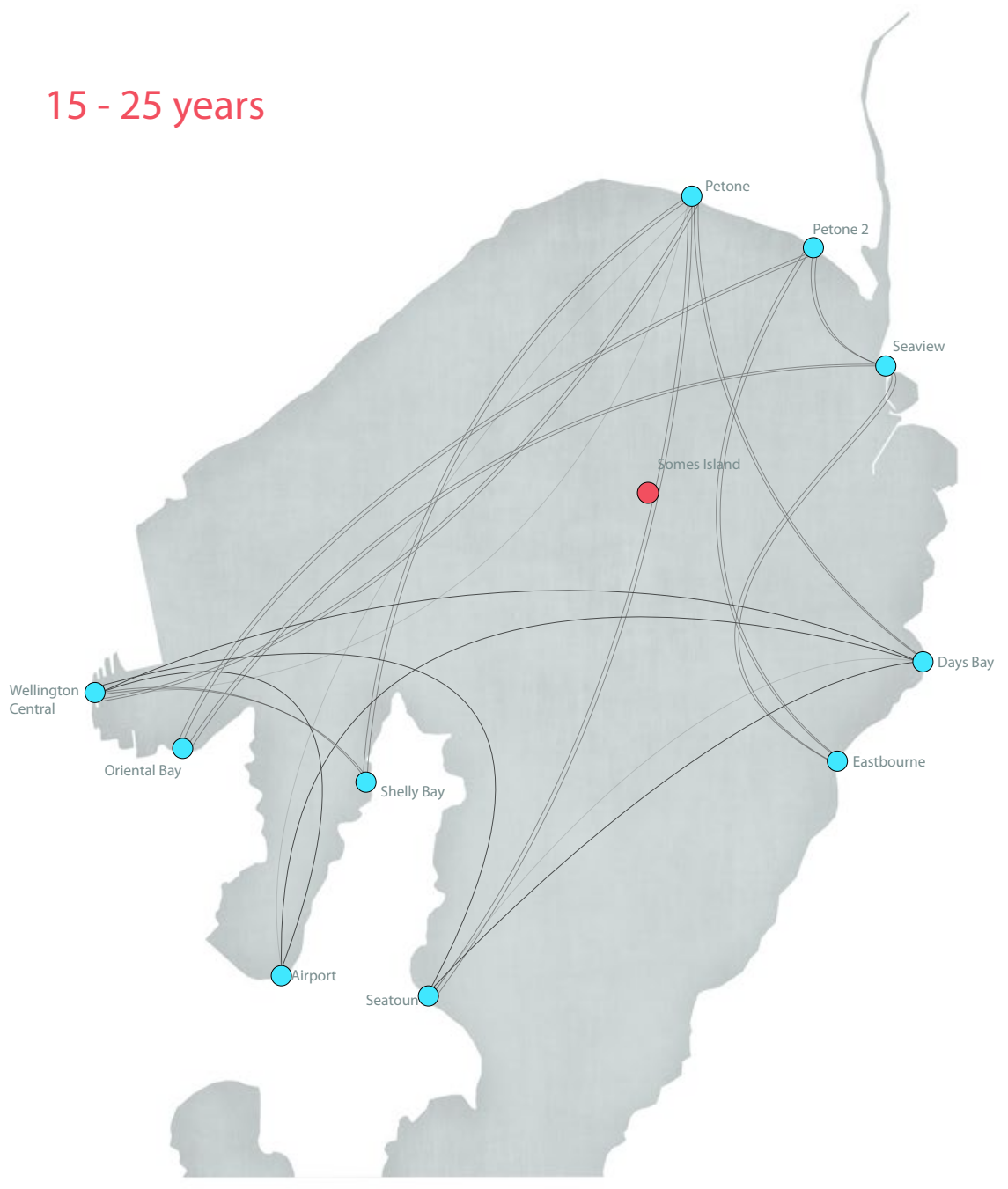

Figure 5.3.4 (Above)_ Series of maps explaining how the ferry system phased. (Authors own image). 


\section{4_ Typologies}

Although each ferry site is unique and has site-specific issues the different sites can be grouped into typologies. These typologies can allow for scale of development, atmosphere, and potential material palettes to be established that can create a unified system. This thesis argues that functional transport infrastructure shouldn't be the end result but rather part of the process that allows the transport system to influence the public life of the city. As the functional aspects of the ferry infrastructure have been established, the catalyst effects of this infrastructure can be explored. What kind of public life can be generated through the development of this system?

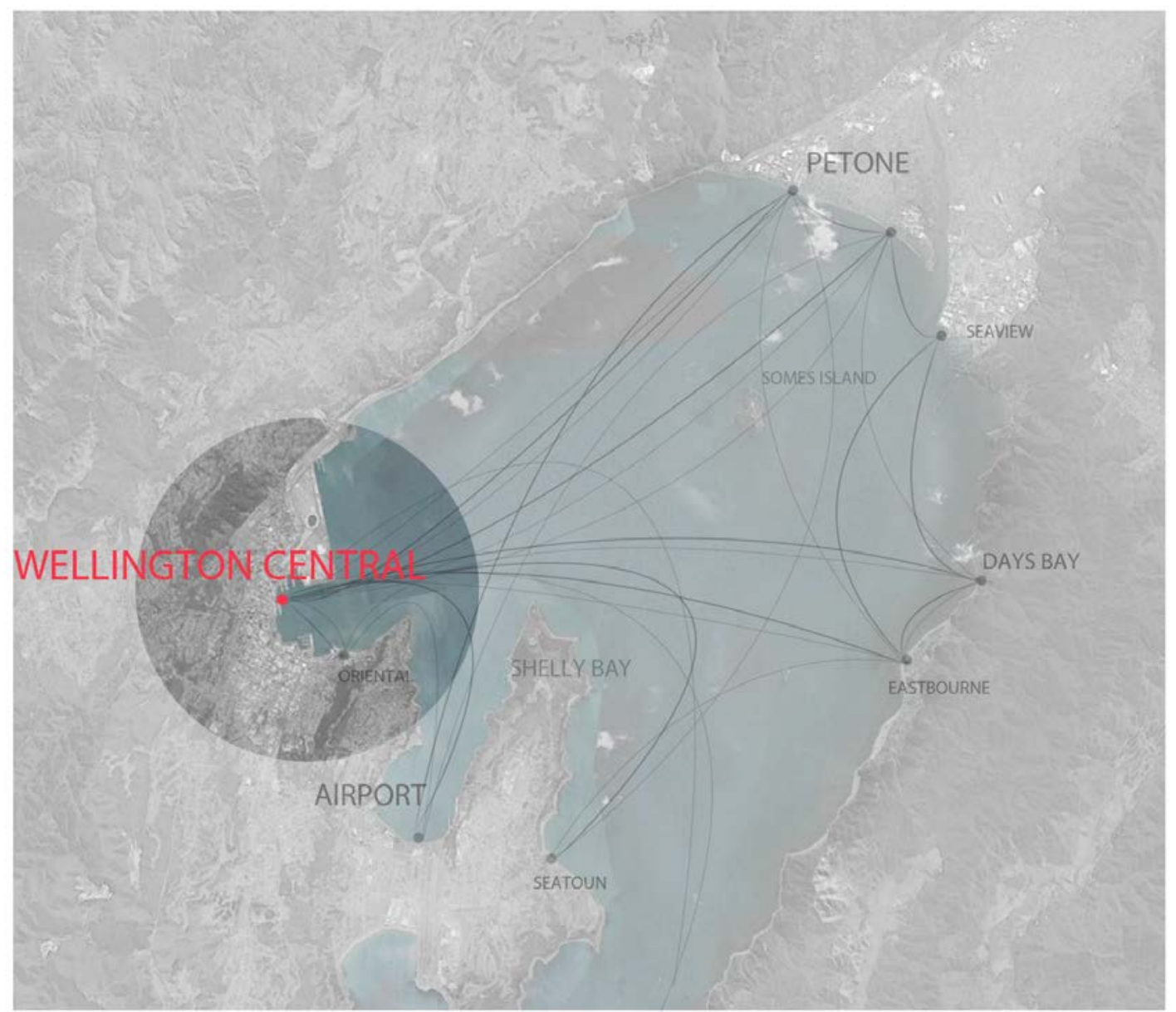

_ This ferry site is about introducing people to Wellington City.

_ Majority of people using the ferry service will pass through this terminal which allows for a larger development with more amenities. Being close to the CBD supports this development and could support larger public buildings such as conference space, museums, and large scale public space.

_Majority of the flow will be people arriving in the morning for work and departing in the evening on their way home. 


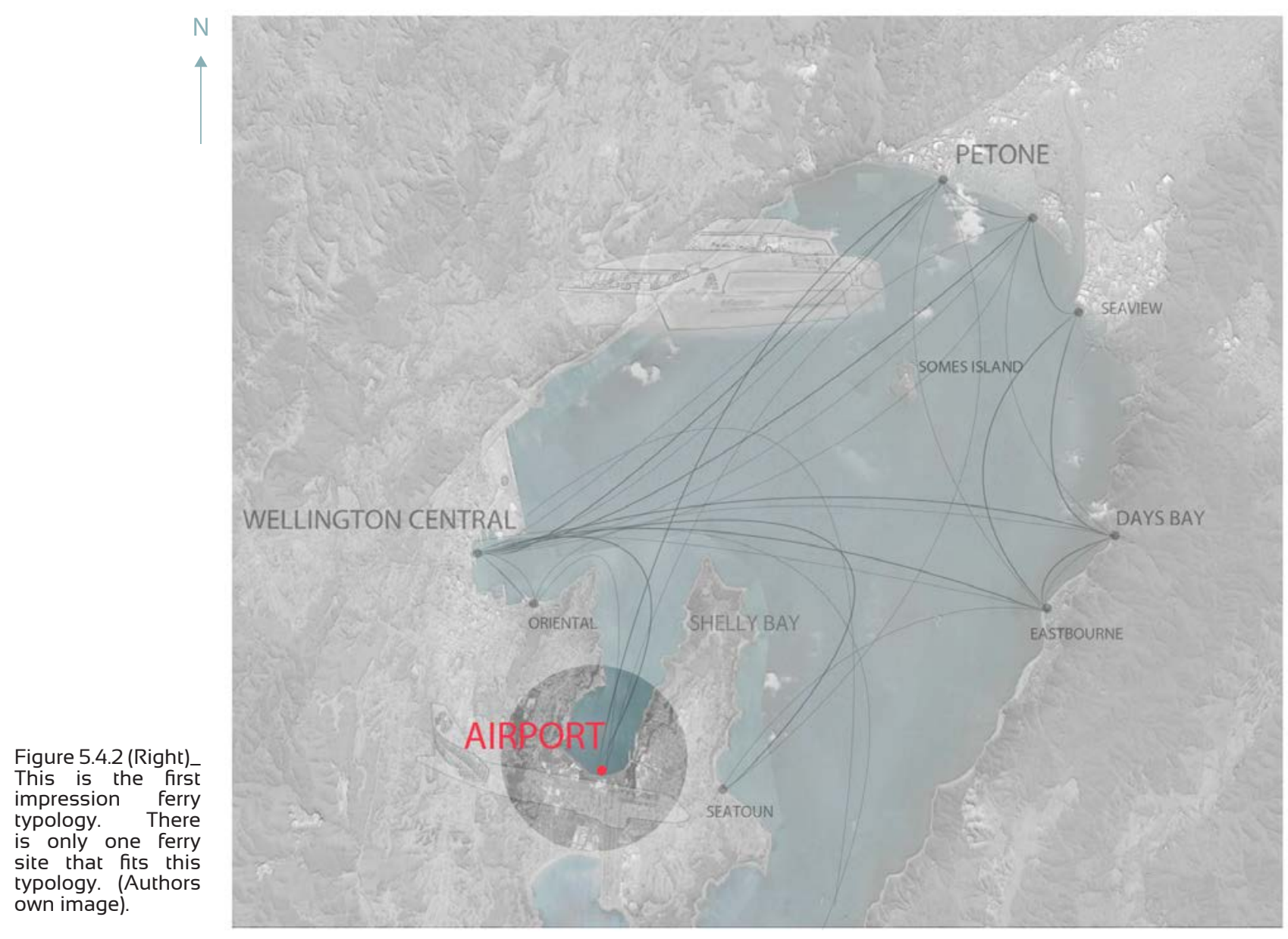

_ The airport terminal provides an entrance to the city for international and domestic visitors. This is an alternate route to the existing highway that provides this connection.

_ This terminal is the first impression made on the visitors to Wellington and gives the potential to establish the identity of the city as a harbourside community.

_ People will be moving through this terminal at all times. This development would be worked in with the runway extension. 

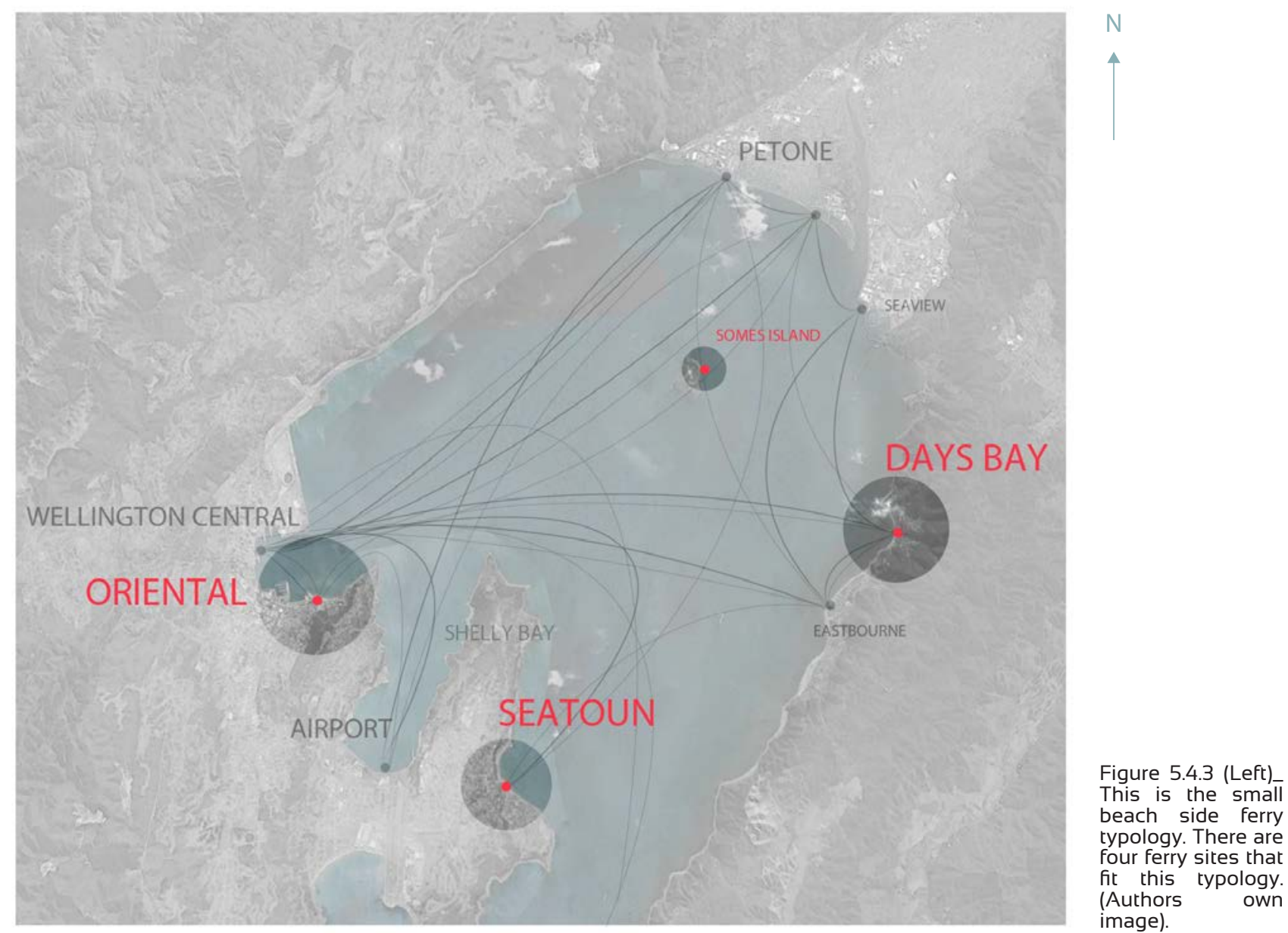

_This collection of ferry sites is characterised by small ferry wharves that have a small population associated with them.

_ They may also serve as a destination because of the beach. There are recreational activities associated with this, such as swimming, tanning, and jumping from the wharf.

_ The development around these sites may be smaller than the other terminals, but could be focused on the recreational aspects of the site. 


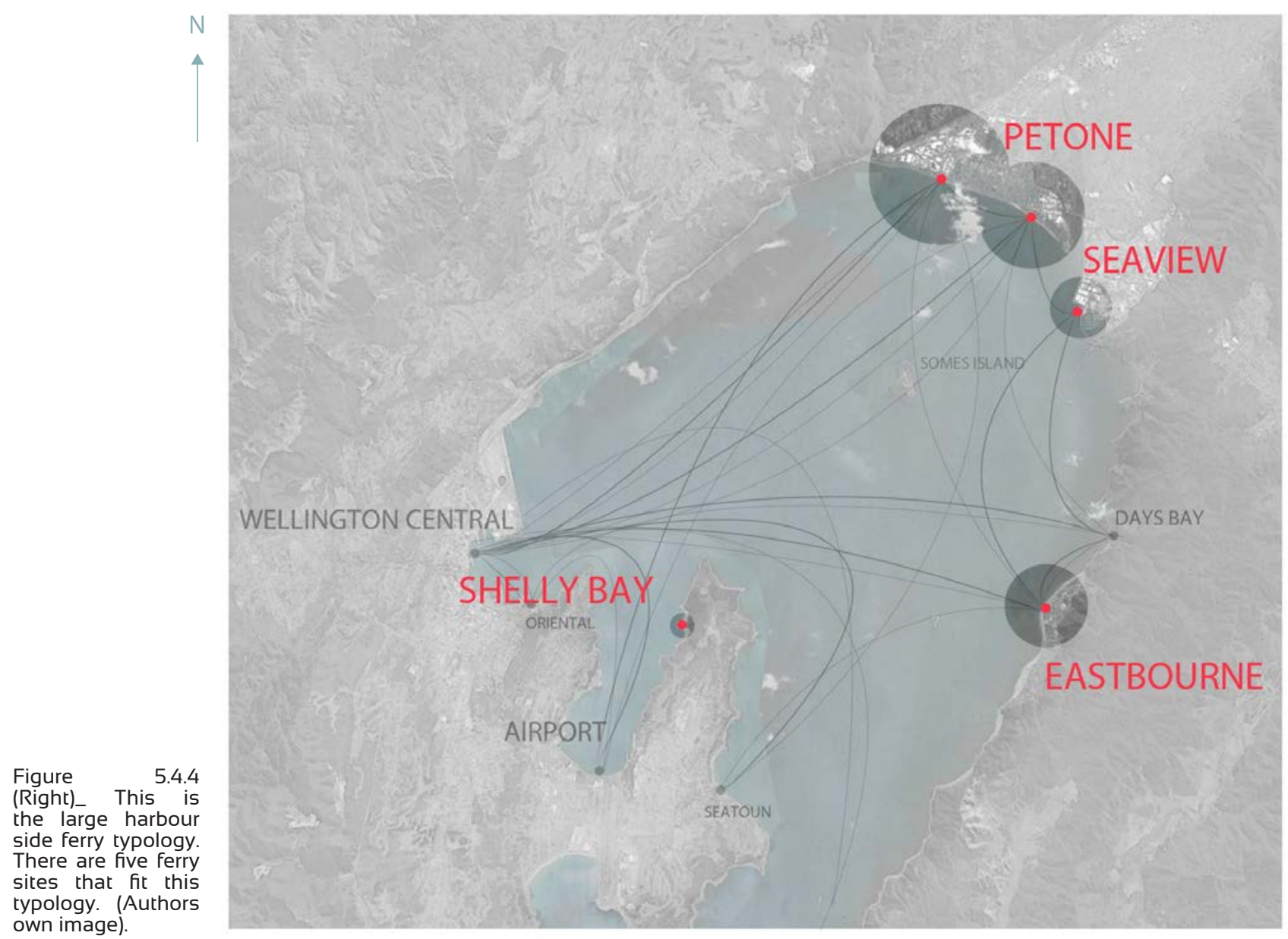

_ The large harbour side communities are terminals located around more significant populations.

- These sites could sustain large scale development and are based around populations that travel into Wellington Central for work.

_ Majority of people will be departing these sites in the morning on the way to work and arriving at these sites in the afternoon on their way home.

The ferry system functions as a whole, yet each site is unique to its specific area. This thesis argues that a ferry infrastructure project needs to work at the large scale of the system and intimately at the scale of each landing site. The next chapters takes one site from each of the design typologies and undertakes a design process, driven by the design strategies, to see how each typology might manifest physically. The terminal sites chosen are Wellington Central, Airport, Oriental Bay, and Seaview. Each site is designed to a level of detail suited to each typology. The designs are by no means finalised designs. They are concepts to understand how the research into transport infrastructure might affect the design of space. 


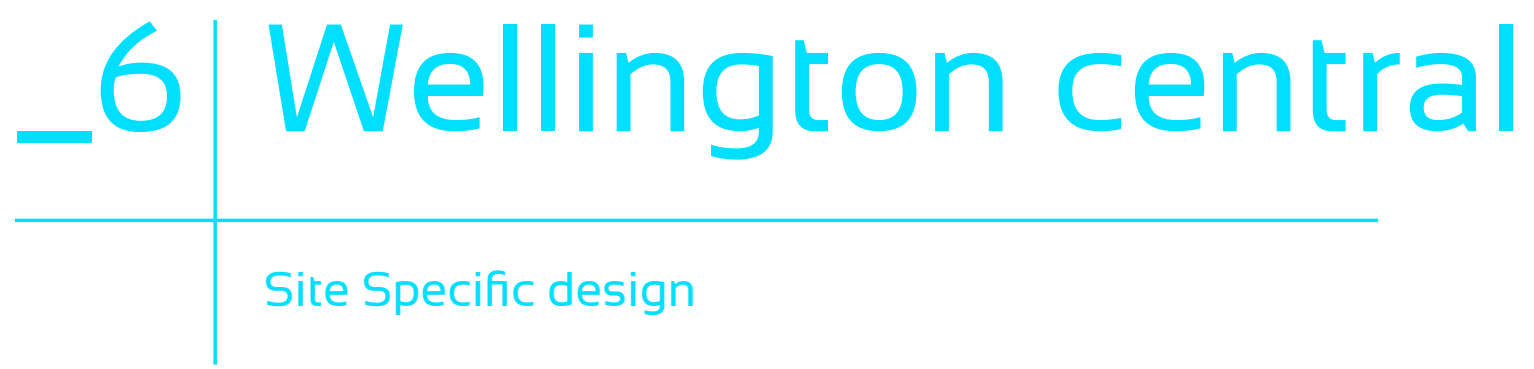




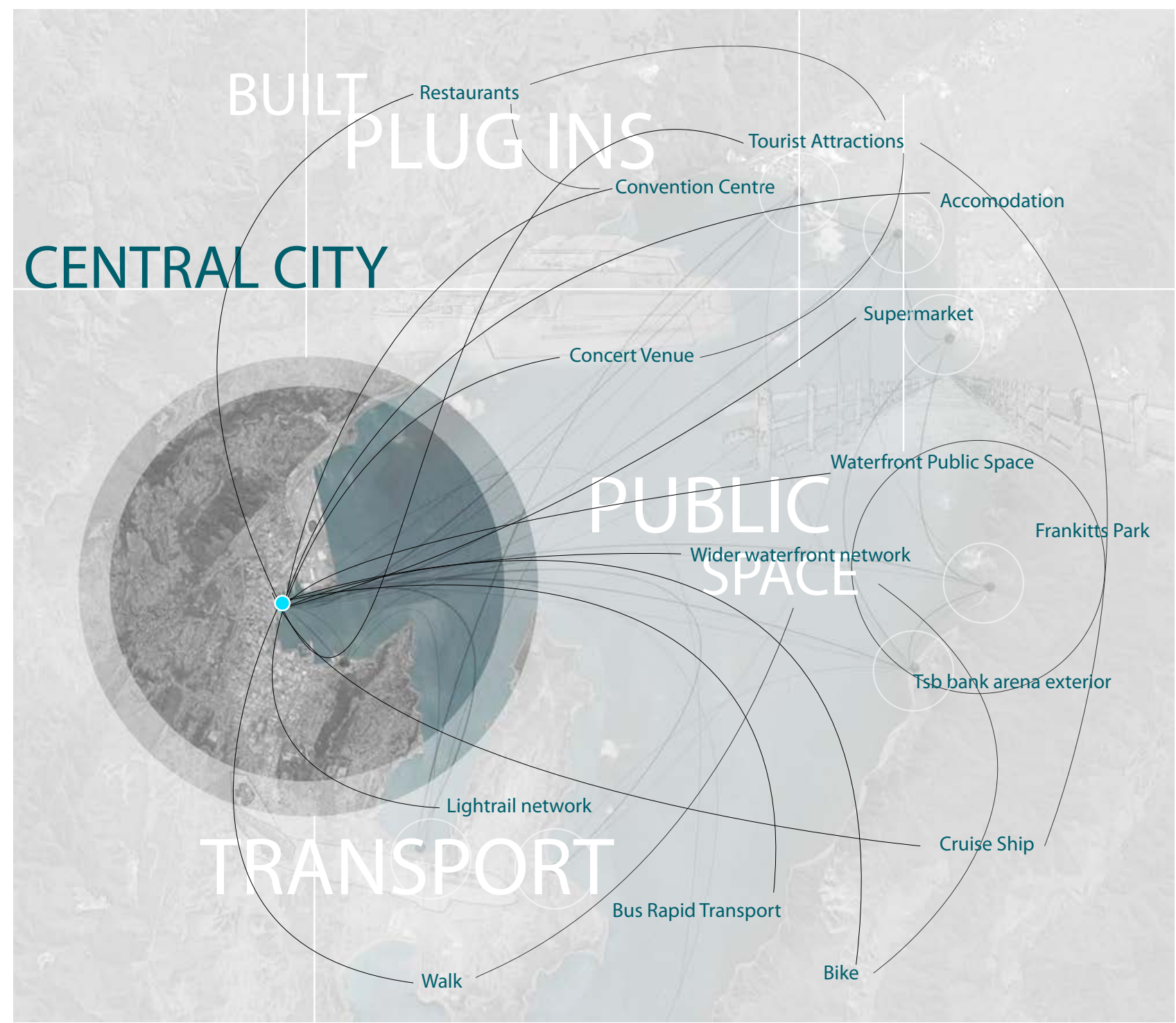

Figure 6.1.1 (Above)_ Mapping the central hub typology in relation to the design strategies. (Authors own image).

Wellington Central is the ferry site in the central hub typology. It is the gateway into Wellington CBD and would become one of the most significant ferry sites in the system. In terms of size it will be the largest site as it needs to accommodate ferries from all ferry routes. The large pulse of people moving through the site offers a potential for diverse development. 


\section{1._ Site Analysis}

\subsection{1_ Grid system}

The grid system in Wellington funnels people down to the waterfront. The grid then shifts, isolating the waterfront from the rest of the city. It creates the sense that the waterfront is a separate place. This is reinforced by the street system.

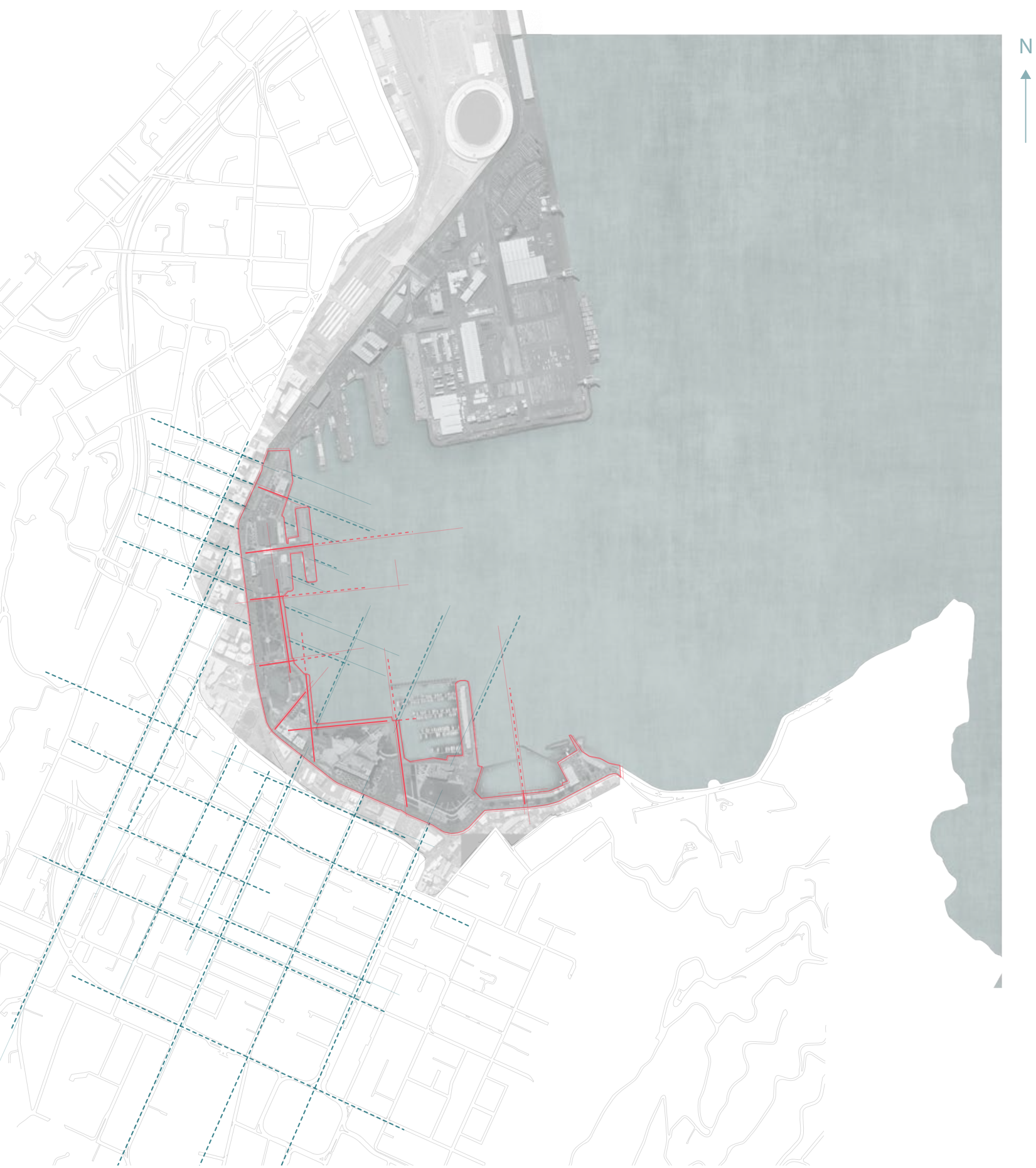

Figure 6.1.2 (Above)_ Diagram of the grid shift that occurs in Wellington City. . (Authors own image). 


\subsection{2_ Current transport system}

The ferry system needs to plug in to the existing ferry system in Wellington. This will increase viability in the system and encourage more people to use it.

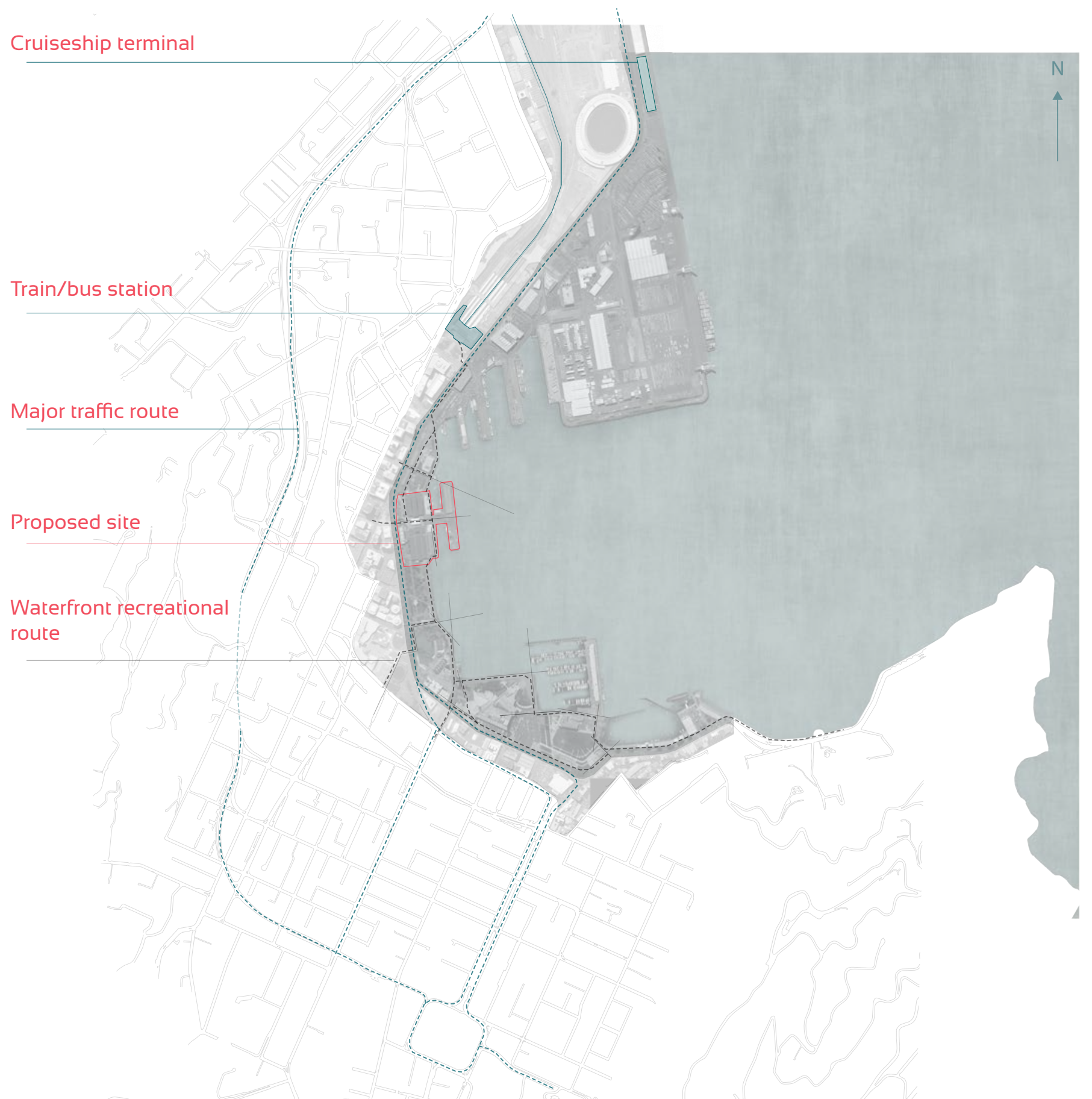

Figure 6.1.3 (Above)_ Mapping of the existing transport network in Wellington City. (Authors own image). 


\subsection{3_ Waterfront desire lines}

It is important to understand how pedestrians move to and from the ferry terminal. It was established in the case studies that ferry designs often finish at the end of the terminal. By understanding how people move through to the site hopefully this can influence the design.

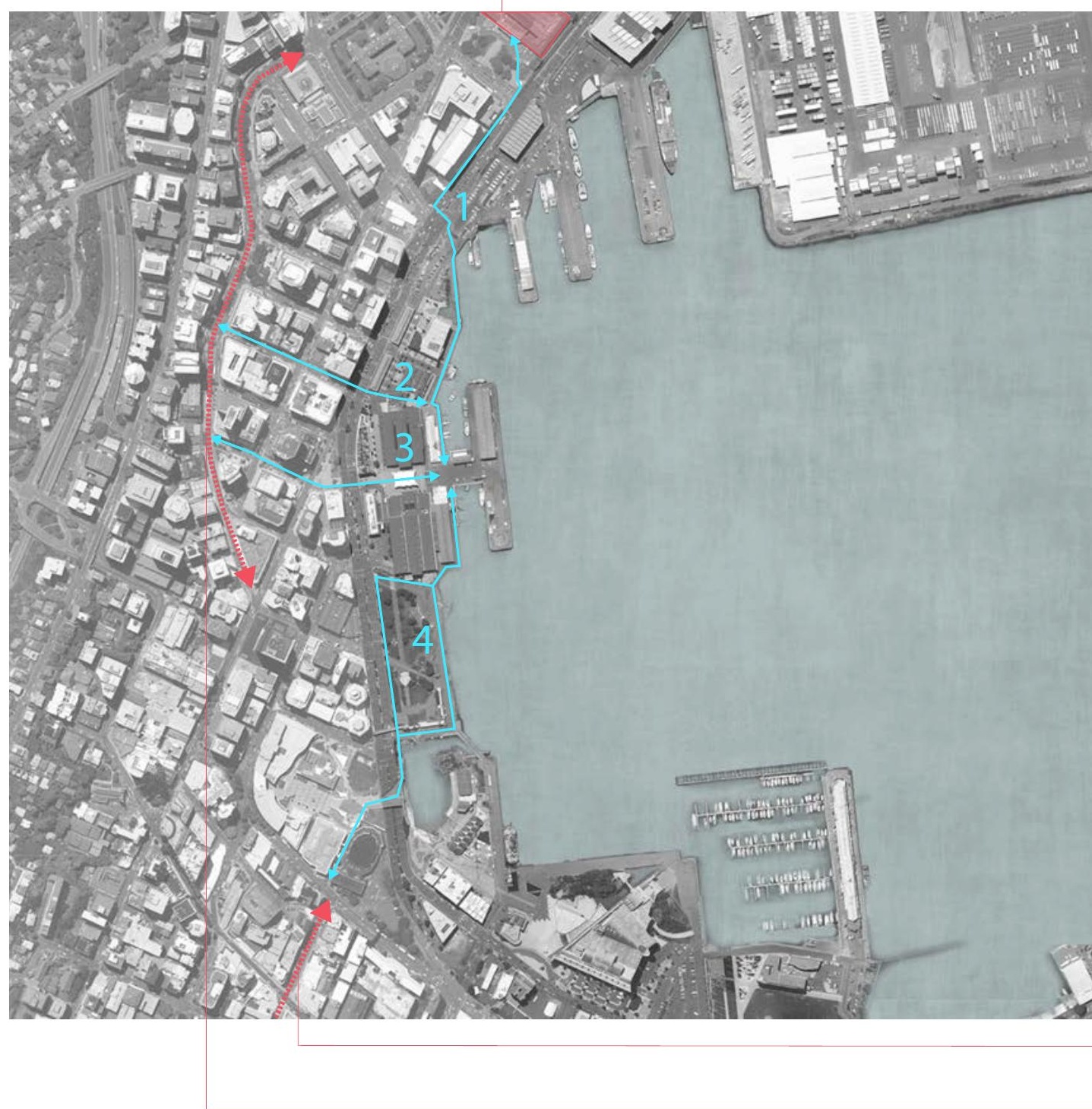

Figure 6.1.4 (Above)_ Mapping the desire lines to the harbour edge. There are KEY four main routes that pedestrians take to get onto the waterfront. Images show the view pedestrians will see. (Authors own image).

1_ Moving betweer

2 Connection back

3_ Connection back

4_ Movement from 

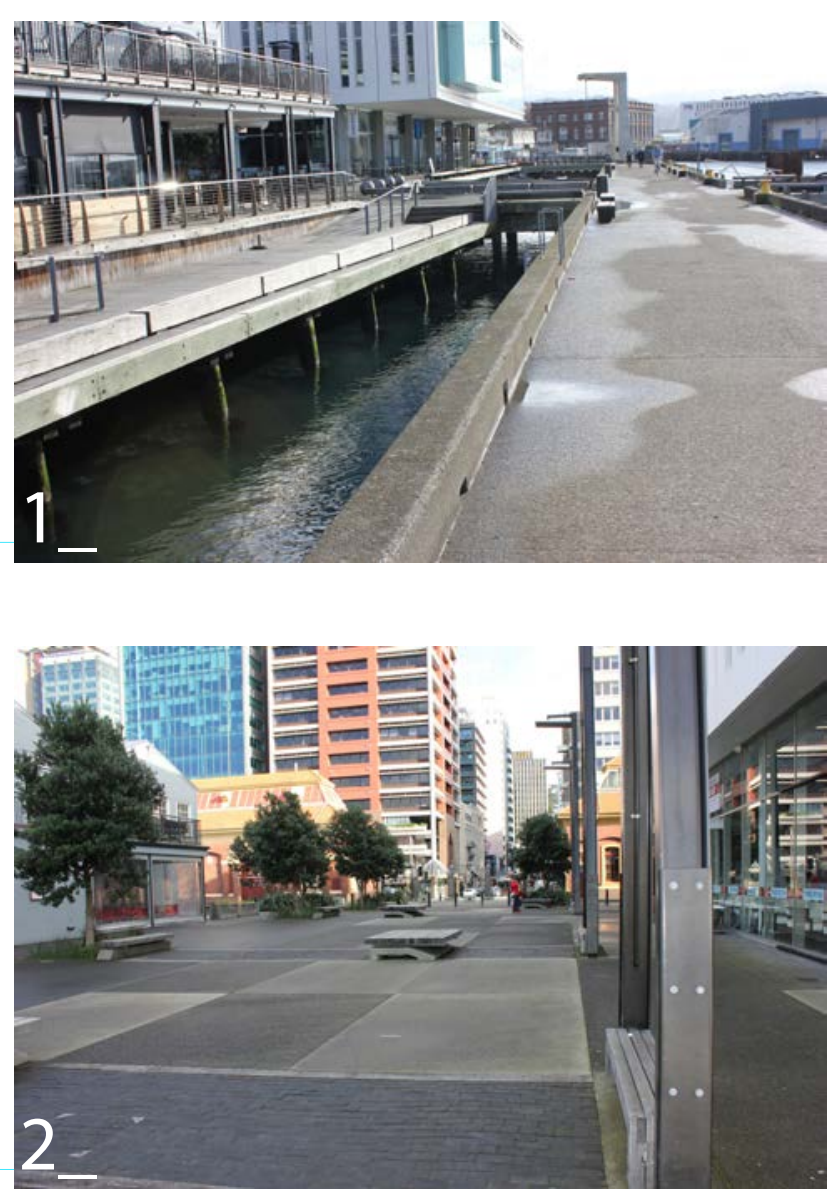

\section{Cuba street}

Lambton Quay

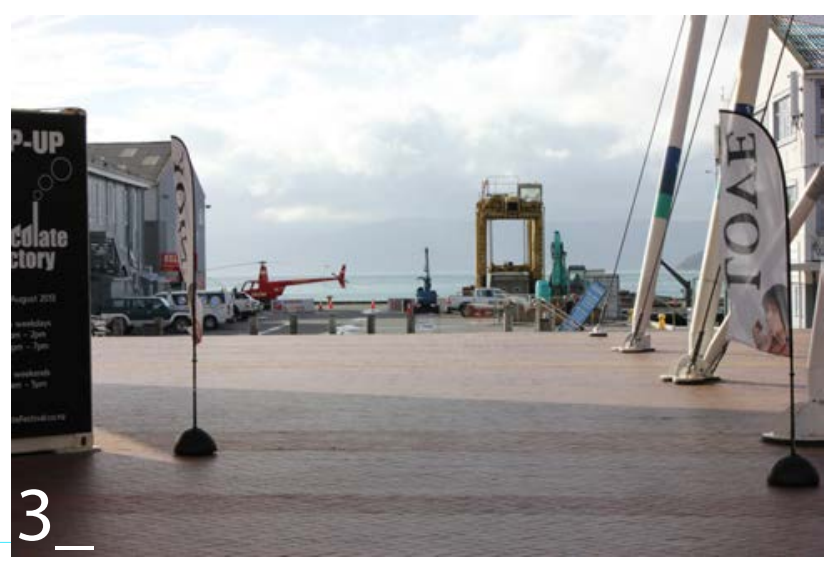

the city and the train station to the Lambton Quay to the Lambton Quay the site to cuba street

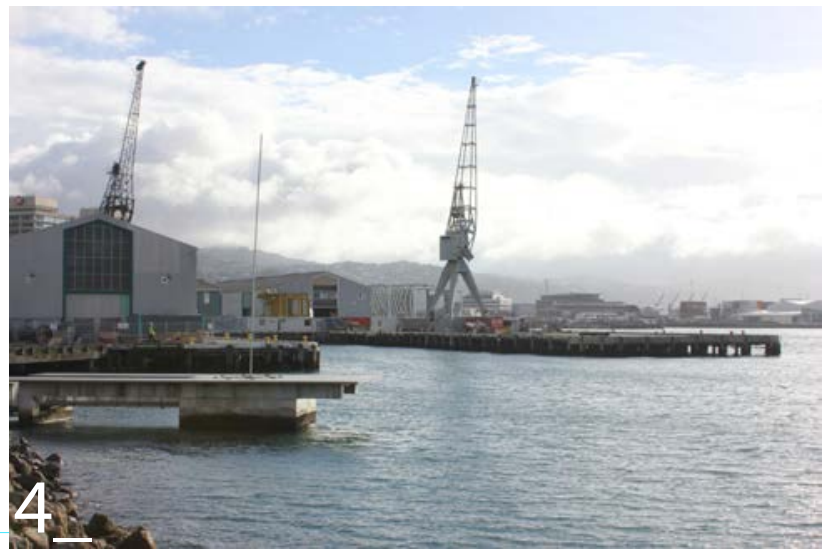




\subsection{4_ Waterfront zone}

There is a definite threshold between the city and the waterfront. This allows the waterfront to feel like a separated place, yet it is only a few minutes from the CBD. This increases viability of the ferry service as people are brought into the waterfront but are only a short walk to the CBD.

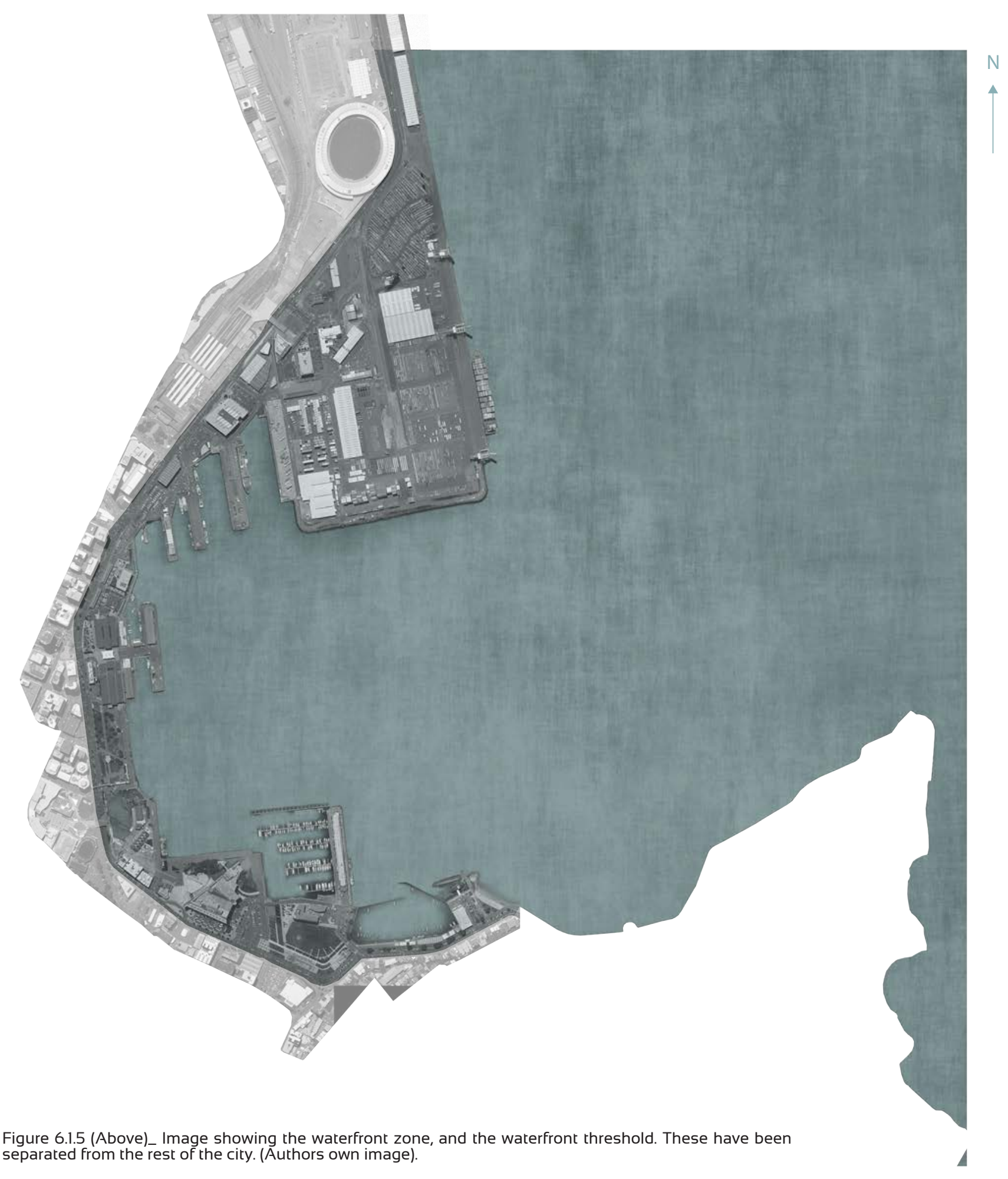




\subsection{5_ Terminal location}

It was established through the fieldwork that the current ferry terminal in Wellington isn't designed to enhance public life. It also currently wouldn't handle the amount of ferries needed for this ferry network. This has led to the testing of the rest of the wharf edge to see what other site could be suitable.

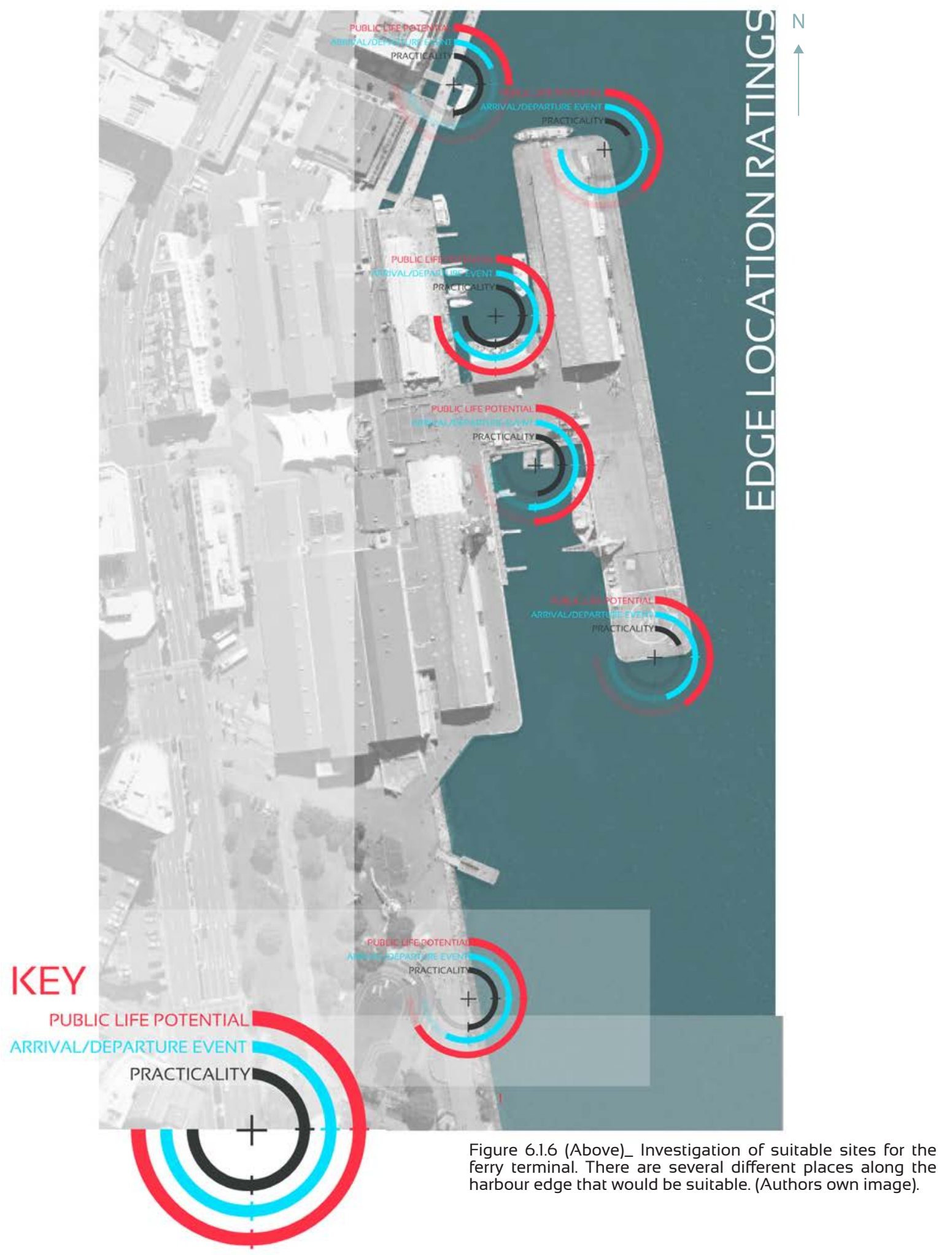




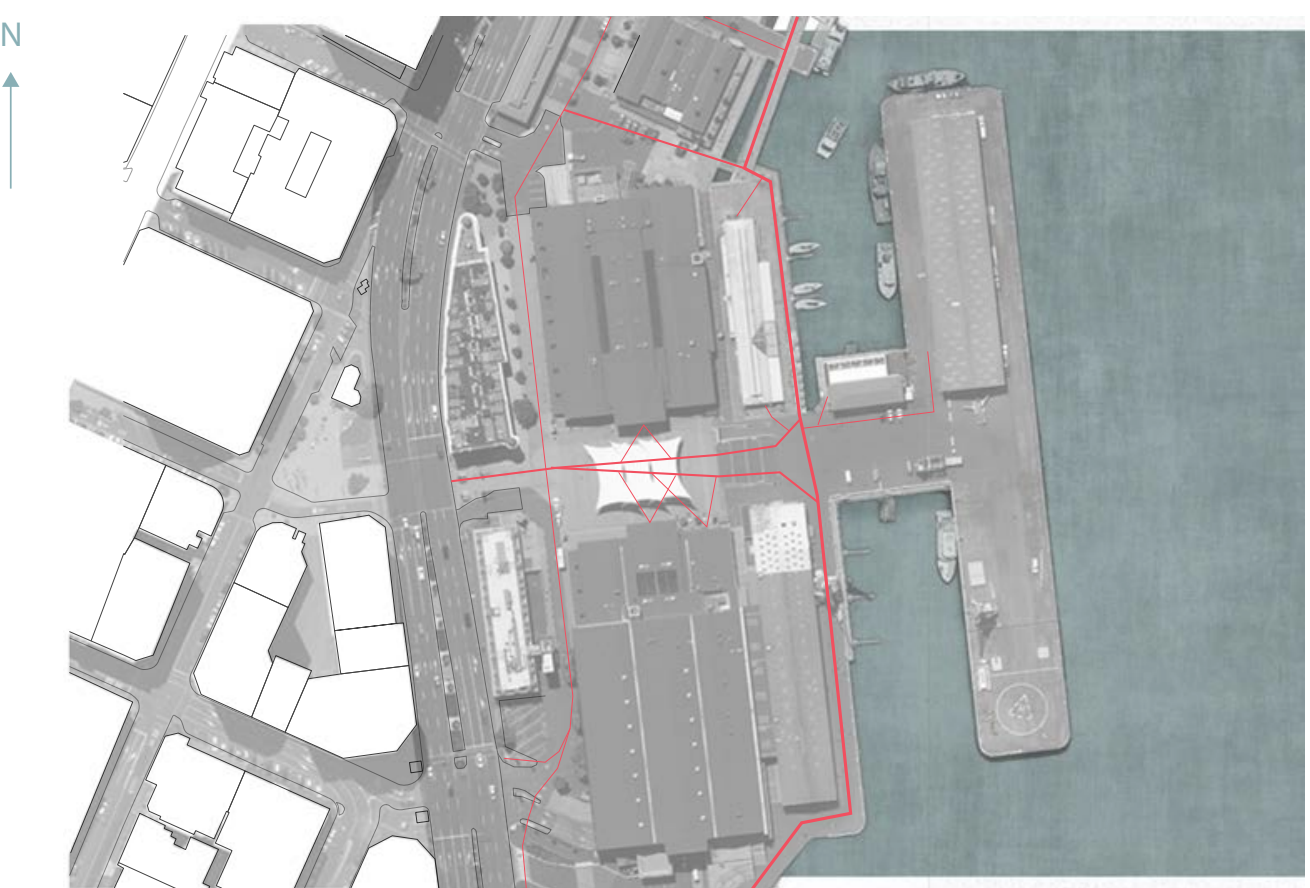

Figure 6.1.7 (Above)_ Investigation of desire lines around the selected ferry location. (Authors own image).

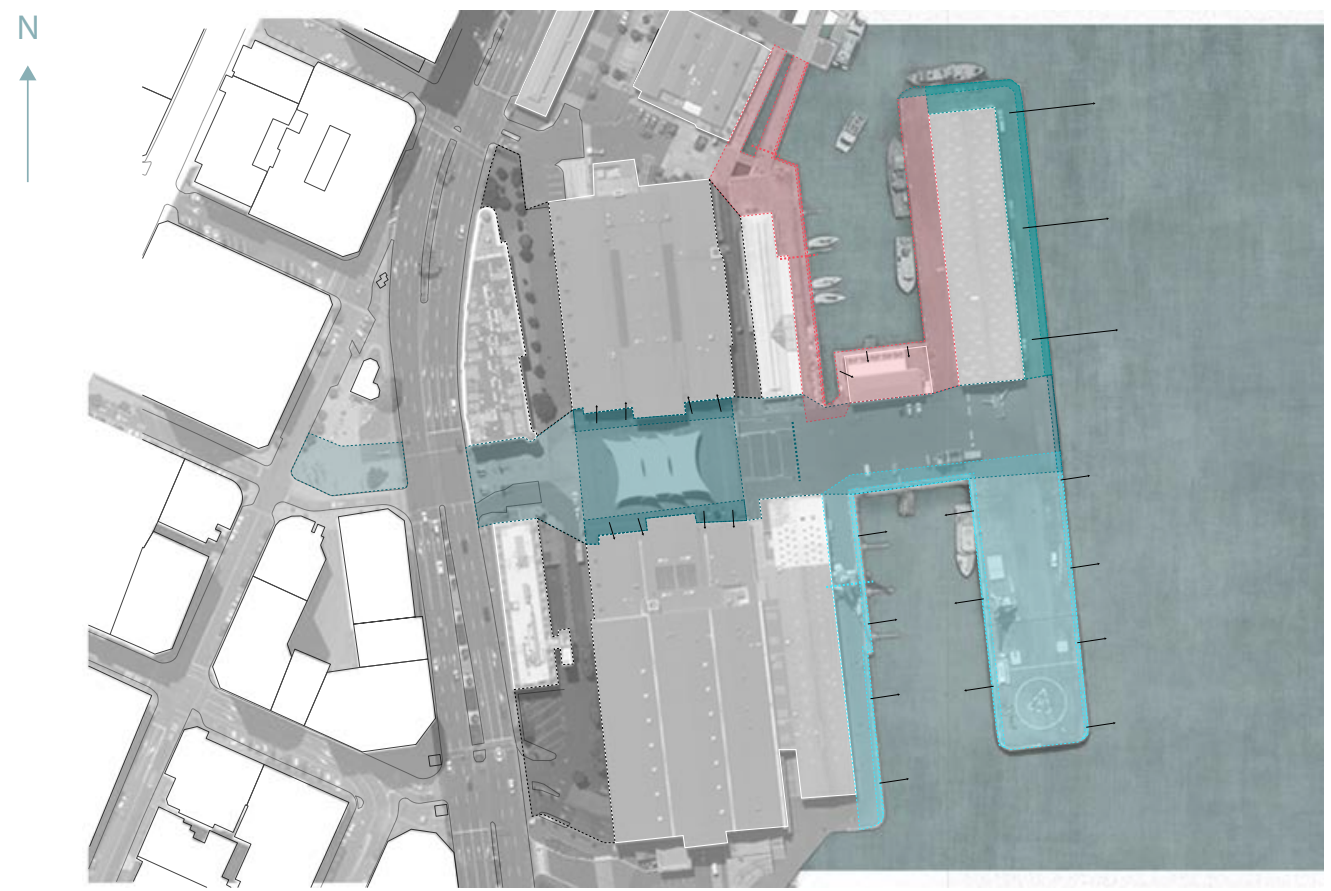

Figure 6.1.8 (Above)_ The different zones that exist within the selected ferry location. (Authors own image).

\subsection{6_ Desire Lines}

The main movement channel through Queens Wharf is along the waterfront, right on the edge. There are then several smaller movement channels that branch off that. This is potentially because people are moving between town and the train station. If the ferry service fits into where people move then it will increase system viability.

\subsection{7_ Waterfront zones}

Queens wharf is split into several different 'zones'. They are distinctly different and could be utilised in the design process. The main zones are the space running back into the city, The southern bay, and the northern bay. 


\subsection{8_ Wind and Sun}

The buildings surrounding the northern bay block the wind, which creates a sheltered area. The site also gets good sun access that gives the effect of the site being a little sheltered harbour, within the harbour. This is positive for the ferry sites as it means that people already come down to spend time in the site due to the natural conditions.

\subsection{9_ Building heights}

The building heights are all relatively low, two to three floors. This brings the scale of the site down to a human scale which compared to the city is more comfortable for people spending time. It also has the added benefit of letting in the sun.

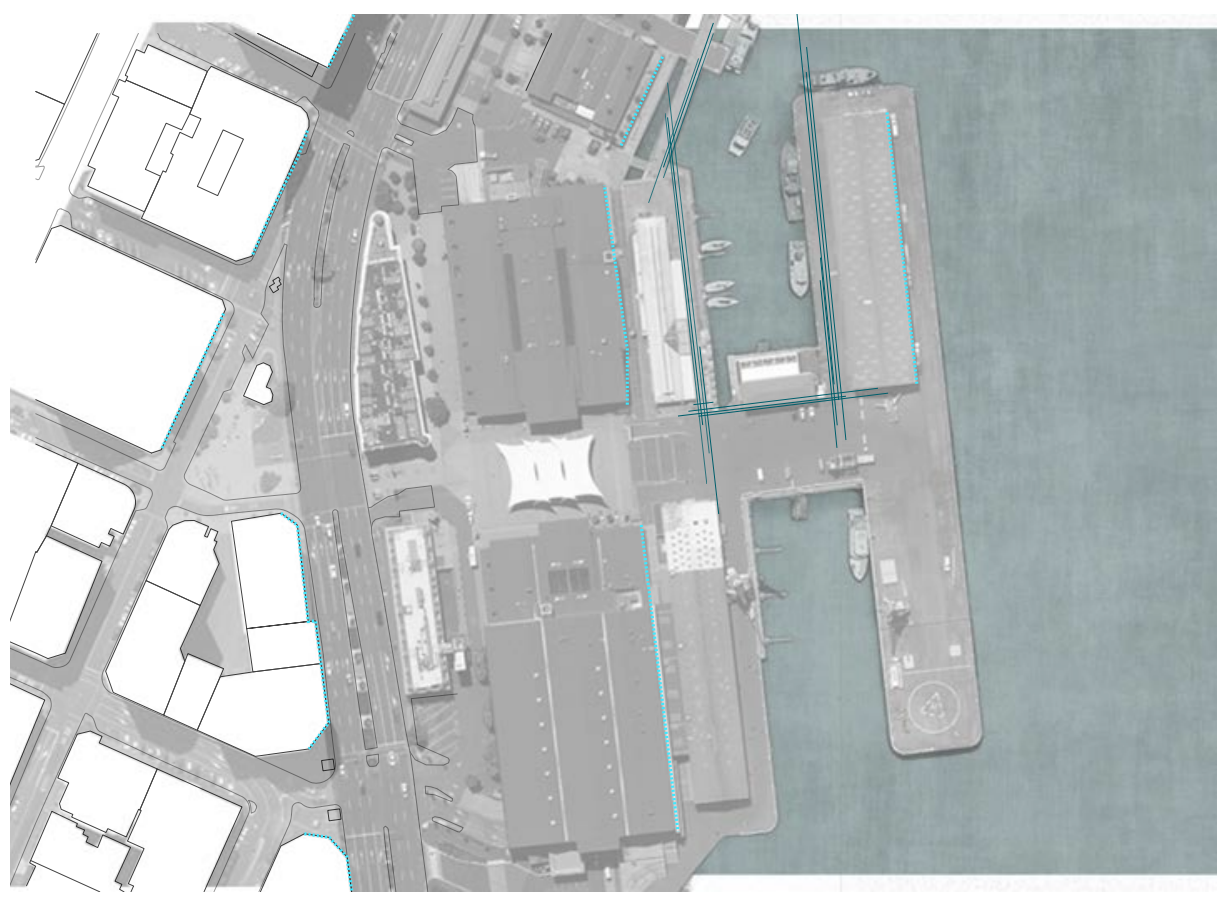

Figure 6.1.9 (Above)_ Diagramming wind and sun on the selected ferry location. (Authors own image).

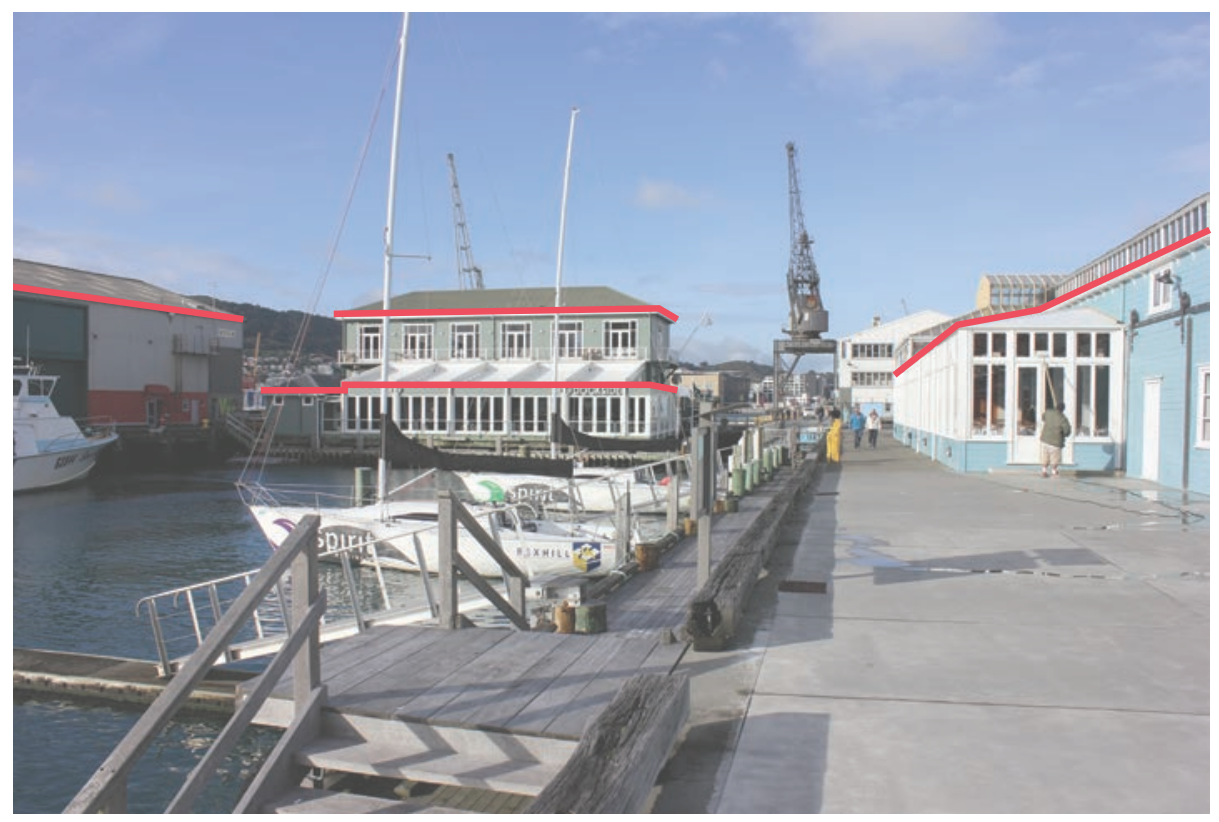

Figure 6.1.10 (Above)_ Images looking at the building heights in Queens wharf. (Authors own image). 


\section{2_ Design Testing}

\subsection{1_ Wharf move}

To facilitate more ferries in the harbour the outside of the $T$ on the wharf needs to be pushed out to double the width. This will allow the number of ferries to come right into the bay, creating a real event of the ferry, as opposed to having one terminal bolted onto the side of a walkway.

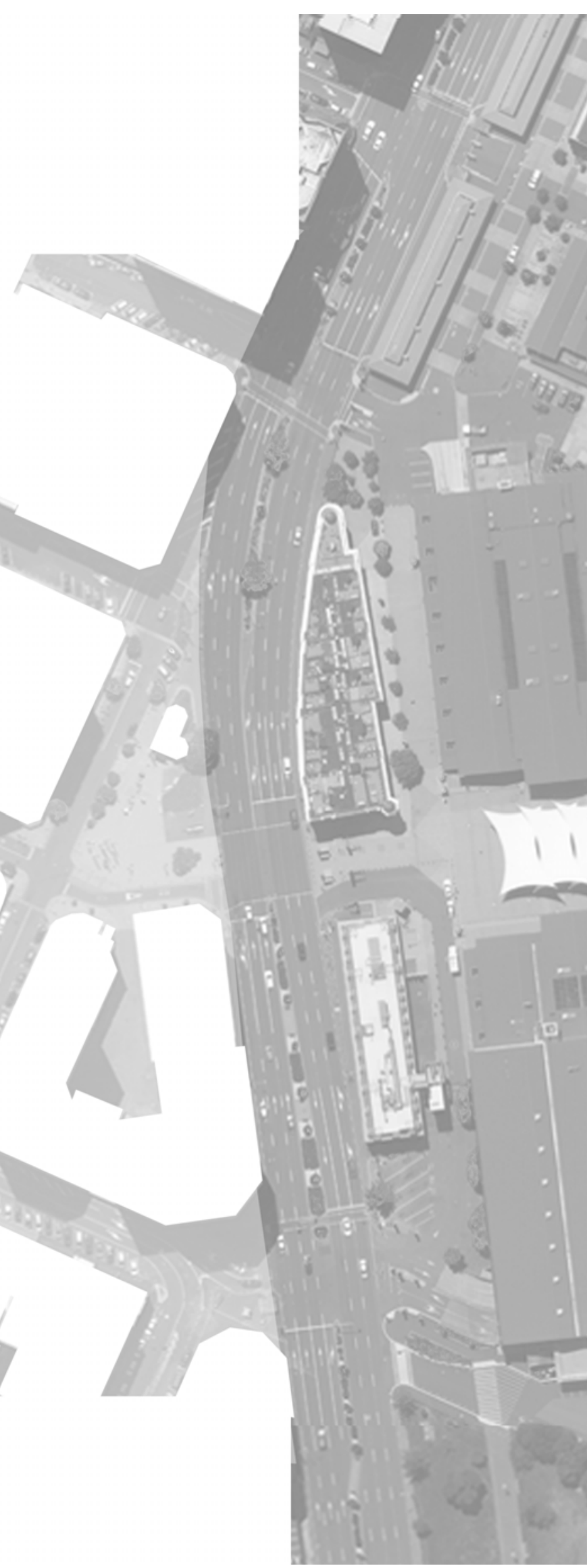




\subsection{2_ Wharf configuration}

The widening of the wharf offers up design opportunities in terms of the configuration of the space. There is the potential to create a real event of the ferry that creates a vibrant space on the waterfront. This means that both the ferry users and people using the space recreationally need to be designed for.

Built form with public space interaction could be utilised in this site to allow people to spend time here, even when not using the ferry.

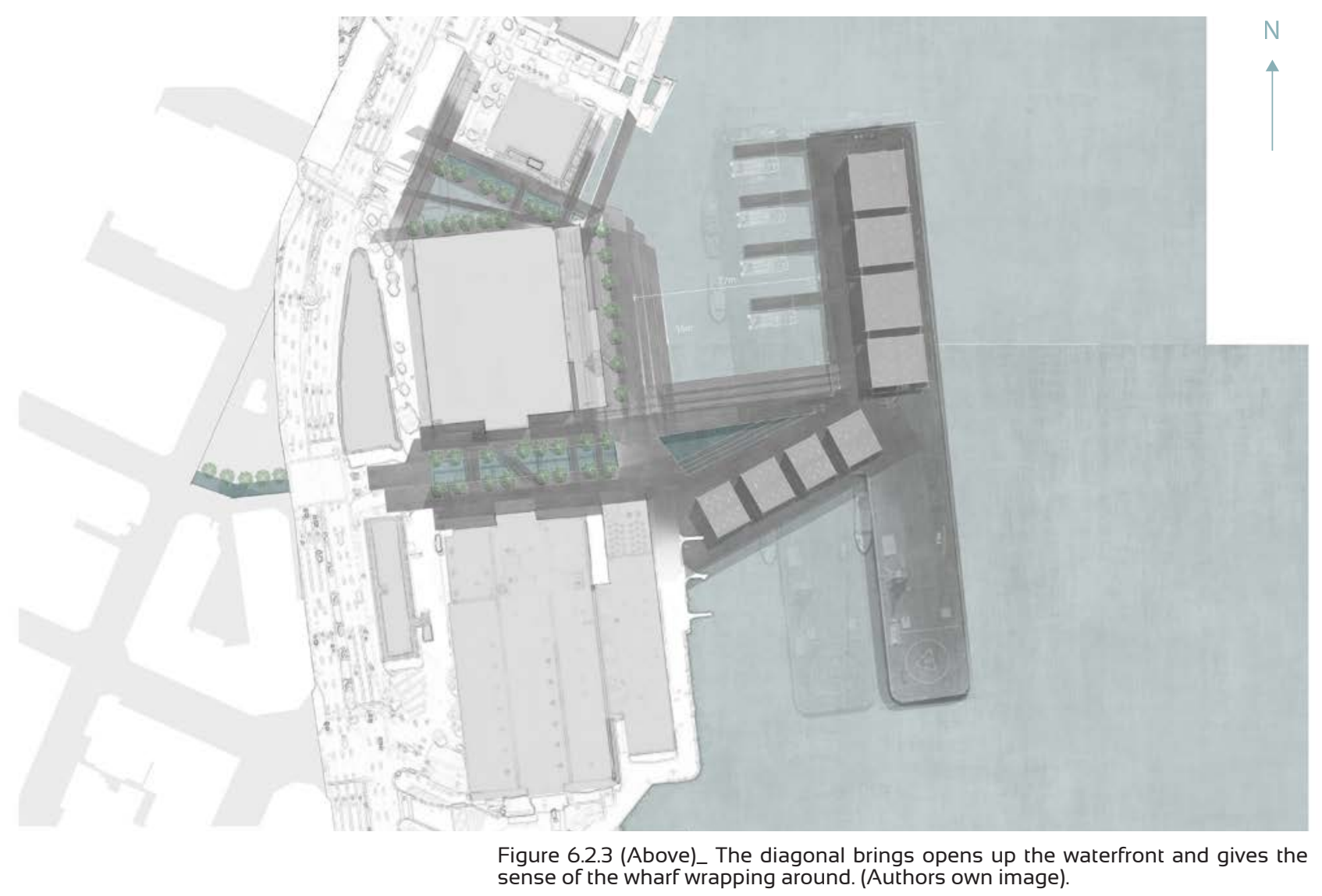




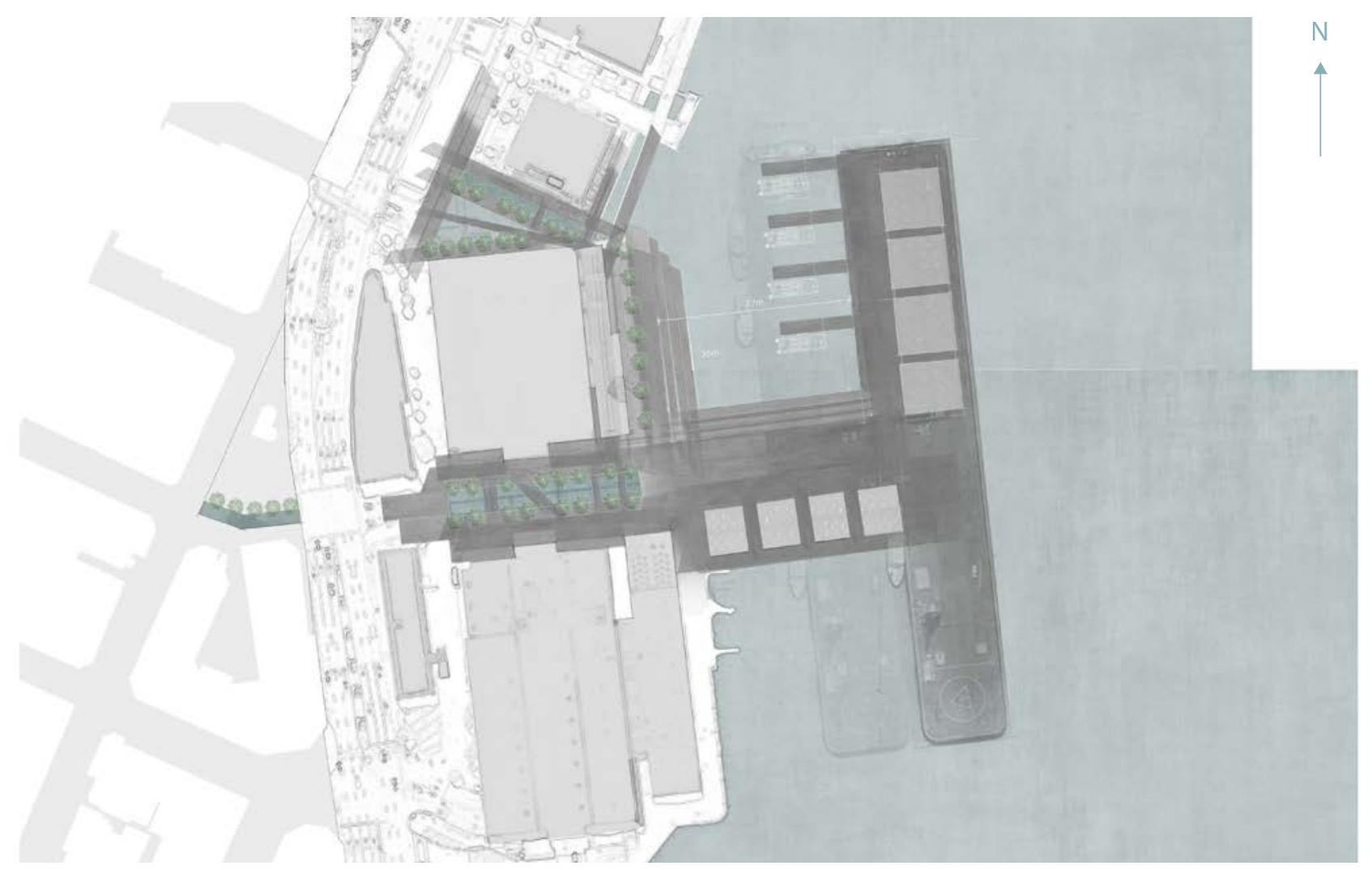

Figure 6.2.2 (Above)_ Similar wharf configuration but widening allows the ferries to come in. Water is drawn back in land to connect with the city. (Authors own image).

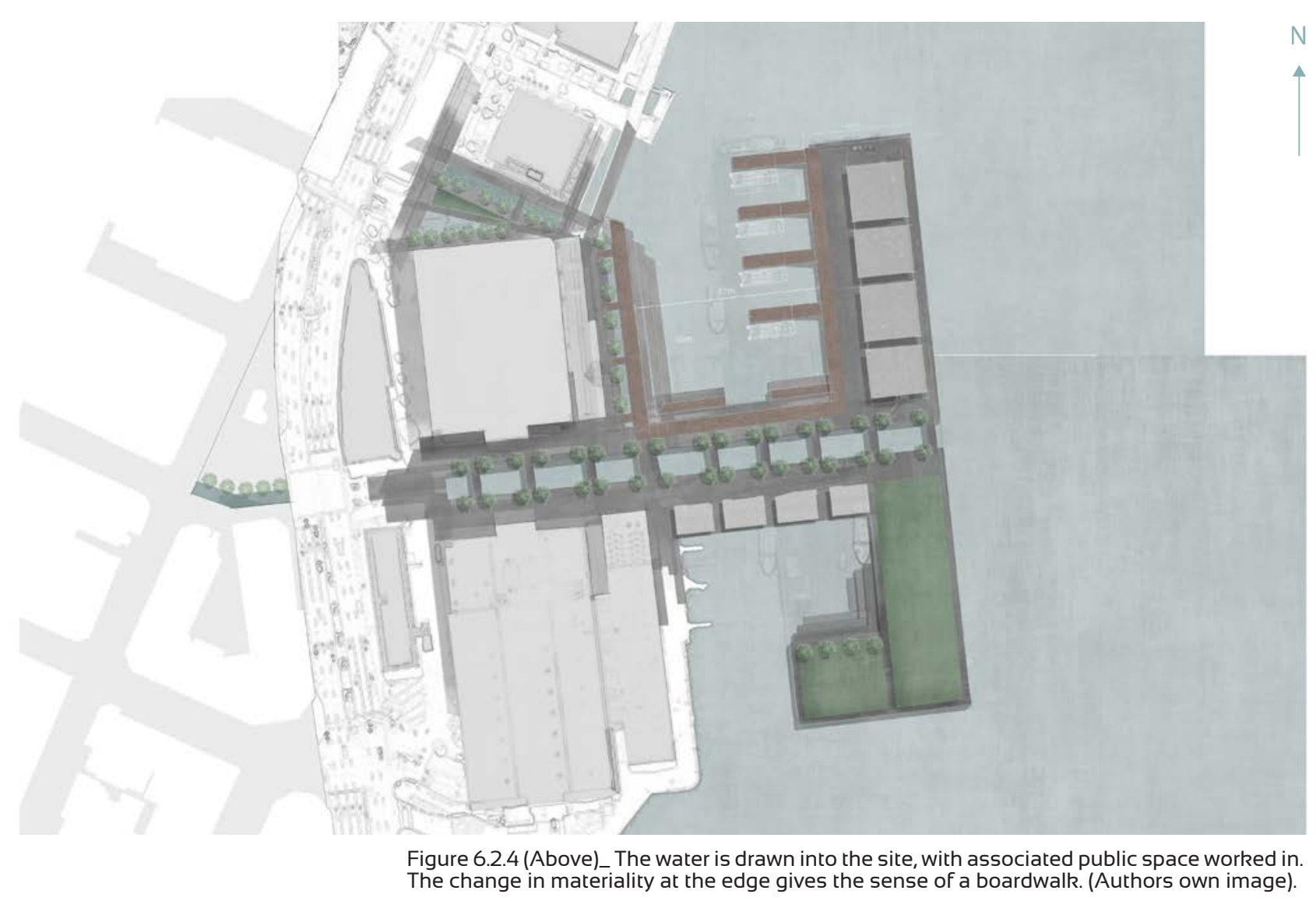




\subsection{3_ Plug in to the existing transport system}

The site and the ferry system must both plug into existing modes of transport to enhance the network. Jervois Quay is a vehicle traffic heavy route that separates the CBD and the waterfront. There have been suggestions that the duplication of the Terrace Tunnel would remove a lot of traffic from Jervois Quay. NZTA are currently investigating this as a viable option ${ }^{27}$.

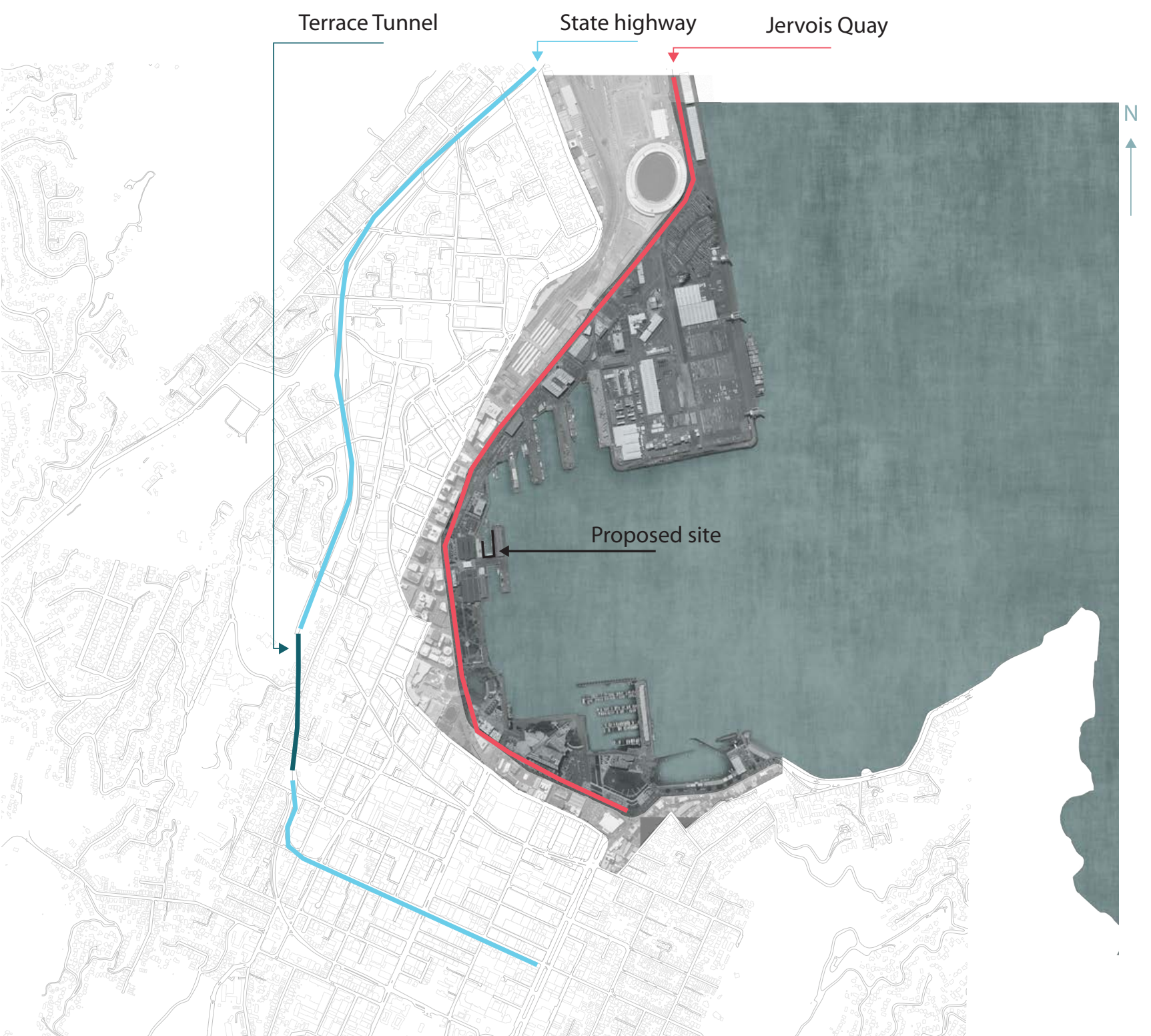

Figure 6.2.5 (Above)_ Location diagram for Jervois Quay and Terrace Tunnel. (Authors own image).

With the duplication of the tunnel Jervois Quay could become more like a city boulevard as opposed to an urban motorway ${ }^{28}$. This will make crossing easier for pedestrian and the lanes can be cut down from six to four. Aside from easier pedestrian flow this also opens up the possibility of light rail or bus rapid transit along the corridor that the ferry service could plug into. For the purpose of this project I will assume that the tunnel widening and light rail/BRT options get the go ahead and are completed. 


\subsection{4_ Built Plug-In Testing}

The scale of the site and importance of the ferry terminal as an entry to the city means that the site could support significant development. These are just suggestions as this thesis cant prescribe what exact functions the built form will have forever.

Residential space is hugely viable as waterfront real estate is in demand. Being situated by the transport network will make them even more marketable and having residential space will create passive surveillance that will help make the space safe and full of people at all times.

Restaurant, bar, and café space would also help to draw people to the site at all times. The pulse of transport will support business and allow the eateries to be well connected to the surrounding context. A small supermarket could allow people to grab groceries on the way home from work.

There is the potential for some large-scale development as well in this site. As it is the entrance to Wellington there could be museum or gallery space that welcomes people. This would also help introduce visitors from the airport to Wellington City.

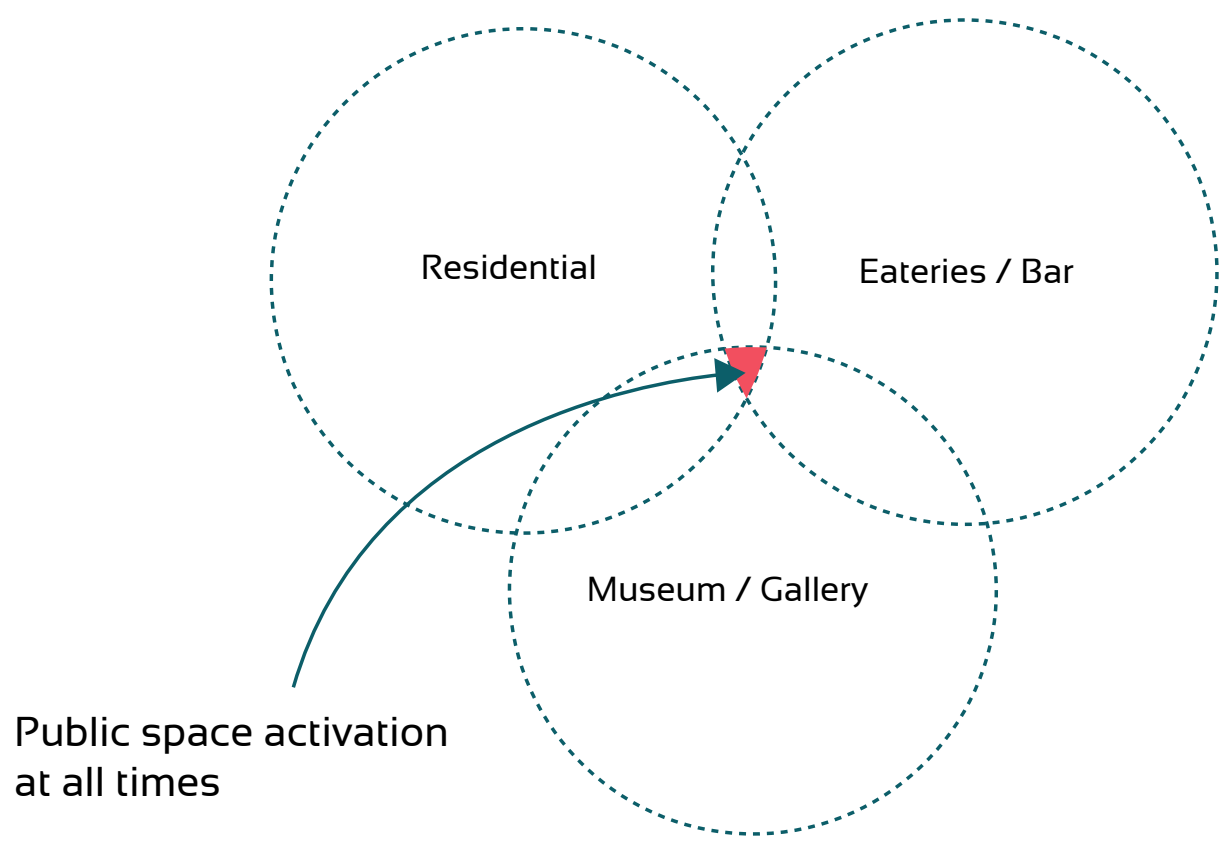

Figure 6.2.6 (Above)_Diagramming the different plug ins and their public space activation (Authors own image). 


\section{3_ Design Detail}

\subsection{1_ Plan}
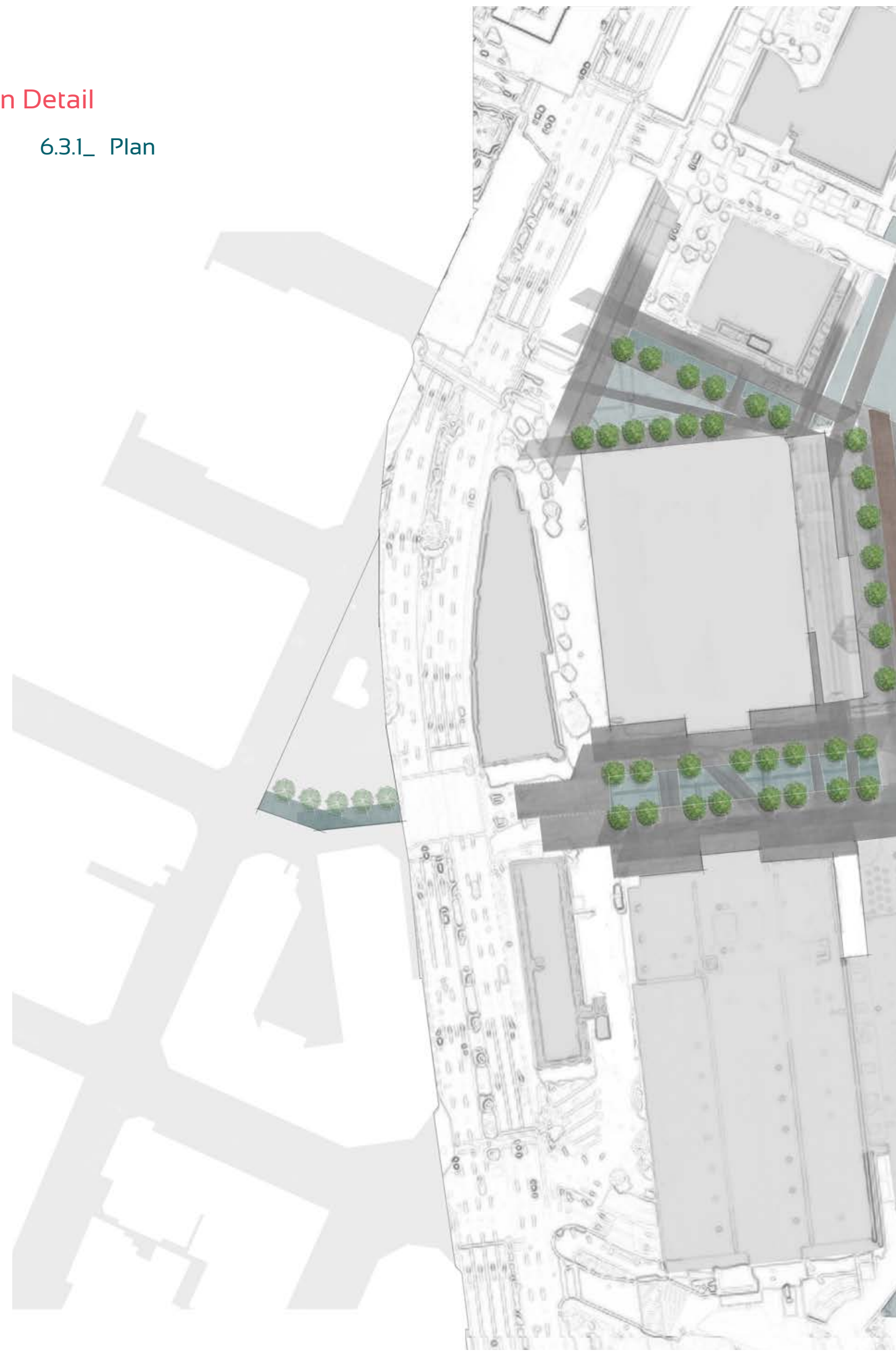

Figure 6.3.1 (Above)_ Plan of proposed design layout. (Authors own image). 


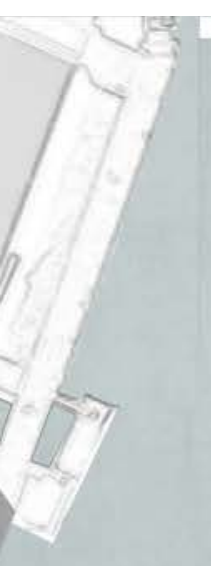

\section{N}
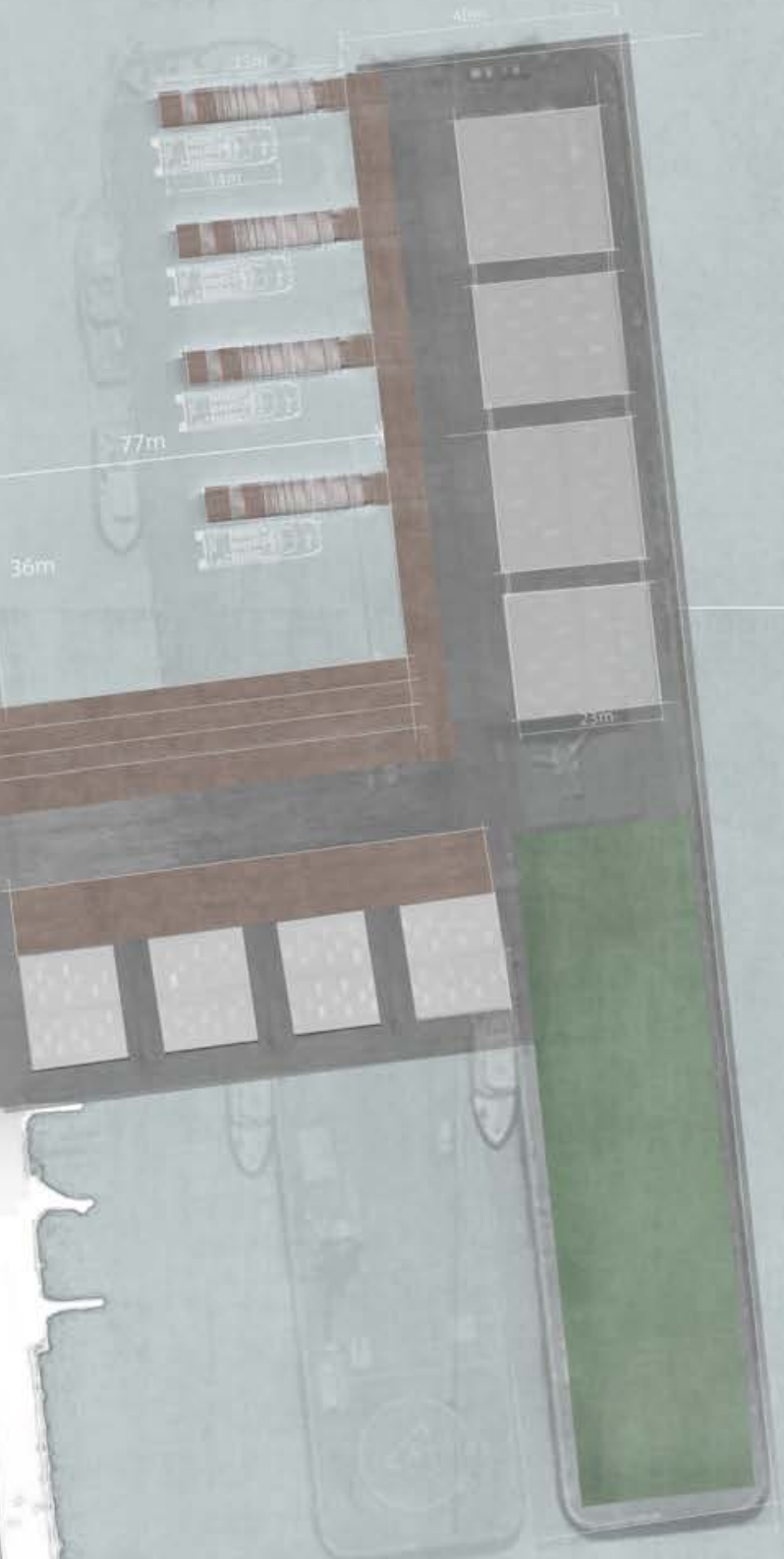


\subsection{2_ CBD to waterfront connection}

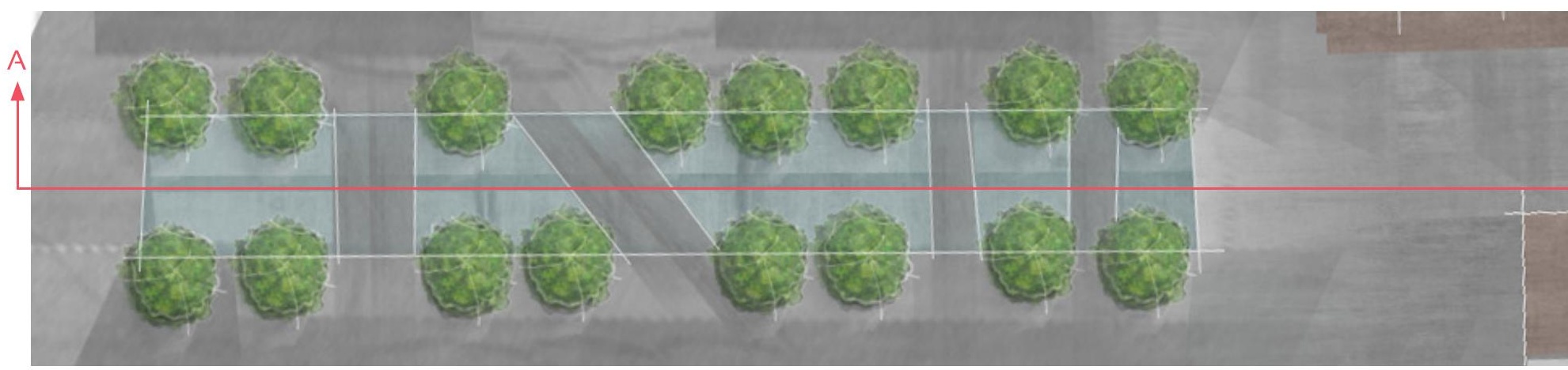

Section A-A

Scale 1 to 250

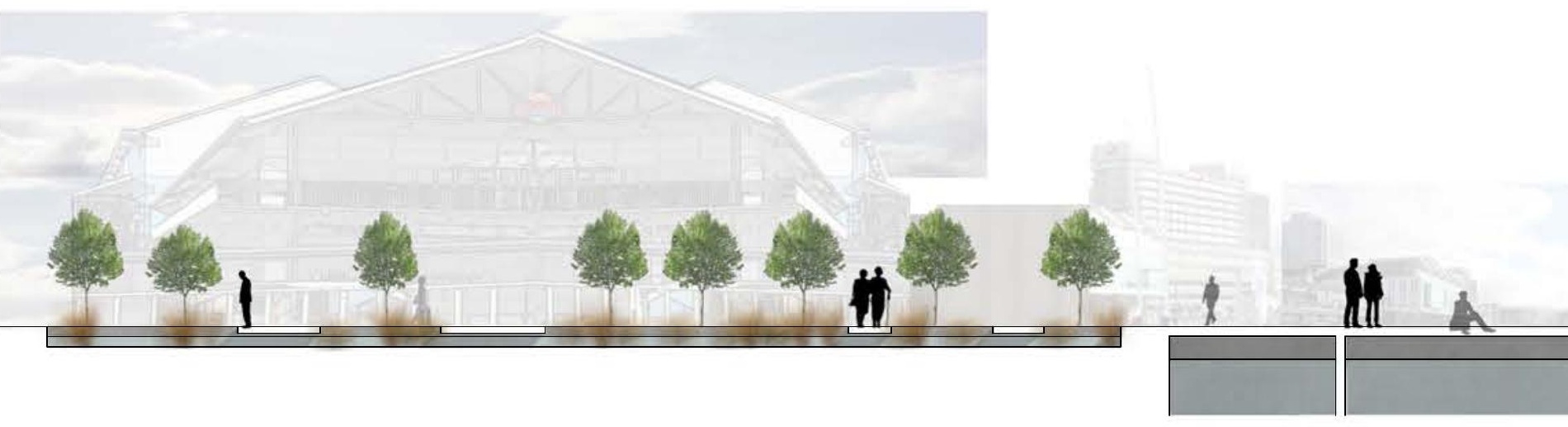



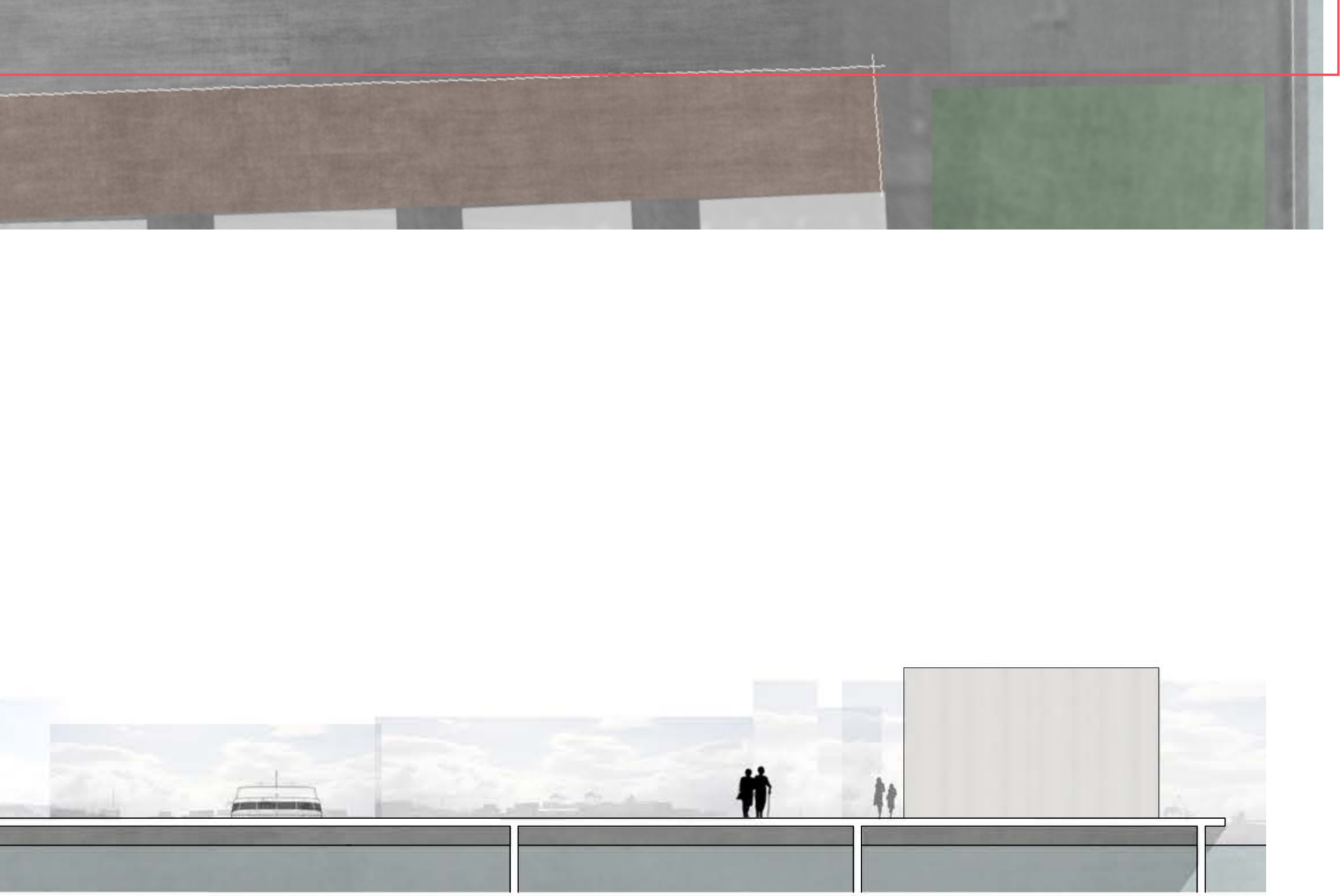

Figure 6.3.2 (Above)_ Transect and section showing the connection between the waterfront and the city. (Authors own image). 


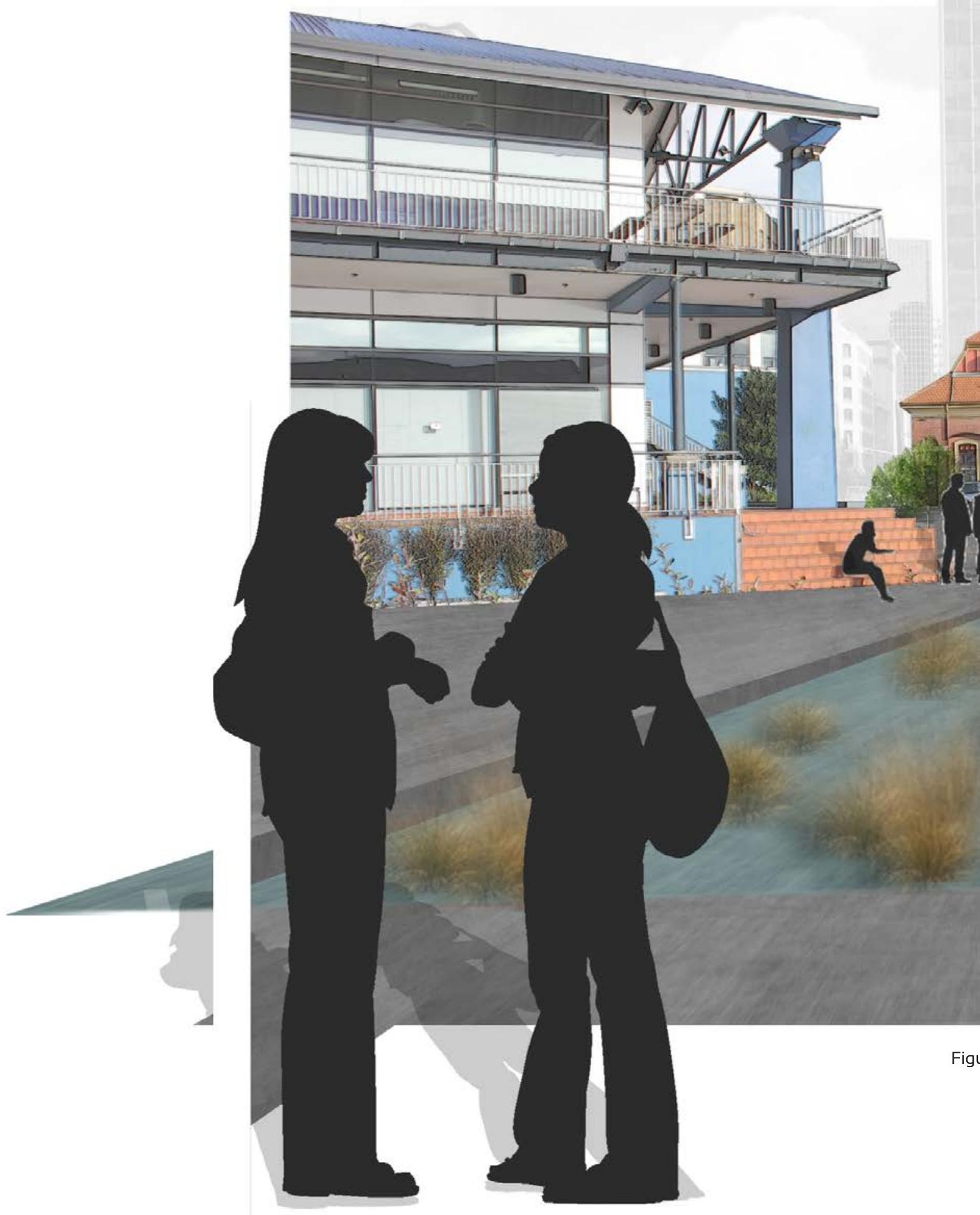




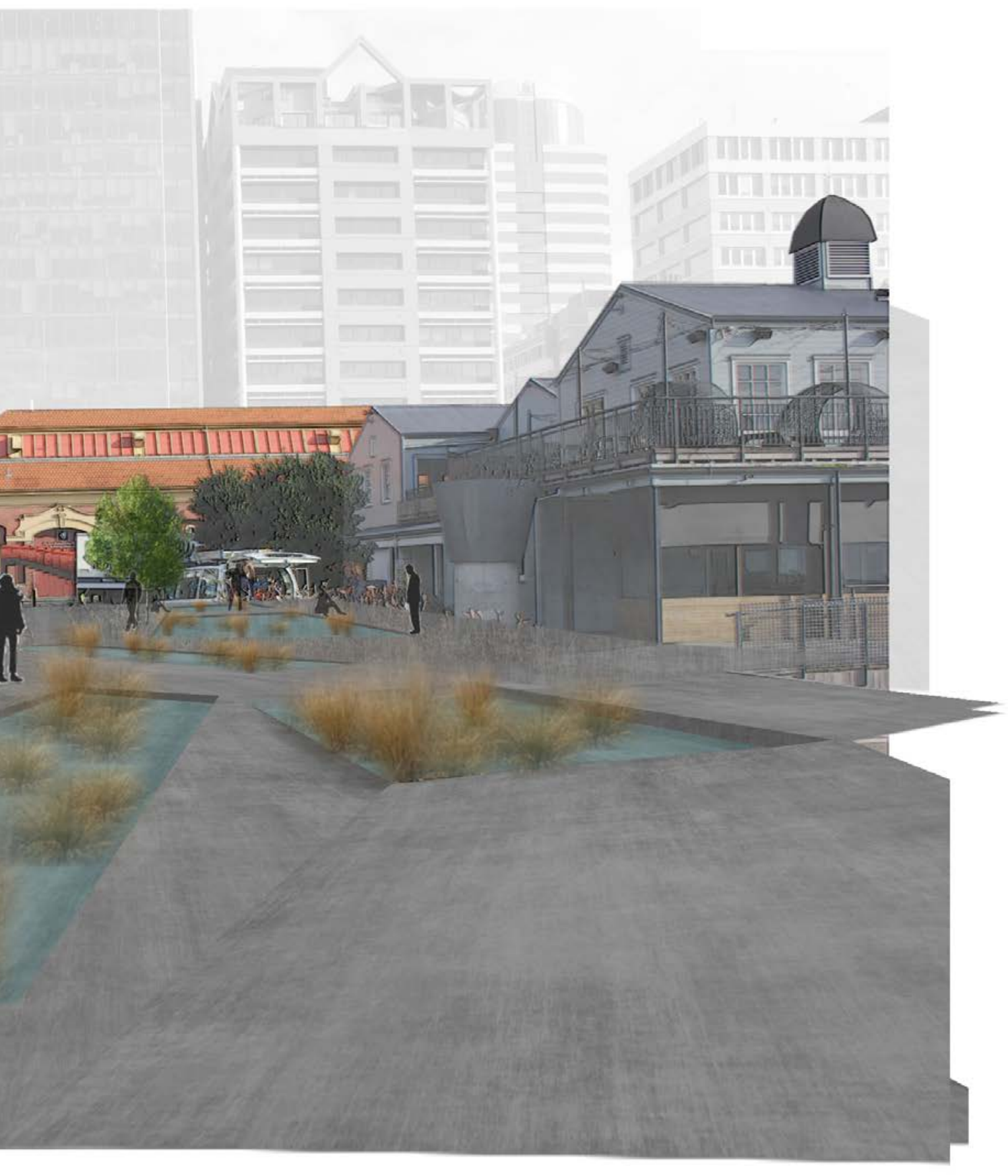

„re 6.3.3 (Above)_ Perspective looking at how water is used to draw people back into the city. (Authors own image). 


\subsection{3_ Multi modal transport hub}

Figure 6.3.4 shows the different movement channels through the site. Number one shows light rail and bus transport being diverted off Jervois Quay and up into the site. There is an interchange that allows people to move between modes of transport with their Wellington public transport card.

Number two shows current pedestrian movement through the site that can help add vibrancy and passive surveillance to the waterfront.

Number three shows where the ferry comes into the mini harbour and docks up. The placement of the wharf stretches the arrival event and means people need to walk past all the built form.

Number 4 shows the connections back into the CBD. Water channels have been used to draw people along the route and help connect the CBD with the waterfront.

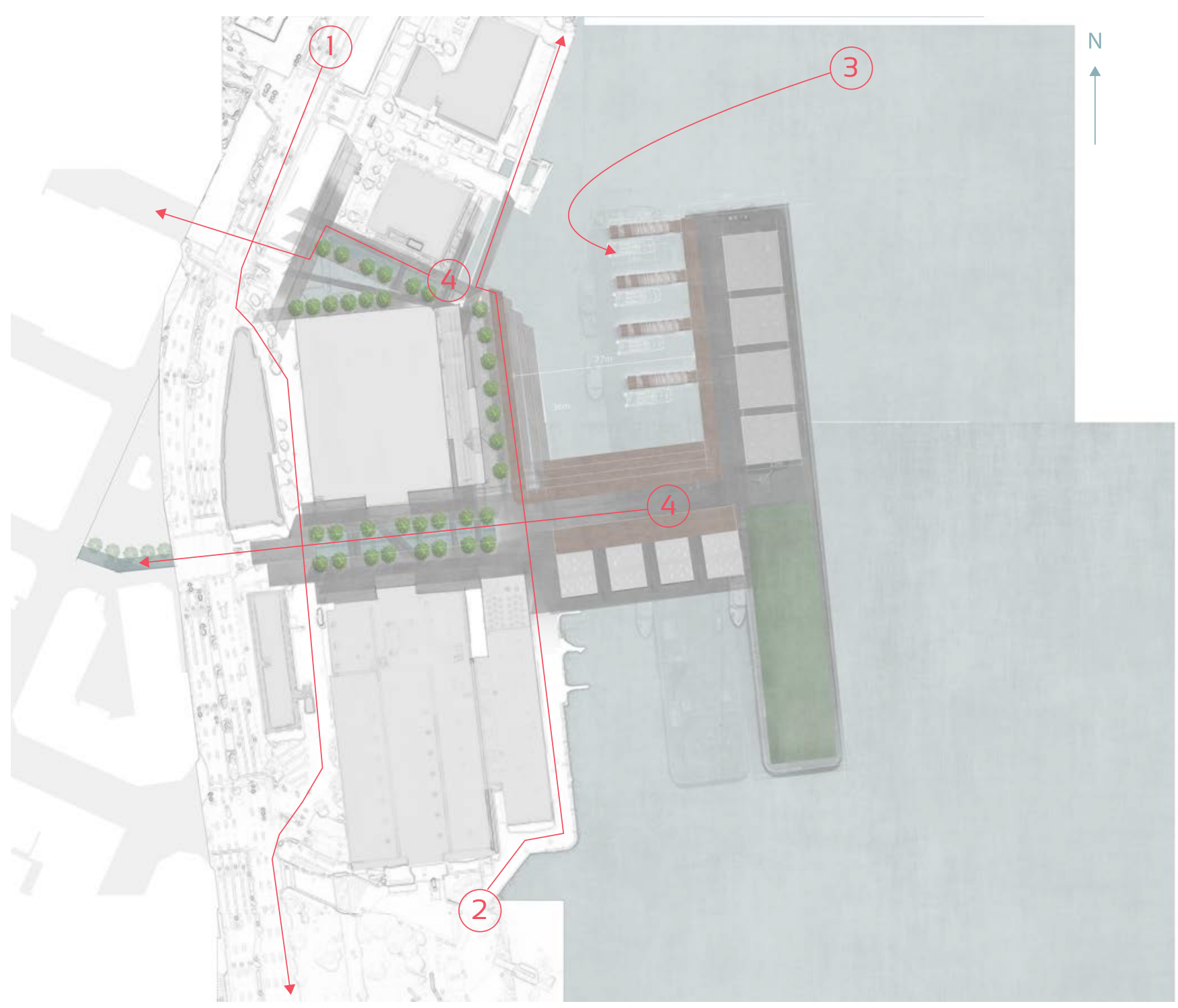

Figure 6.3.4 (Above)_ Mapping the way the design integrates other forms of transport. (Authors own image). 


\subsection{4_ Pedestrian movement}

There are two main uses of the waterfront. The first is for public space/recreational space, and the second is for movement. Materiality has been used to differentiate between the two functions. Timber and grass has been used to signify spaces of rest and relaxation where people can spend time and enjoy being on the waterfront. Concrete provides the materiality for the key movement channels and walkways that allow people to move through the site.

There is a large amount of un-programmed public space within the design. This allows for the design to develop and grow over time as the public use the site. There may need to be another set of buildings to provide built plug-ins to service the area. The grass may not be suited to the weather here and could be swapped for timber. The site is programmed to a level where the design intentions can be understood, yet there is still the looseness for it to evolve over time.

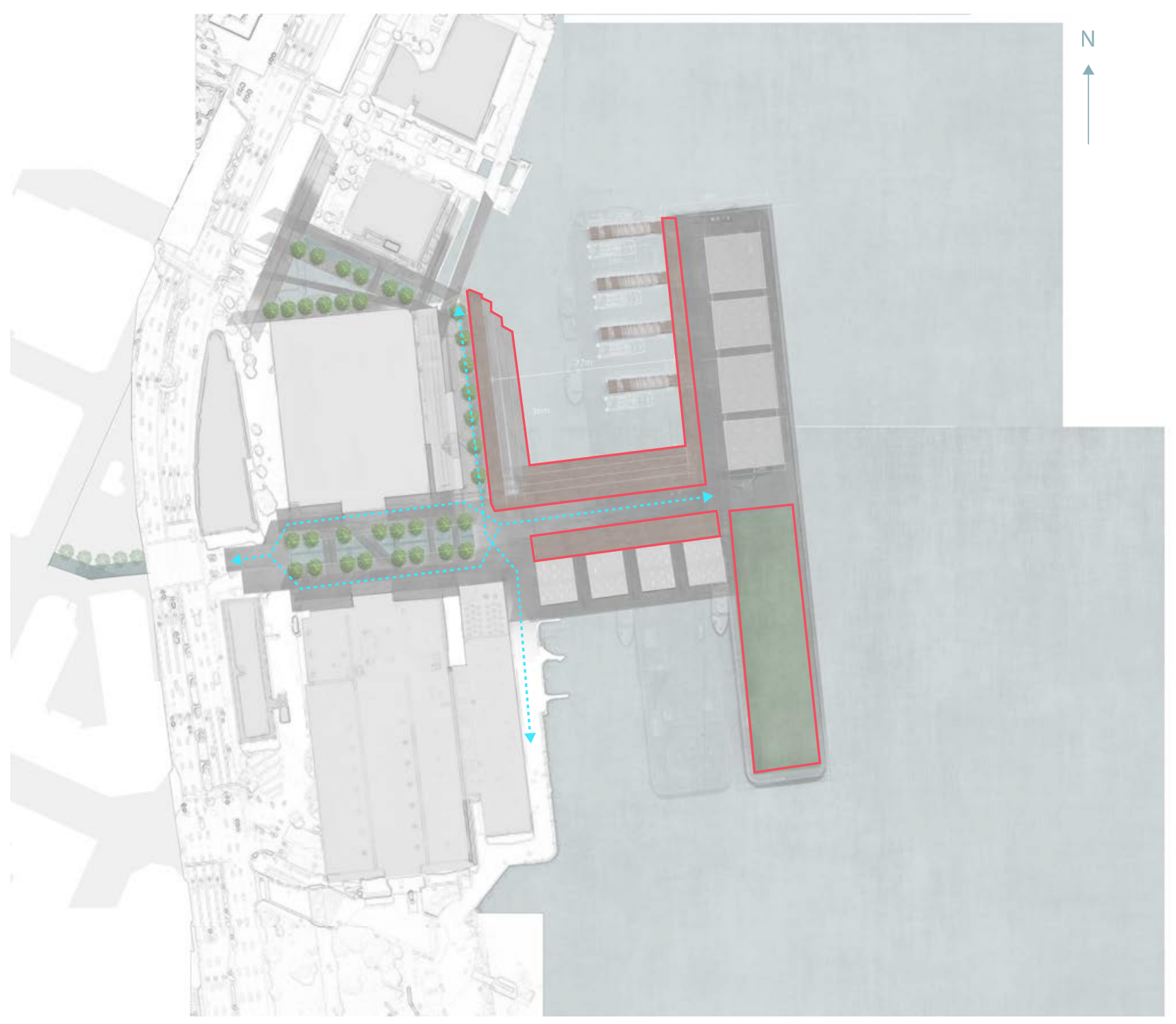

Figure 6.3.5 (Above)_ Mapping of movement channels and public space. (Authors own image). 


\subsection{3_ Ferry Terminal Plan}

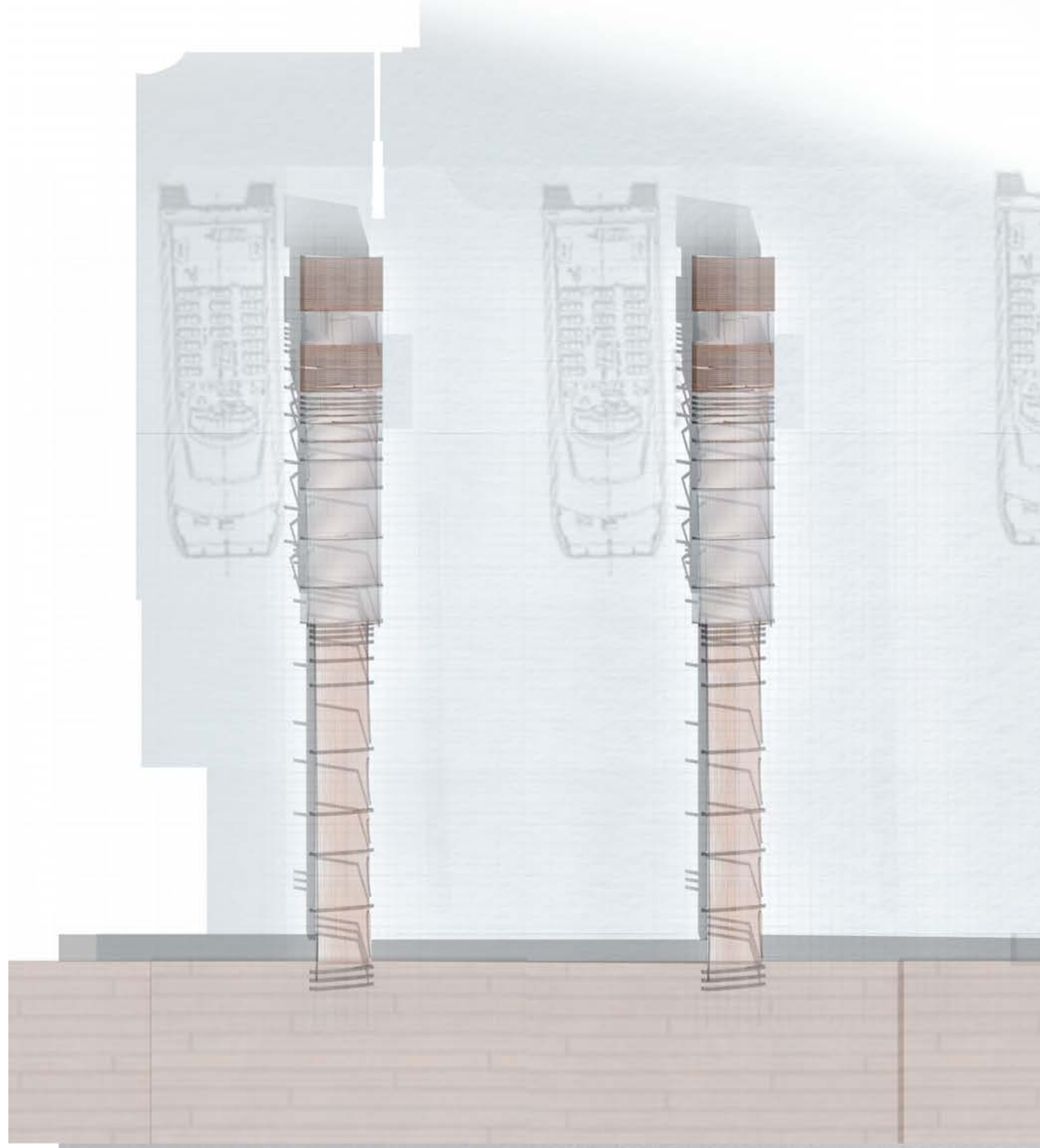

Figure 6.3.6 (Above)_ Plan of ferry terminal layout. (Authors own image). 

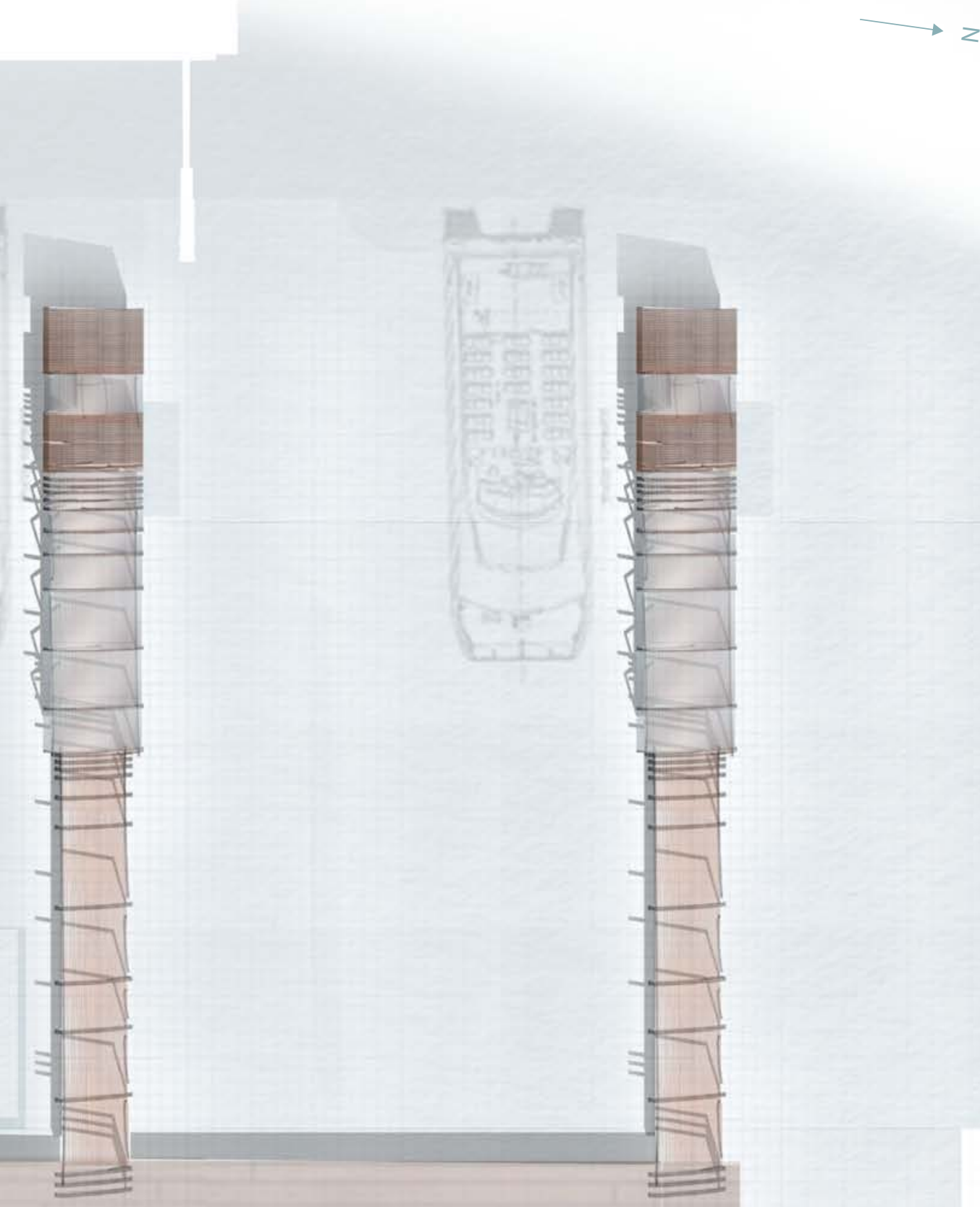


\subsection{4_ Ferry Terminal Perspective}

The design of the terminal itself has been heavily influenced by the design strategies. The terminal provides a sense of discovery for people moving towards the land, and also isolation for those waiting for the ferry. Level change immerses the user in the site and the play on light enhances the arrival event.

The ferry terminals will be similar for each of the ferry sites in the system. Although each will be site specific the materials palette and general form will remain similar to create a sense of cohesiveness in the system.

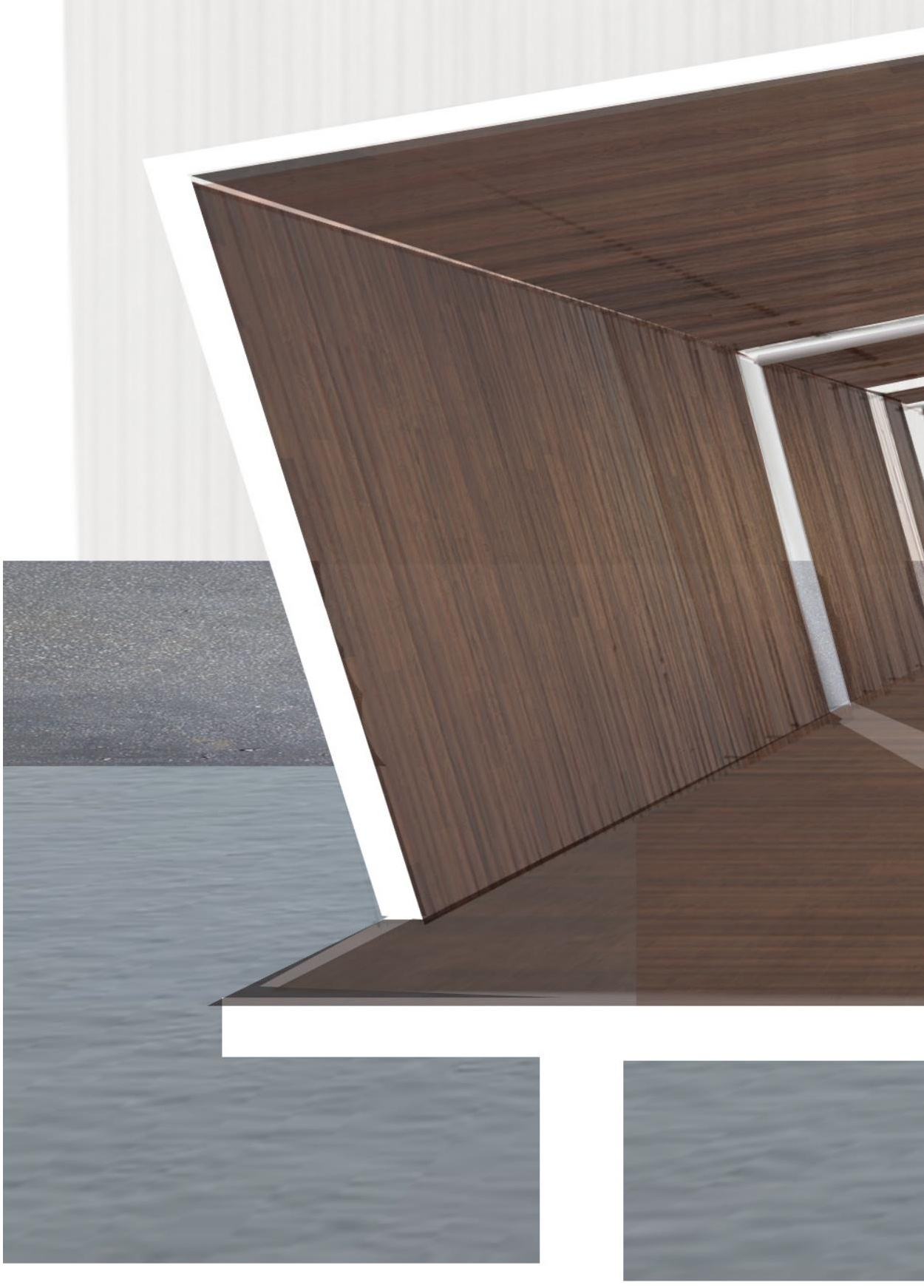




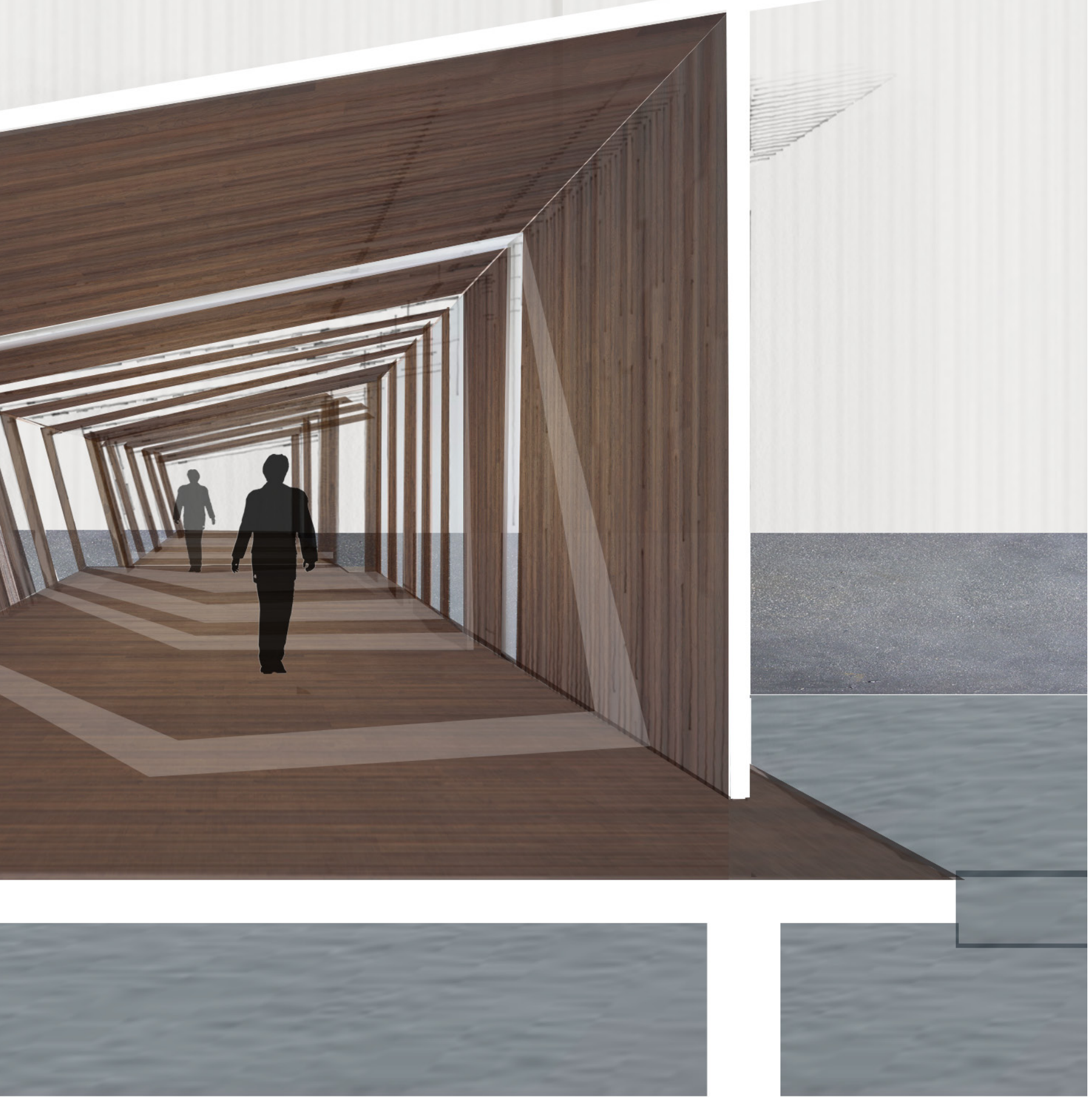

Figure 6.3.7 (Above)__Perspective showing atmosphere inside of ferry terminal. (Authors own image). 


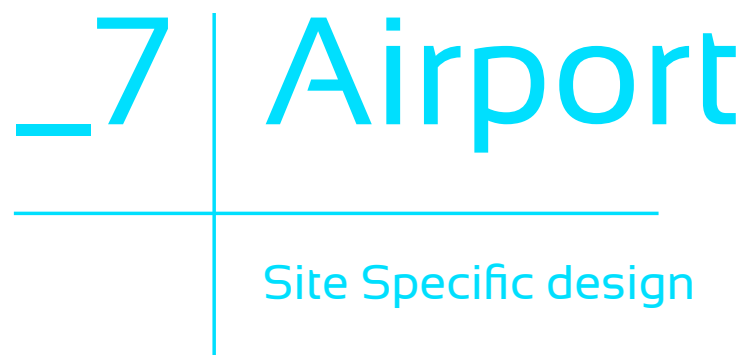




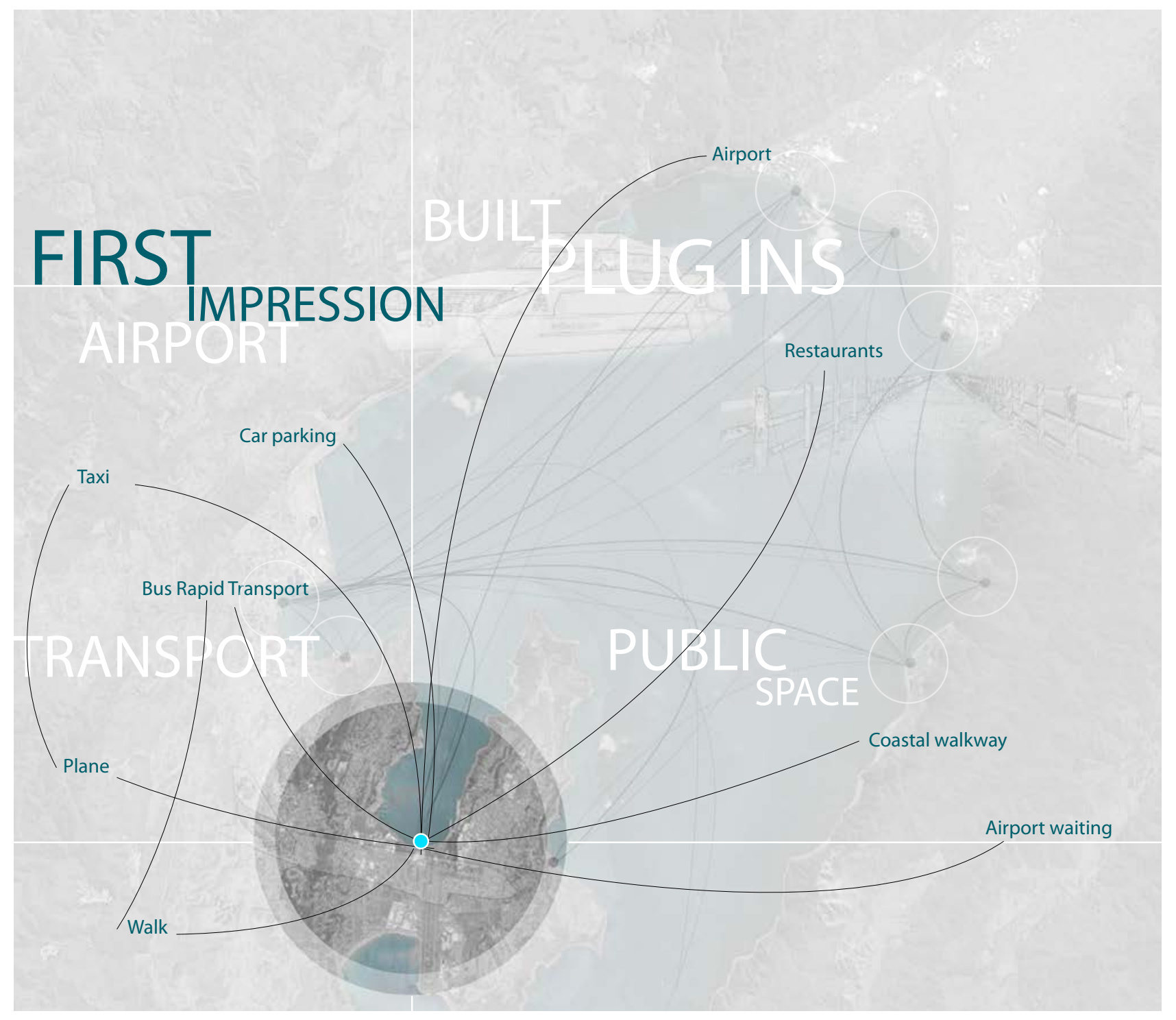

The airport terminal represents the first impression typology. This is a key link in the system as it allows the transport system to influence how Wellington City is perceived at a national and global scale. The current road infrastructure connecting Wellington CBD with the airport is not visually appealing and is prone to congestion issues, yet this is the first impression given to people entering Wellington. An approach from the water would provide another transport option that has the potential to strengthen Wellington City's identity as a harbour city. 


\section{1_ Site Analysis}

\subsection{1_ Current first impression}

When people fly into Wellington they are faced with a long drive, taxi, or bus through roading infrastructure, which is often congested at peak times, to reach the CBD. This is an issue faced by many cities, as the space needed for an airport doesn't fit within the central city.

Figure 7.1.1 shows an abstract representation of the current first impression given to travellers.

This is a problem that other outlying suburbs such as Petone and Hutt Valley face, which this thesis is trying to address.

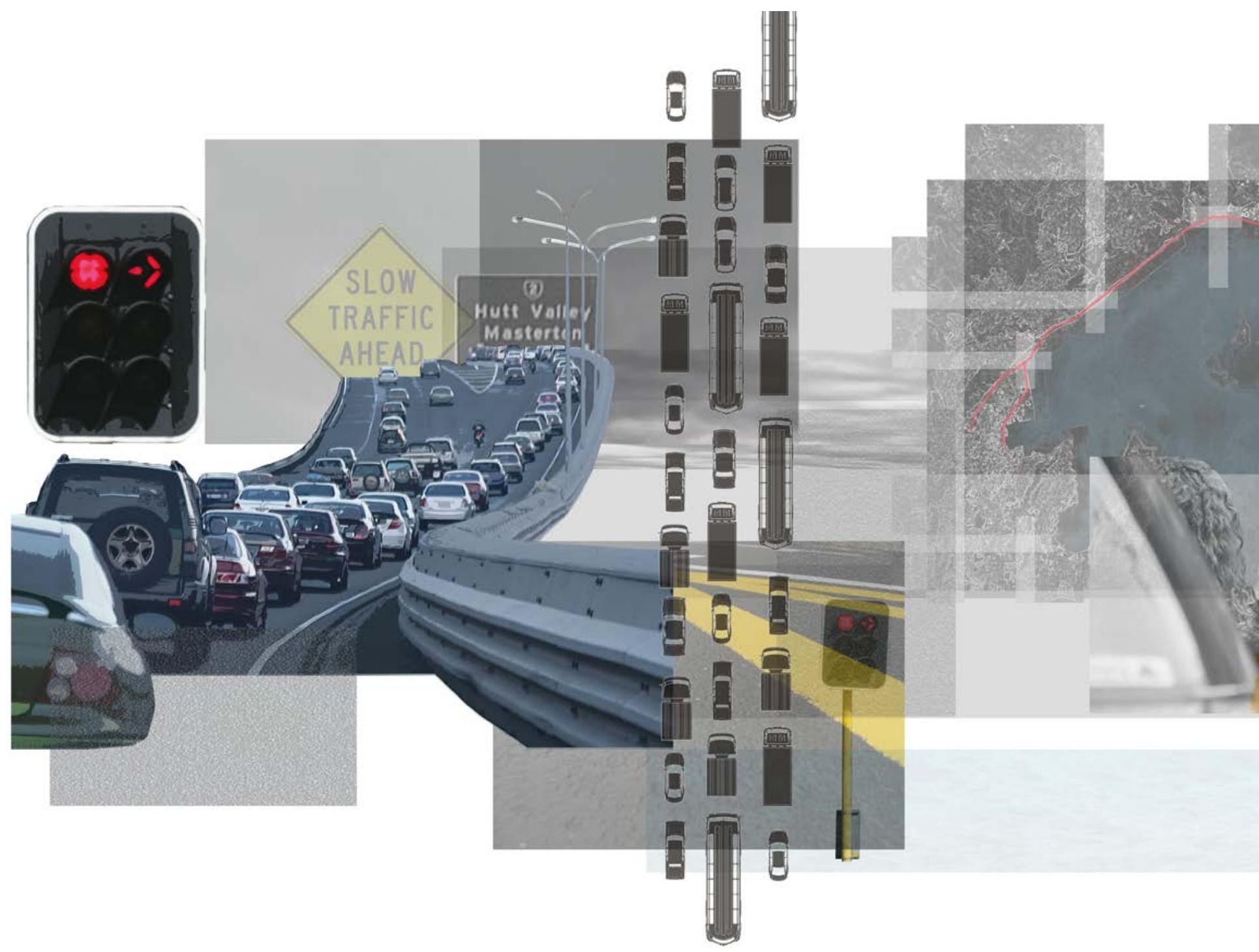




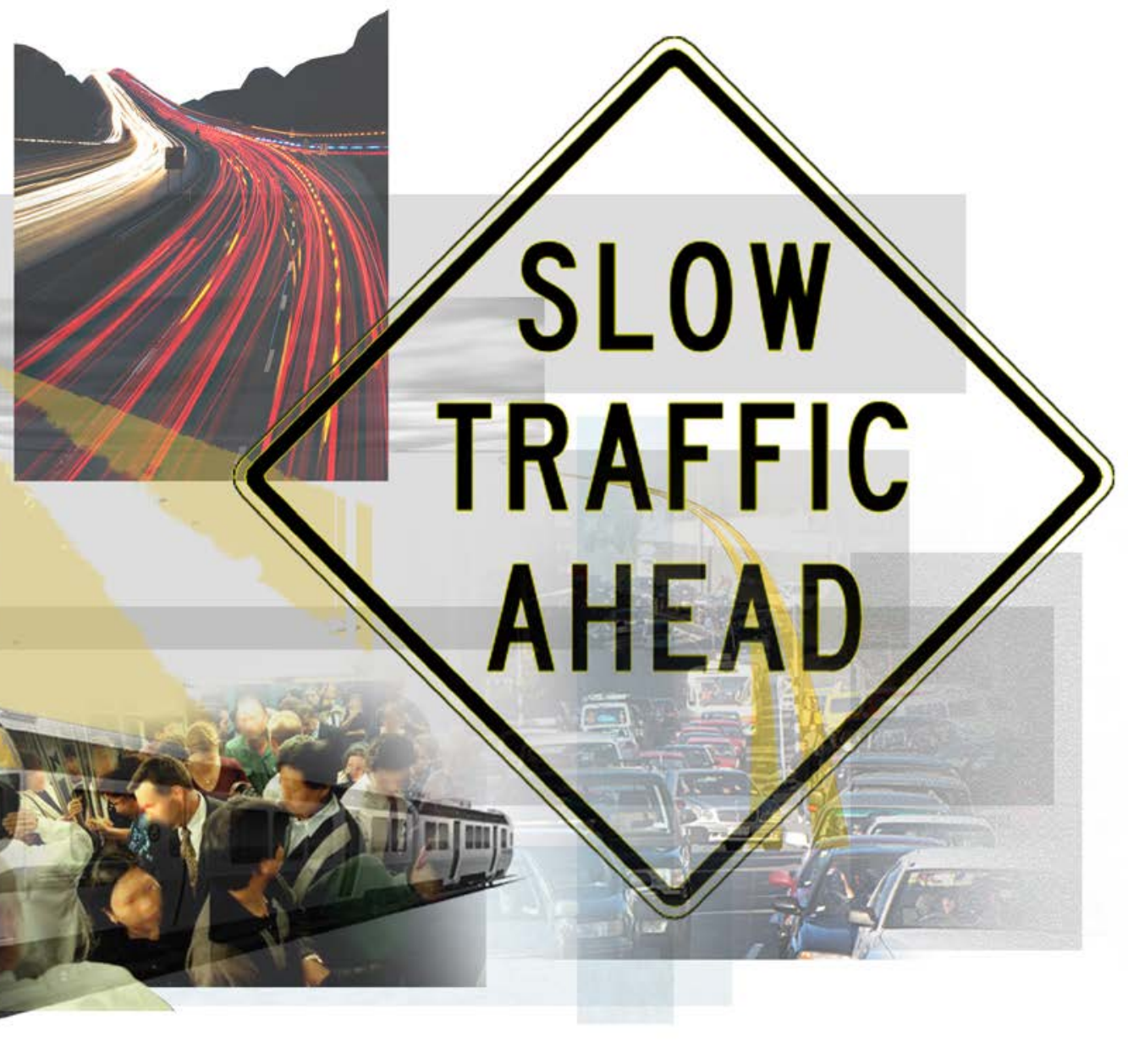

Figure 7.1.1 (Above)_ Diagram of the current atmosphere going from the airport to the CBD. (Authors own image). 
7.1.2_ Proposed first impression

By taking passengers to the CBD via the water, as opposed to through the roads, waiting times are decreased and a strong connection is established between Wellington City and the harbour. This route will bring them into the heart of Wellington City where they can catch a cheap taxi or walk to their accommodation.

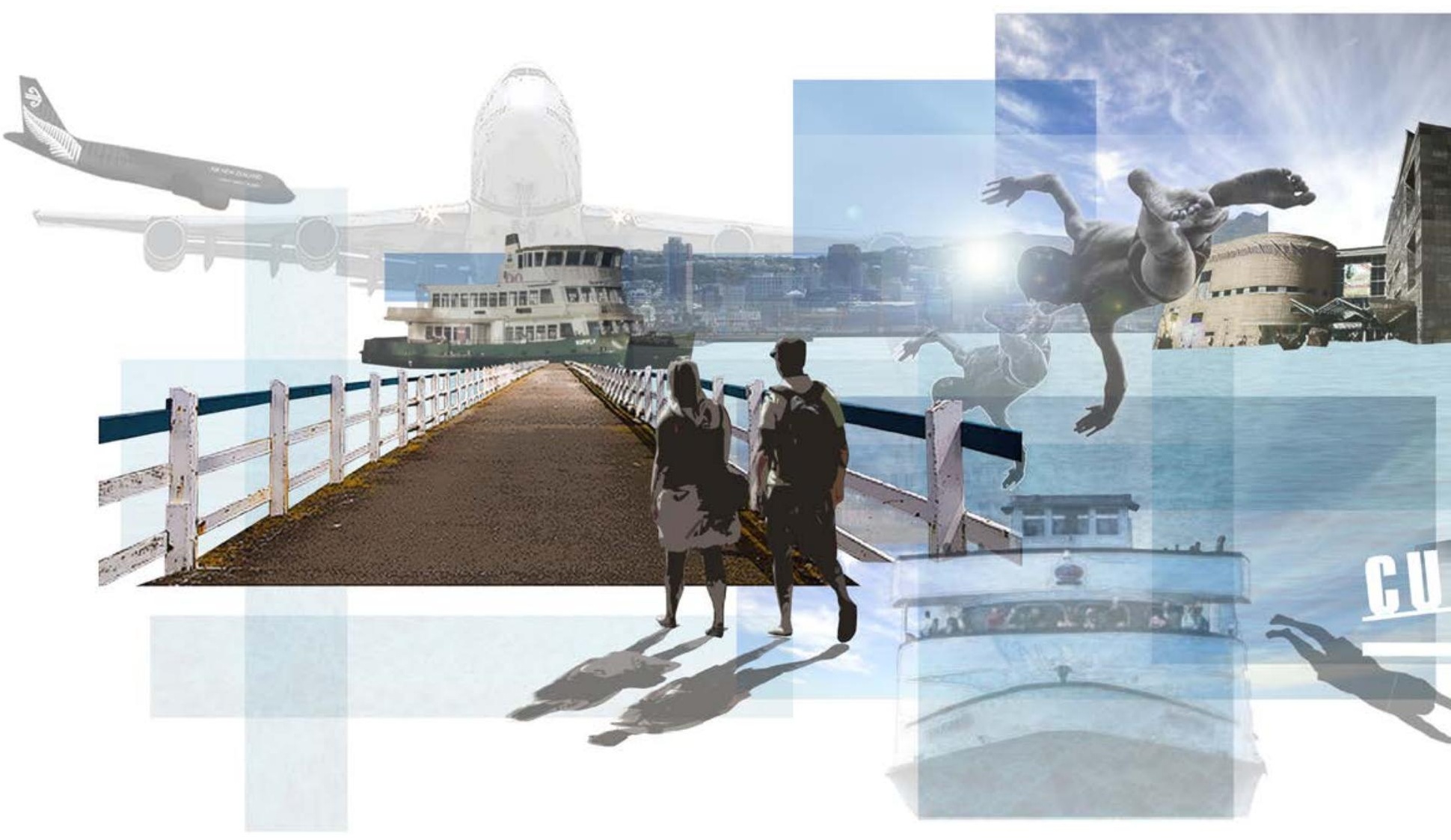




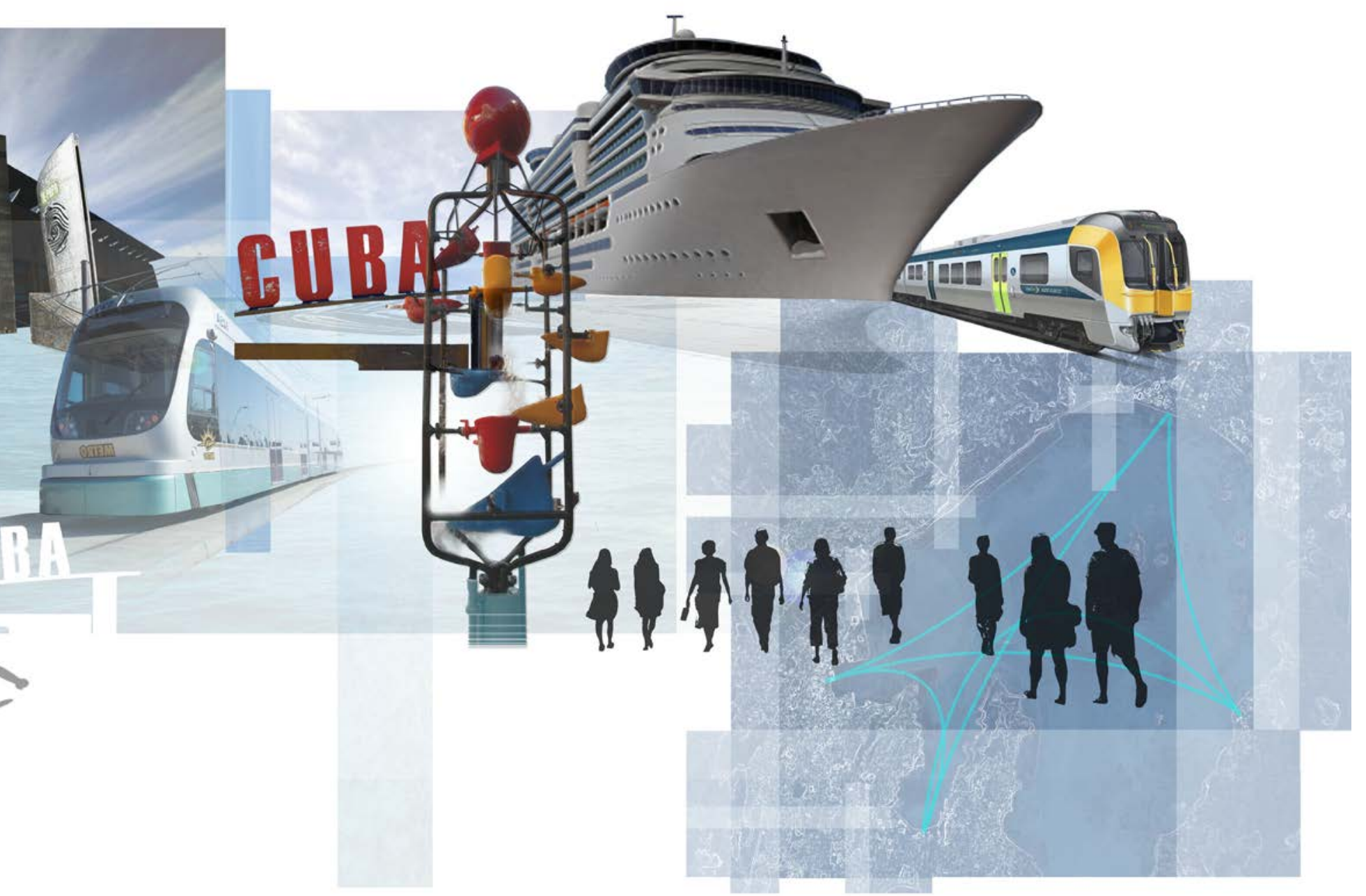

Figure 7.1.2 (Above)_ Diagram of the proposed atmosphere going from the airport to the CBD through the implementation of the ferry service. (Authors own image). 


\subsection{3_ Airport runway extension}

There is a plan by Wellington Airport plan to extend the runway to allow for larger planes to come into Wellington. The airport is currently in early stages of seeking resource consent for the extension29. The plan involves lengthening the runway by 100 metres to the north and 500 metres to the south 30 . Figure 7.1.3 shows the runway in its current state whilst figure 7.1.4 shows the length of the extension.

This thesis makes an assumption that the runway extension will go ahead. The design process will test what opportunities this can make available for the ferry system.

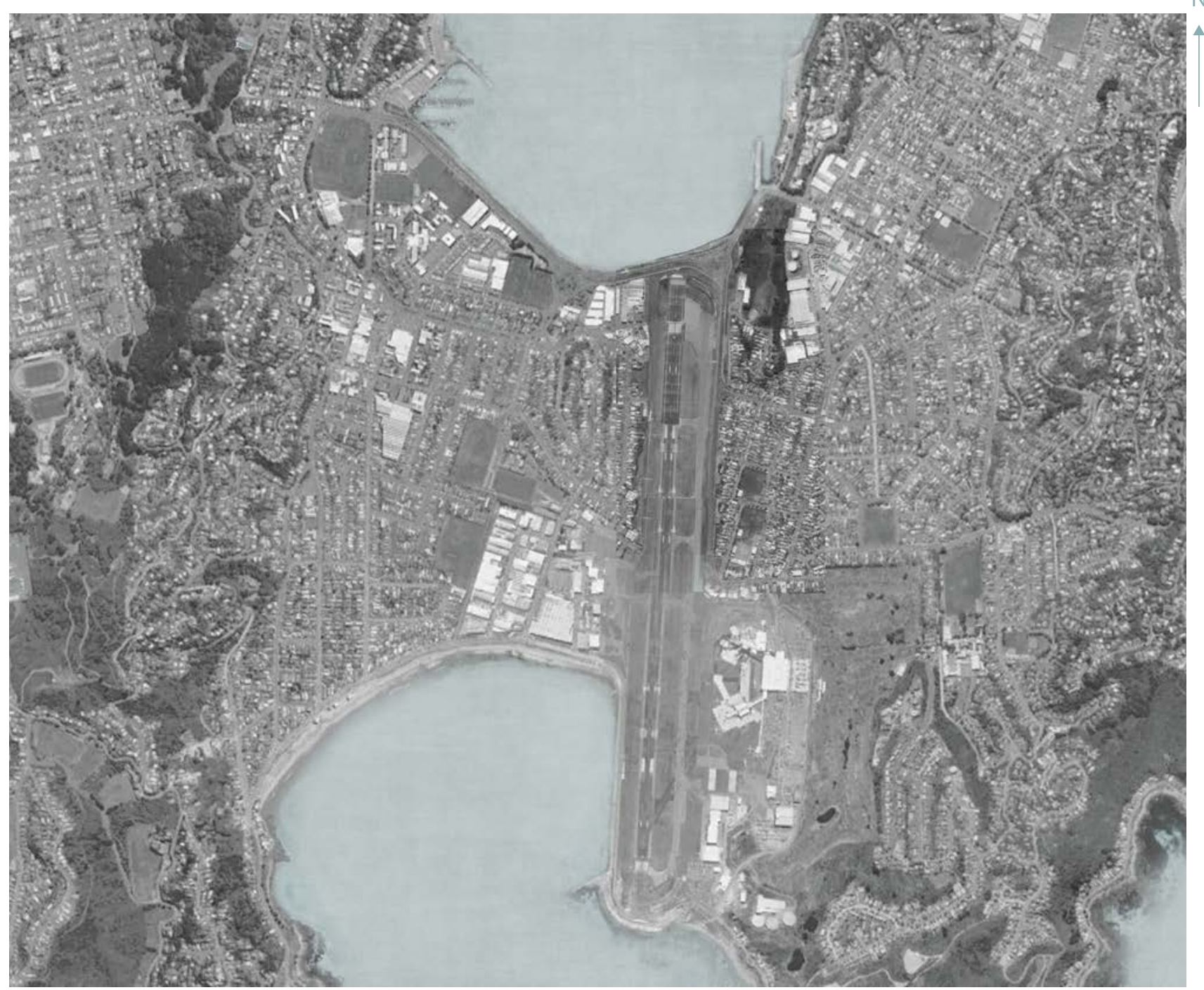

Figure 7.1.3 (Above)_ The current layout of Wellington airport. (Authors own image). 


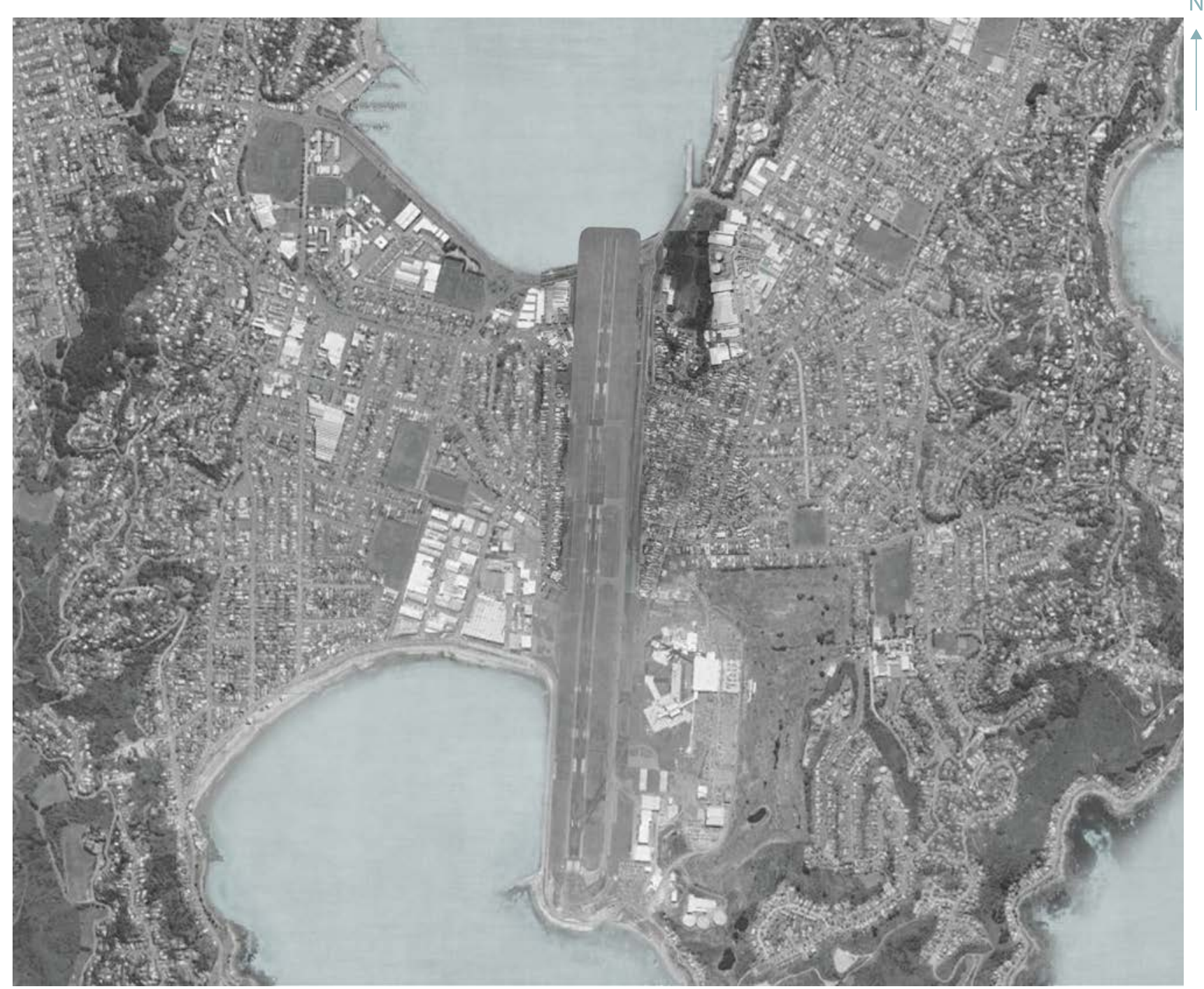

Figure 7.1 .4 (Above)_ 100 metre airport extension to the north. (Authors own image). 


\section{2_ Design Testing}

\subsection{1_ Airport ferry options}

There are three options that would allow the ferry service to run from the airport to Wellington CBD. The first is that a ferry wharf is built in Evans Bay and the ferry stops there. The passengers then get into a shuttle that brings them to the airport terminal.

The second option involves using the runway extension as a reason to move the terminal north towards the water so the ferry can come right up to the airport. This would remove the need for a shuttle.

The third option involves somehow bringing the water inland so that it meets the airport terminal.

$V_{5}$

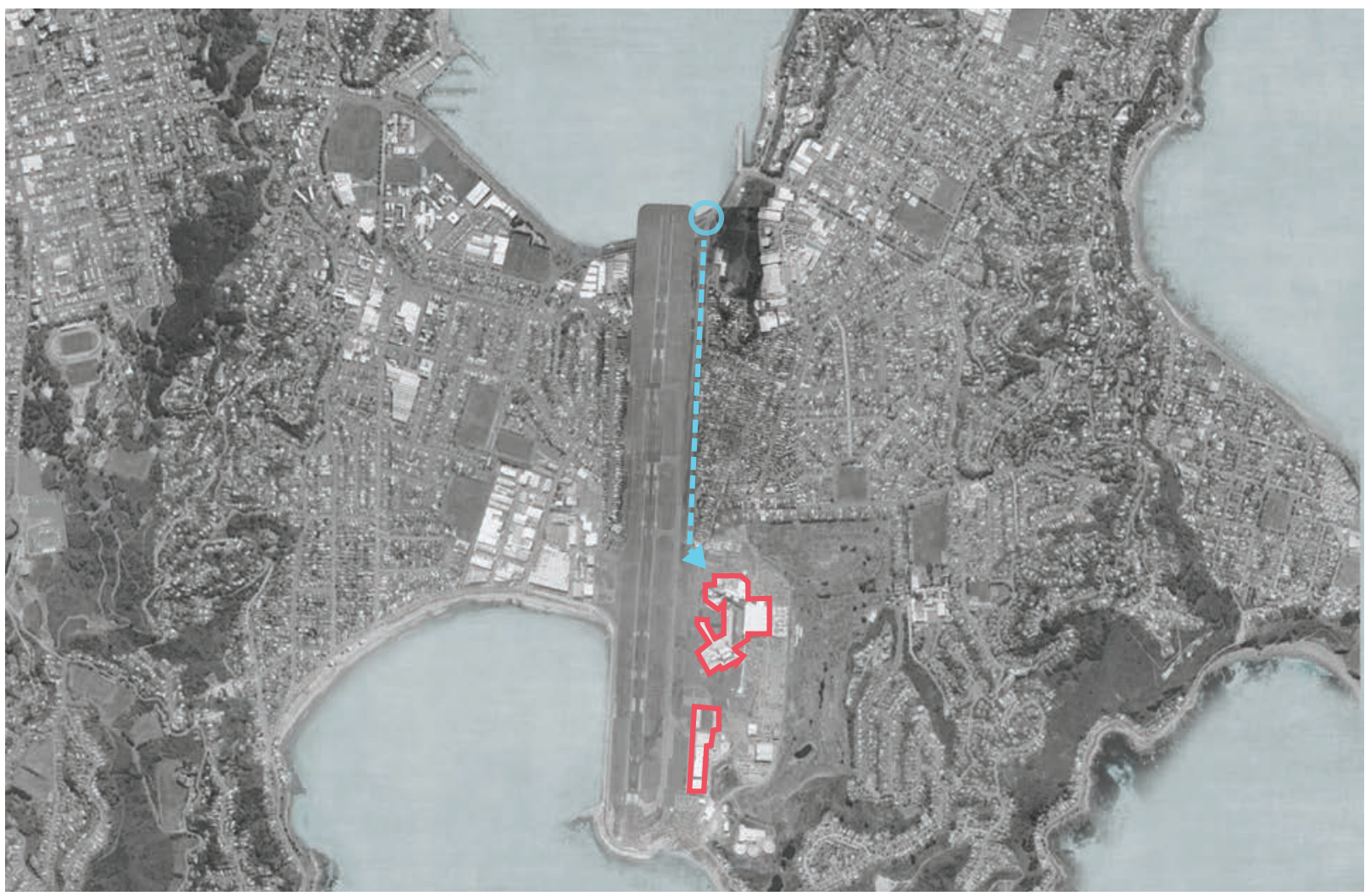

Figure 7.2.1 (Above)_ Ferry wharf in Evans bay with a taxi bringing people to the airport terminal. (Authors own image). 

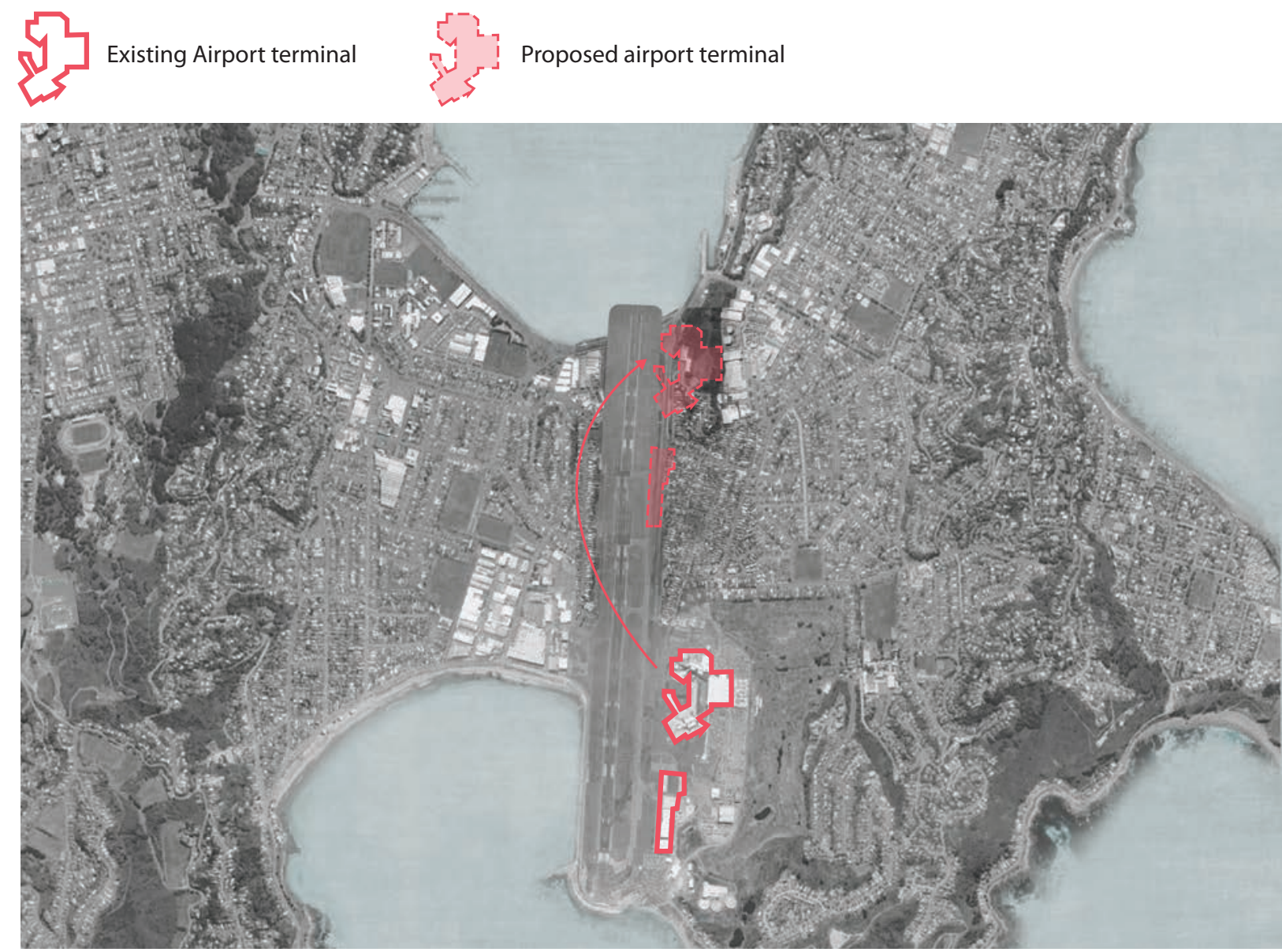

Figure 7.2.2 (Above)_ As part of the airport extension the airport terminal could move north so the ferry could link straight into the terminal cutting out the need for a taxi. (Authors own image).

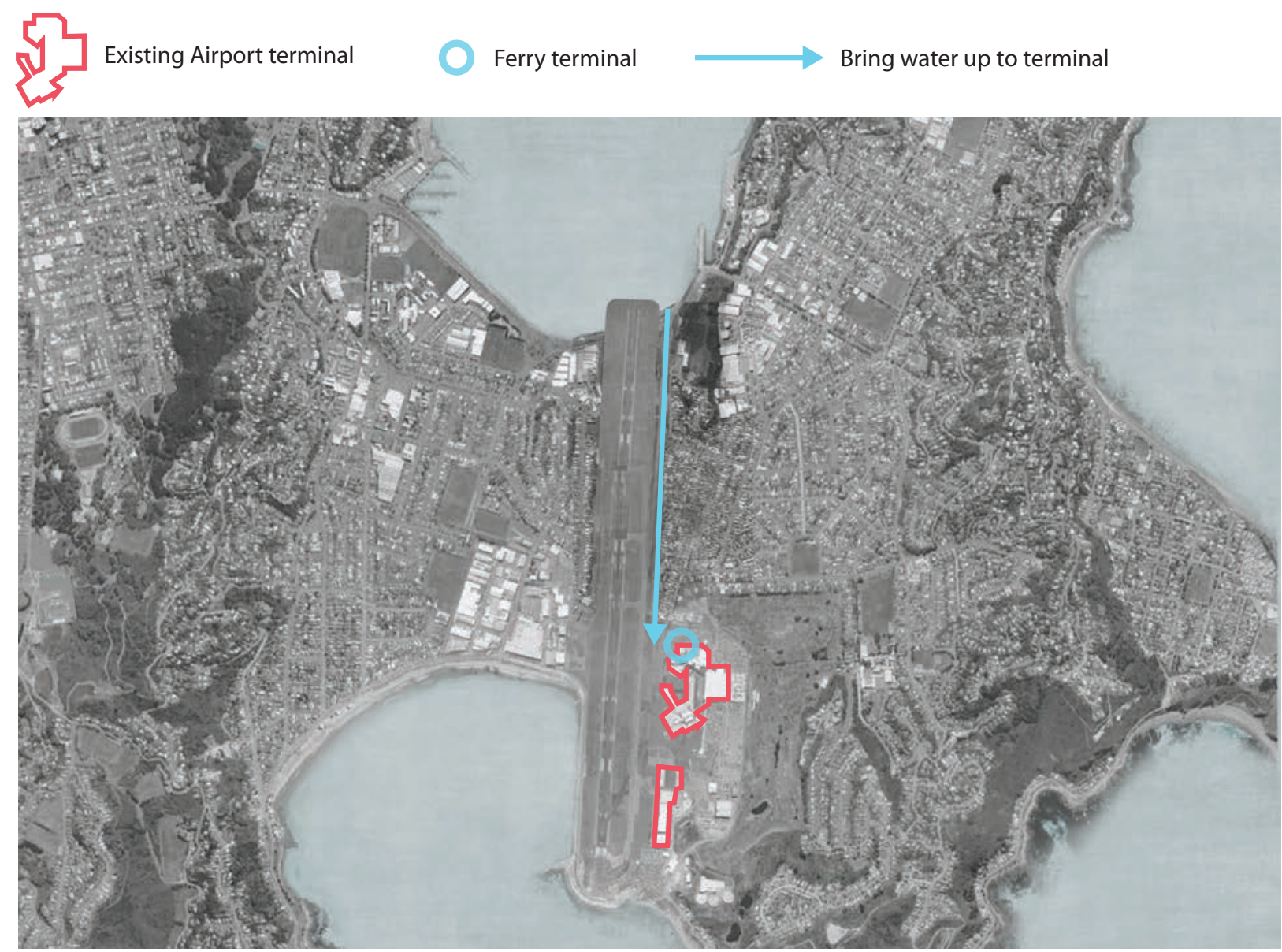

Figure 7.2 .3 (Above)_ The second option to connect the ferry into the terminal is to bring the water up to the existing airport terminal. (Authors own image). 


\subsection{2_ Connection to terminal}

The option that has been chosen is to connect the water to the airport terminal by means of a canal that runs along the side of the runway. Although not the cheapest option this provides the best sensory experience for people travelling to and from Wellington and could make a real lasting impression.

This option becomes more feasible when the runway extension is considered as the cut and fill needed to create the canal could then be used in Evans Bay to create the extra runway. This would mean that the canal cut doesn't need to be trucked away, which would be very expensive, and the runway extension has a source of fill that is close by.

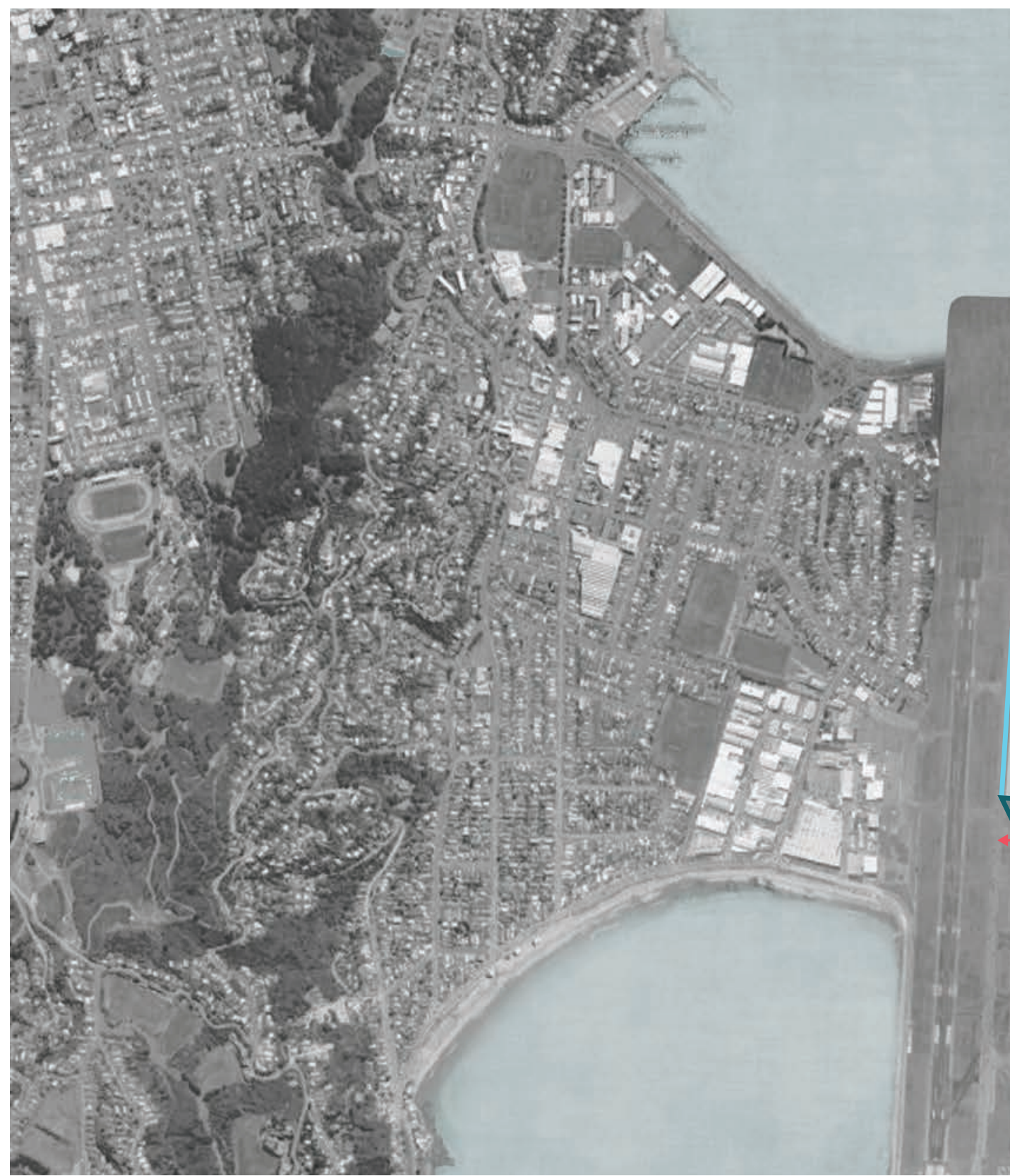




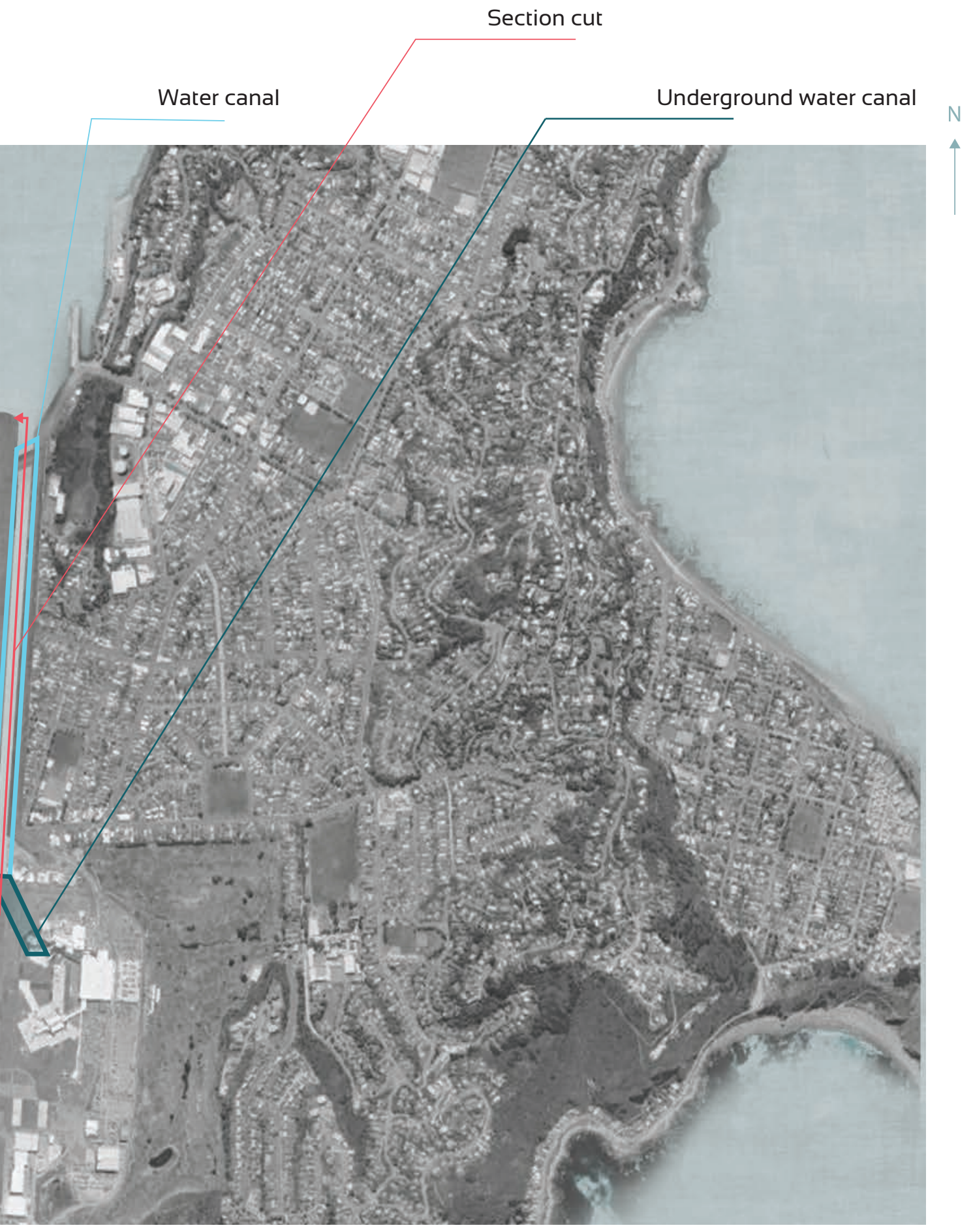

Figure 7.2.4 (Above)_ Diagram looking at where the canal would be cut. (Authors own image). 
7.2.3_ Cut and Fill testing

There is a significant rise in topography as people travel by car from the water to the airport. It peaks at 13 metres before dropping back down to four at the airport terminal. To stop there being a large drop from the top of the road to the bottom of the canal the road should be cut to a lower topography.

The airport sits four metres above sea level. The ferry should be able to run right underneath the terminal, allowing passengers to move down a floor straight onto the ferry.

Current topography 
New road level

$650 \mathrm{~m}$

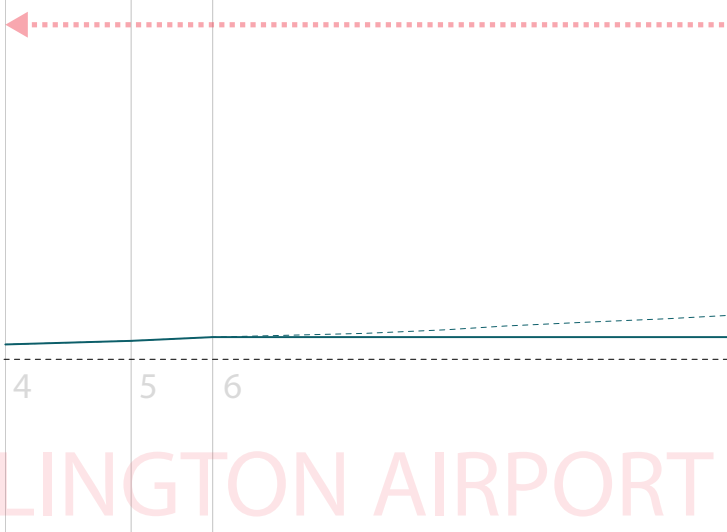

Depth needed for ferry

$650 \mathrm{~m}$

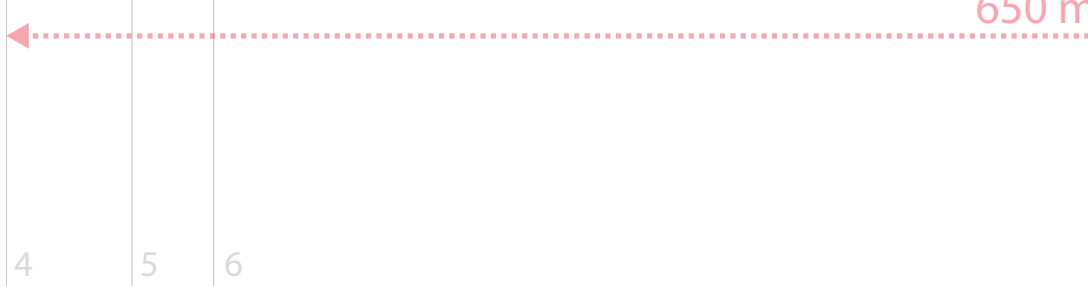

Road level

$4 \mathrm{~m}$ cut underwater

WELLINGTON AIRPORT 


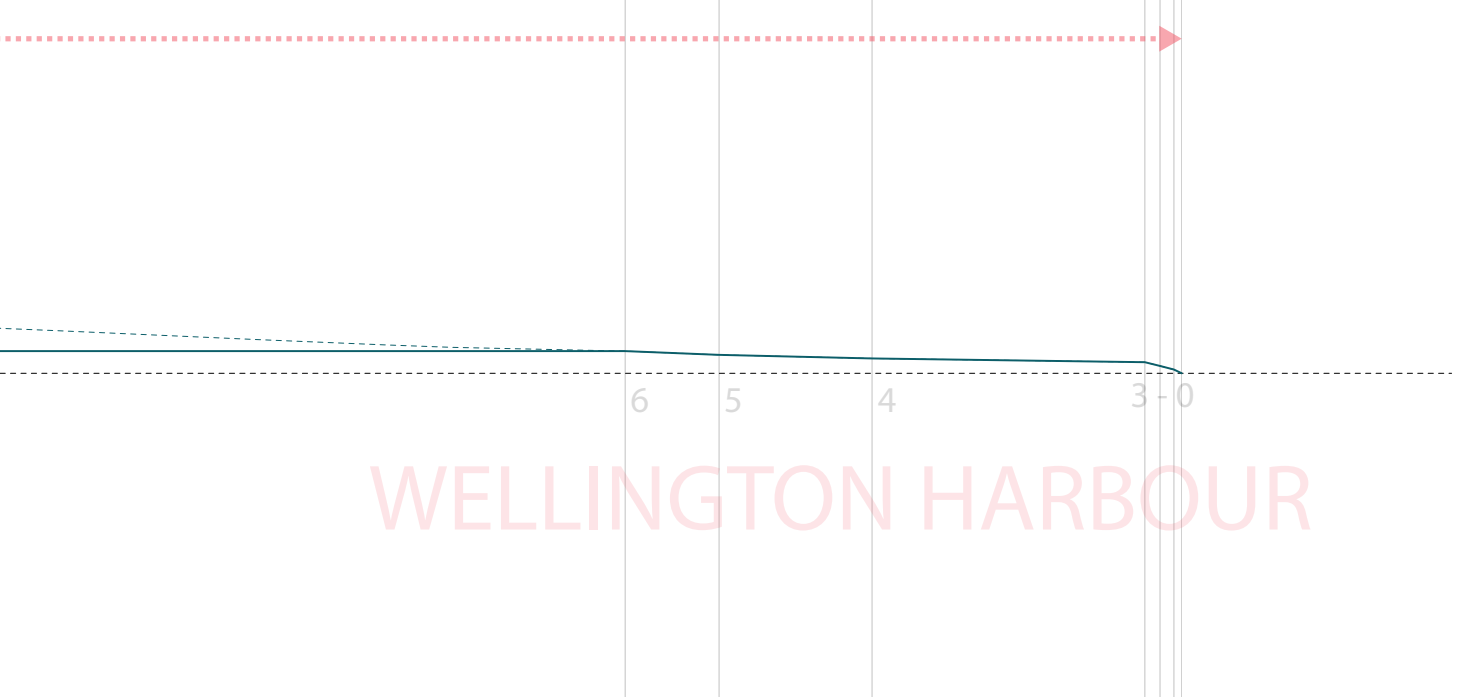

Figure 7.2.7 (Above)_ This is the new road level, with the old level shown above. (Authors own image).
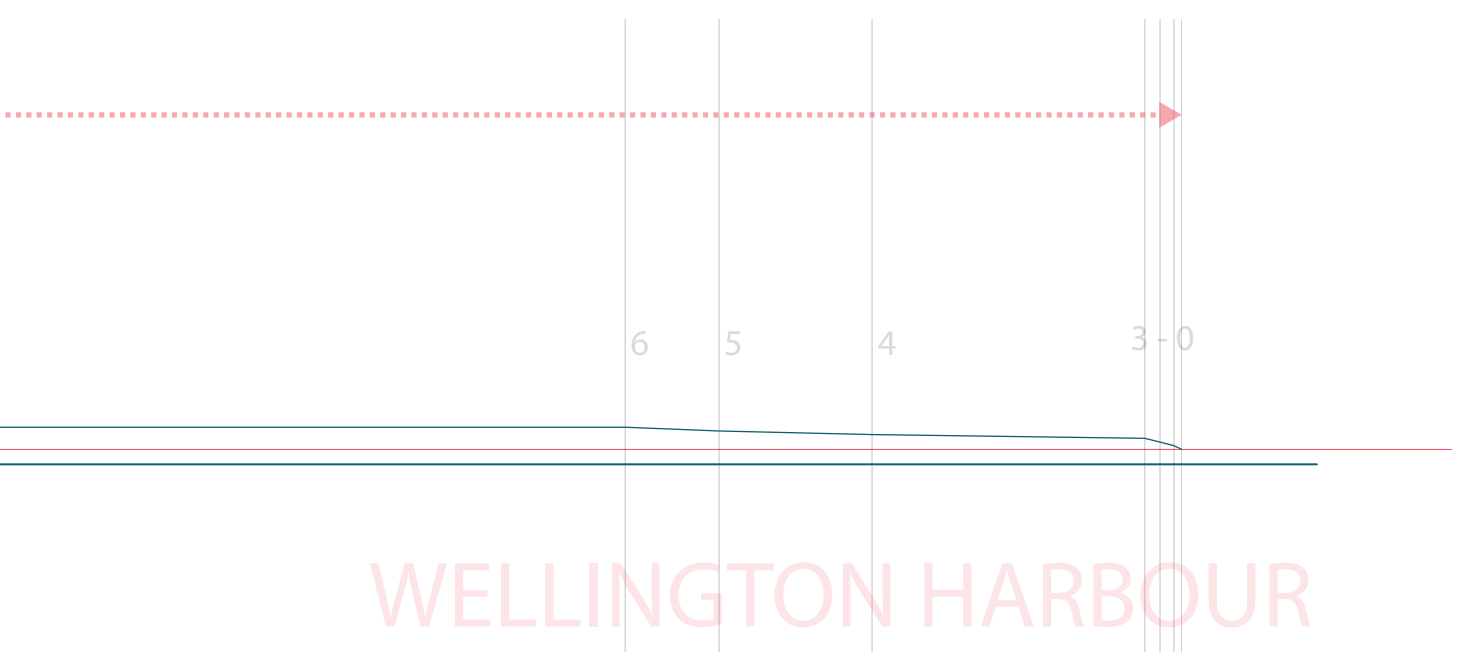

Figure 7.2.8 (Above)_ The canal would need to run around four metres underwater to make it safe for the ferry to travel along. (Authors own image). 
Area cut to level road

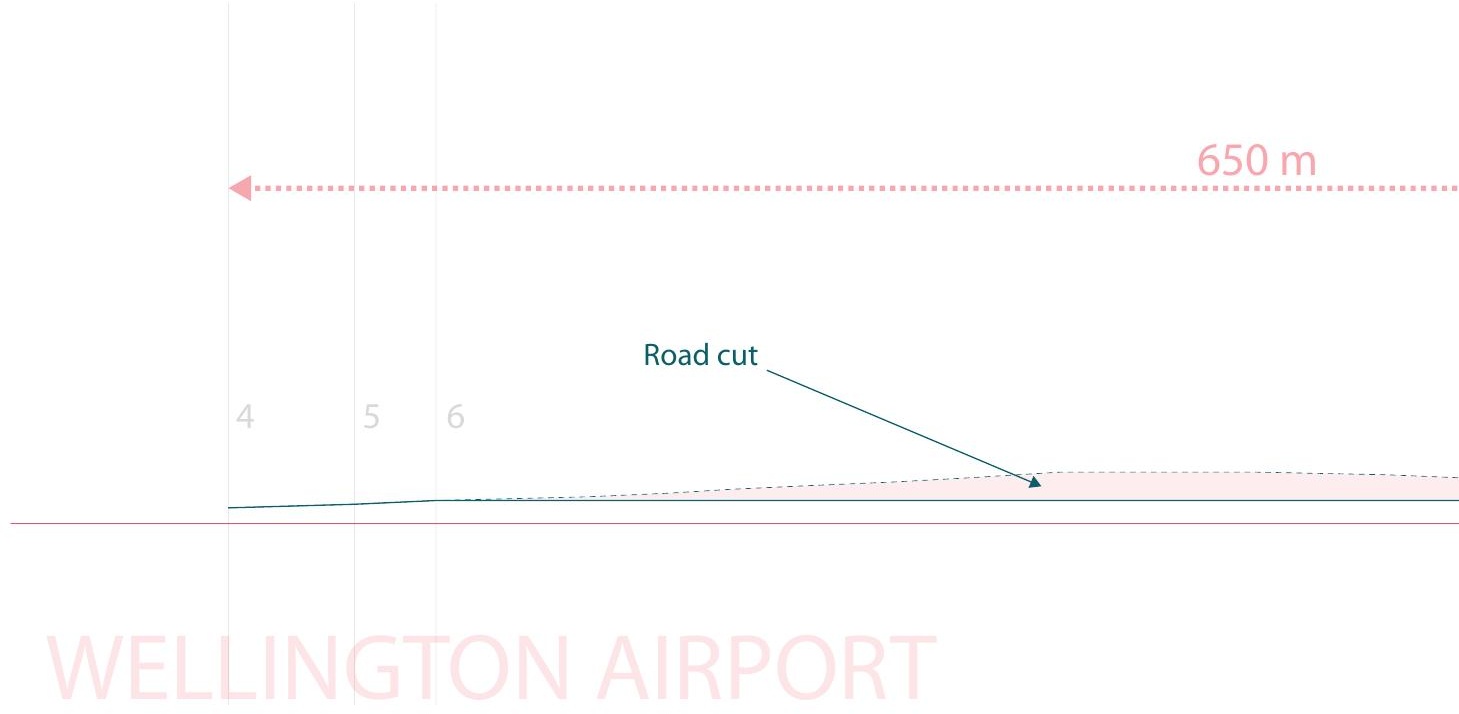

Area cut for ferry canal

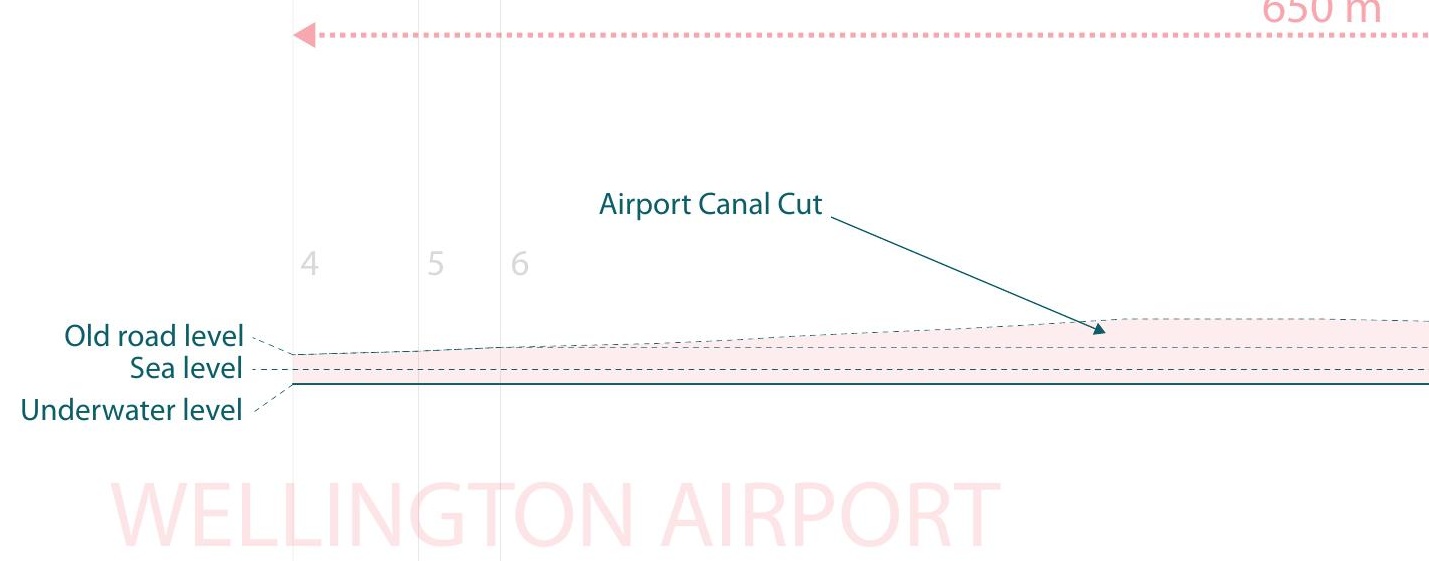




\subsection{4_ Canal investigation}

This series of images starts to look at the canal and how it would interact with the road. The road would need to move east slightly to allow for the canal. At some points the cars would be able to see the ferry, whilst at others it would be hidden from view.

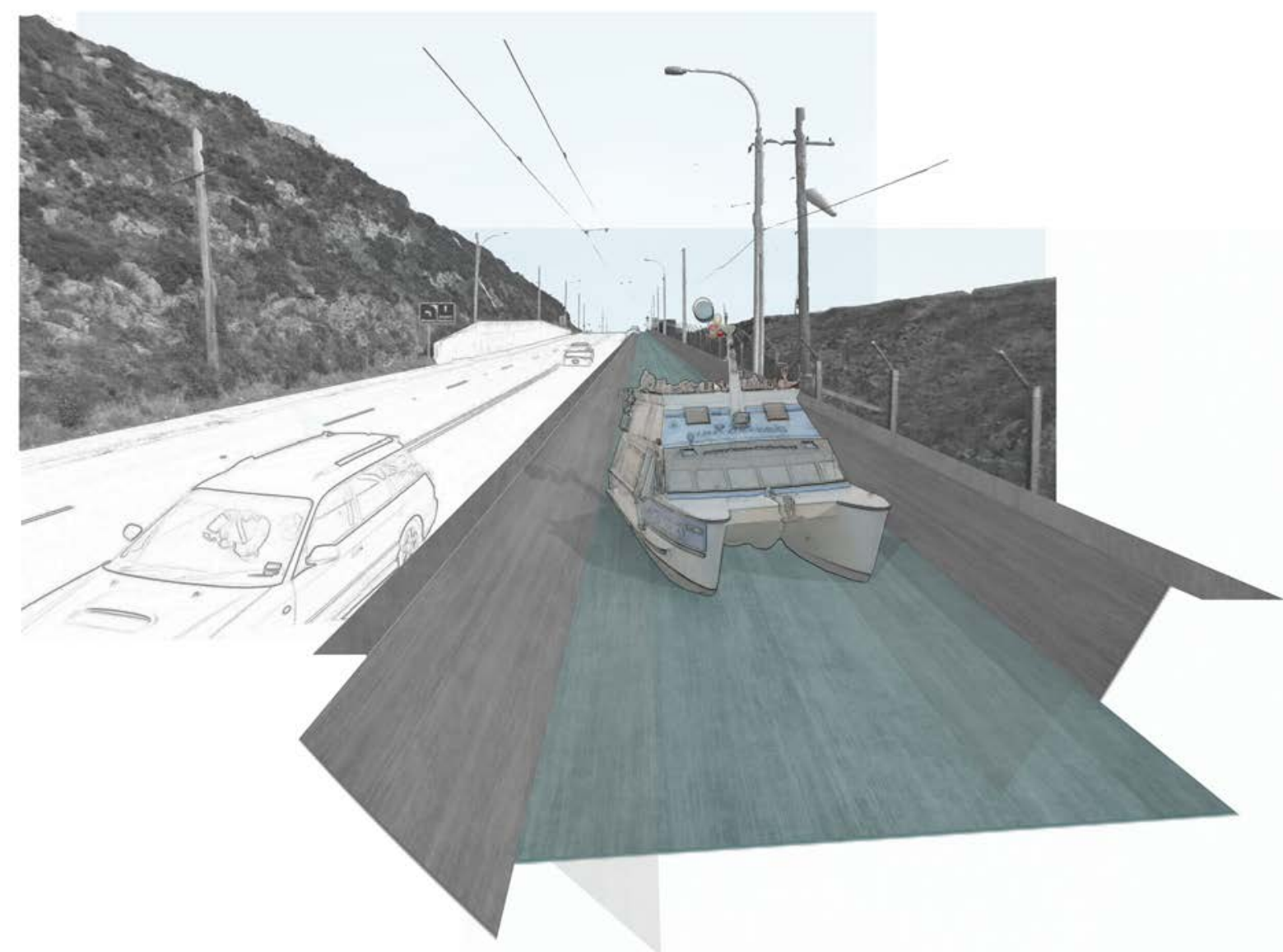

Figure 7.2.11 (Above)_View of the ferry as it approaches the mouth of the canal. It would be close to car level through here. (Authors own image). 


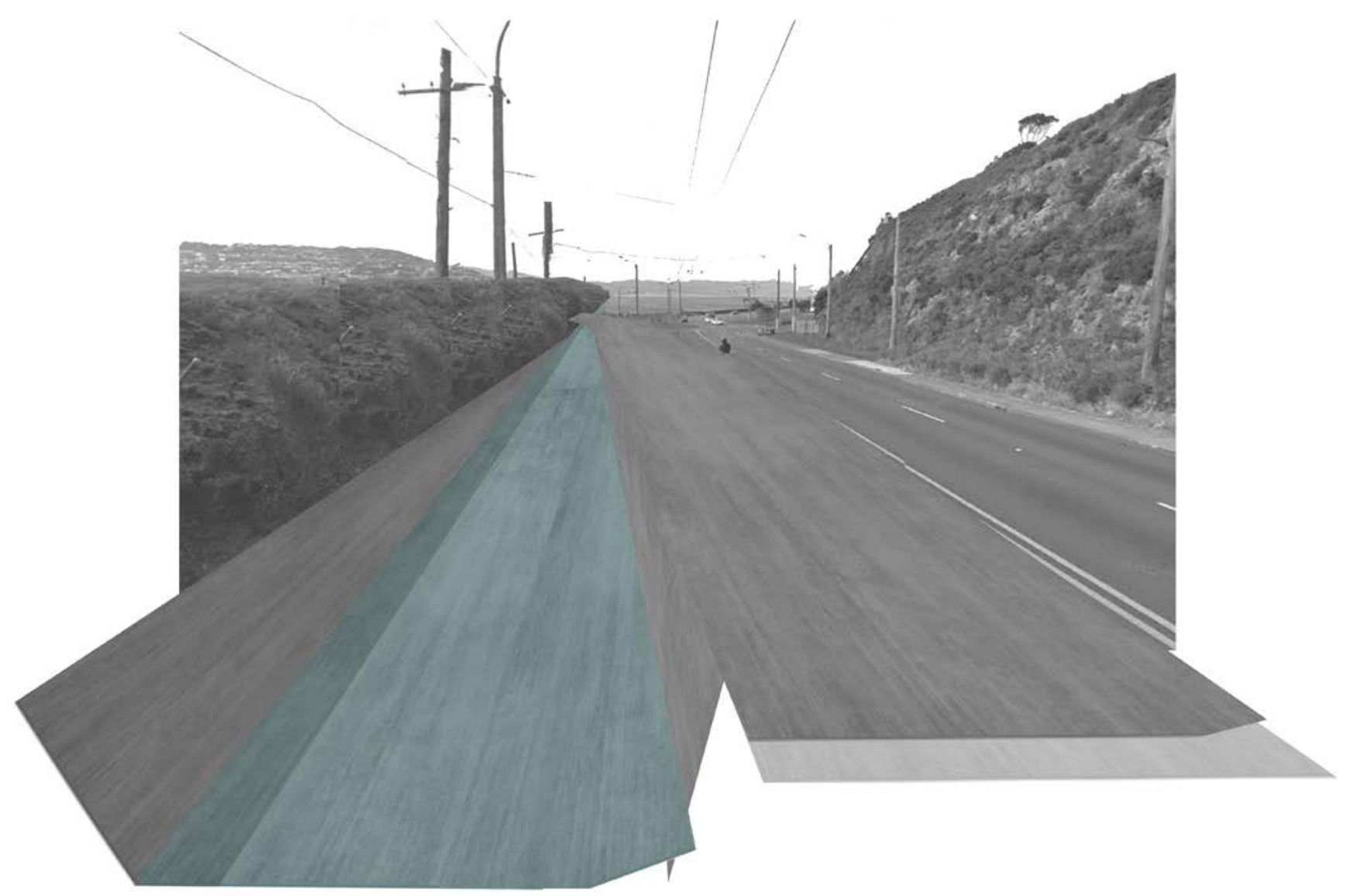

Figure 7.2.12 (Above)_Looking back out to the mouth of the canal. (Authors own image).

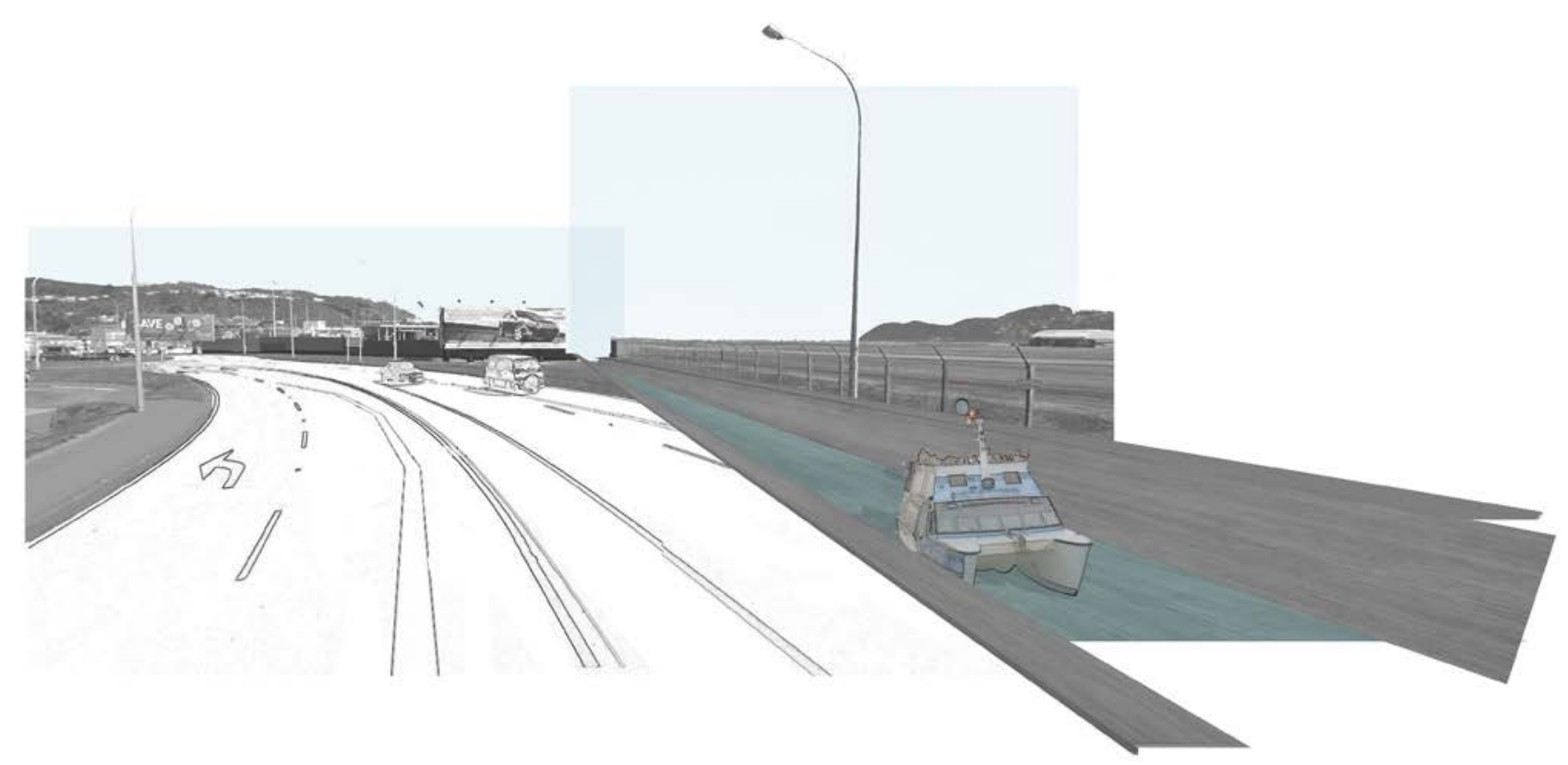

Figure 7.2.13 (Above)_As the ferry leaves the terminal it would move from being underground to being open to the elements. (Authors own image). 


\subsection{5_ Sensory experience}

This is the kind of sensory experience that should be created with the design of this terminal. The passengers would start underground where lighting could be manipulated to create shadow and reflection. As the ferry moves along the canal the roof starts to break up, playing with the light and becoming lighter. The ferry is then pushed out into the harbour, revealing Wellington and its surrounding shoreline.

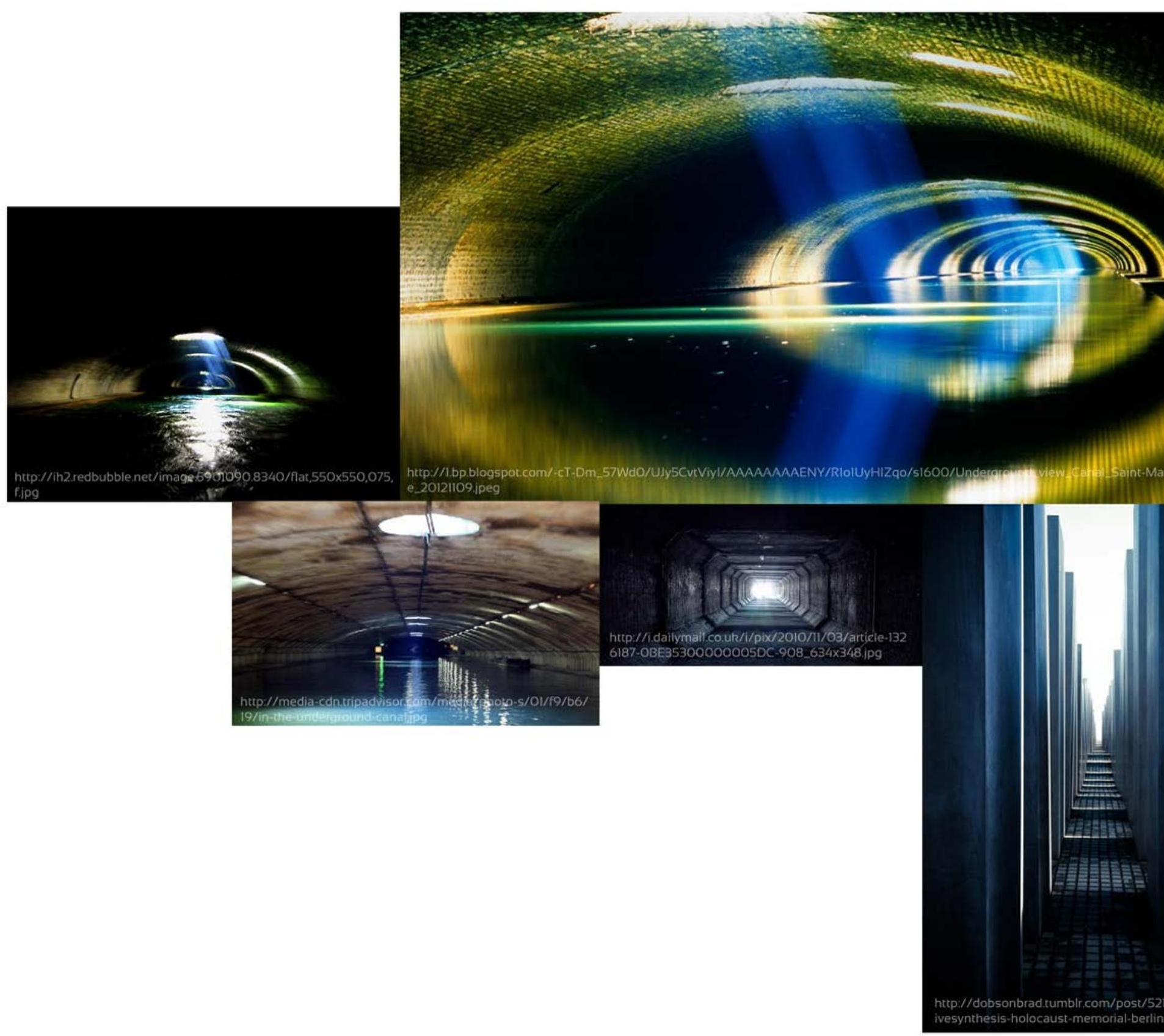


7.3_ Design Detail

\subsection{1_ Design Plan}

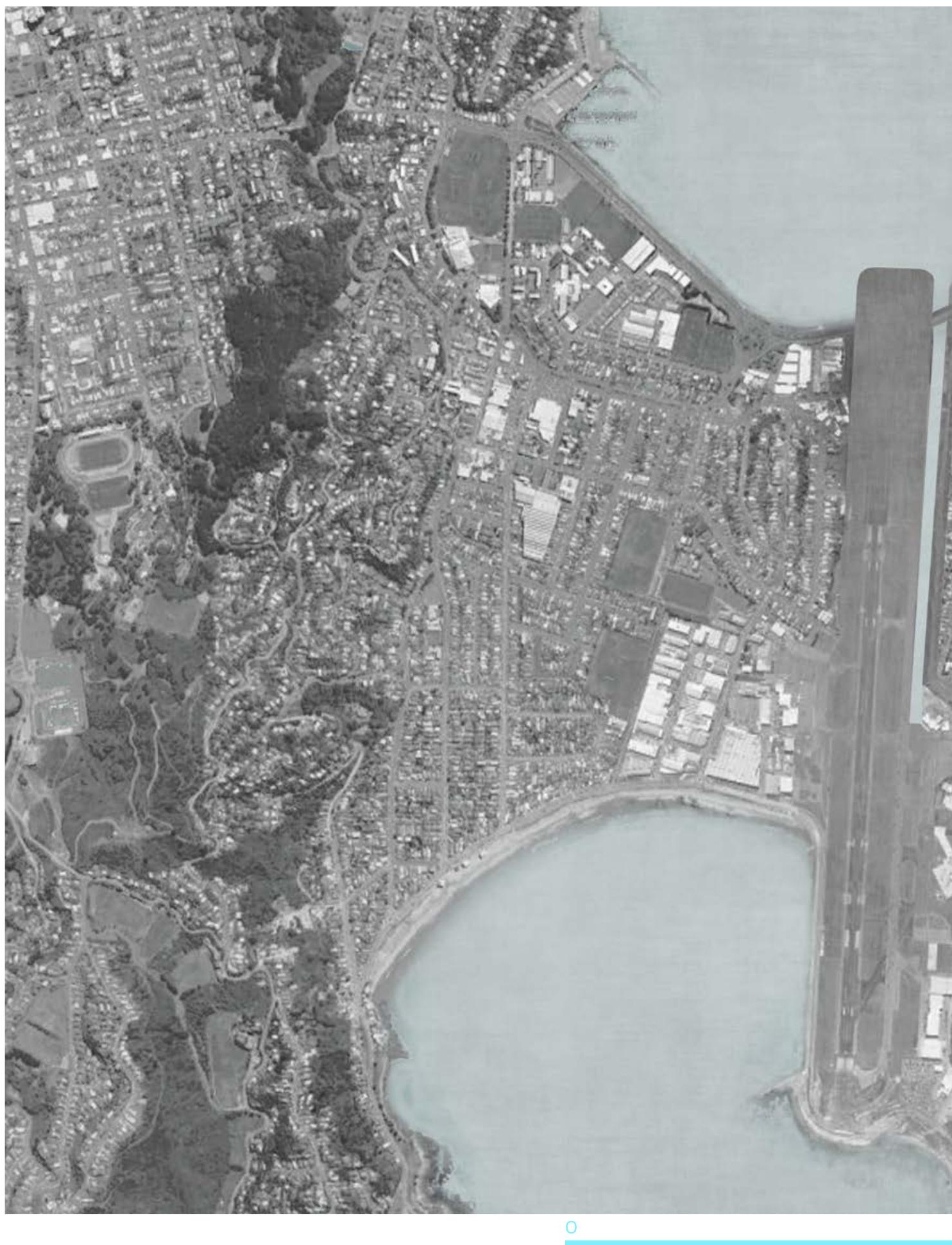




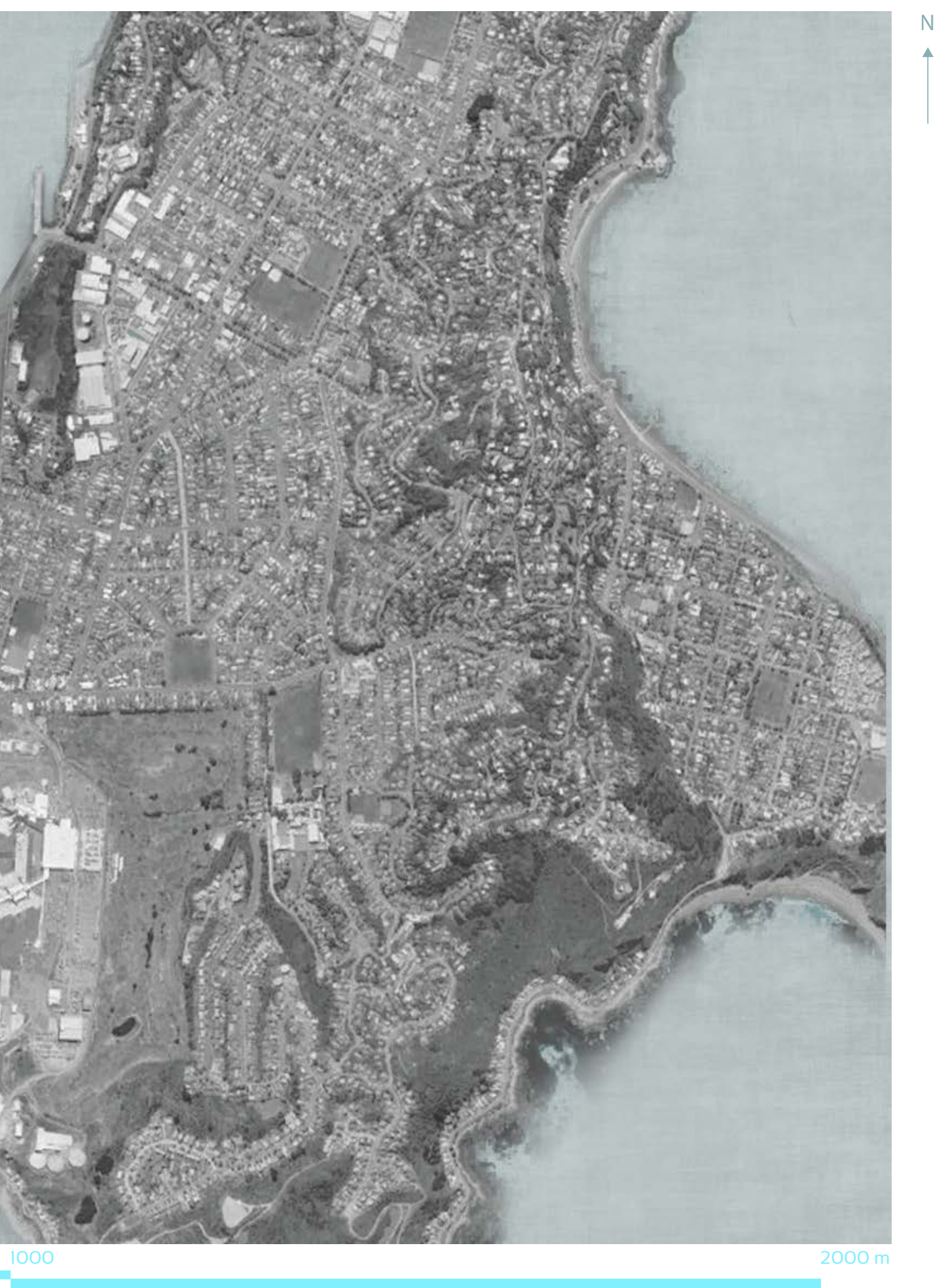

Figure 7.3.1 (Above)_Plan view showing the layout for the design. (Authors own image). 
7.3.2_ Canal Section

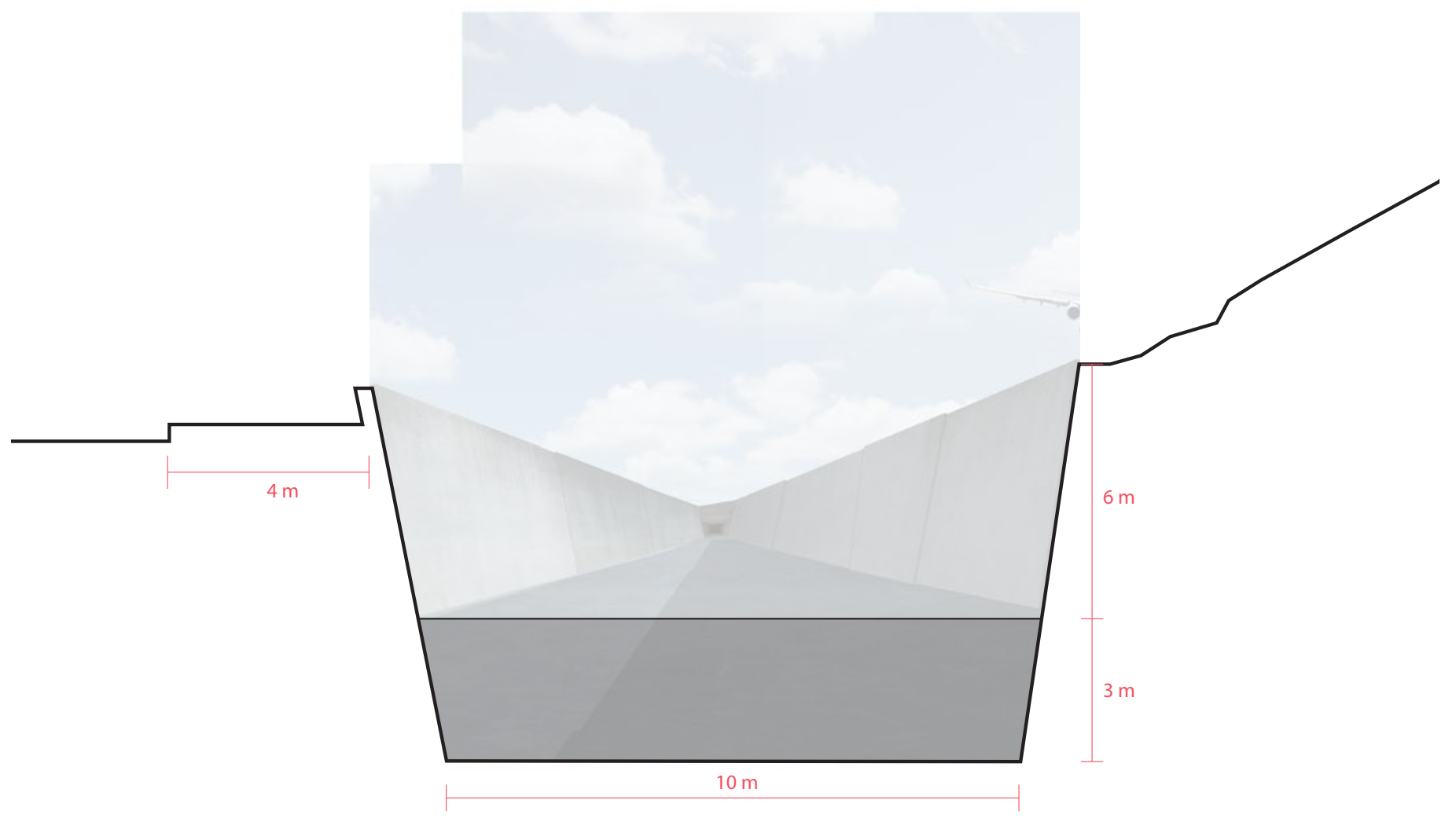

Figure 7.3.2 (Above)_ Section through the canal investigating wall heights and water depth. (Authors own image) 


\subsection{3_ Community interaction}

There needs to be a level of community interaction with this mode of transport. By digging the canal up the side of the airport there is the opportunity to include community interaction with this project. Tested here is a series of community pools that are located next to the canal. They would be blocked off from the canal so people can't swim into the ferry.

This would allow the local community to get some benefit out of the scheme as opposed to people just using the transport system.

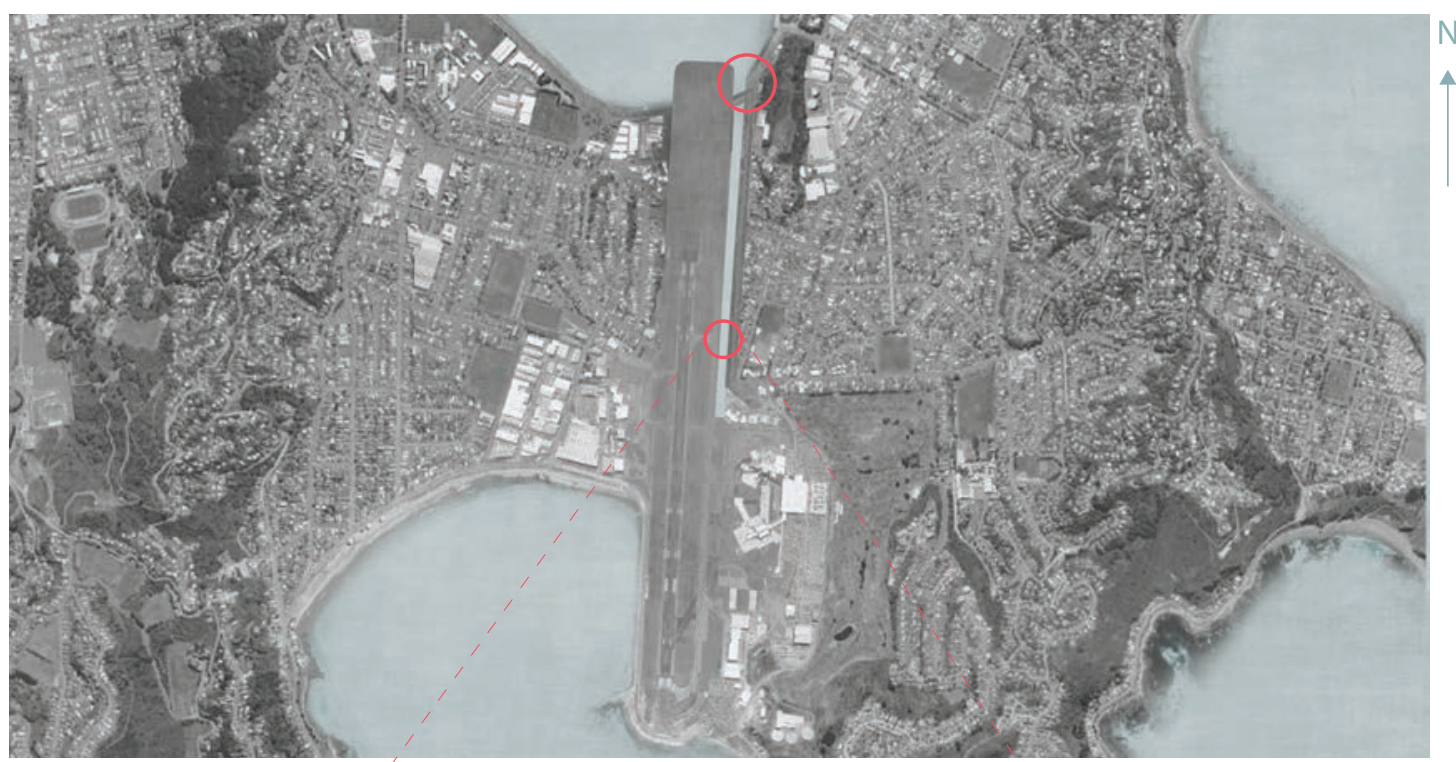

Figure 7.3.3 (Above)_ Location diagram looking at potential areas for community pools. (Authors own image).

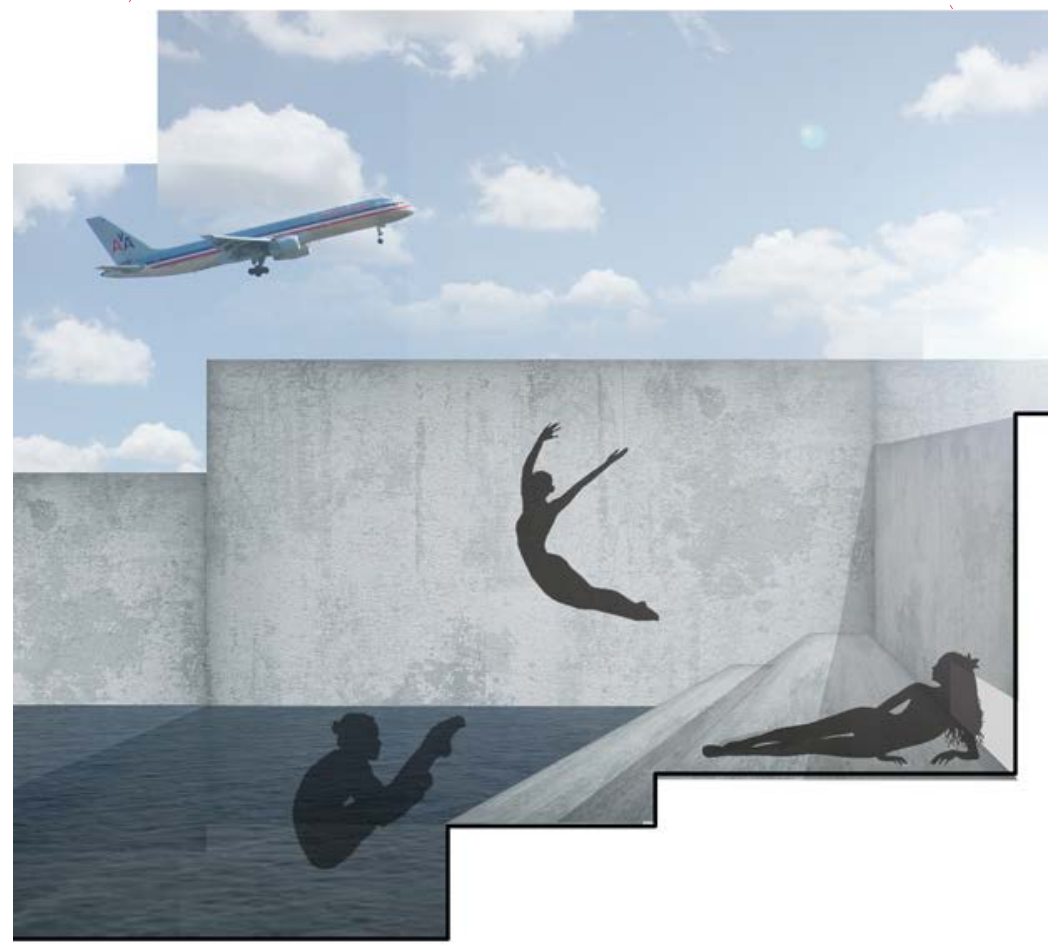

Figure 7.3.4 (Above)_ Section perspective investigating the community pool in relationship to the airport. (Authors own image). 


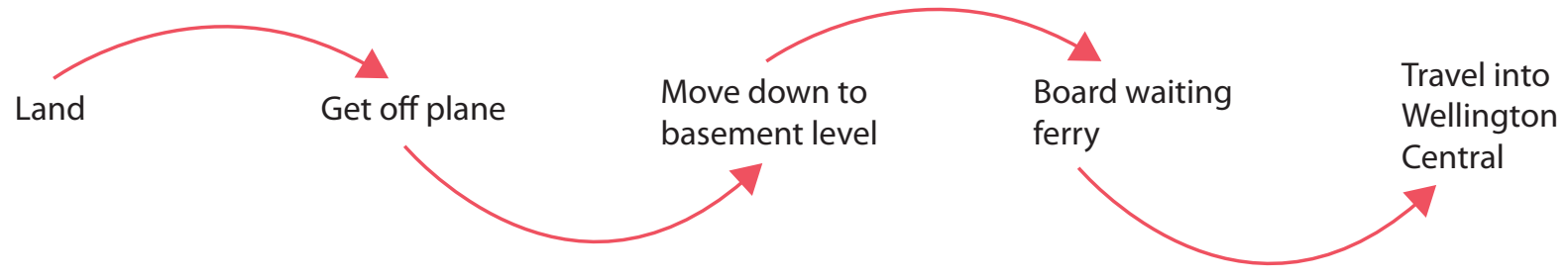

Figure 7.3.5 (Above)_ Flow diagram looking at how people will move through the airport to the ferry. (Authors own image).

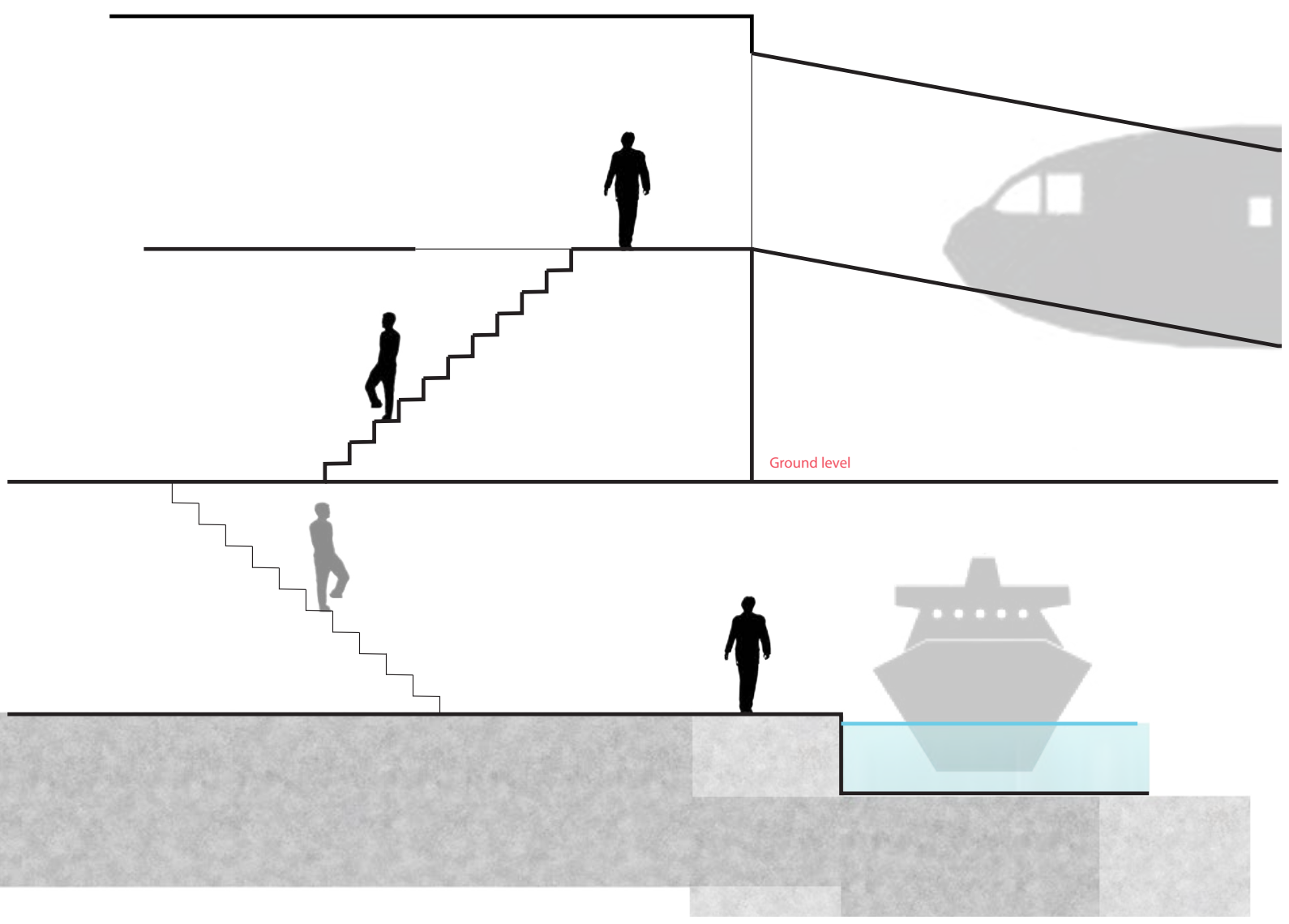

Figure 7.3.6 (Above)_Sectional diagram showing levels in airport with the new basement level of the ferry terminal. (Authors own image). 


\subsection{5_ Control of water flow}

A water gate at the harbour end of the canal will help control the water that runs through the design. It should make it calmer and allow the ferry easy travel down to the airport. The driver of the driver would be able to operate the gate so that it is open when they arrive.

\section{Gate closed}

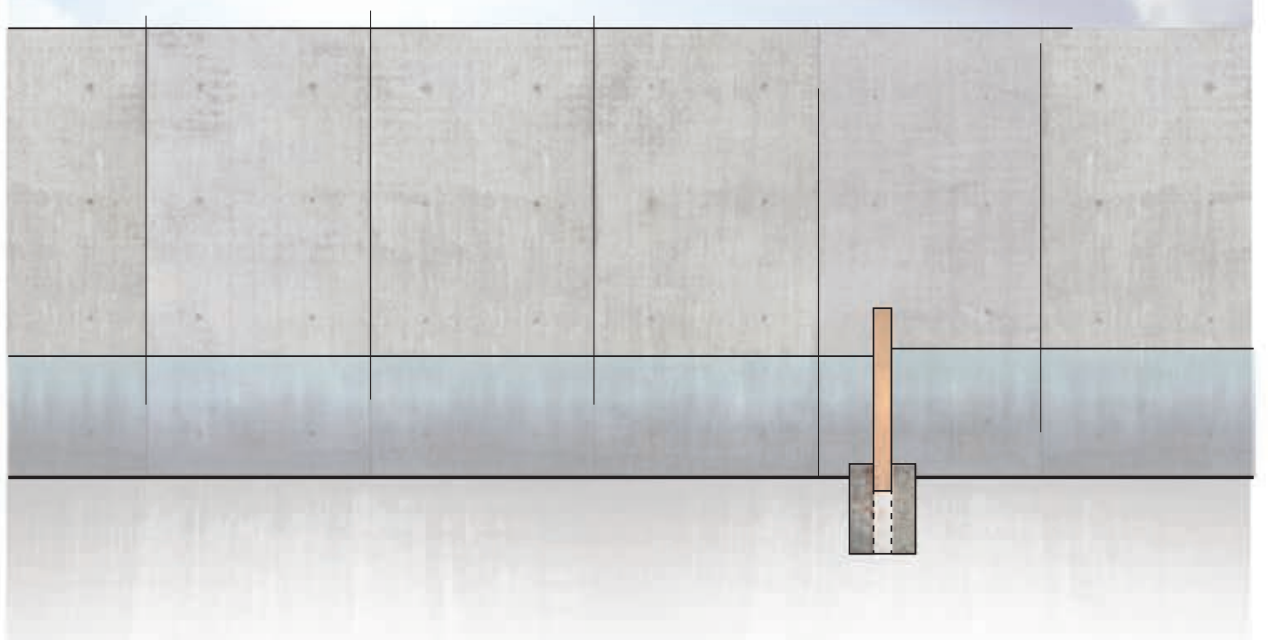

Gate open

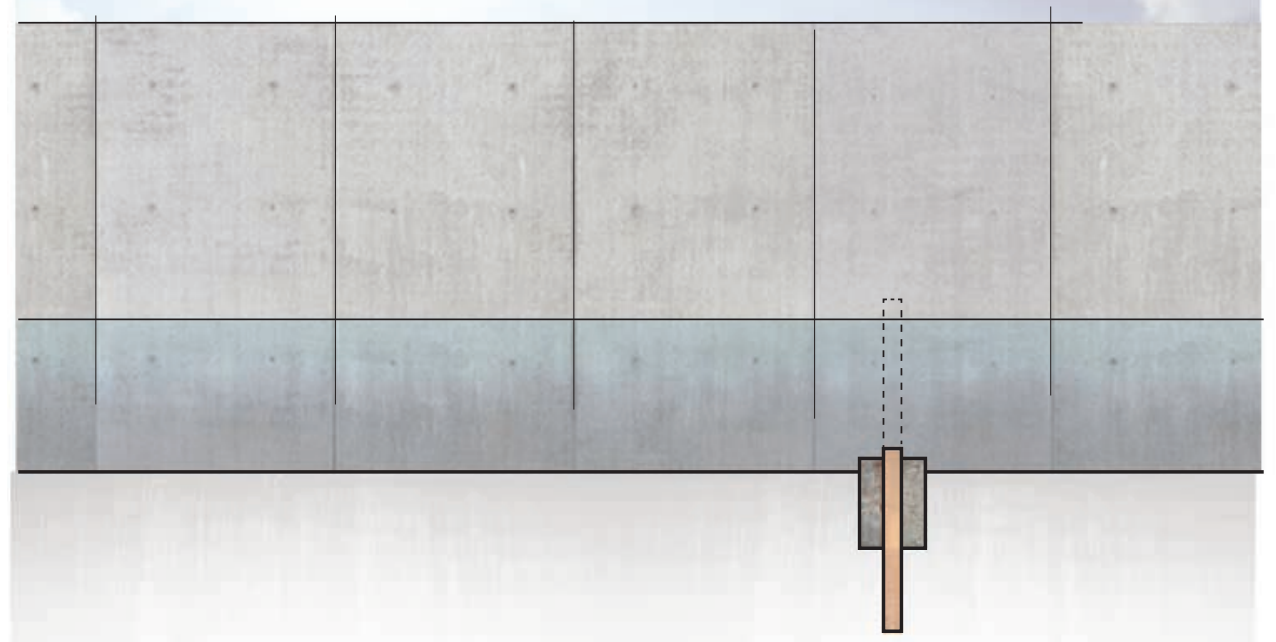

Figure 7.3.7 (Above)_Sectional view investigating the water gate which will help keep the canal calm. (Authors own image). 
7.3.6_ Atmosphere

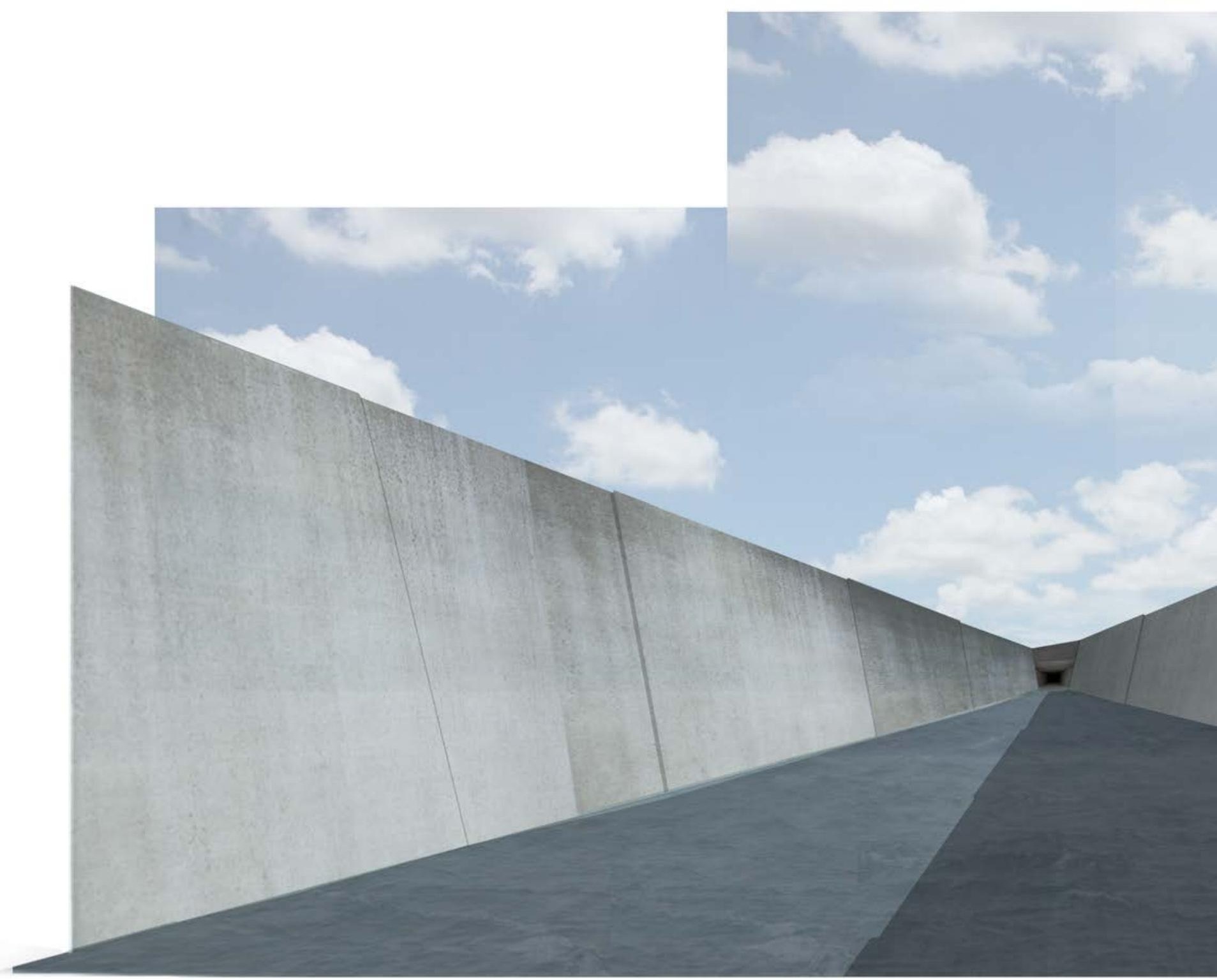


7.3.7_ Design Evolution

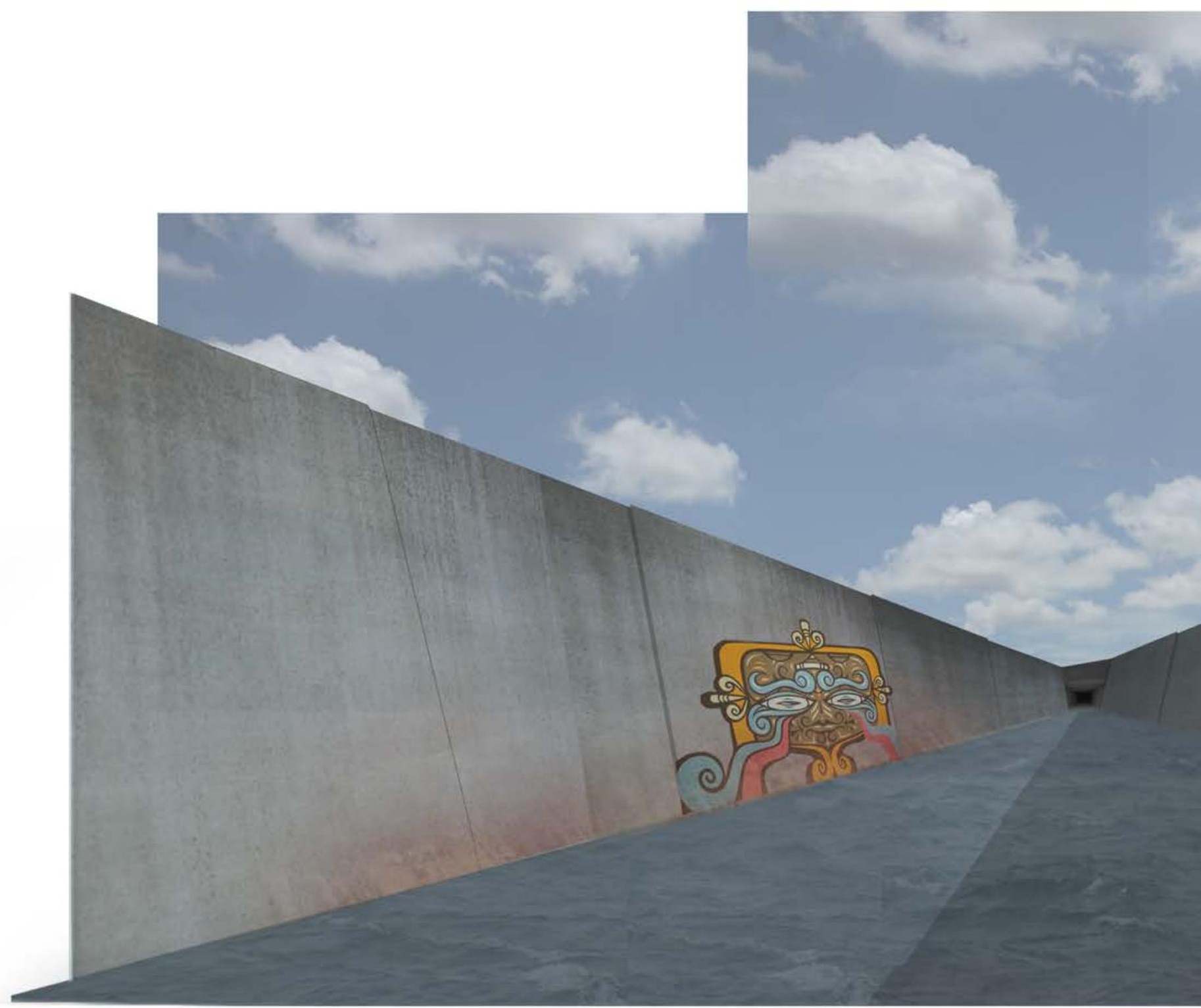




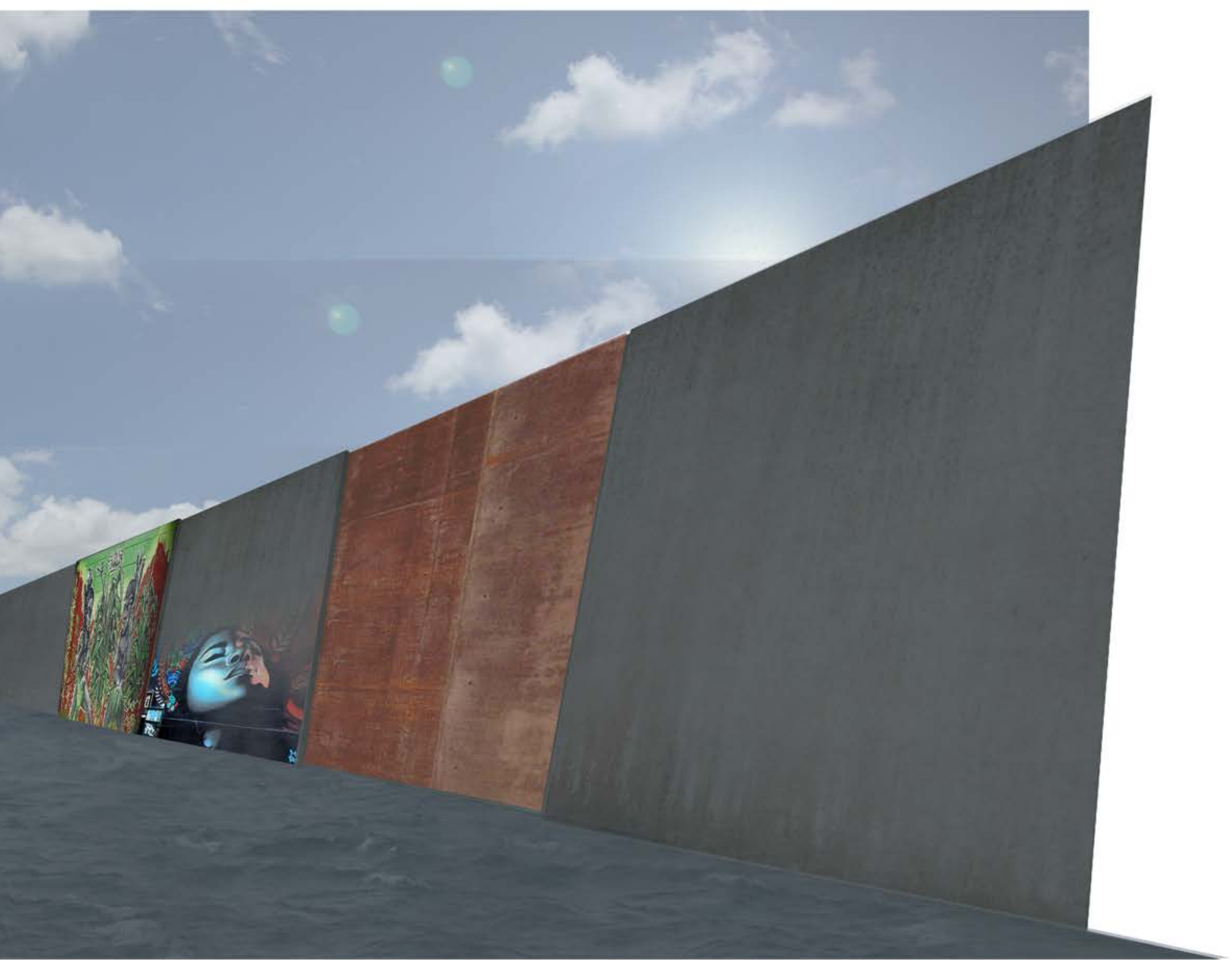

Figure 7.3.9 (Above)_Perspective view looking at the potential for evolution in the design. Graffiti artists could work on the walls or new materials could be incorporated to introduce passengers to the city. (Authors own image). 


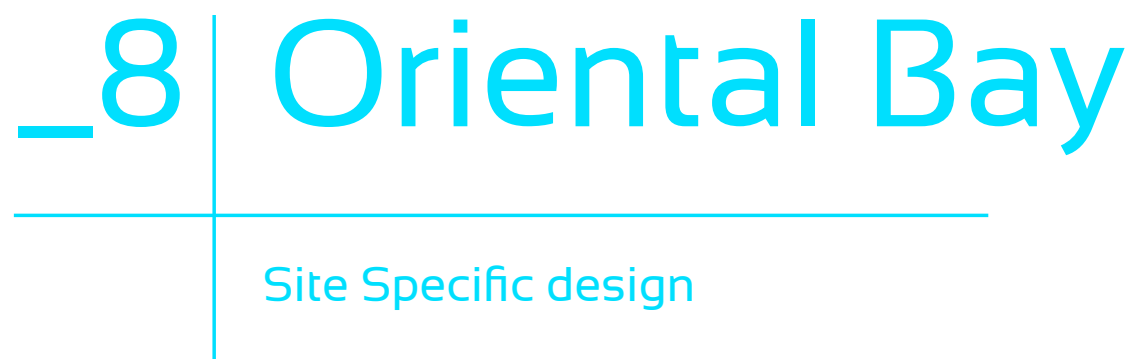




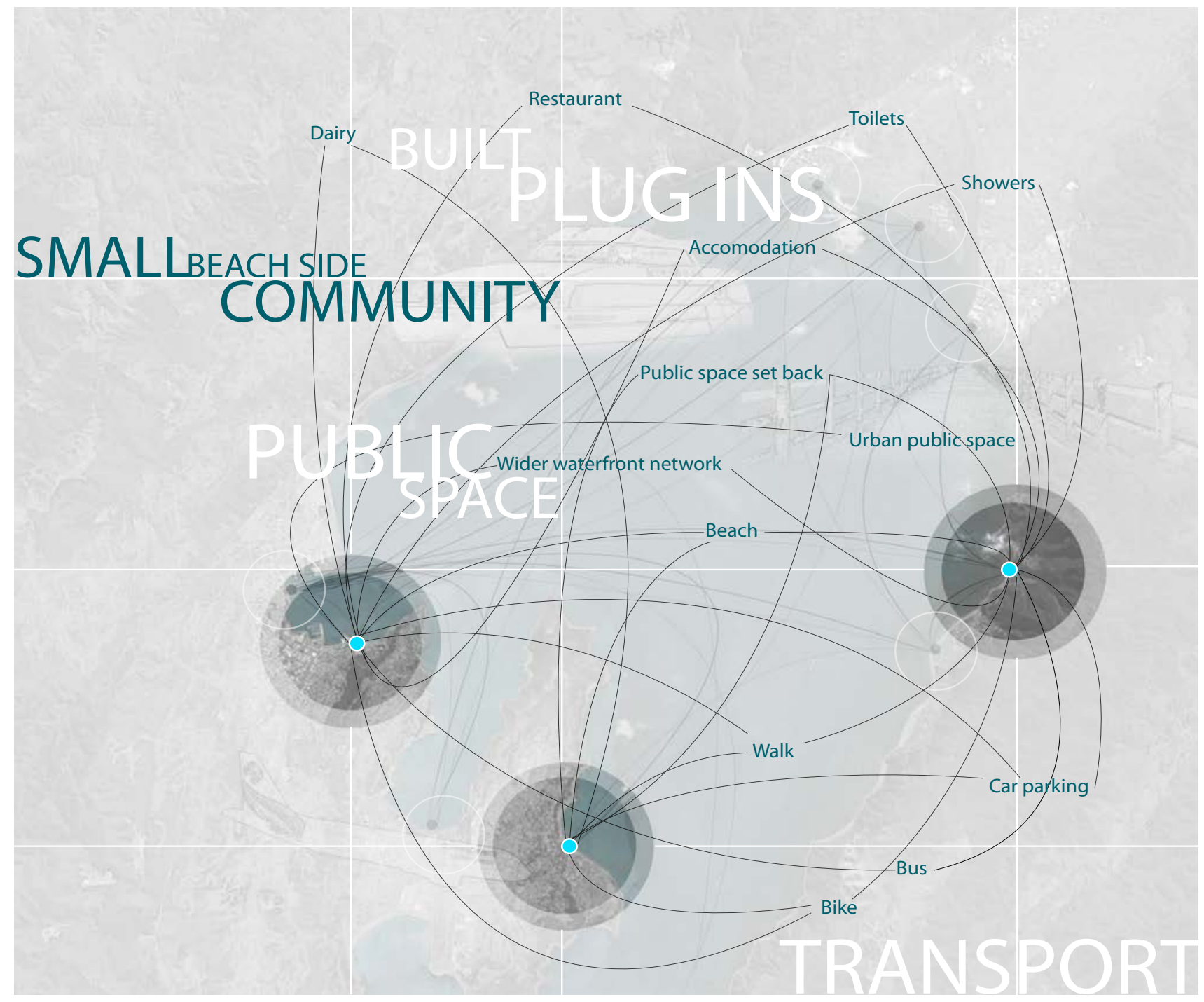

Oriental Bay is the chosen site for the small beach side community typology. The site is characterised by the large beach that has made it a destination for the people living in Wellington. There is a small population that lives in Oriental Bay but the beach needs to cater for much larger populations. During summer days the beach becomes full of people, most of which don't actually live in Oriental Bay. This ferry site investigates how a small-scale ferry intervention can amplify the public life already associated with the site. 


\section{1_ Site Analysis}

\subsection{1_ Existing Public Space}

There is a large amount of public space existing in Oriental Bay. The beach provides the bulk of the public space, yet the walkway is also an important public space component. It adds movement and vibrancy, as there is a constant pulse of people.

There is also a small amount of green space on the other side of the road. This area is on a slope and doesn't seem to get much use.

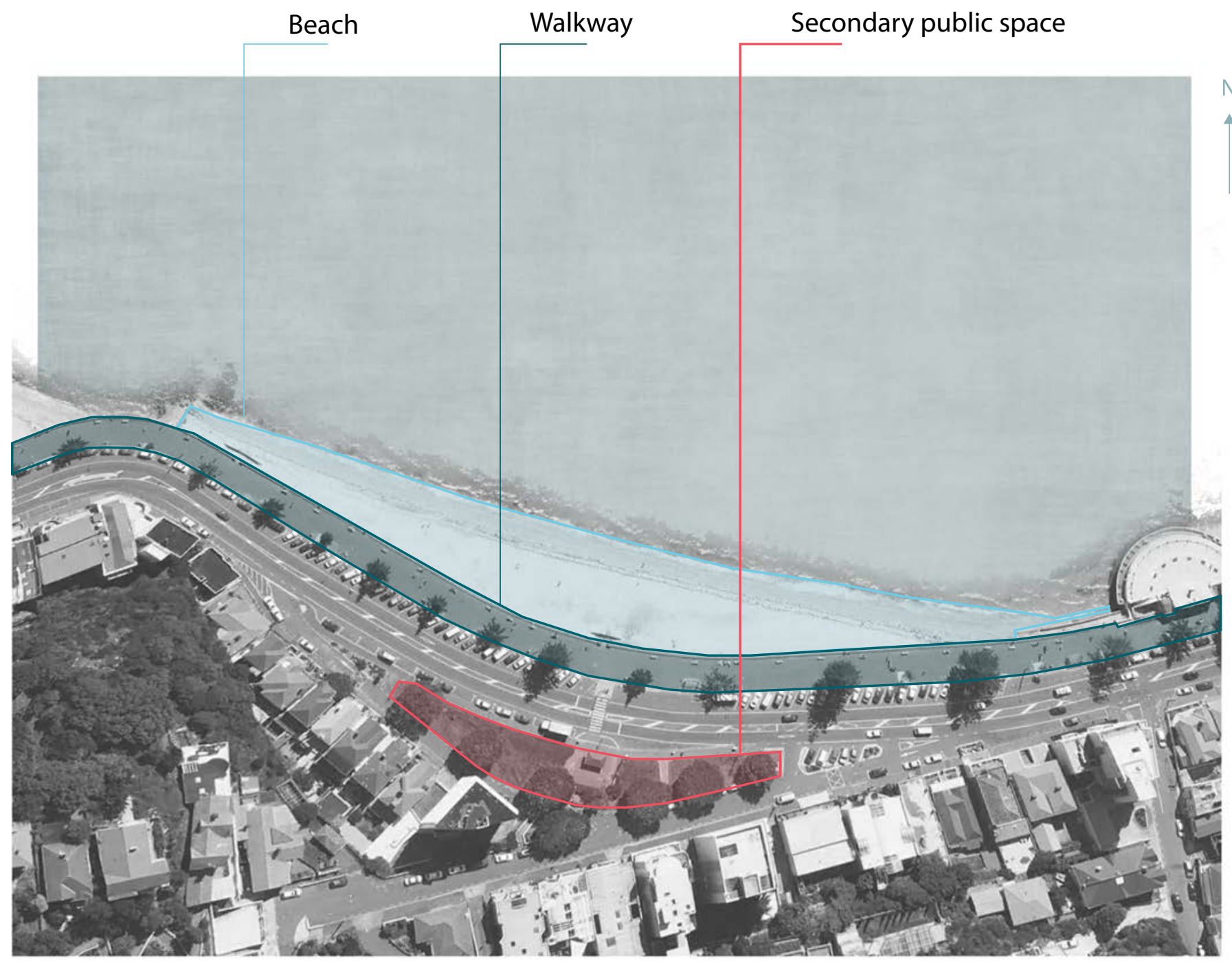

Figure 8.1.1 (Above)_ Mapping of the public space in Oriental Bay. (Authors own image) 
There are two entry points that allow pedestrians to move from the walkway down onto the beach. The rest of the edge is blocked off by a sea wall that stops people interacting with the beach.

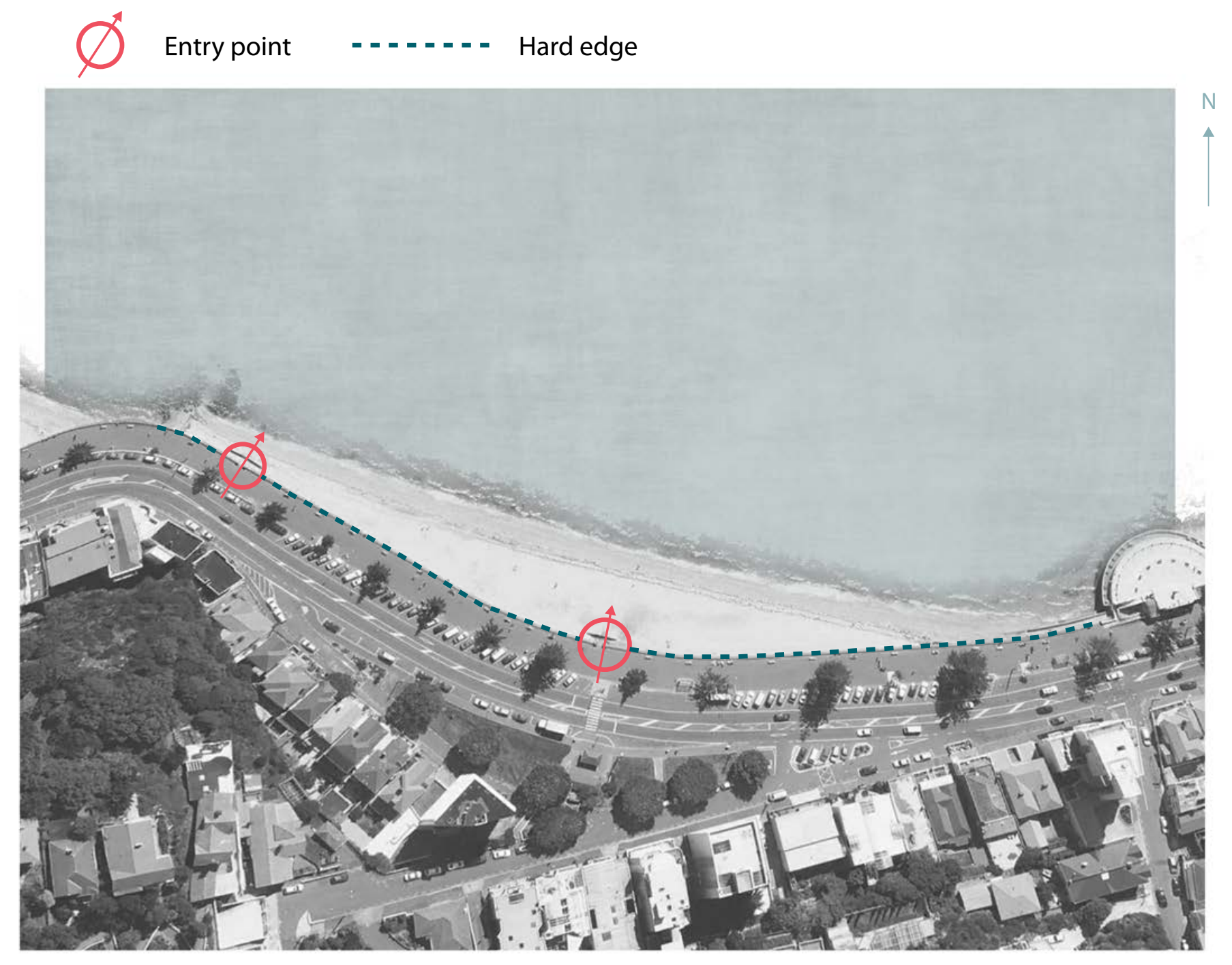

Figure 8.1.2 (Above)_ Entry points to Oriental Bay. (Authors own image). 


\subsection{3_ Movement}

There is quite heavy vehicle traffic that runs along the coastline. There is also a large amount of car parking to facilitate people coming to the beach.

Pedestrian movement through this area is very high. There are a large number of runners and walkers that use this route because of the scenic qualities. The movement is blocked from the beach by the sea wall.

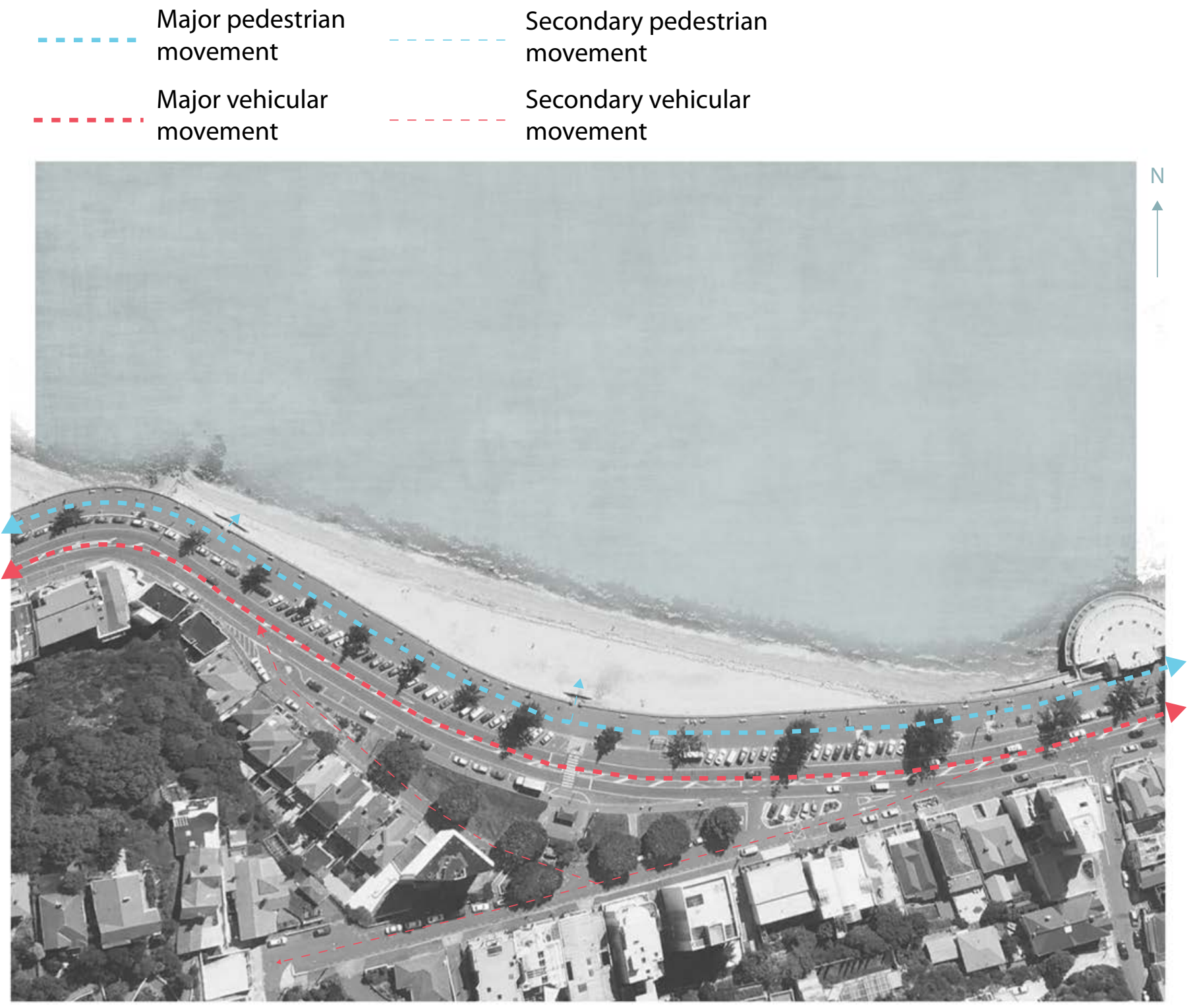

Figure 8.1.3 (Above)_ Movement mapping in Oriental Bay. (Authors own image). 


\subsection{4_ Topography}

There is a thin band of flat land that the road and walkways run along. The landform rises up into the hillsides on one side and drops down to the sea on the other. This creates a sense of movement down and along the waterfront that closely associates Oriental Bay to the harbour. The open nature of the waterfront means that people would be able to see the ferry coming from a distance away.

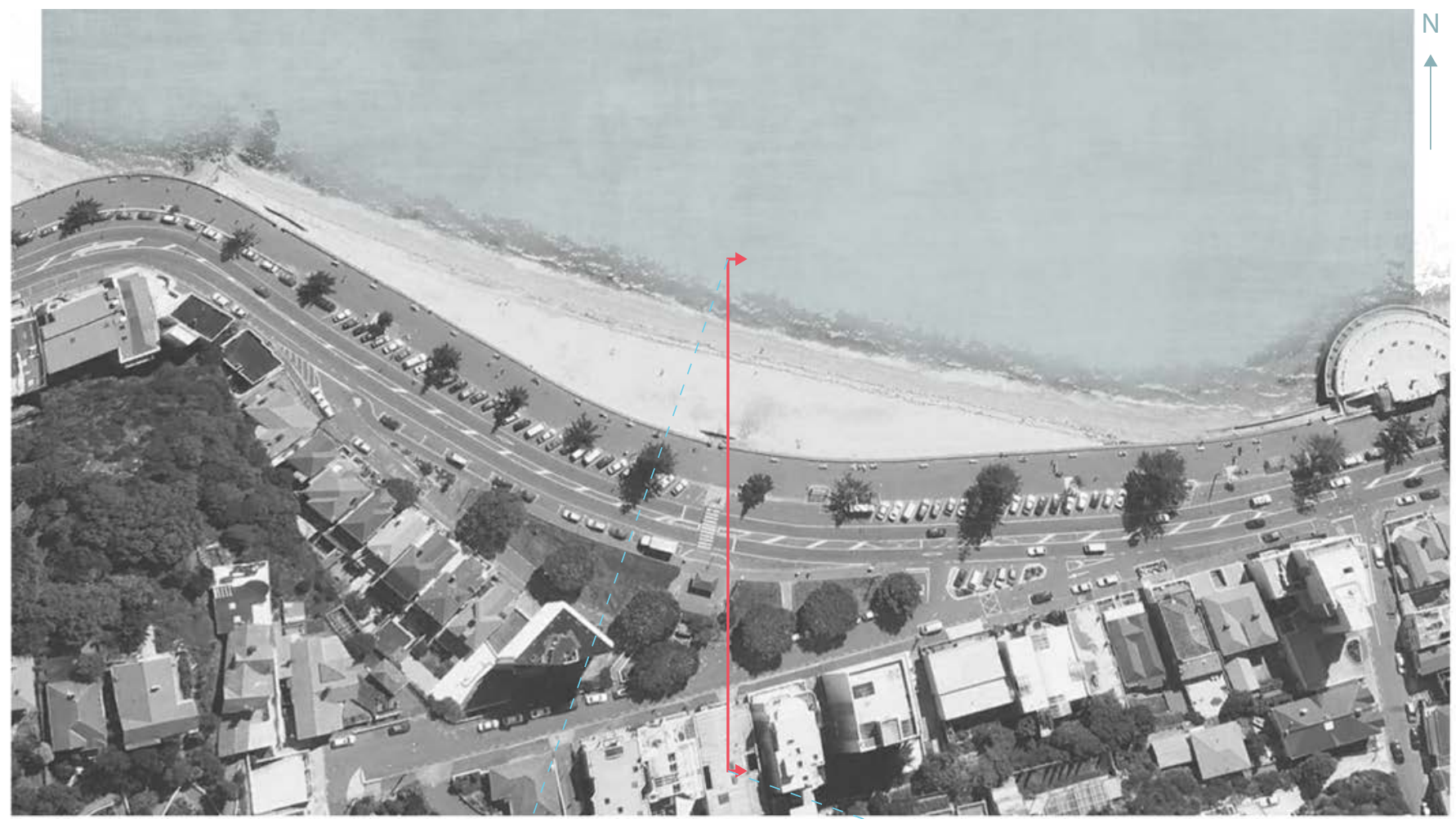

Figure 8.1 .4 (Above)_ Plan and section investigating the topography in Oriental bay. (Authors own image). 


\section{2_ Design Testing}

\subsection{1_ Initial wharf placement}

There needs to be a ferry wharf to allow the ferry to connect into Oriental Bay. Through testing of the placement it starts to become clear the effect the wharf could have on the public life of Oriental. Original thoughts were to place it in the centre of the beach, yet it became clear this could split the beach. It would make it hard to move from one side to the other and take up useable beach space.

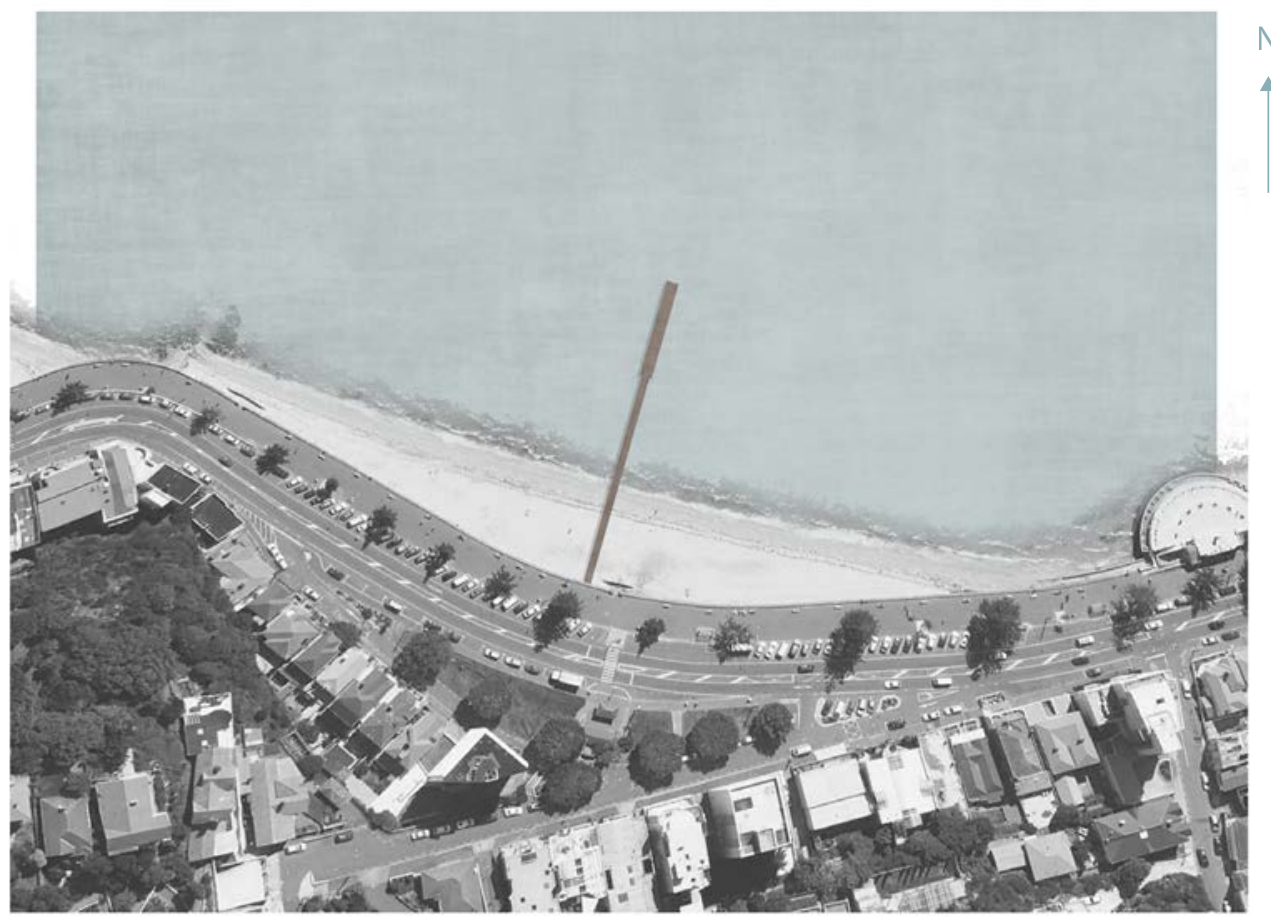

Figure 8.2.1 (Above)_ Initial wharf placement. (Authors own image).

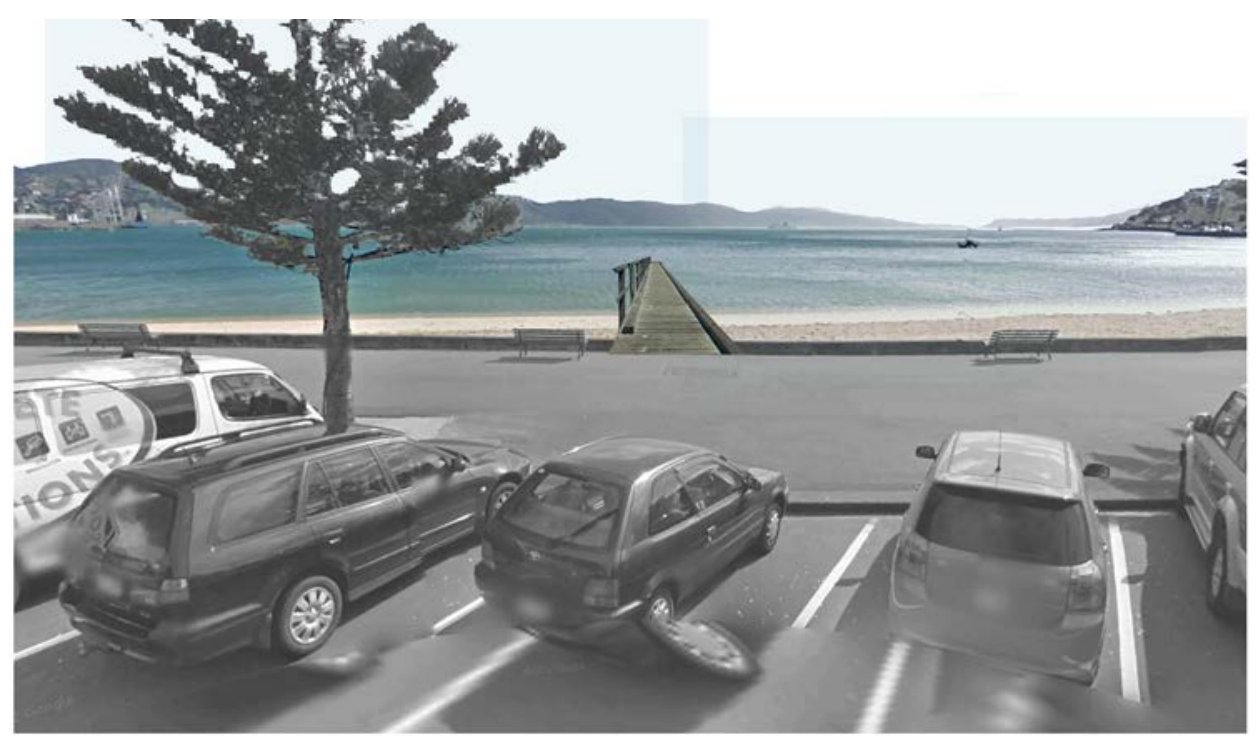

Figure 8.2.2 (Above)_ Perspective looking down wharf out to the water. (Authors own image). 


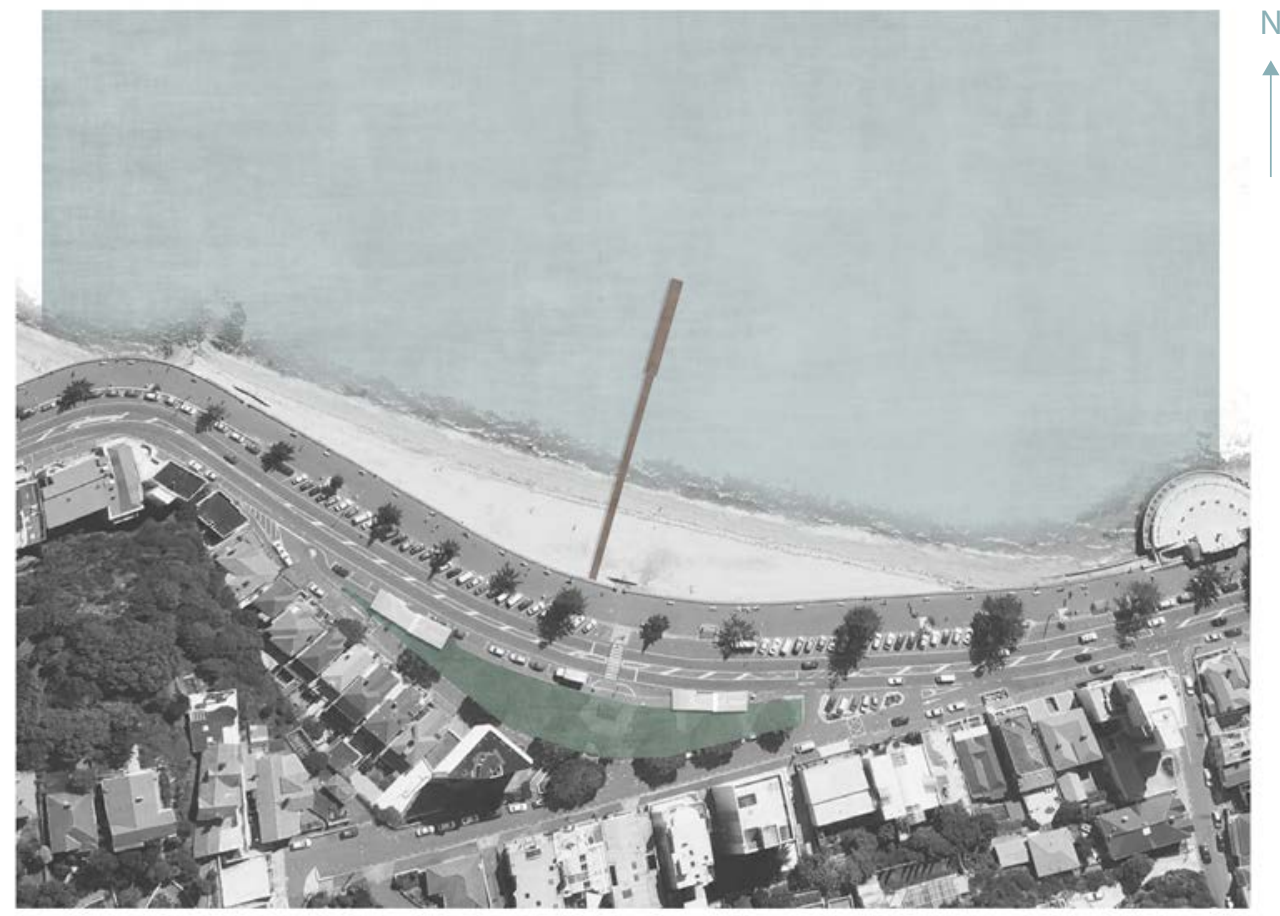

Figure 8.2.3 (Above)_ Diagramming the wharf and other potential associated public space that could support the beach. (Authors own image).

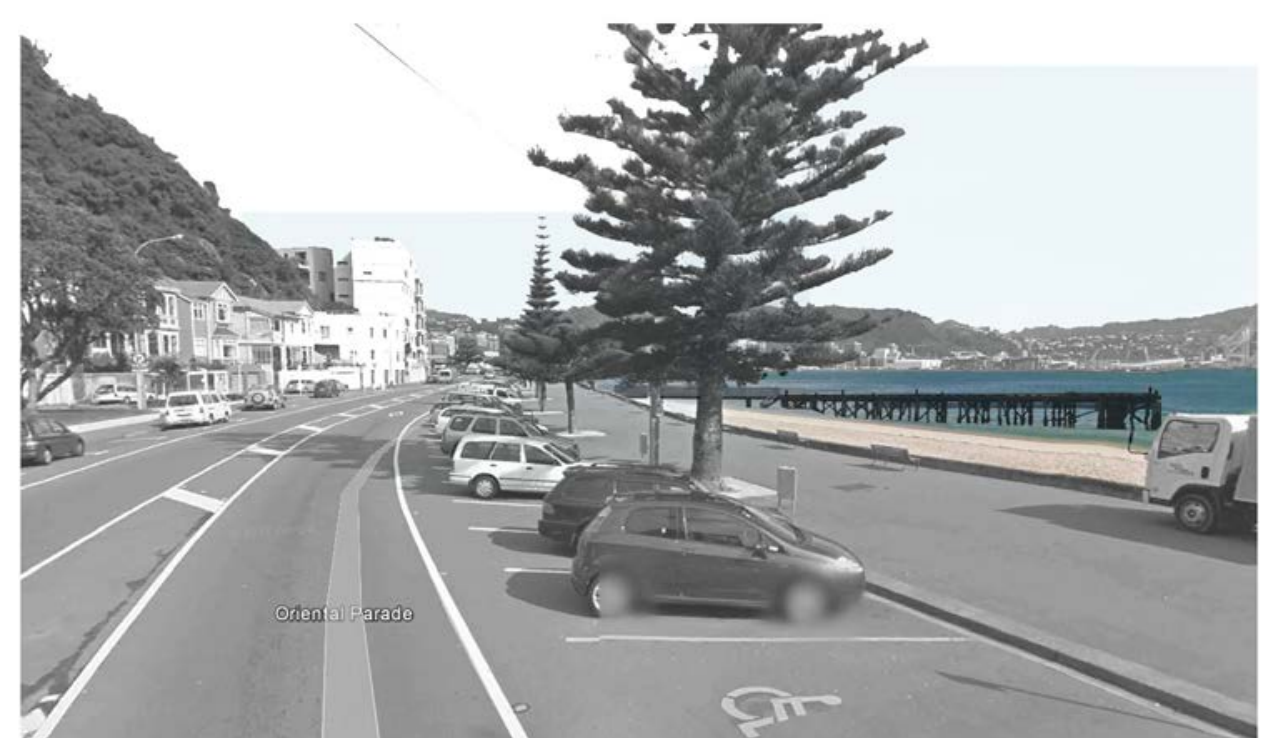

Figure 8.2.4 (Above)_ Perspective looking back towards Wellington Central with the wharf splitting the beach. (Authors own image). 


\subsection{2_ Enhancing the beach}

There could be the potential for some small retail / restaurant space that could enhance Oriental Bay and allow people to stay there for a longer period of time. There is currently parking right up to the edge of the walkway, which then steps down to the beach. This isn't the nicest edge for people walking along the beach. Built form along this edge could enhance the walkway, split the beach from the parking, and also provide built form with public space interaction.

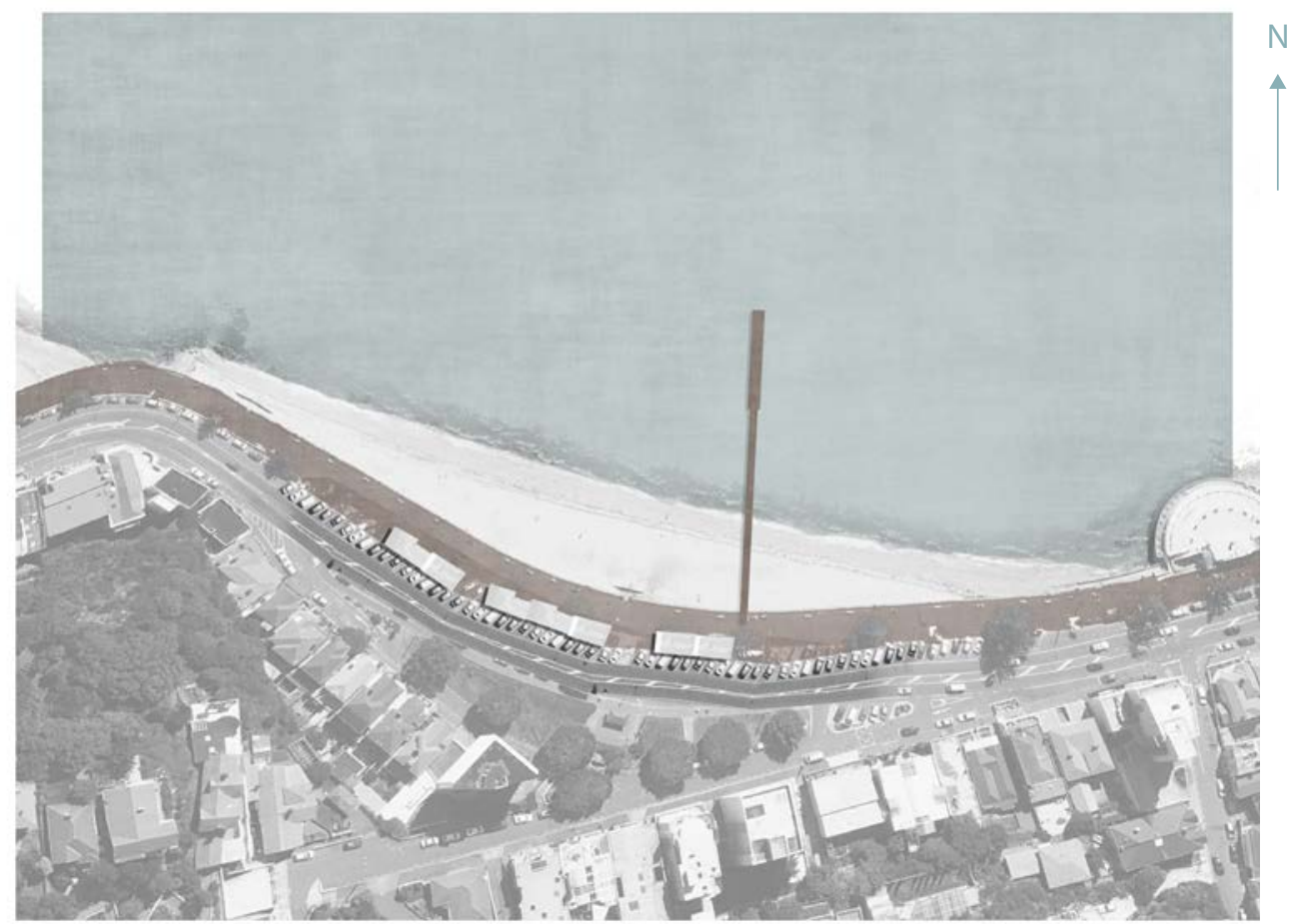

Figure 8.2.5 (Above)_ The road could be pushed back slightly which would allow for a row of small low rise built form along the beach edge. (Authors own image). 


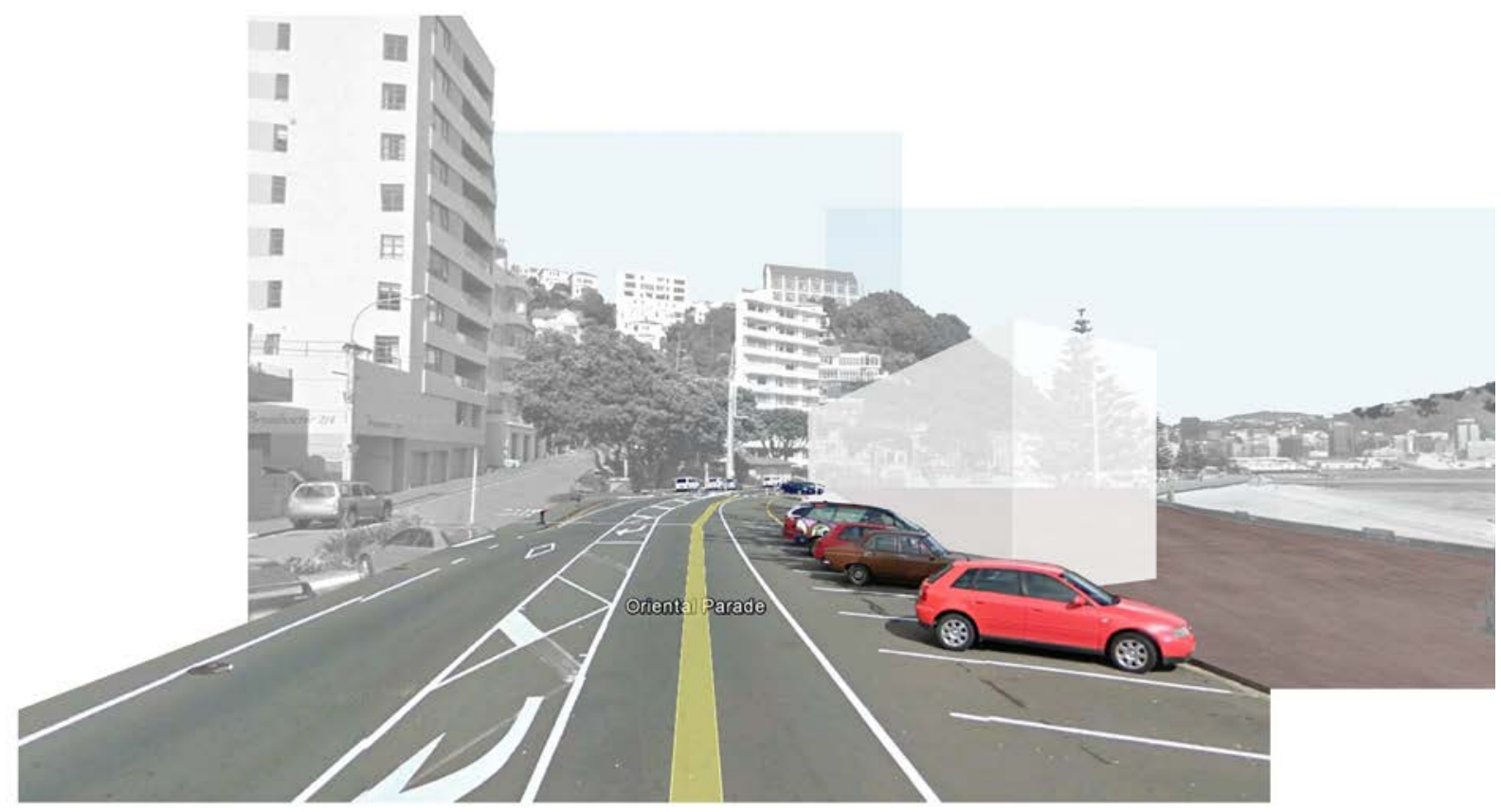

Figure 8.2.6 (Above)_ Perspective looking at the way the built form could split the road and the beach walkway. (Authors own image).

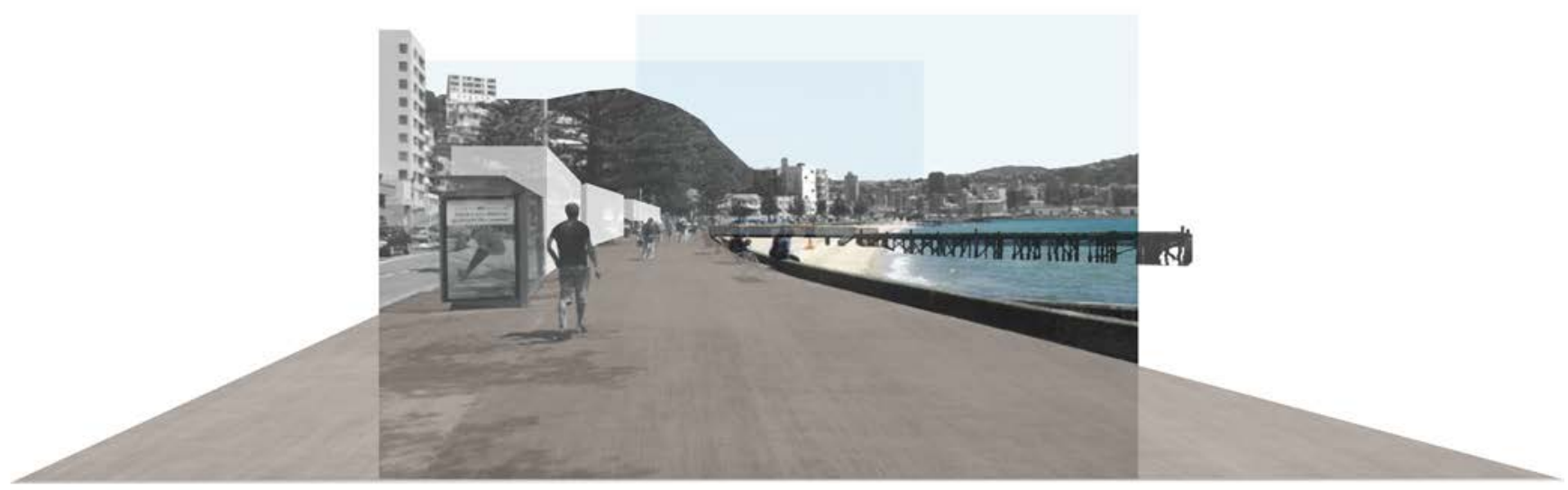

Figure 8.2.7 (Above)__ Perspective looking at the walkway and its connection to the beach and the built form. (Authors own image). 


\subsection{3_ Increasing the waterfront}

The eastern end of the beach gets much thinner and doesn't have as many people using the space. There is the opportunity for this area to be built out to provide more public space associated with the beach. This extra public space would allow people to spend time at the waterfront without actually being on the beach. It also increases built form opportunities.

This would also allow for the wharf to be placed to the side of the beach. This stops it becoming a divisive element on the beach.

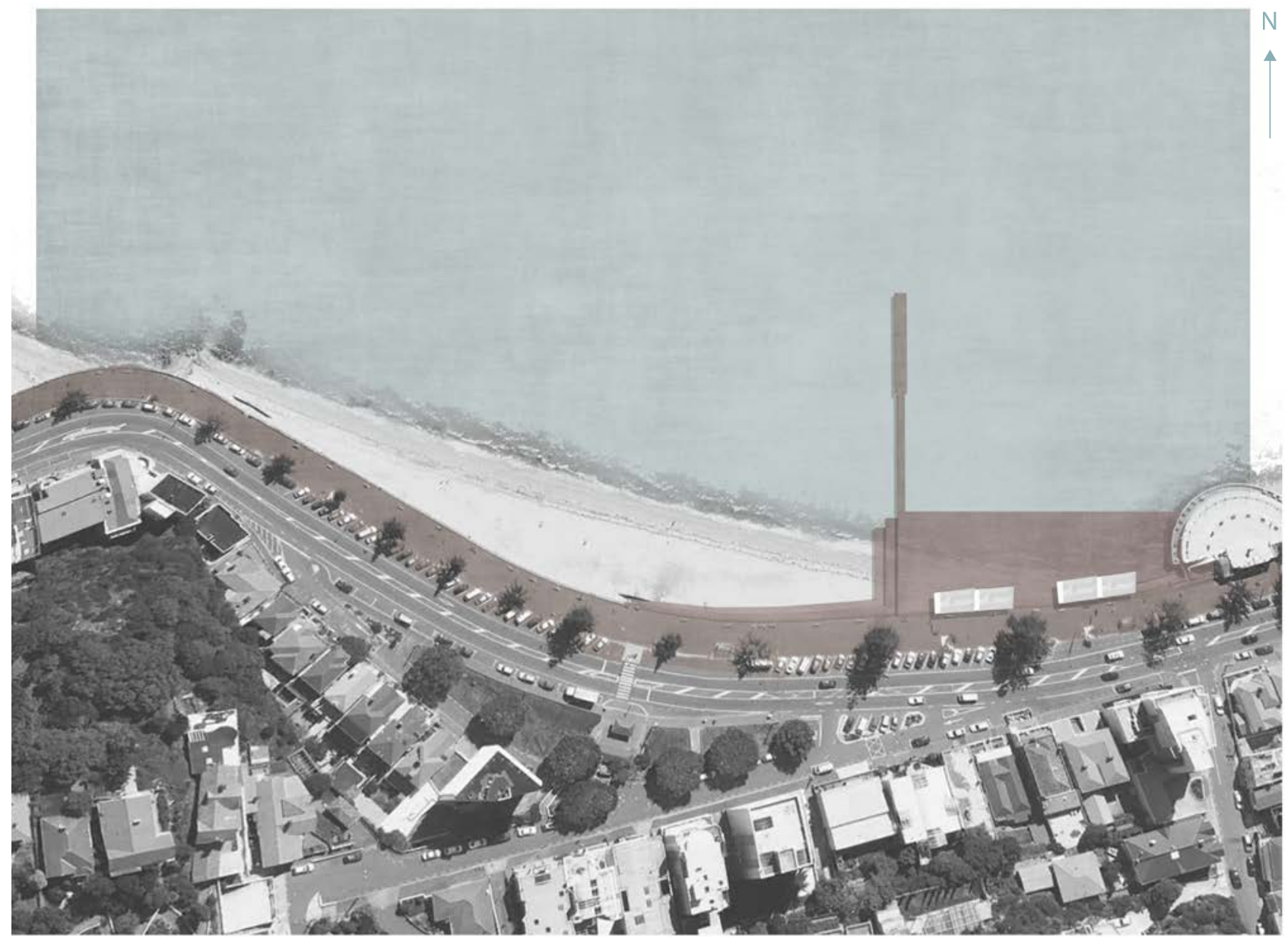

Figure 8.2.8 (Above)_Plan of the decked area to the east that expands the public space. (Authors own image). 


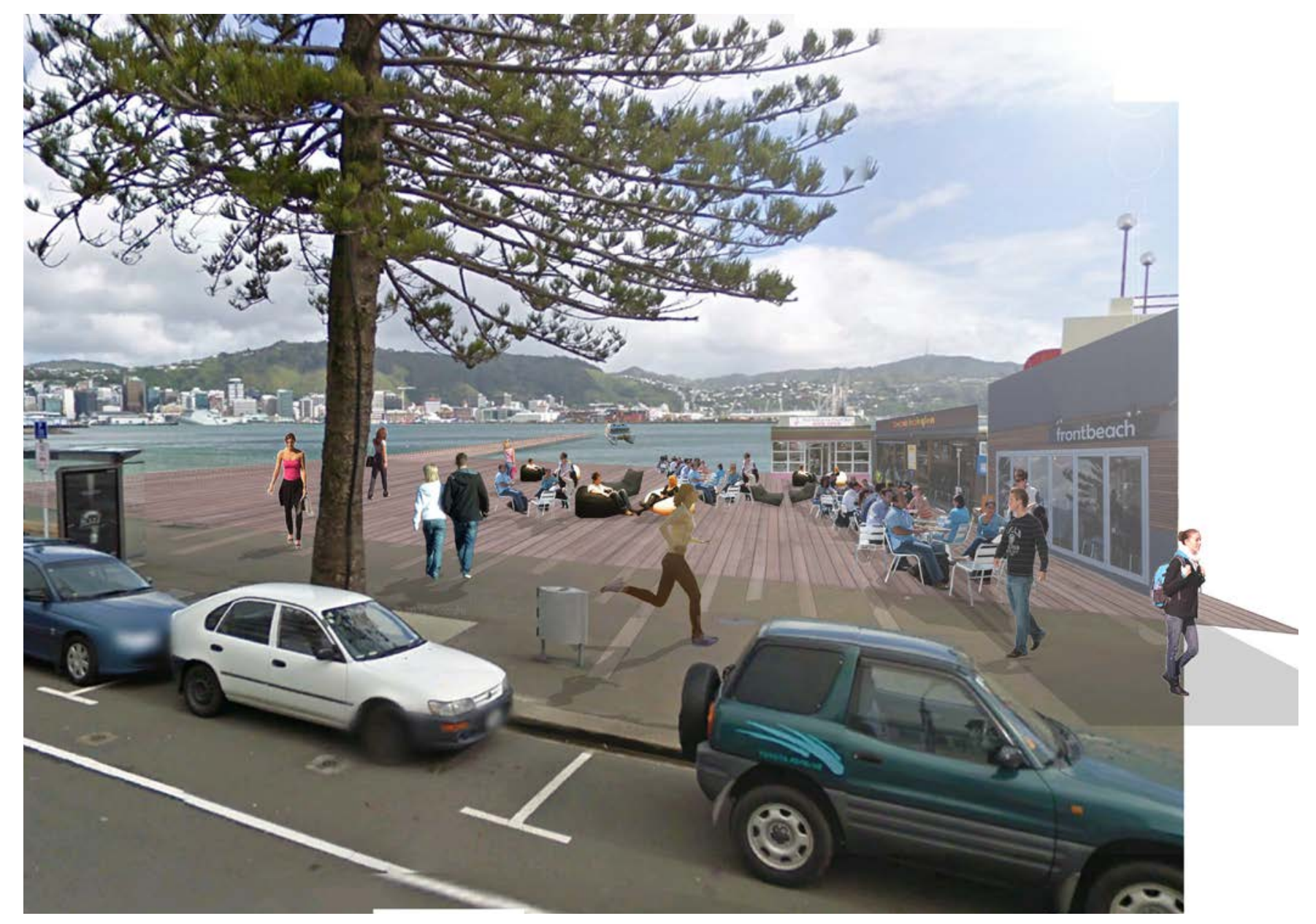

Figure 8.2.9 (Above)__Perspective looking at the decked area adjacent to the beach. (Authors own image). 


\subsection{4_ Breaking down solid edge}

There is a significant height difference between the beach and the walkway. The current edge condition is a sea wall that has two entrances down onto the beach. This edge could be broken down to allow for a greater interaction between the beach and pedestrians moving along the walkway. This also increases the edge providing people space to sit.

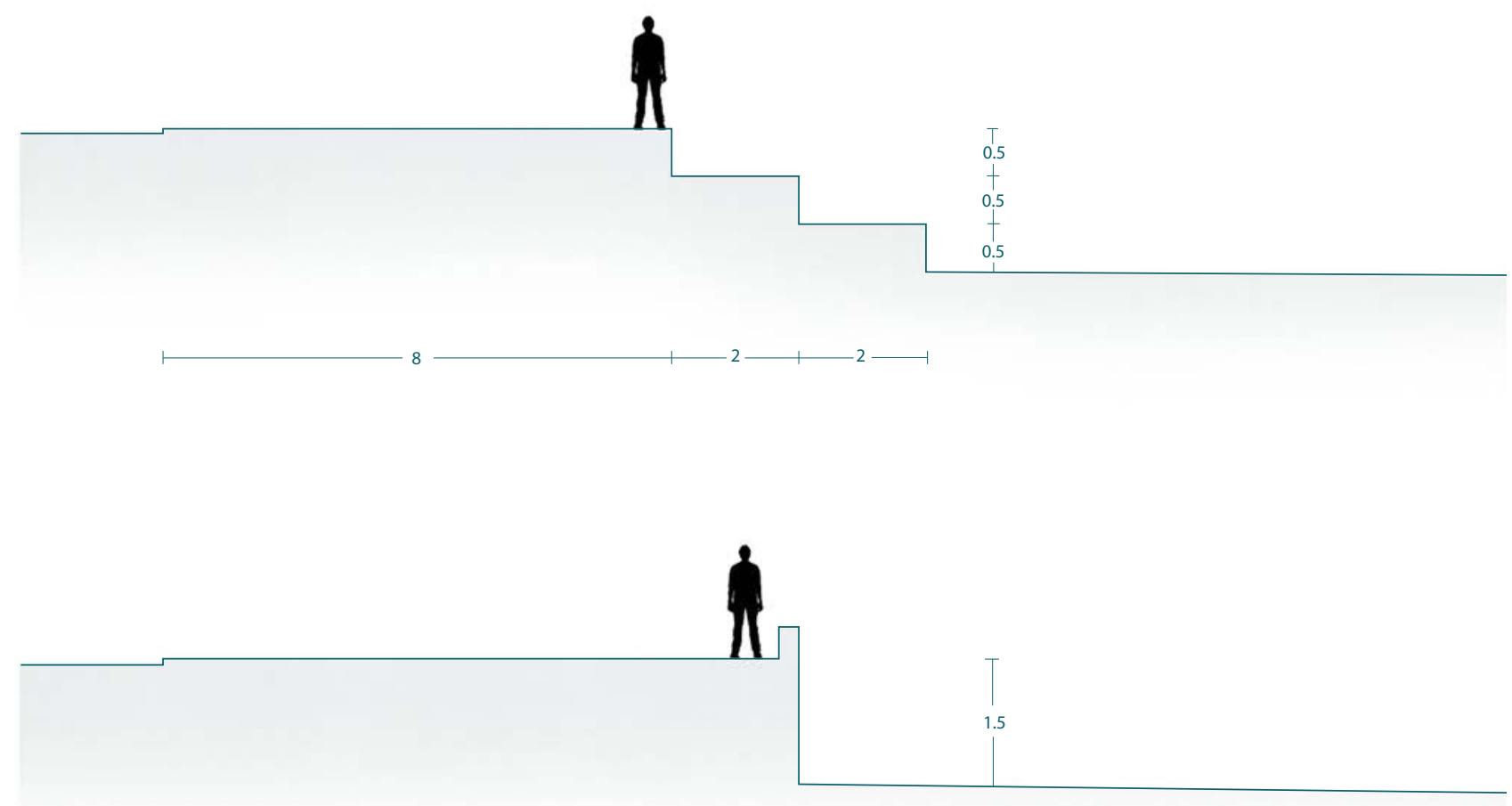
10

Figure 8.2.10 (Above)_ Sectional analysis of the sea wall and way it could be broken down to expand the edge condition. (Authors own image). 


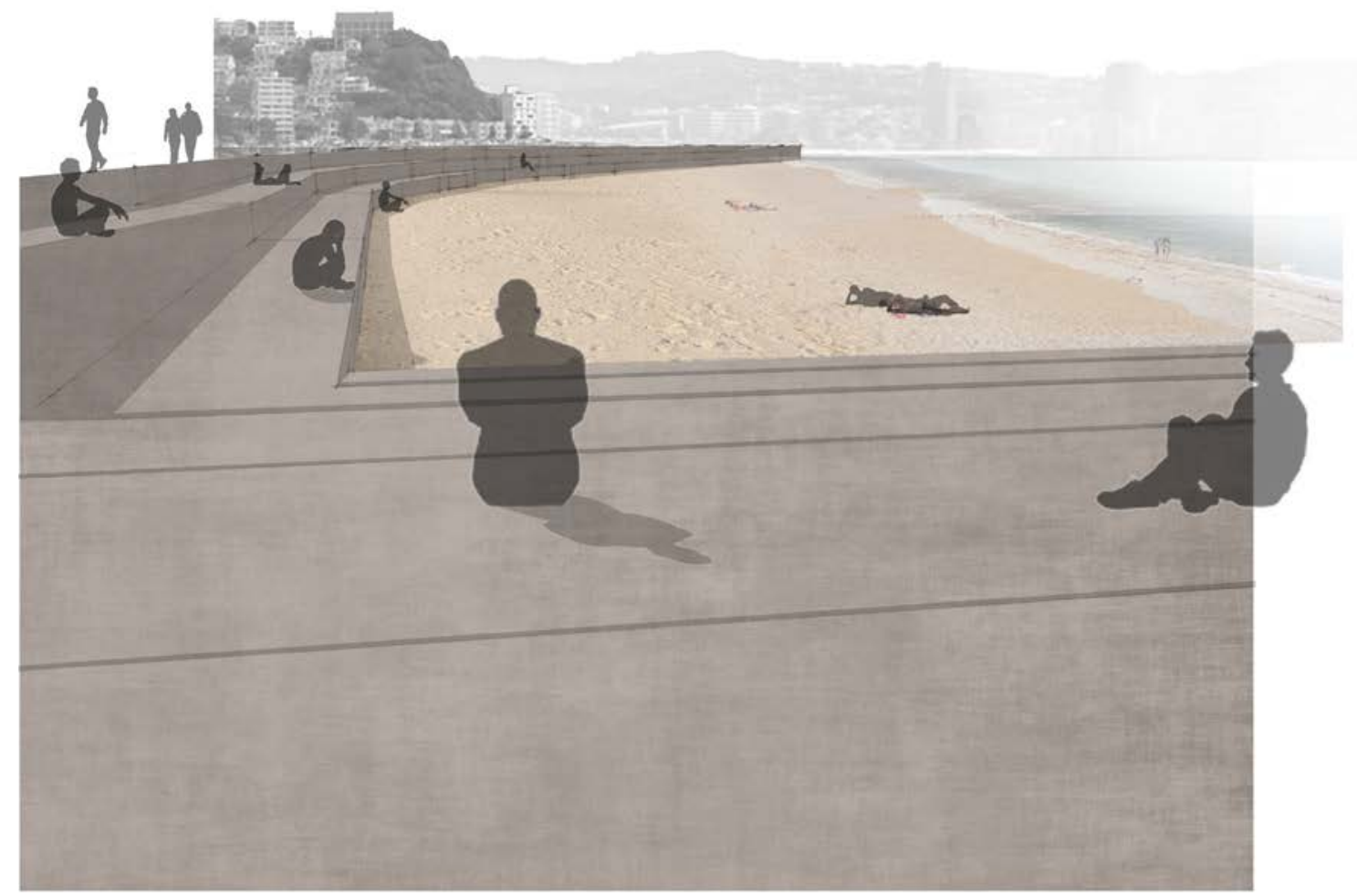

Figure 8.2.11 (Above)_ Perspective testing the edge terraced entry to the beach. (Authors own image).

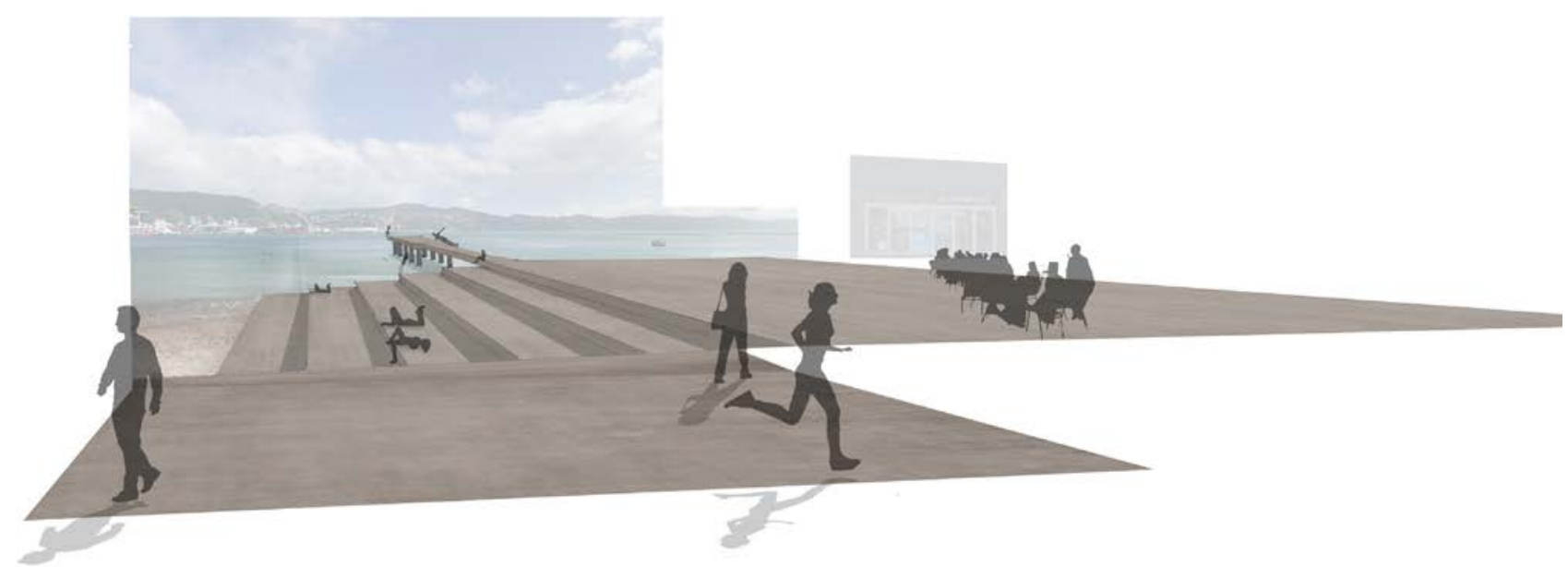

Figure 8.2.12 (Above)__Perspective looking out to the wharf with the terracing down to the water. (Authors own image). 
8.3_ Design Detail

8.3.1_ Plan

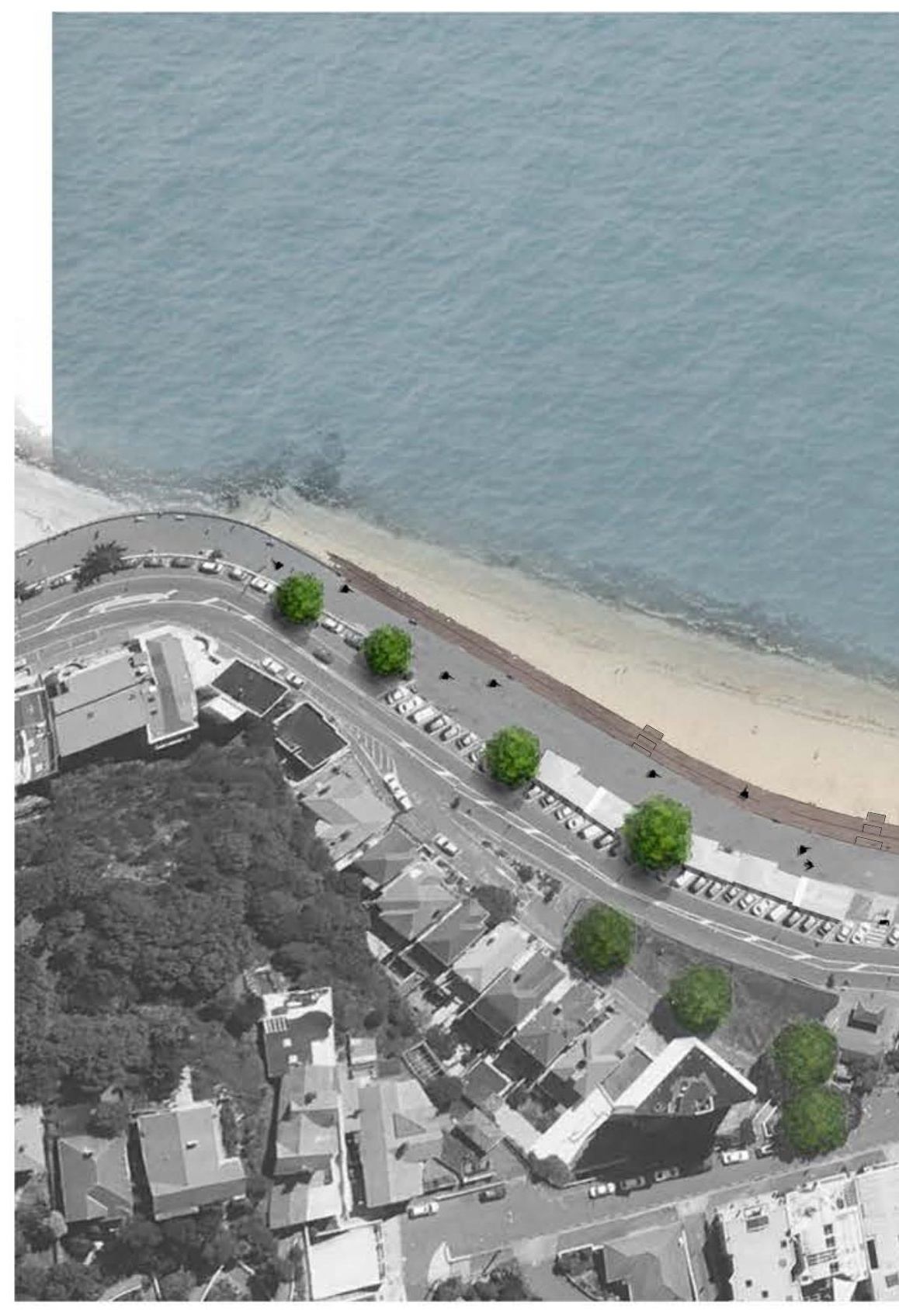




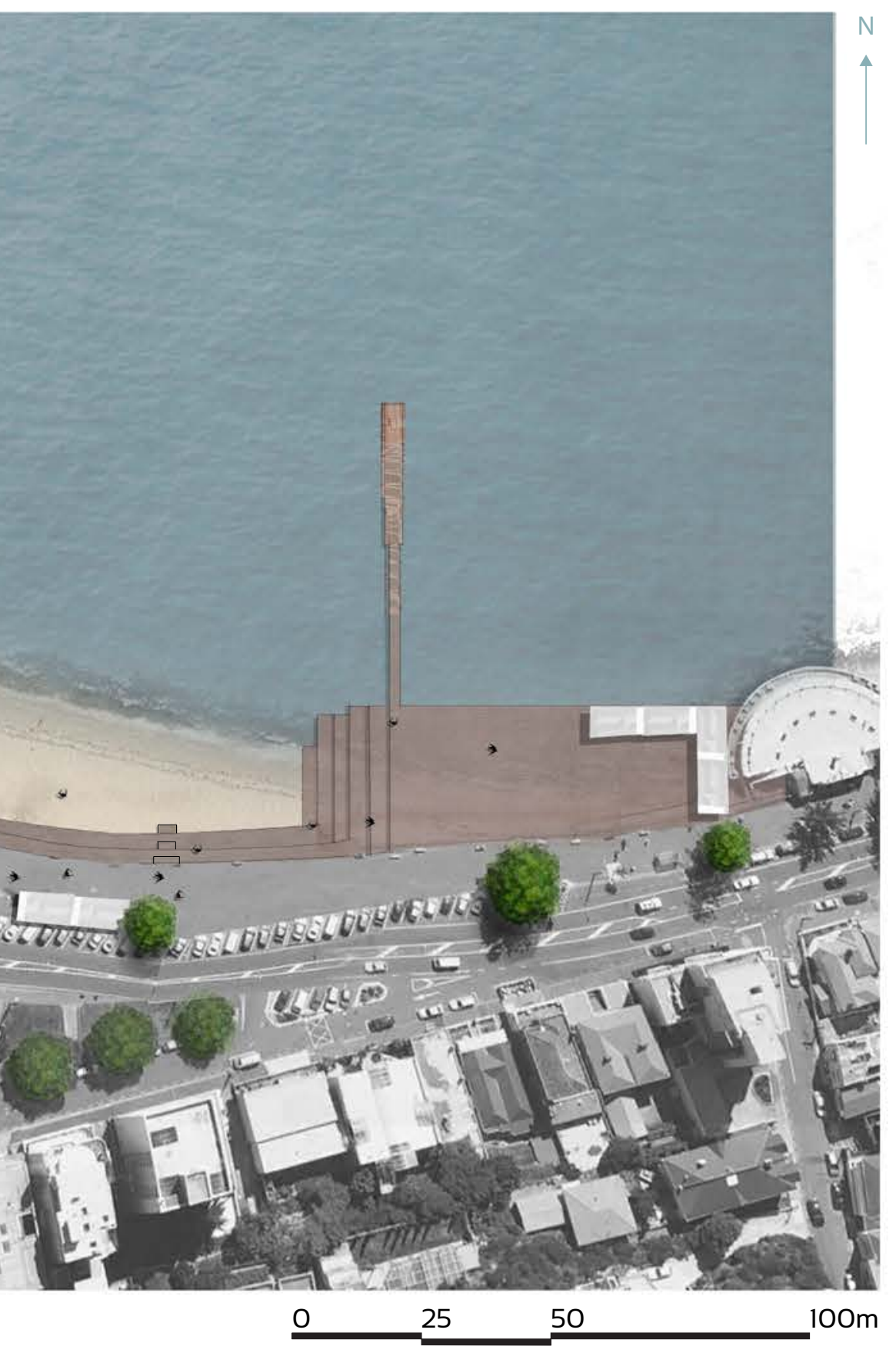

Figure 8.3.1 (Above)_ Detail plan of final design. (Authors own image). 


\subsection{2_ Edge condition}

The hard edge has been broken down to make a stronger relationship between the beach and the walkway. This should make the space seem more vibrant as there is now a dialogue between the two spaces.

By increasing the amount of edges through terraces the design has multiplied the amount of occupiable space in area. Now people can sit or sunbathe on these areas.

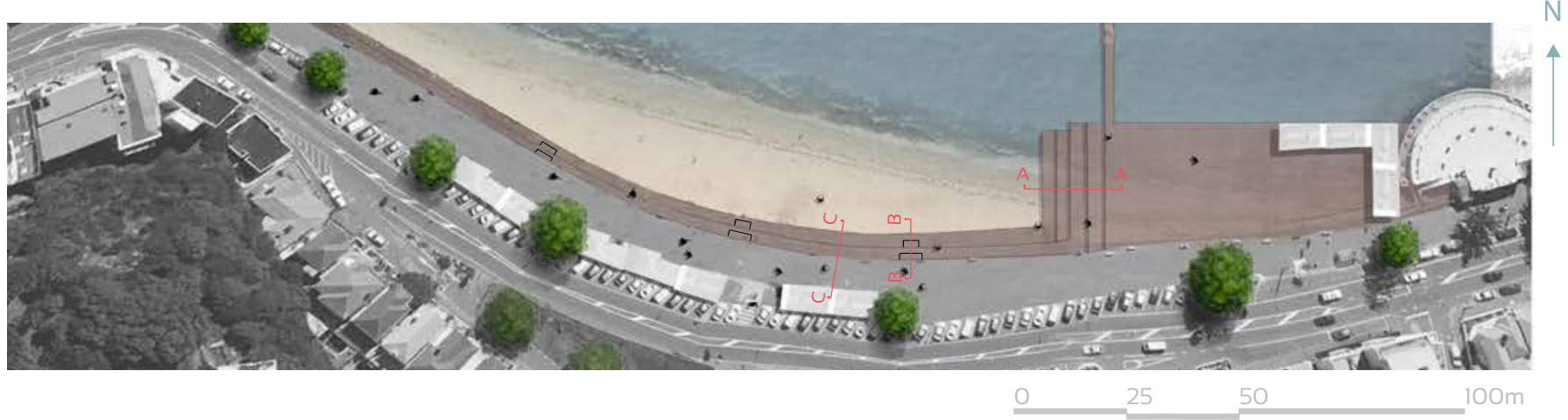

Figure 8.3.2 (Above)_ Reference plan for sections. (Authors own image)

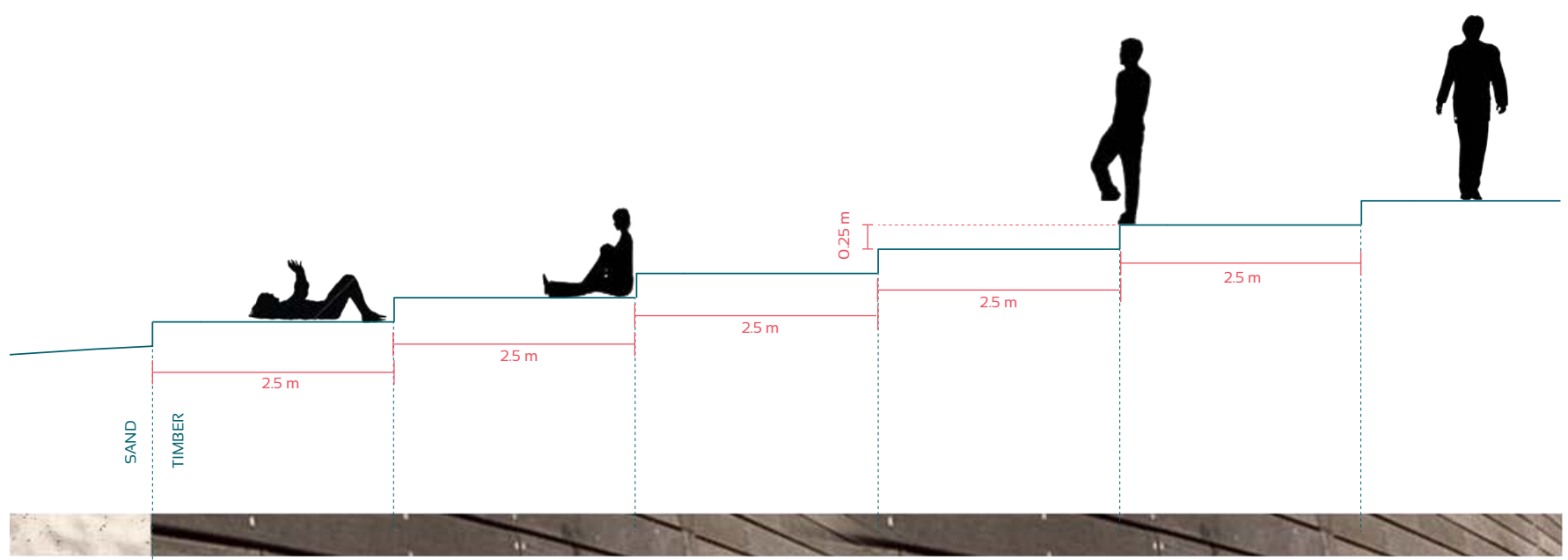

Figure 8.3.3 (Above)__Section A-A. (Authors own image). 


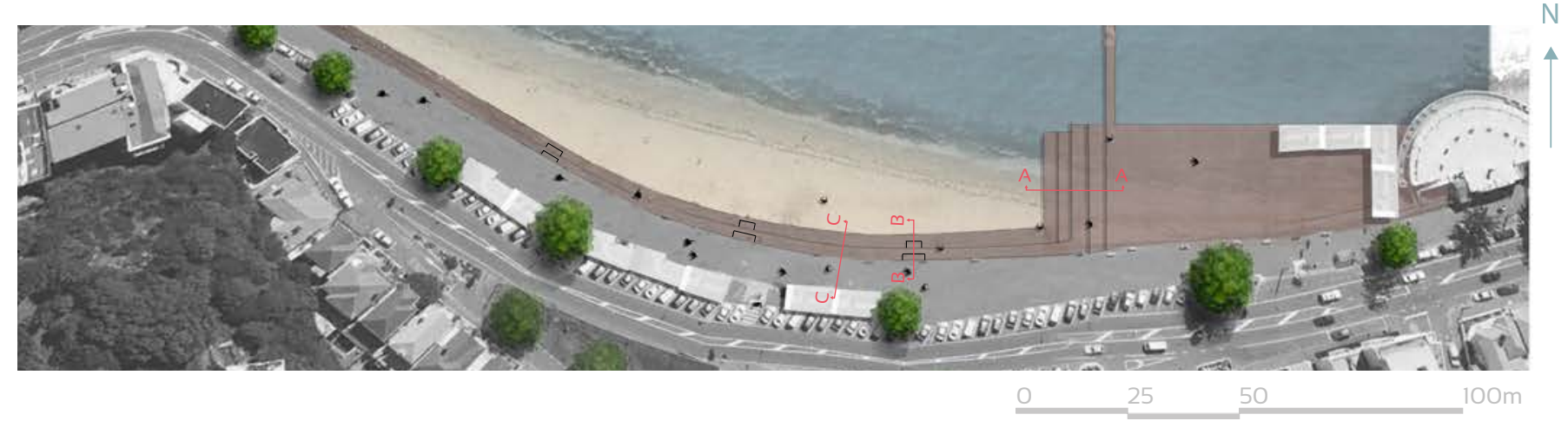

Figure 8.3.2 (Above)_ Reference plan for sections. (Authors own image).

Figure 8.3.4 (Above)_ Section B-B. (Authors own image)

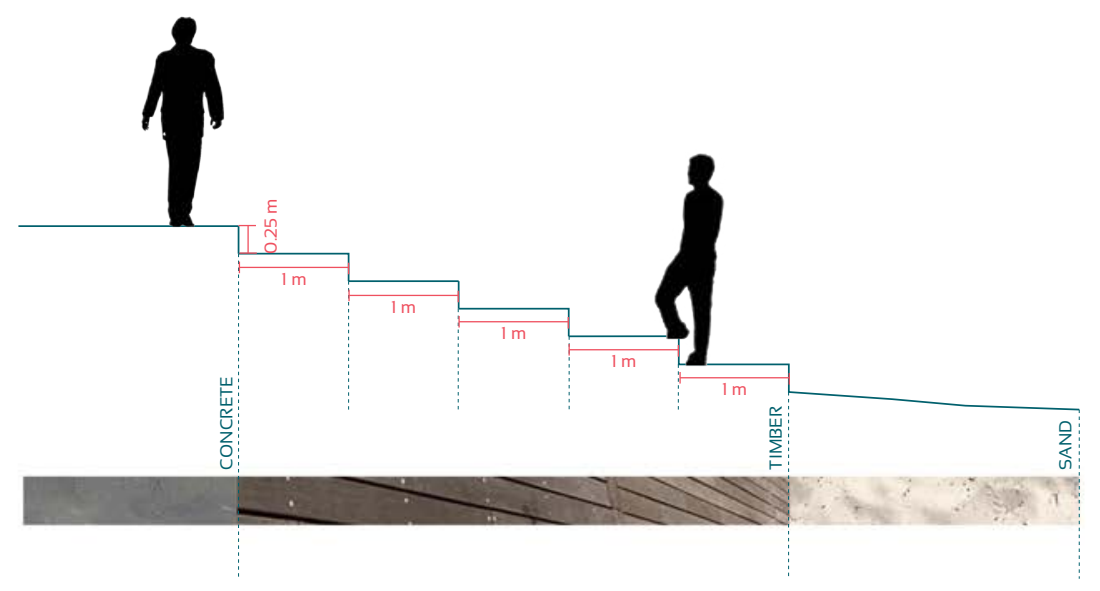

Figure 8.3.5 (Above)__Section C-C. (Authors own image) 


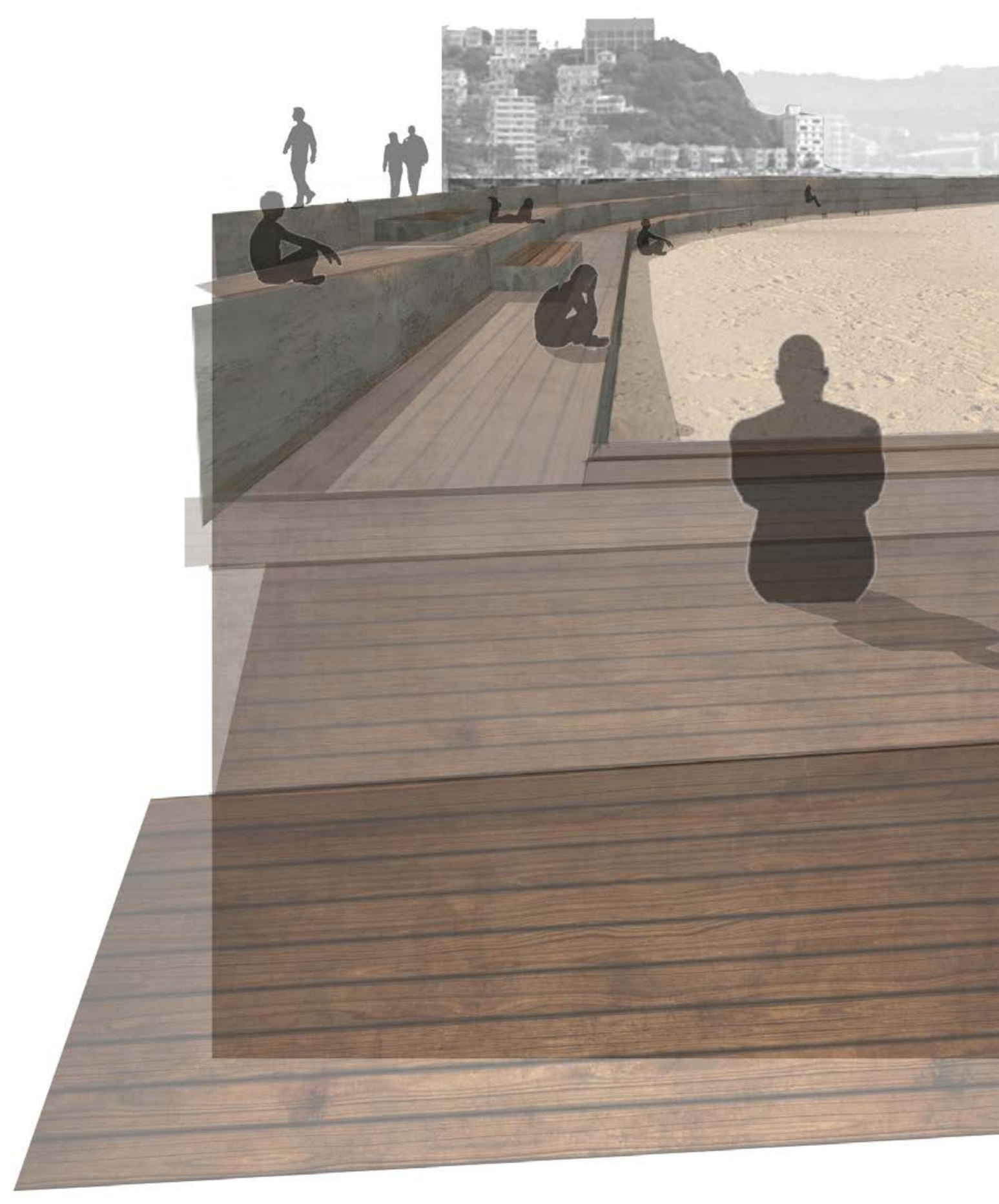




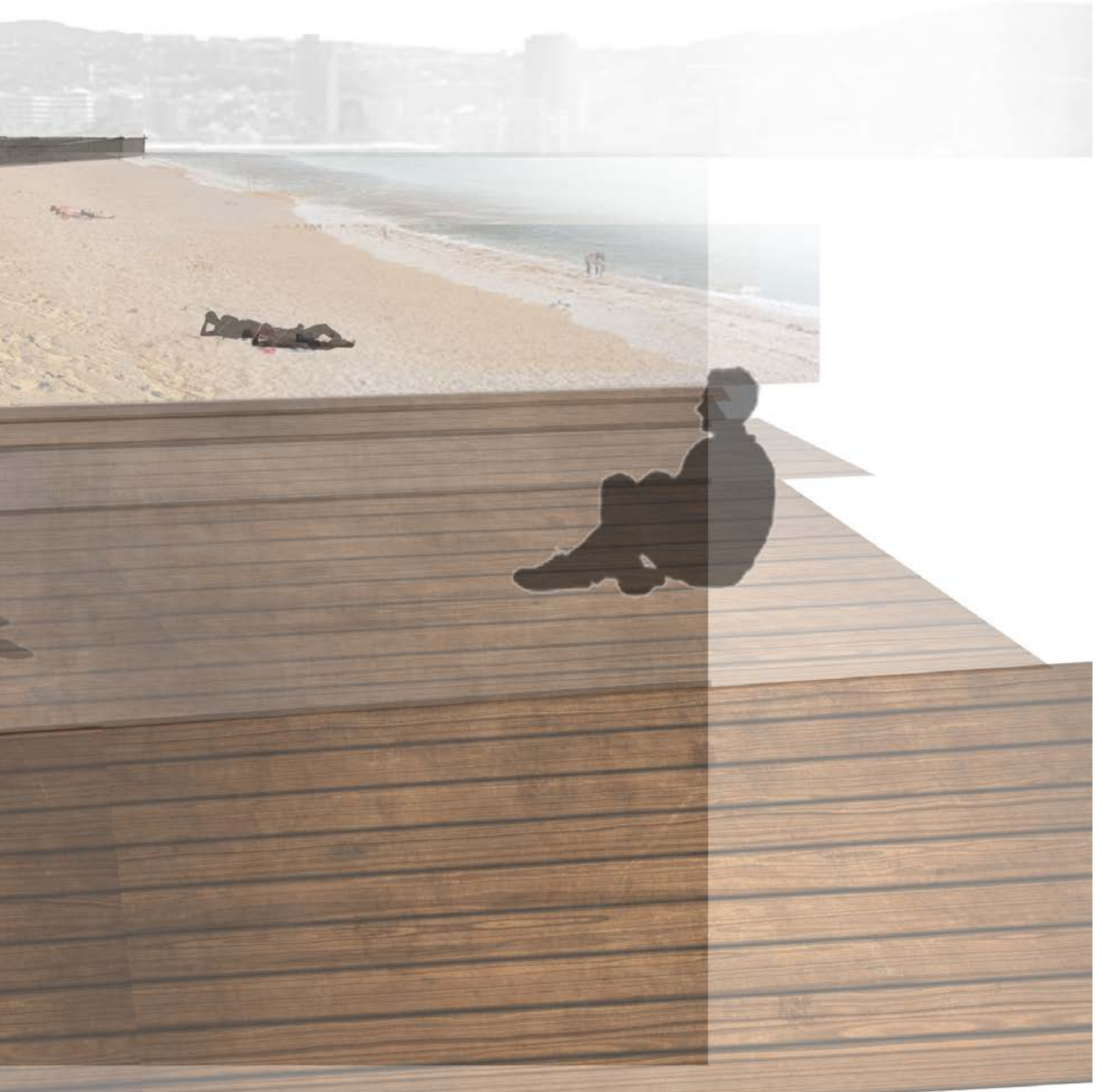

Figure 8.3.6 (Above)_ Perspective showing the new edge condition. (Authors own image). 


\subsection{3_ Ferry terminal design}

The design uses timber and glass to block and then show a staggered view back to the beach. This adds to the arrival and departure event.

The beach is activated by this design as it can be used to jump off into the water. This is something currently missing from oriental and will positively affect the public life.

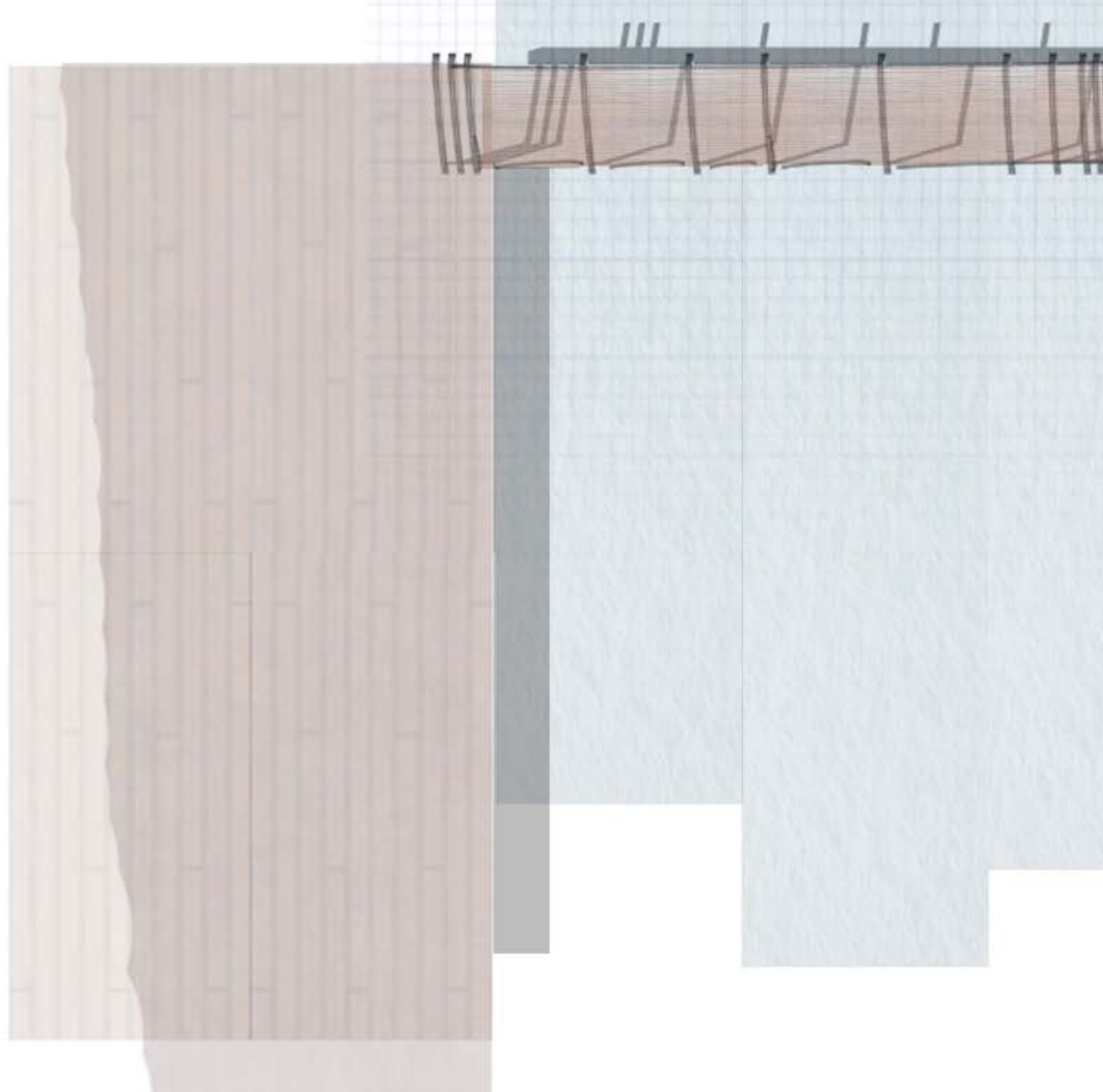

Figure 8.3.7 (Above)_ Plan view showing the ferry terminal. (Authors own image). 


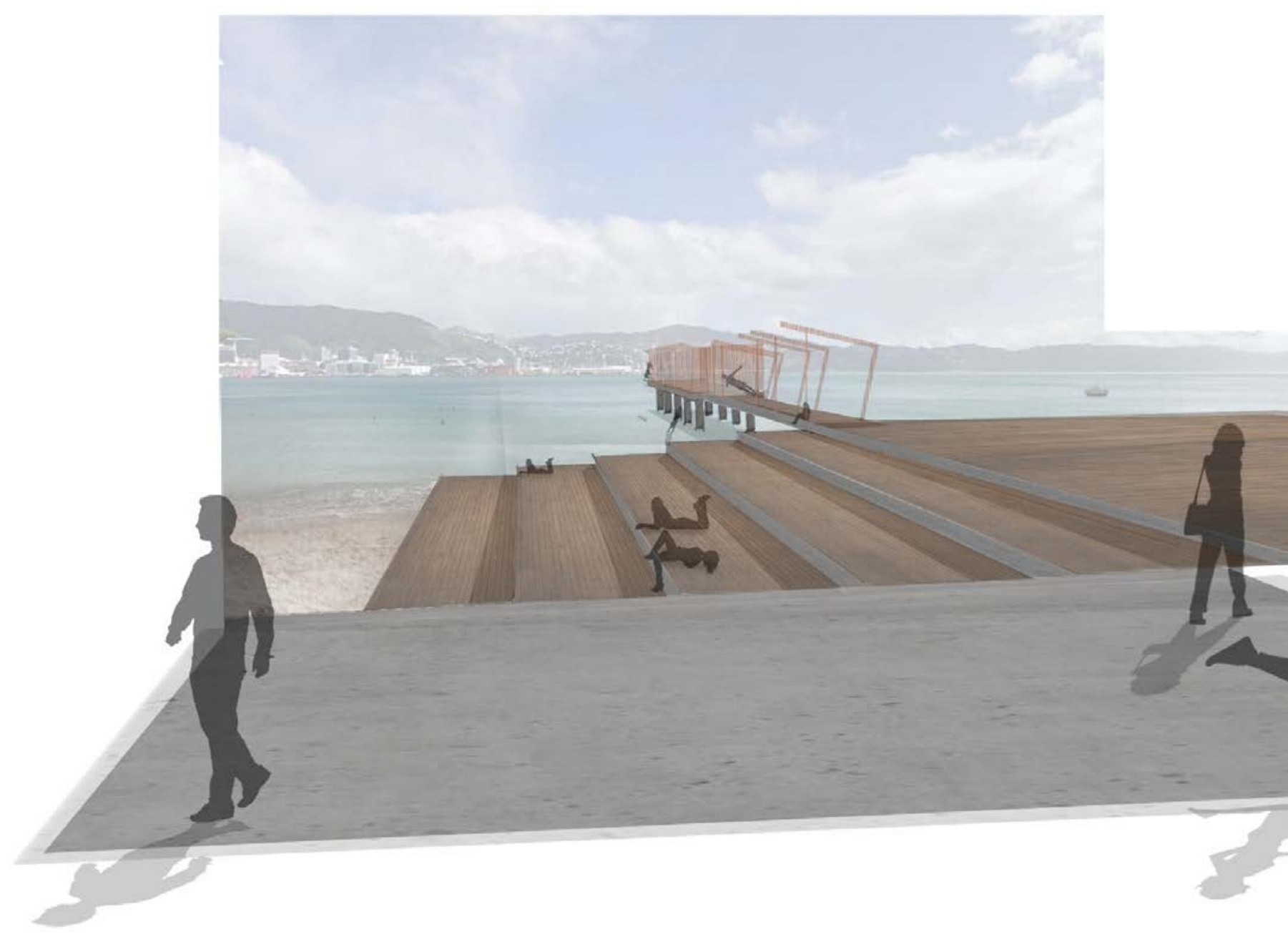




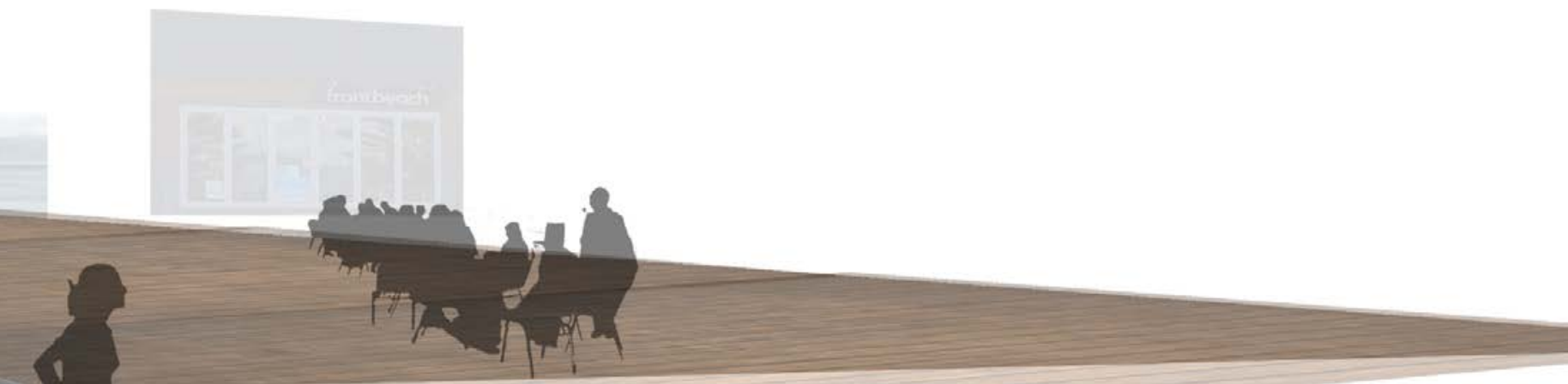

Figure 8.3.8 (Above)_ Perspective showing the terraced area and how it relates to the terminal. (Authors own image). 


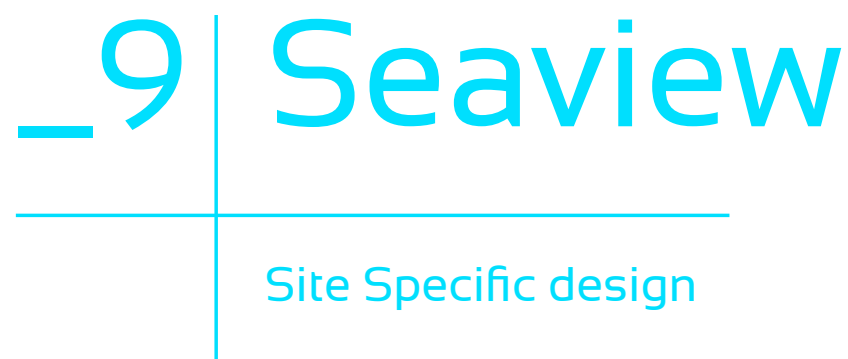



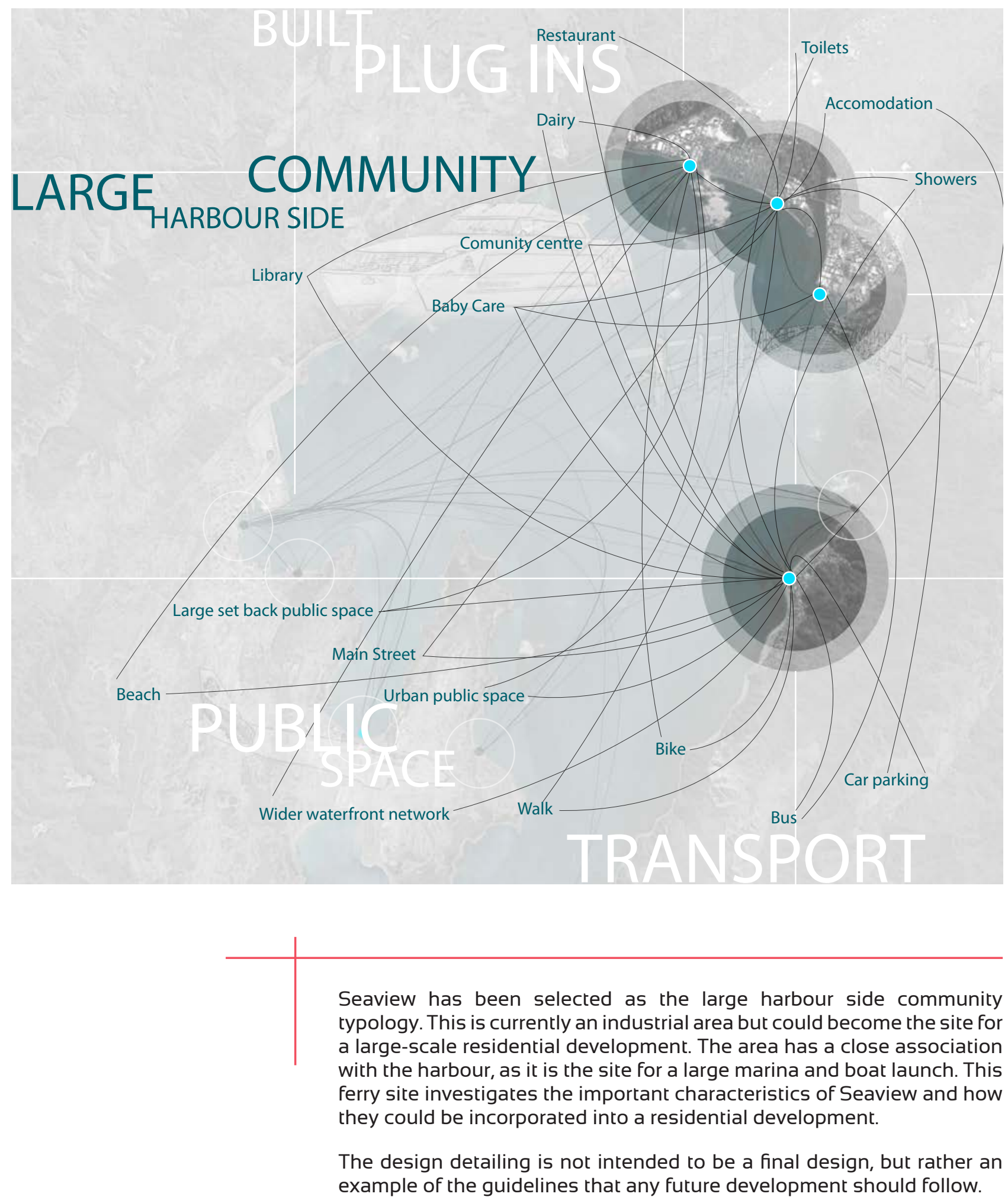


\subsection{1_ Site harbour relationship}

Seaview has a strong connection to the water because of its geographic location and history. Located out on a corner the site gets views out to the entire harbour. It is also located at the mouth of the Hutt River, which runs along its western edge.

The marina is a large part of the identity of Seaview, enhancing the connection to the water. There are many boats moored there constantly, whilst the site also provides a launching point for private boats.

The harbour is an important aspect of Seaview and this must be taken into account with any large development.

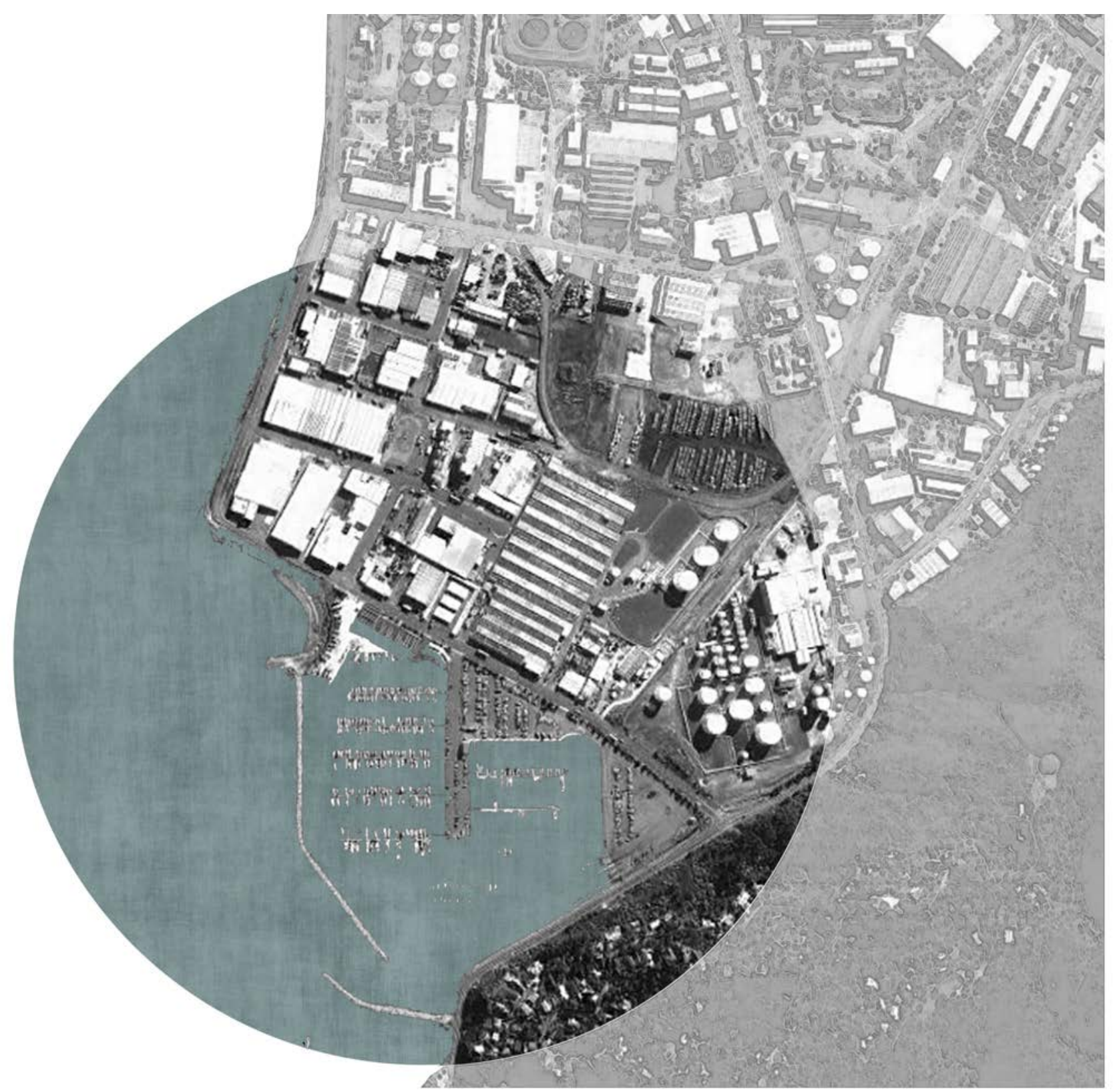

Figure 9.1.1 (Above)_ Aerial image of Seaview with the 800-metre development radius. (Authors own image). 


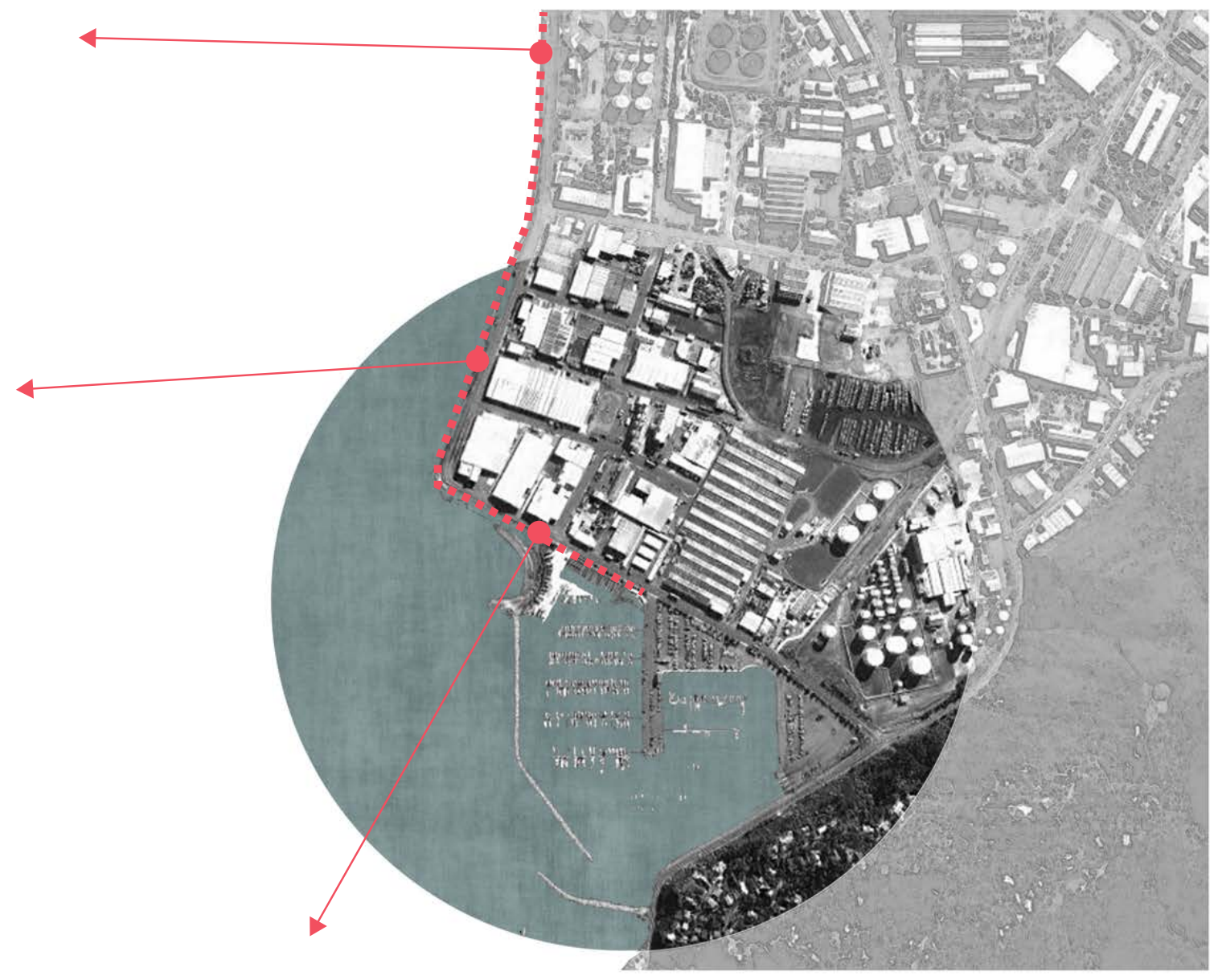

N

Figure 9.1.2 (Above)_ Diagram looking at the edge and the open nature of that edge. (Authors own image).

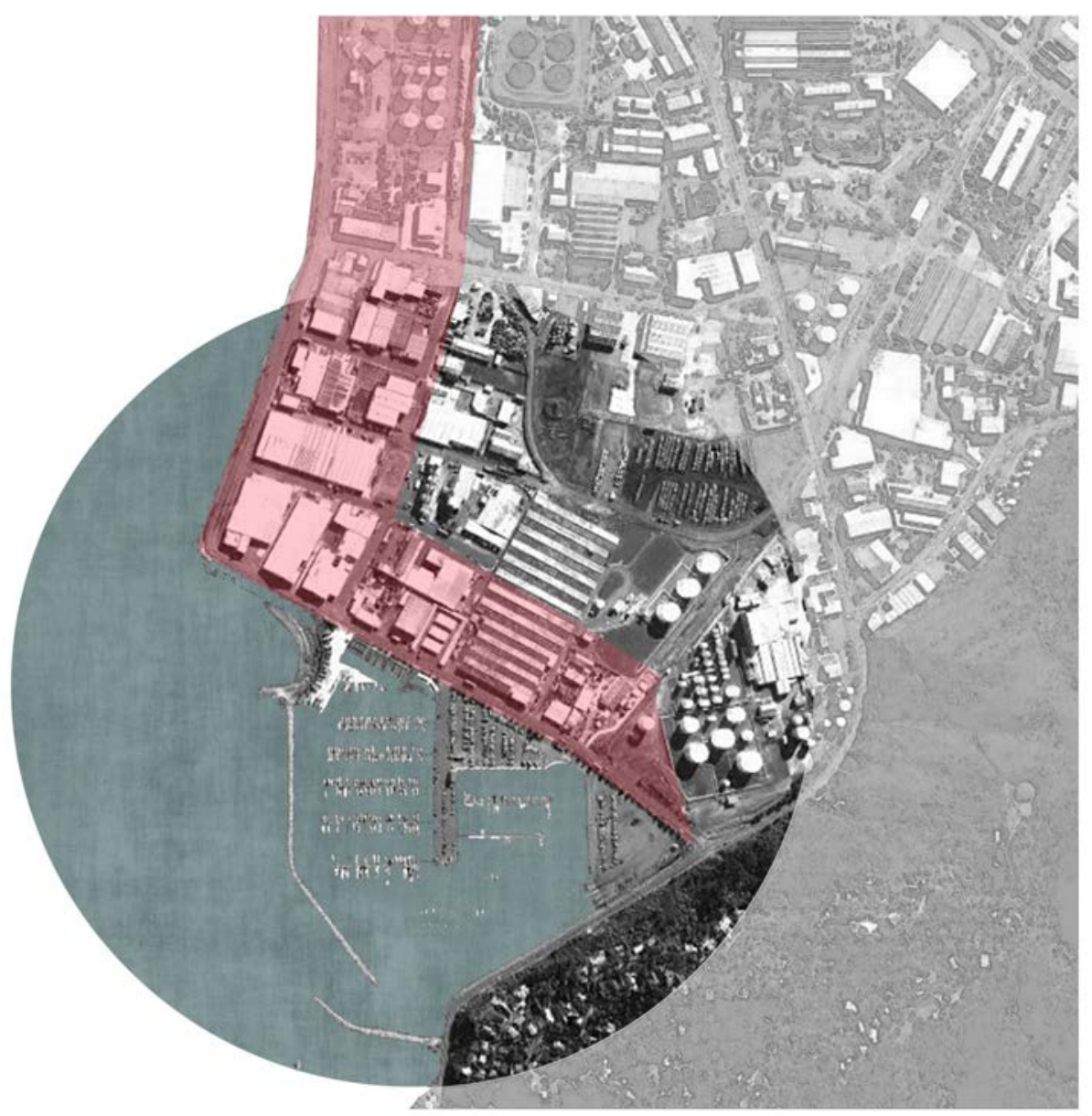

Figure 9.1.3 (Above)_ Diagram of the area most attractive to developers because of the connection and views out into the harbour. (Authors own image). 


\subsection{2_ Site qualities}

The edge to the harbour is very open, allowing the site to have a close association with the water. These images begin to investigate what it currently feels like being in Seaview.

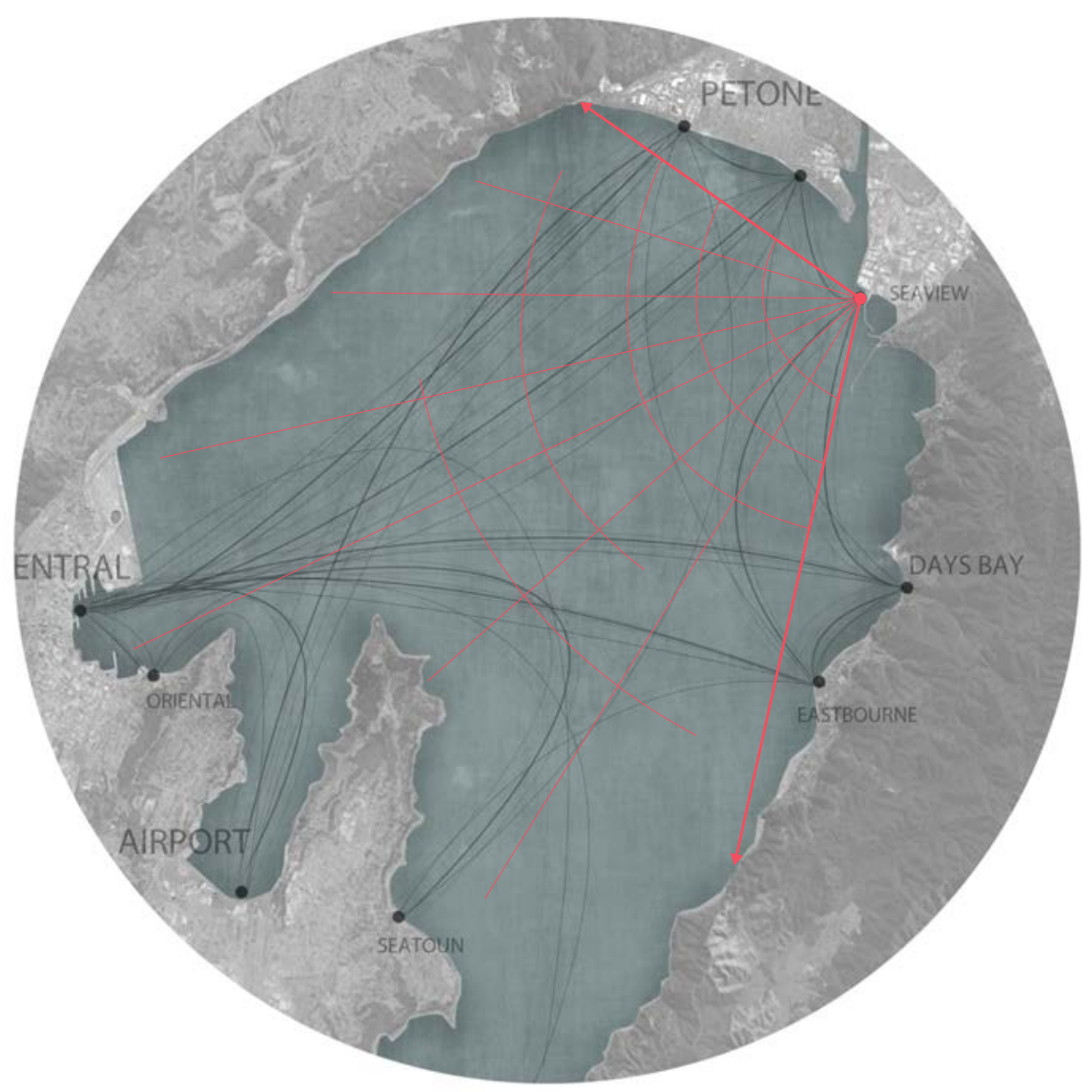

Figure 9.1.4 (Above)_ Diagram locating Seaview in the harbour network and showing visual connections. (Authors own image).

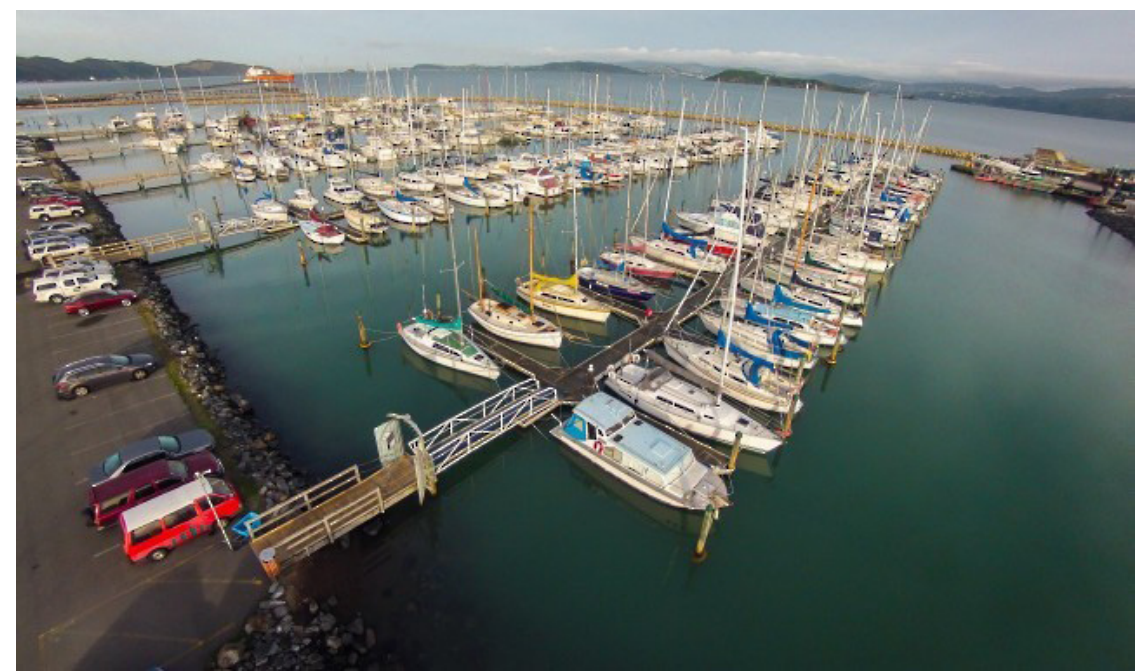

Figure 9.1.5 (Above)_ image of the edge condition in Seaview. Sourced: http://www.seaviewmarina. co.nz/ic/3446853072/Slide_11.jpg 


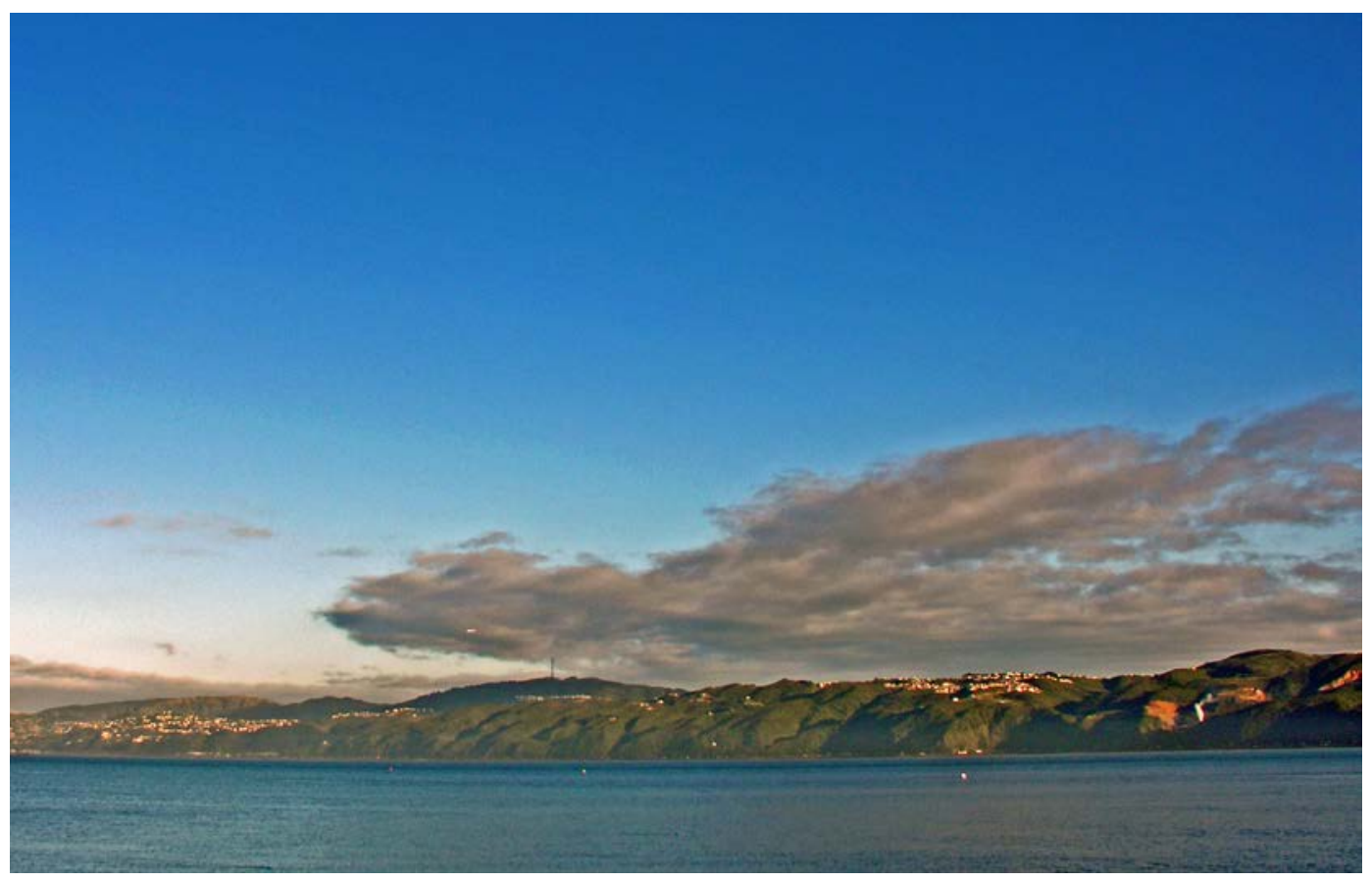

Figure 9.1.6 (Above)_ Image looking at Seaview's connections to the rest of the harbour edge. Sourced: http:// farml.staticflickr.com/70/199477994_fab9324129_o.jpg

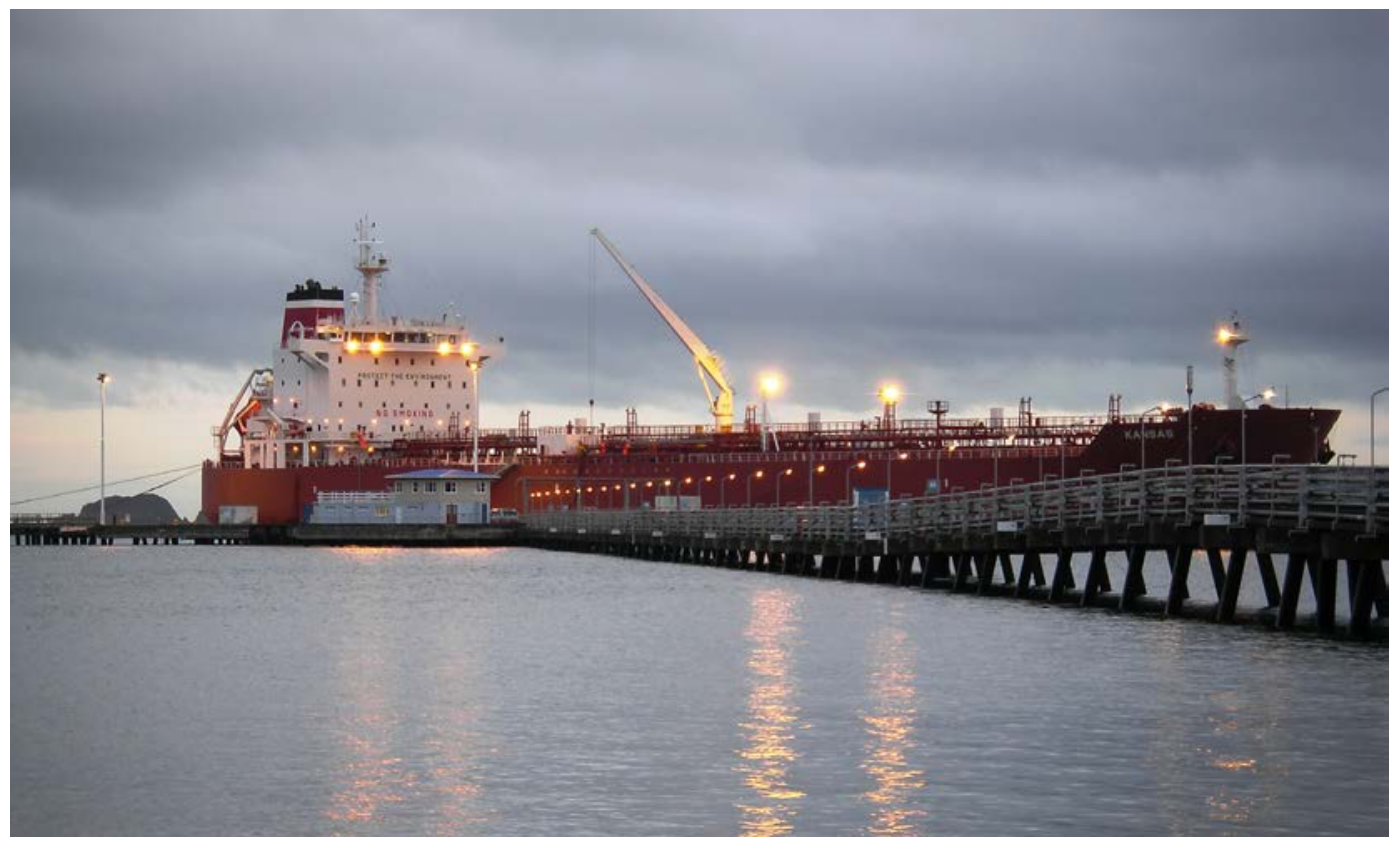

Figure 9.1.7 (Above)_ Image of large ships that dock in Seaview. This is the current area that the large ships come into in Wellington. Sourced: http://www.flickr.com/photos/aidanwojtas/958785395/?rb=1 
Seaview sits alongside a very traffic heavy road that connects Eastbourne with the Hutt Valley. It allows the site to be well connected to traffic flows and public transport networks coming from Eastbourne.

Along the front Seaview the road is very road and caters for the large trucks that service the industrial area of Seaview. This is a vehicular traffic heavy road that separates the waterfront.

There is a boat ramp that allows for traffic flows out into the harbour.

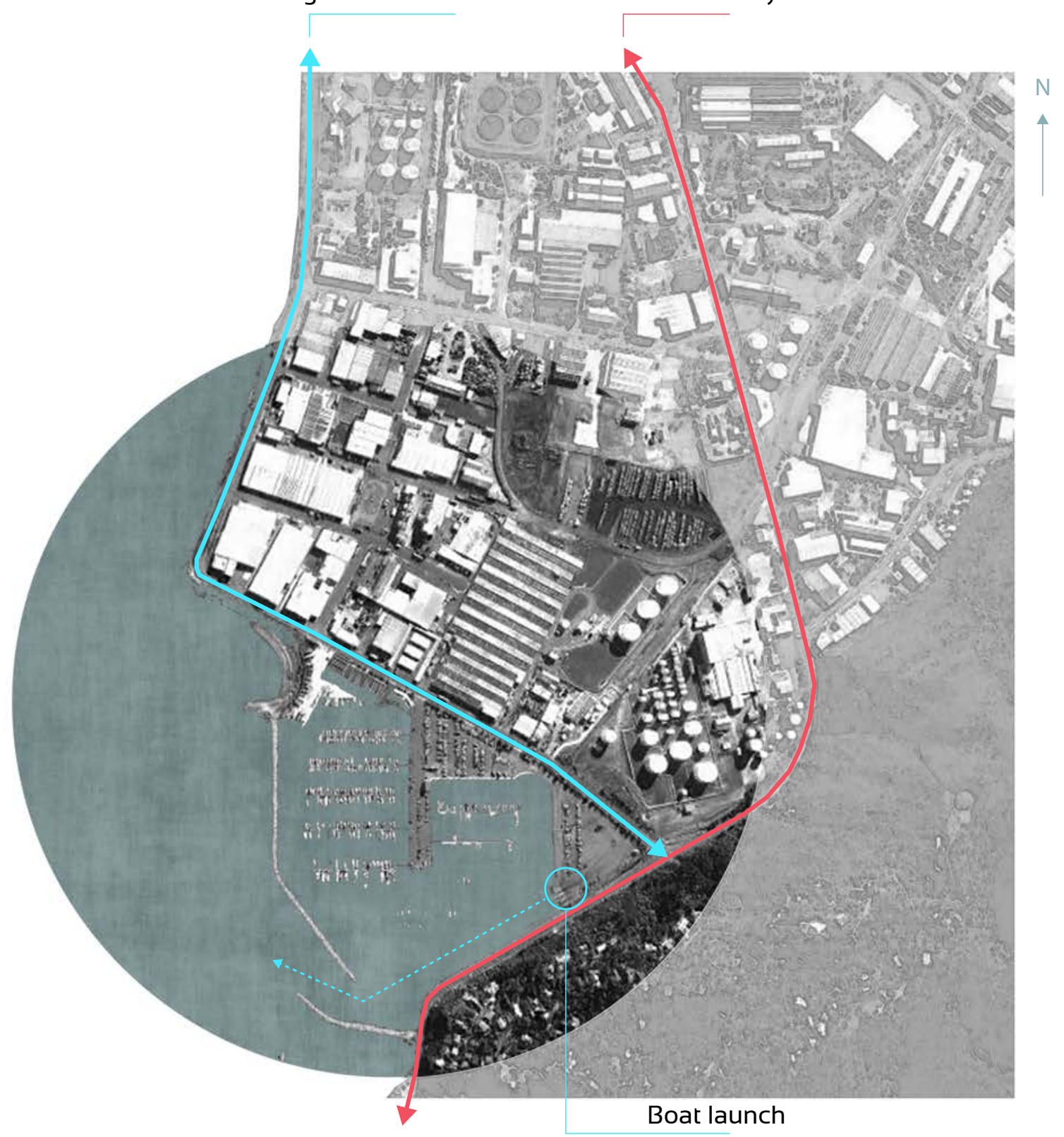

Figure 9.1.8 (Above)_ Diagram of the movement around the site. (Authors own image). 


\subsection{4_ Topography}

The topography in the industrial area of Seaview is very flat, yet to the east of the site the hillside rises up steeply. This area provides expansive views out to the harbour. The people living up there would get good views of the ferry coming into site. There could be opportunity for a look out that links into Seaview and the ferry system.

The flat nature of Seaview increases the viability of people walking to the terminal to catch the ferry and also the viability of them using the associated public space.

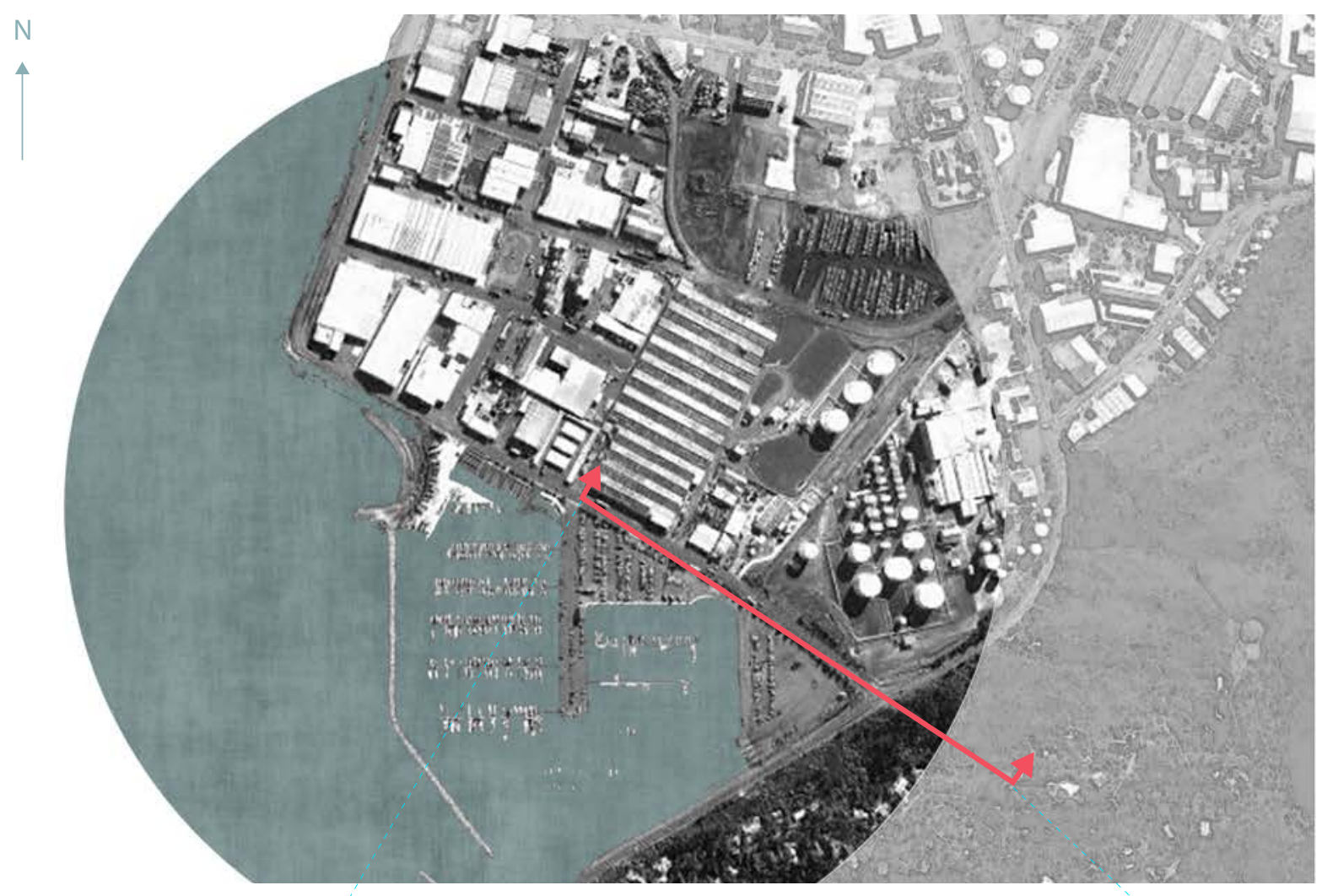

Figure 9.1.9 (Above)_ Plan and section investigating the steep topography to the east of the site. (Authors own image). 


\section{2_ Design Testing}

\subsection{1_ Site development}

The site is mostly an industrial zone and there is a large amount of space that could be developed into waterfront housing. The site is positioned next to the water that could allow a ferry to connect the site into Wellington City for work. The marina already provides a good connection with the water and that could be enhanced if the development was done the right way.

There is also the opportunity to reclaim some land to the west to expand the area for development.

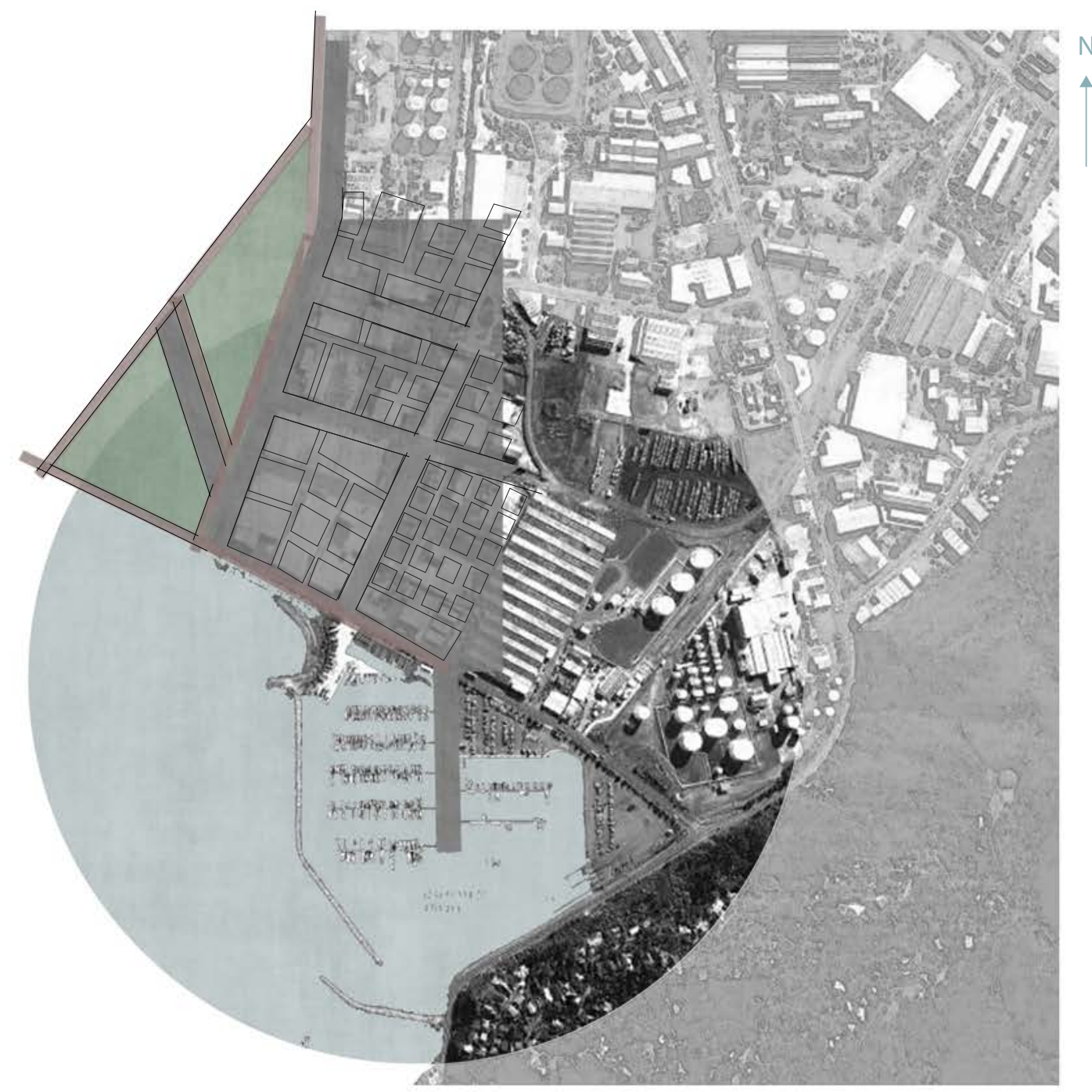

Figure 9.2.1 (Above)_ Investigating the size of block, with the potential to reclaim land for recreational space along the waterfront. This may not be a viable option for developers as it would be expensive to reclaim land an there would be no economic pay back. (Authors own image). 


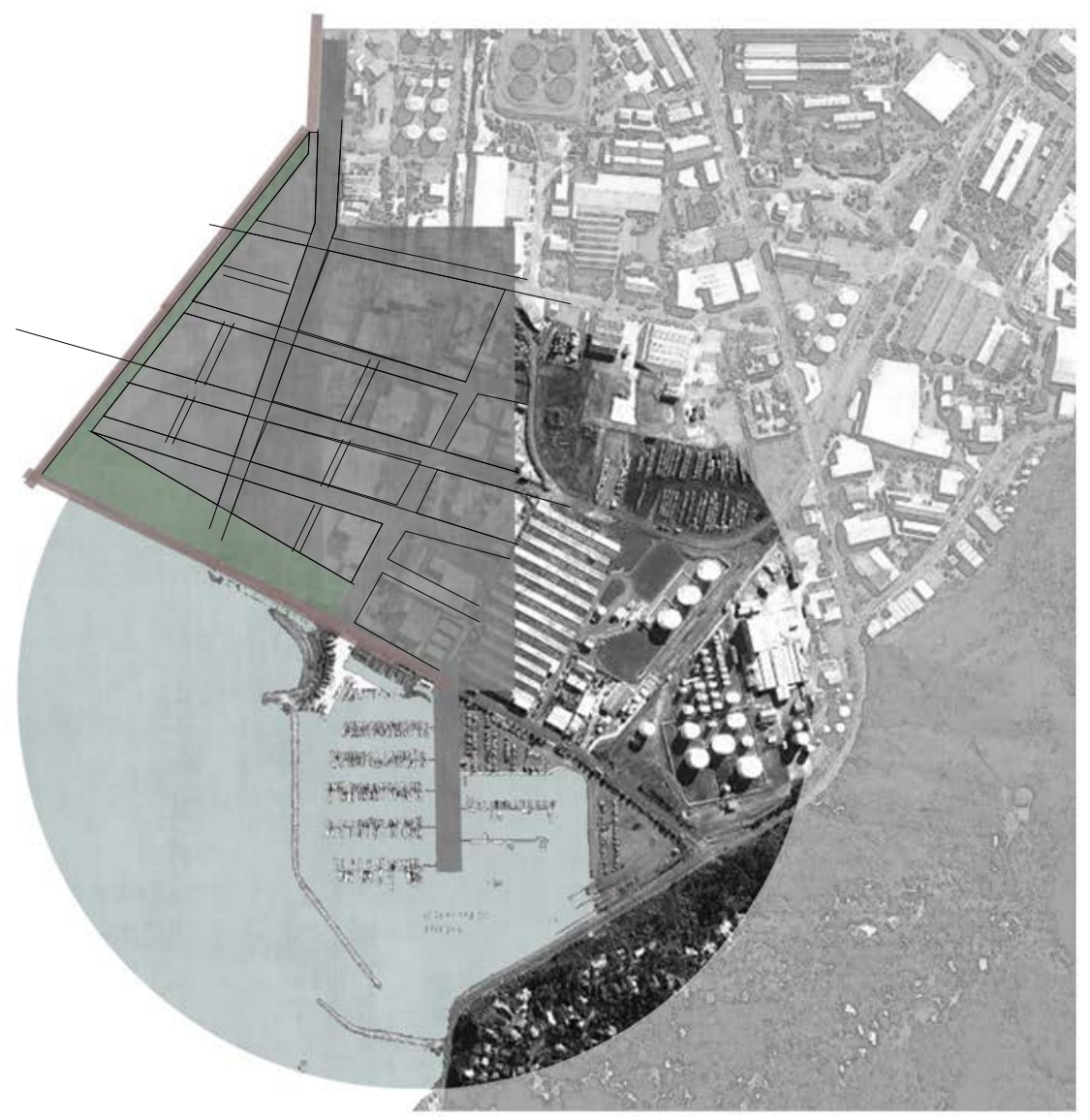

Figure 9.2.2 (Above) Investigating bringing the built form right across the reclaimed land with recreational space on the edge. The boardwalk could become part of a wider network of boardwalks. (Authors own image).

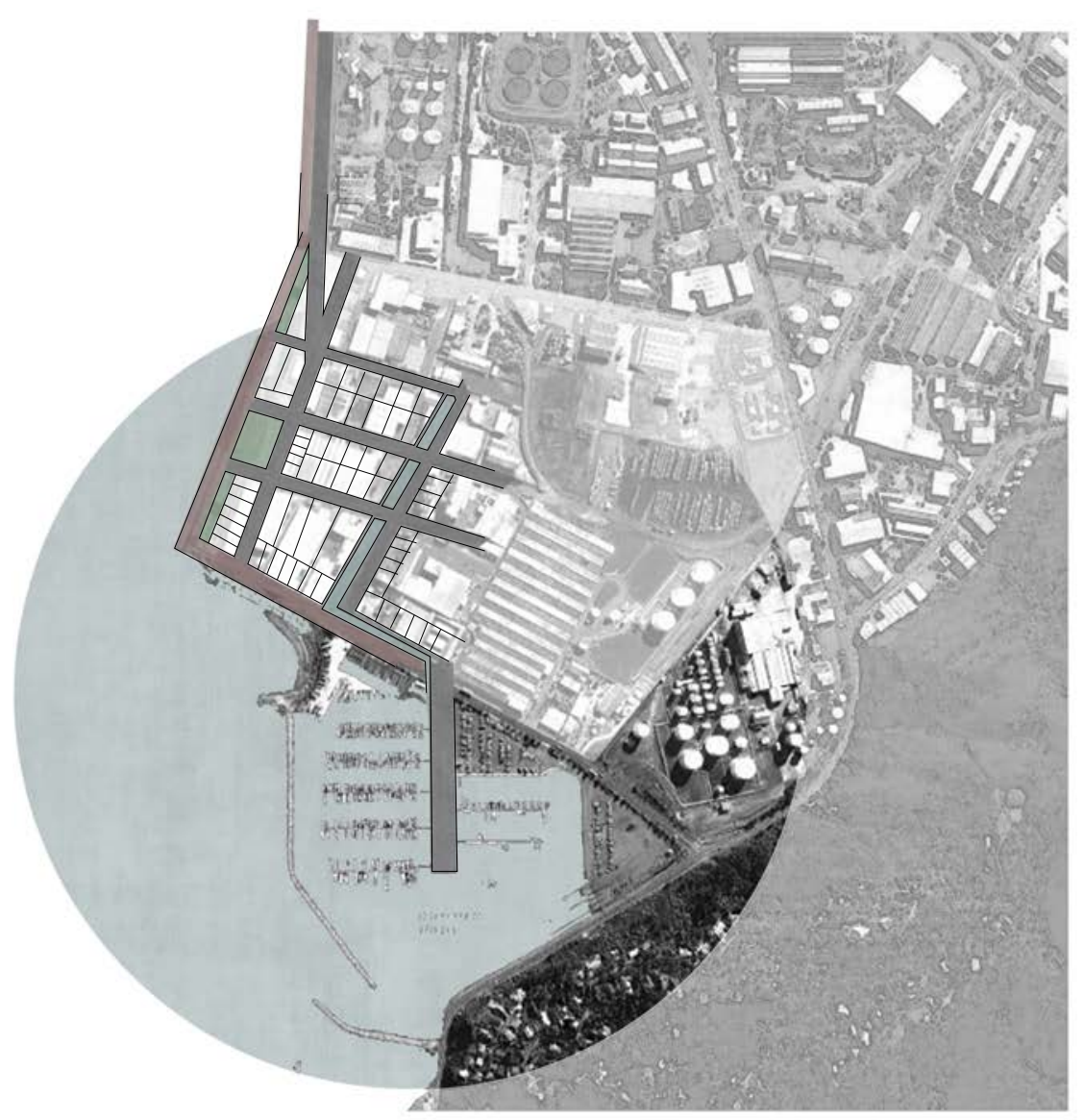

Figure 9.2.3 (Above)_ Investigating development with no reclaimed land. It is a much smaller scale project. Water begins to be drawn back into the site. (Authors own image). 
As the site is so closely associated with the water any large-scale development project should include that in part of the planning. There is the opportunity to run canals up into the development to lead then from the ferry service up through the site to other transport modes or recreational activities.

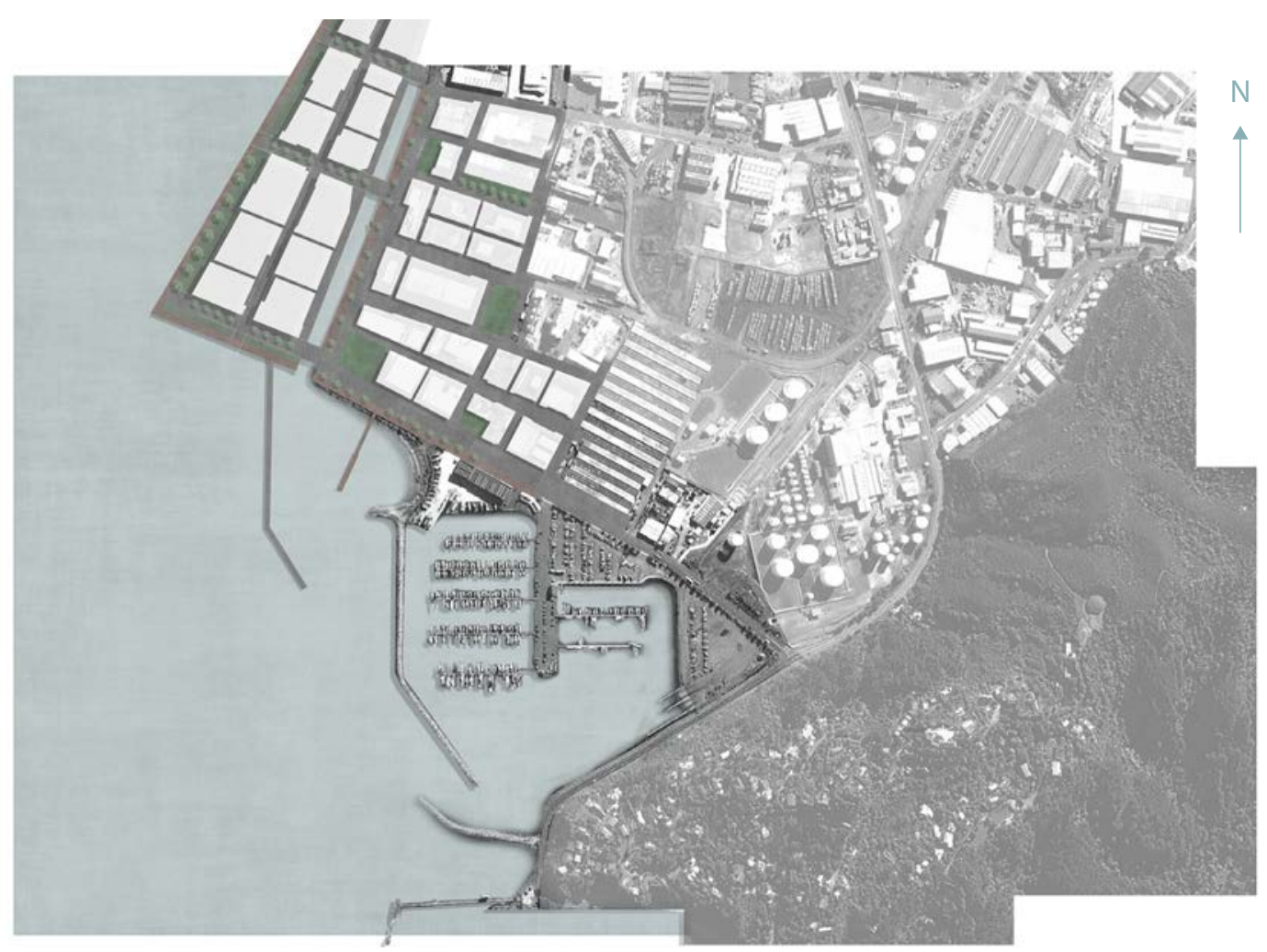

Figure 9.2.4 (Left)_ Investigating development with reclaimed land. There is the opportunity to use a canal to signify the old coast line and bring water up into the site. (Authors own image).

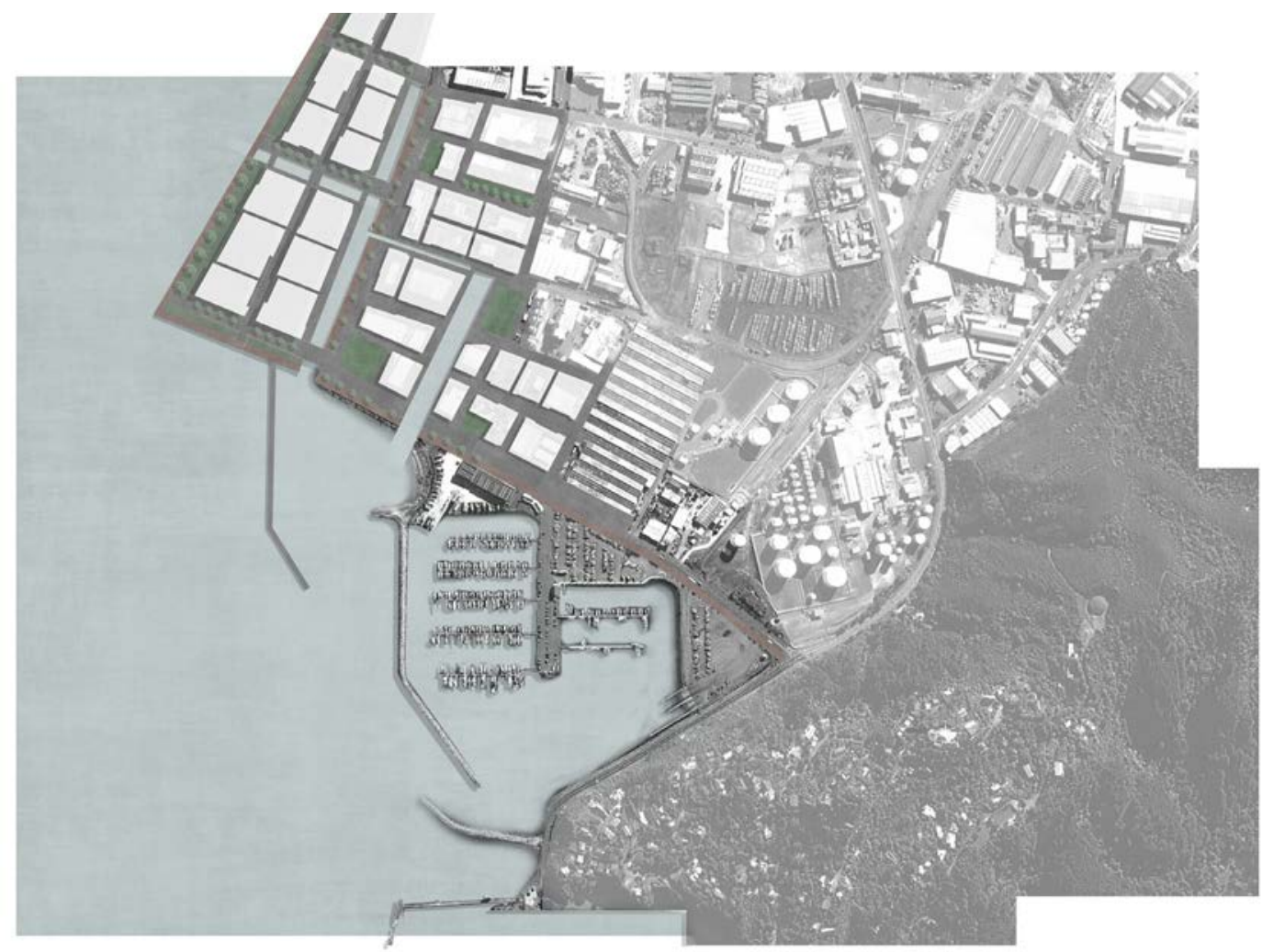

Figure 9.2.5 (Left) Similar to figure 9.2.4 yet this tests increasing the amount of interaction with the water The ferry could potentially be brought up into the centre of the development as opposed to stopping at the edge. (Authors own image). 


\subsection{3_ Breaking down the road}

The current road running along the waterfront is very wide and not pedestrian friendly at all. If this development is about the harbour and Seaview's relationship to the harbour then this road needs to become pedestrian friendly.

The speed along the road could be slowed down and the space broken up so the road operates as a waterfront boulevard as opposed to an urban motorway. This would increase pedestrian flow across the road to the waterfront.

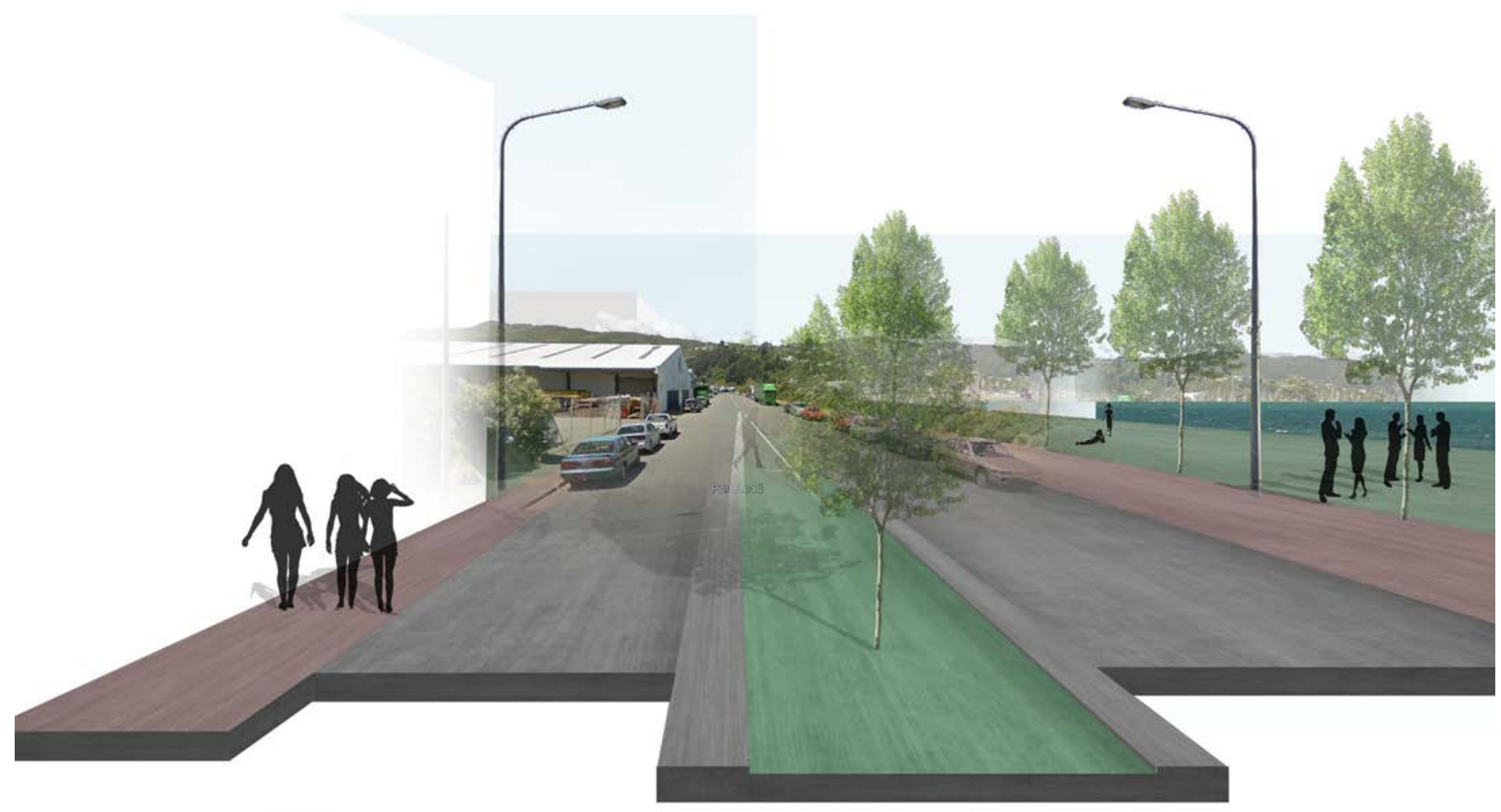

Figure 9.2.6 (Above)_ Rough section through the road investigating how it could be split up to enhance pedestrian friendliness. (Authors own image). 


\subsection{4_ Ferry terminal location}

There are three potential sites for the location of the ferry terminal. The first option is for the wharf to be attached to the edge of the land and have people flow back into the site. A bar could be extended out to the west to shelter the area.

The second option is to make one of the canals wide enough that the ferry could travel right into the centre of Seaview, becoming a real part of the structure of the development.

The third option is to locate the terminal in the marina as the area is already very sheltered. This would be affected by speed and wake rules when entering the marina.

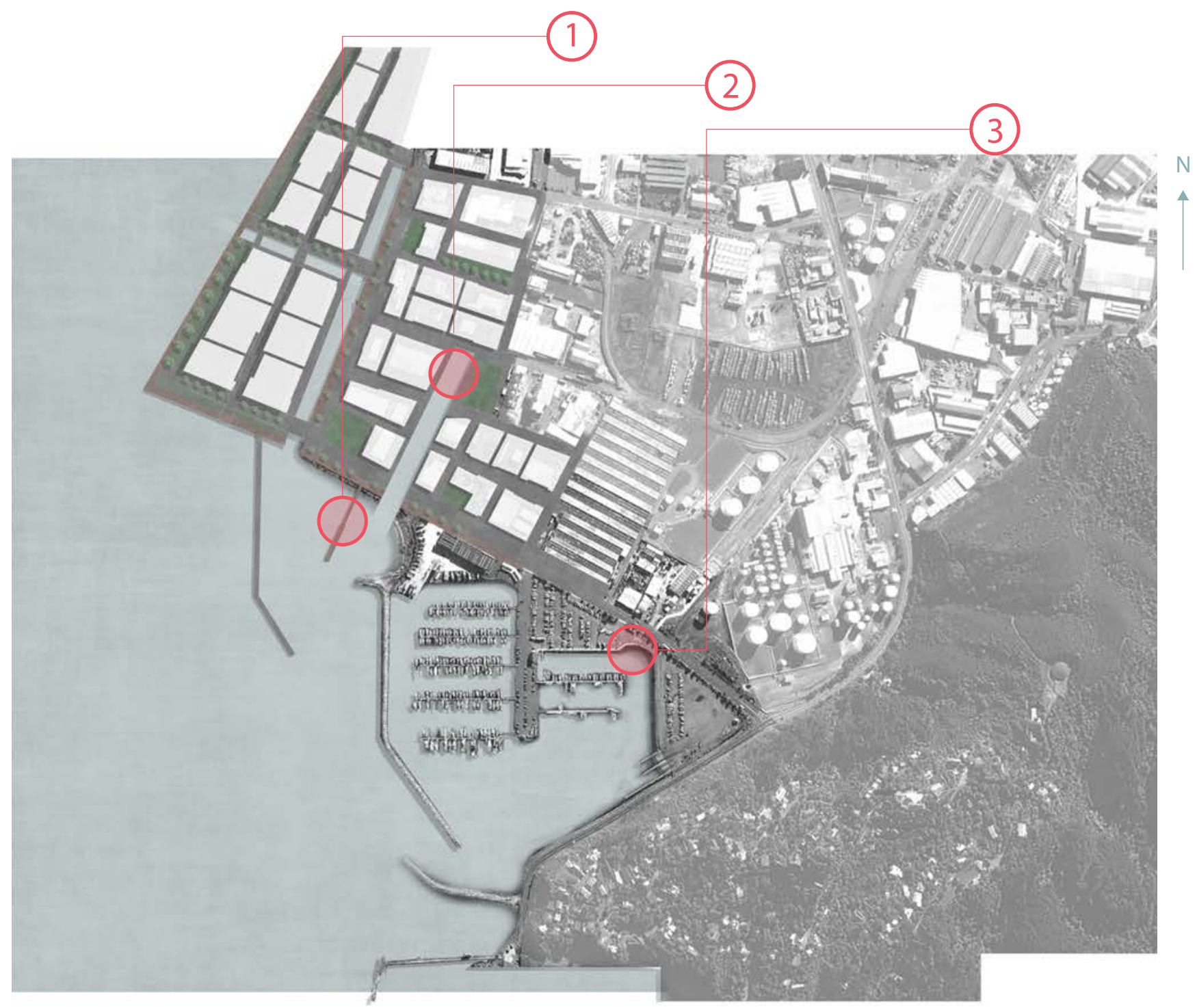

Figure 9.2.7 (Above)__ Plan looking at potential ferry locations. (Authors own image). 


\subsection{5_ Proposed site atmosphere}

This collection images starts to portray the proposed atmosphere for the development. They incorporate water into the design as a key design driver. This is an important aspect of Seaview. The water provides way finding and a way of structuring the design.

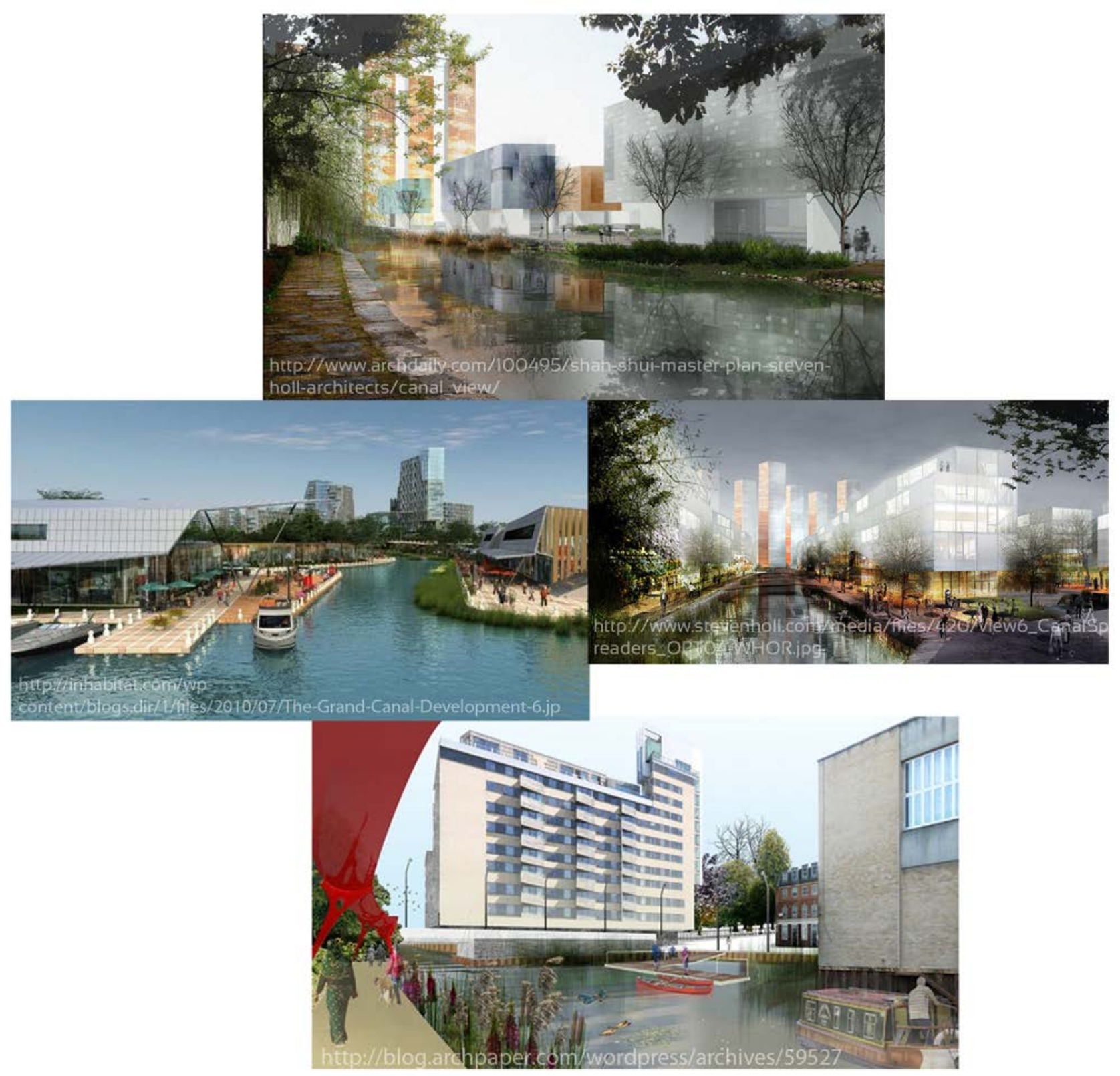

Figure 9.2.8 (Above)_ Collage of potential atmosphere of the development. (All sources supplied on the images). 
9.3_ Design Detail

9.3.1_ Plan

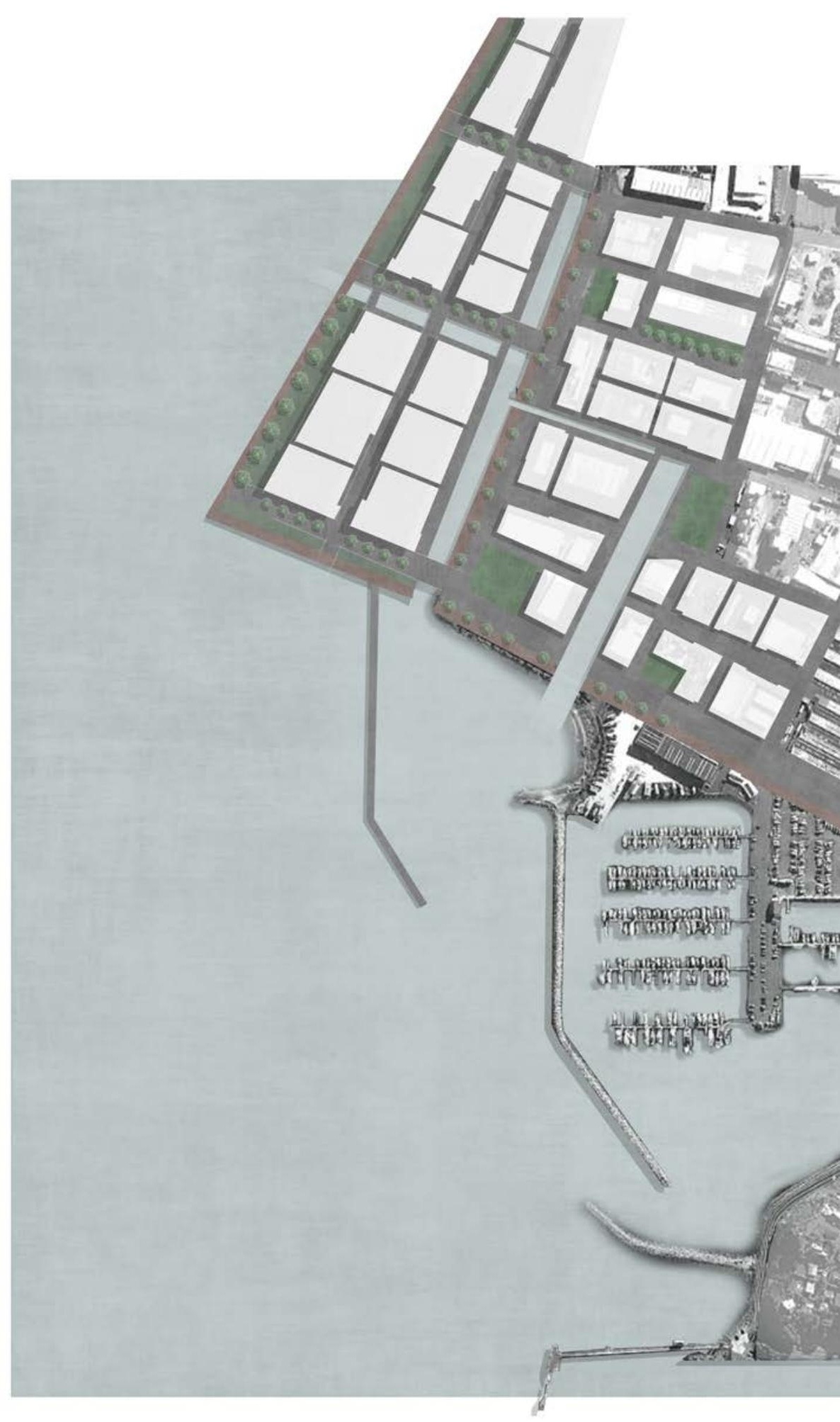




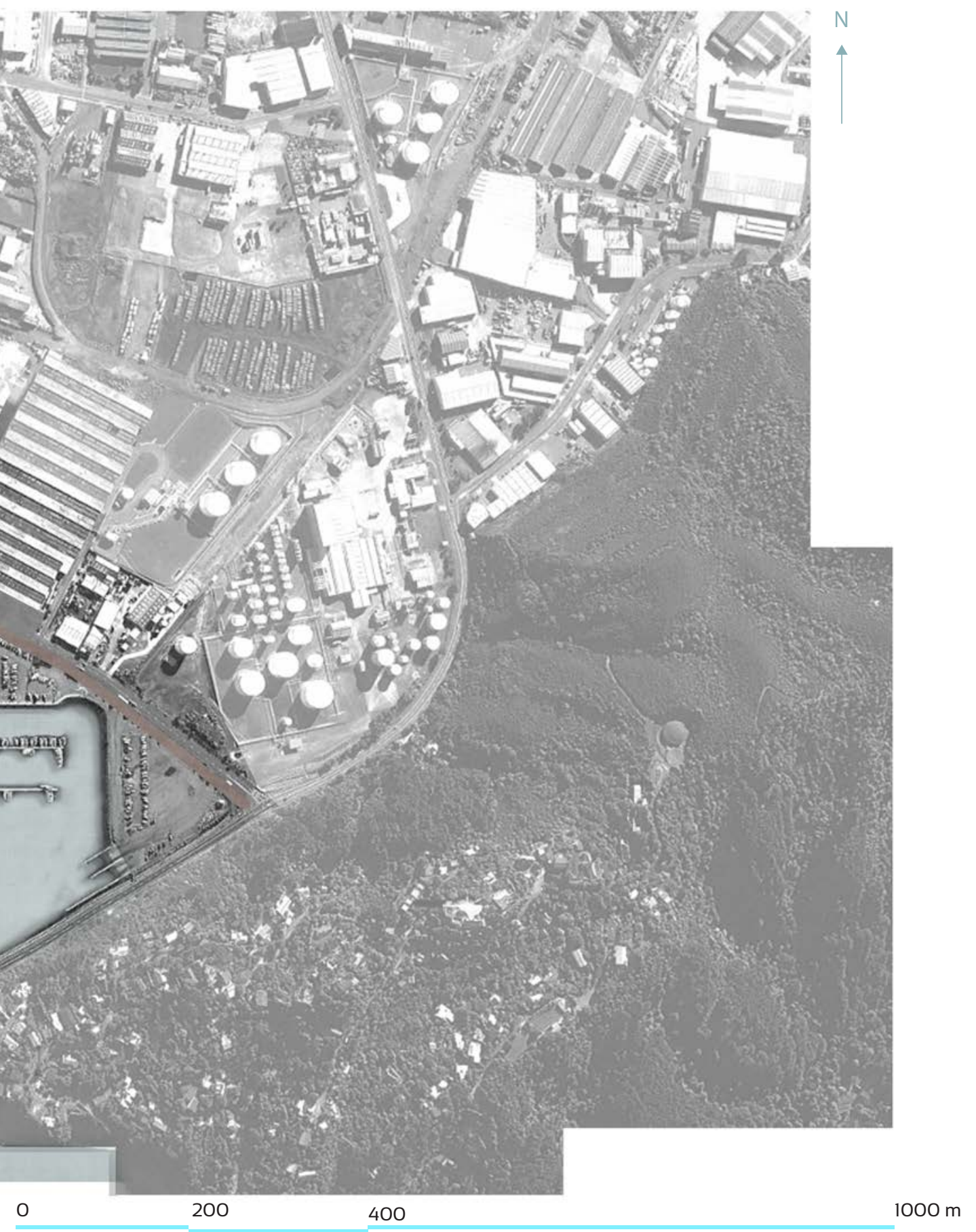

Figure 9.3.1 (Above)_ Detail plan of final design. (Authors own image). 


\subsection{2_ Ferry terminal location}

The ferry should be integrated into the design of the development in Seaview. This opens the opportunity to bring the ferry right into the centre of the space so that it becomes an integral part of the layout and way finding in Seaview.

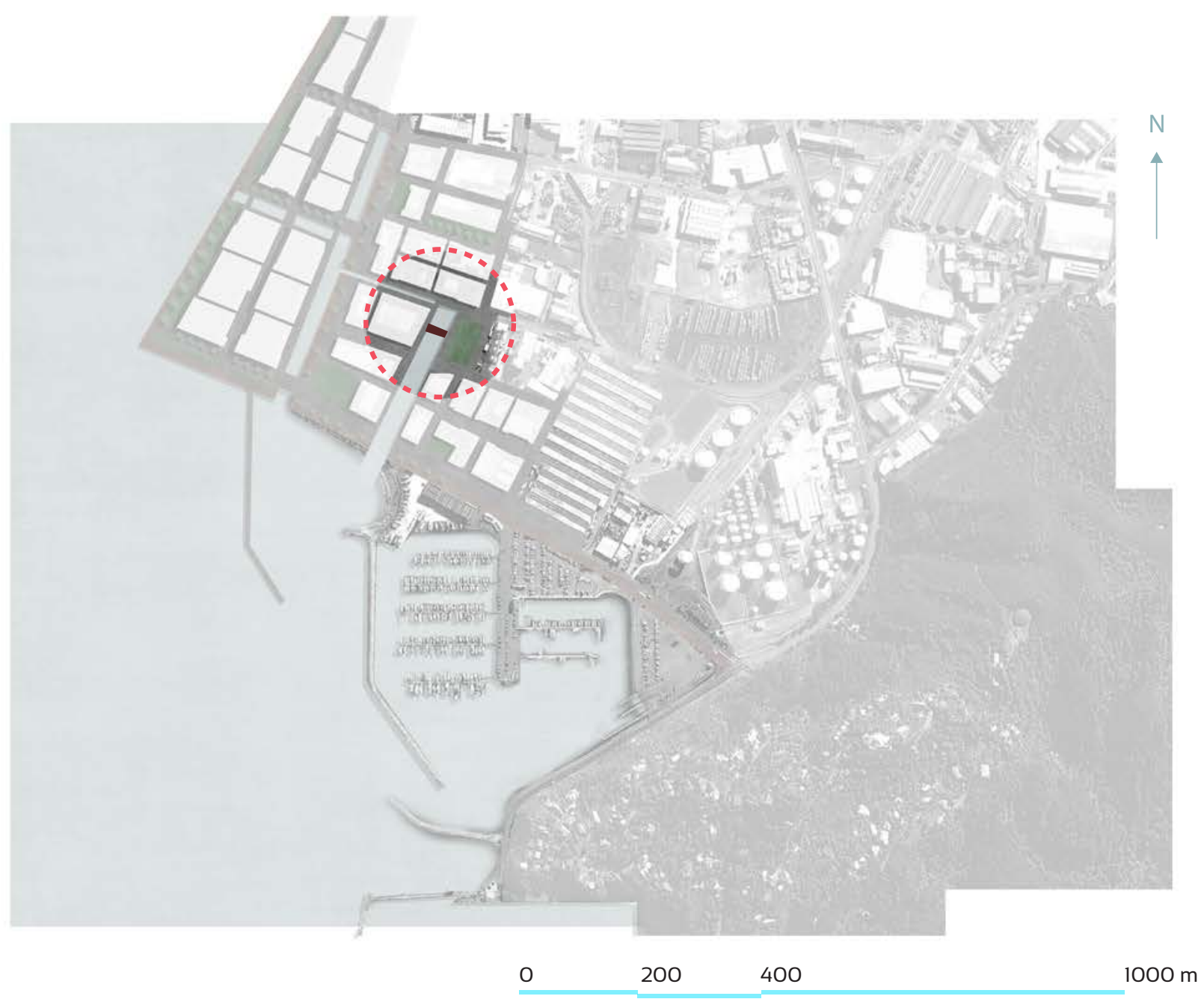

Figure 9.3.2 (Above)_ Location map for the ferry terminal. (Authors own image).

The ferry terminal itself has been designed to become part of the city fabric. The design has become part of the movement stream, allowing people to move across the canal. By bringing the ferry right into the city centre the inhabitants of Seaview become familiar with the ferry as a mode of transport and it increases the chance of people using the ferry. The ferry becomes a daily ritual as it is coming in at the same time every day. 
The terminal also adds to the public space, creating an area that is safe for people to swim and play in. The ferry terminal supports the associated public space and built plug-ins begin to activate the space. This allows the ferry site to become the main hub of activity in Seaview.

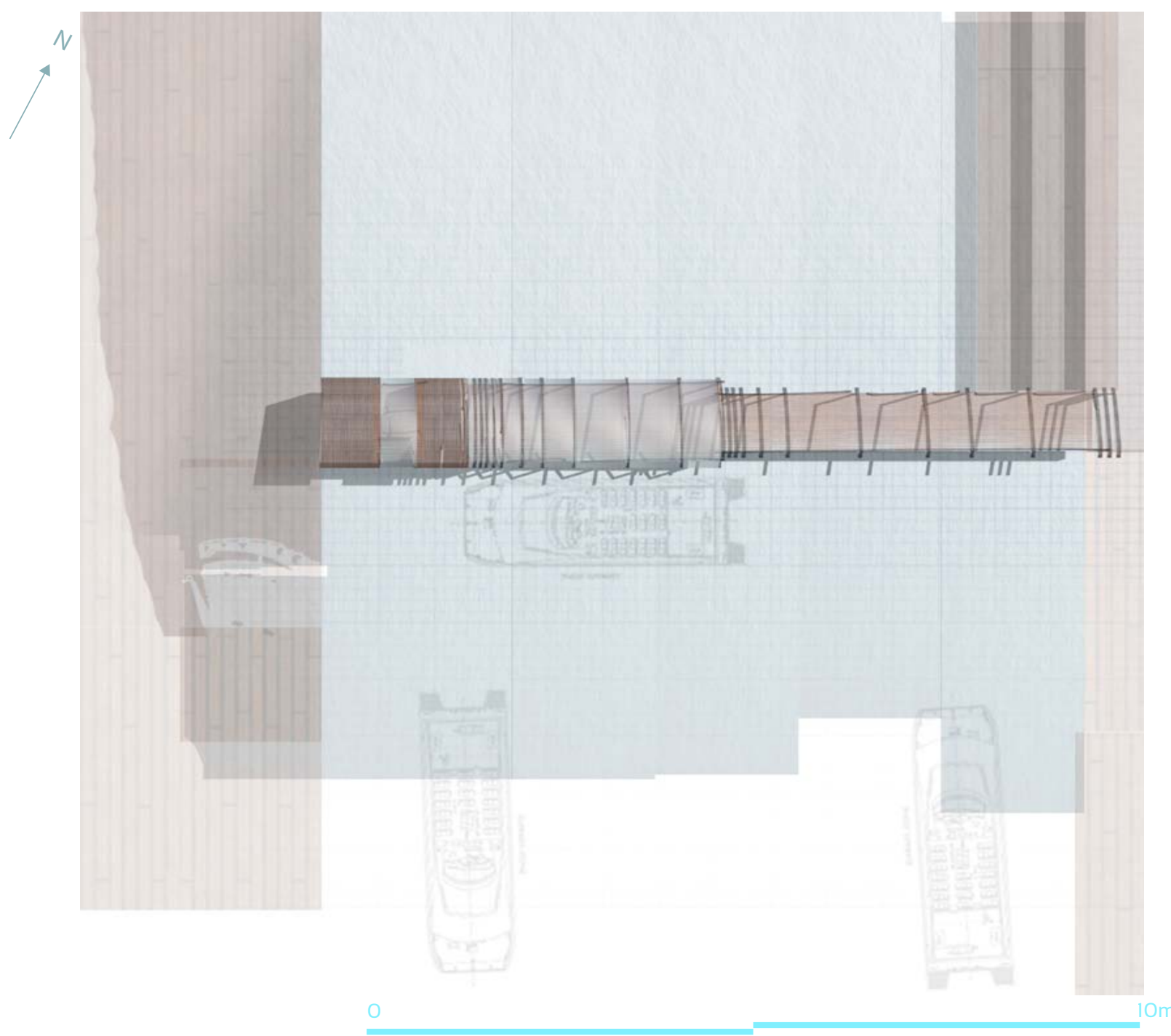

Figure 9.3.3 (Above)_ Detail plan of the ferry terminal. (Authors own images).

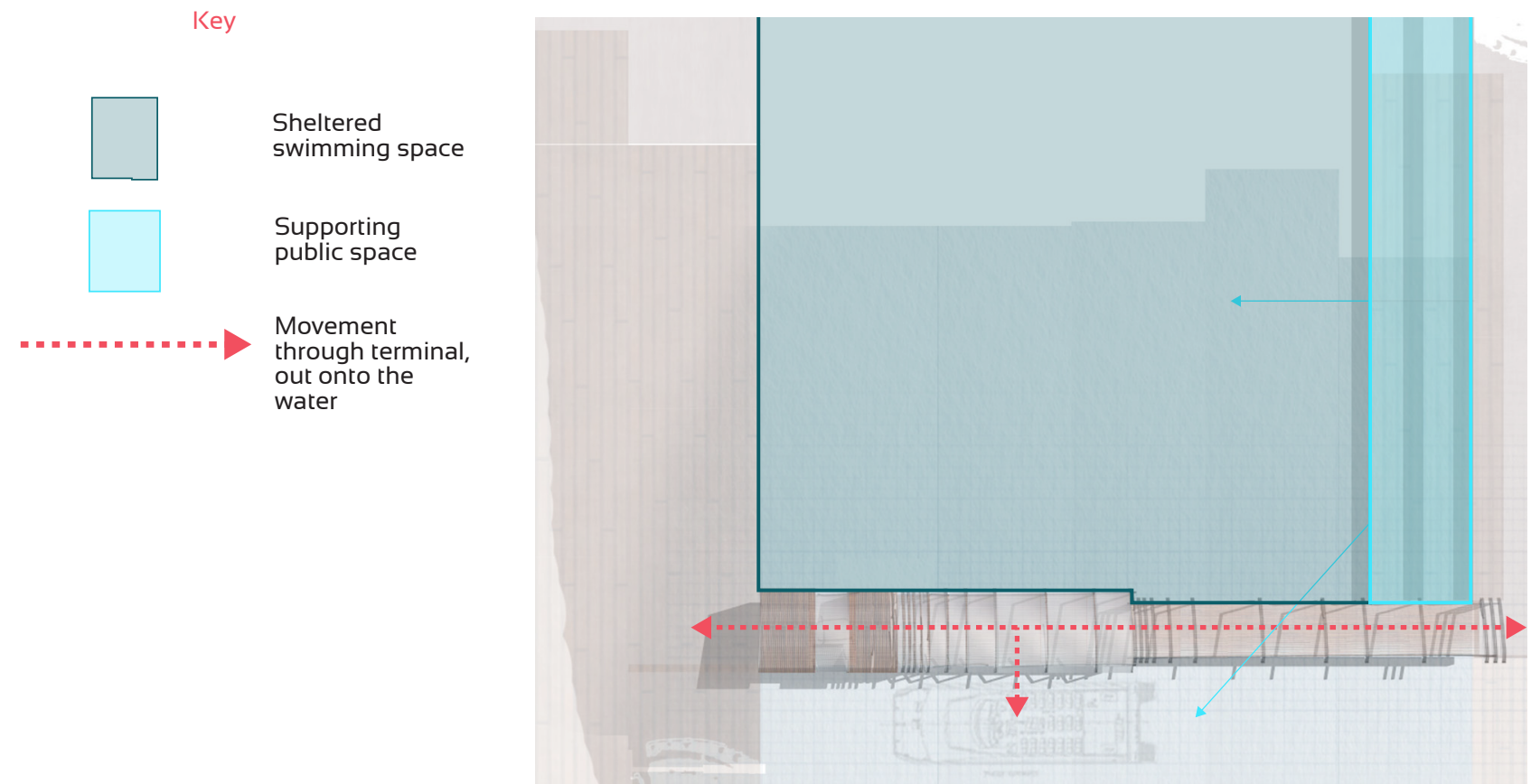

Figure 9.3.4 (Above)_ Diagram of the ferry terminal and the key aspects of the design. (Authors own images). 


\subsection{3_ Waterfront edge}

The harbour edge should be kept open for recreation and pedestrian access. Built form should have public space interaction to enhance the space. There is the opportunity for the development to link into the rest of the harbour edge as a waterfront walkway that connects the entire harbour.

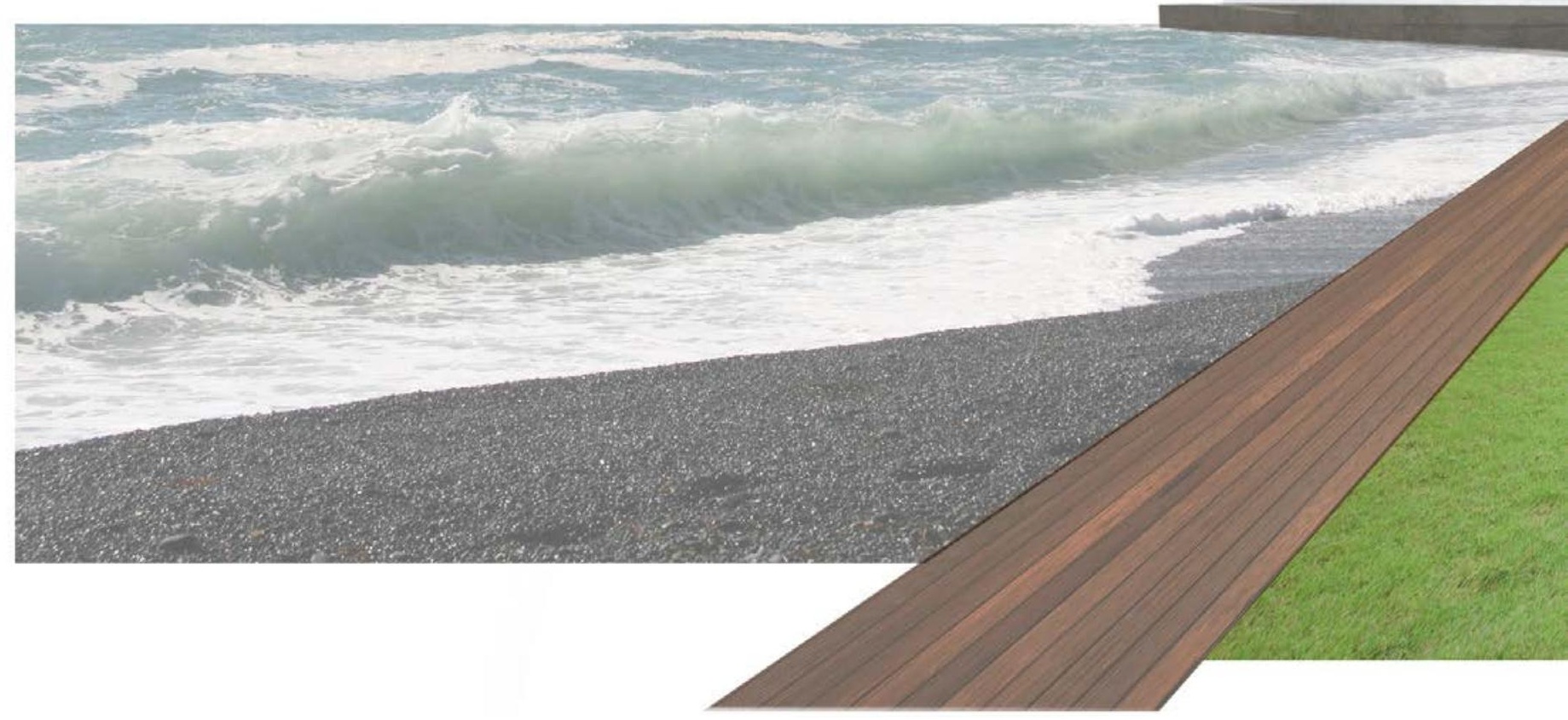



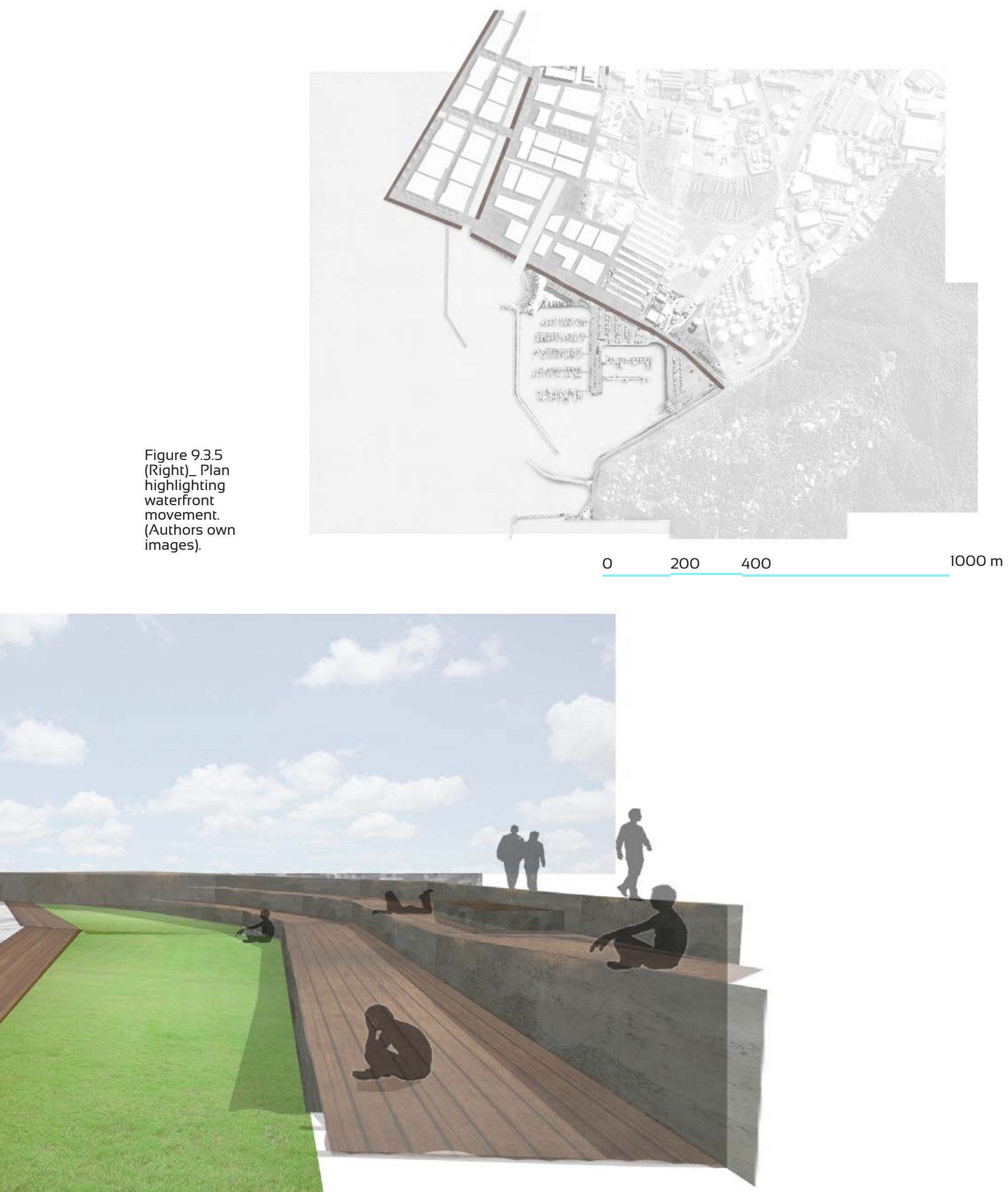

Figure 9.3.6 (Above)__Perspective looking at the quality of space that would allow people to interact with the water. (Authors own image). 


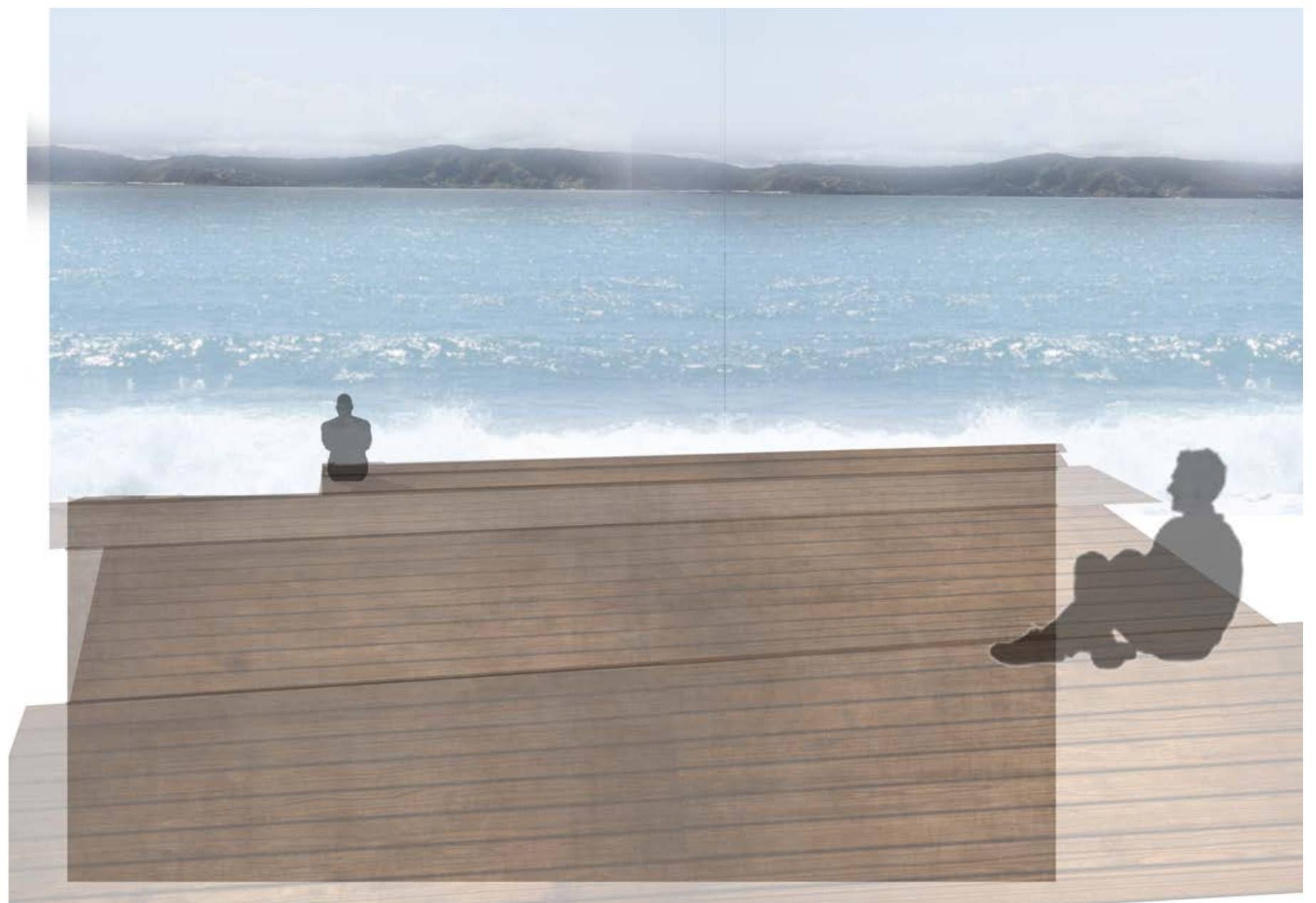

Figure 9.3.7 (Above)__Perspective looking at the terracing down to the water along the harbour edge. (Authors own image). 


\subsection{4_ Block permiability}

The permeability of the blocks is essential to allowing movement down to the waterfront. Large blocks that remove access to the water have been made accessible with lane ways and streets connecting the development. This will encourage walking and will enhance the street life.

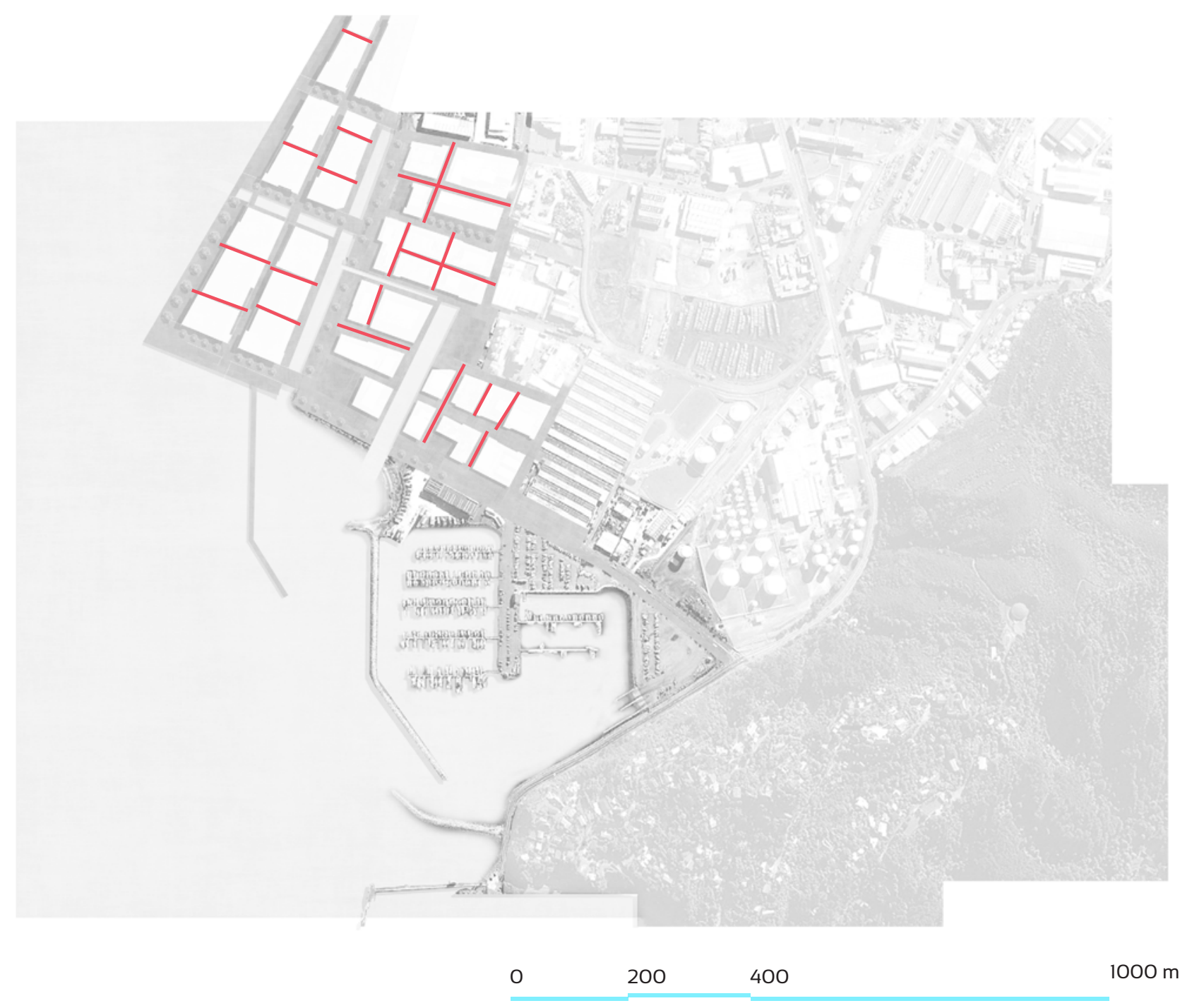

Figure 9.3.8 (Above)_ Diagram of block permeability. (Authors own images). 
\begin{tabular}{l|l} 
_10 & Discussion \\
\hline &
\end{tabular} 


\section{1_ Introduction}

The aim of this research project is to demonstrate that through landscape architecture, transport infrastructure has the potential to generate public life. Throughout the development of this design led research project, a series of discoveries have been made that make a contribution to the disciplines understanding of transport infrastructure. This design has established that;

- $\quad$ Understanding what happens on the ground affects the design process

Understanding how ferry infrastructure affects space around it allows for a design process that amplifies public life

Functional aspects of infrastructure are essential to the viability of the system

Finally, this design not only changes the way Wellingtons transport network functions but re-establishes Wellingtons relationship with the waterfront 


\section{2_ Understanding what happens on the ground}

It was through researching through design that this thesis reinforced the importance of understanding what physically happens on the ground. There are several theories that suggest ways of approaching the design of transport infrastructure, yet one area that seems to be lacking is how this translates into physical space. It wasn't until after the fieldwork that this thesis began to really engage with ferry infrastructure. A series of discoveries were made, in the form of design strategies that allowed for the manipulation of ferry-associated public life.

The way in which landscape theory translates into designed space can often be a problem. When dealing with large projects that are designed to change and develop over time it can be difficult to come up with concrete solutions. Fieldwork was a tool that allowed for the project to push past these issues. It allows for an understanding of problems and potential outcomes faced in a project. The way this actually influences the design process is specific to that project. In this research project it resulted in design strategies that allowed for the manipulation of public life. In another project that has different research problems it may be different. 


\section{3_ Understanding the ferry service and associated public life}

Ferry infrastructure does affect the space around it. The fieldwork on existing ferry sites indicated that there are public space effects associated with ferry infrastructure. By analysing Wellington Central and Days Bays ferry terminals it was found that the interaction between ferries and public space can be manipulated by design. The fieldwork was done on sites where the public life was an unintentional product of the transport infrastructure. This thesis argued that by understanding unintentional effects of transport infrastructure, and designing for them in a purposeful way, public life will be enhanced.

Having investigated the spatial effects of ferry infrastructure, the design process was strengthened. As the aim of this thesis was to use transport infrastructure to generate public life the initial understanding of ferry infrastructure was important for the success of the project. It was established that there are in fact public life effects, and the design principles developed allowed those effects to be manipulated. This took the design process from being a random design process to a design process that specifically dealt with public life.

The aim of the design research was to see if transport infrastructure could be designed in a way that amplifies public life. The findings indicate that ferry infrastructure does in fact have the potential to enhance public life on the waters edge. One key part of the design process that influenced this was giving less tangible things such as public life and quality of public space, the same importance as tangible things, which include functional aspects that can be easily measured. 


\section{4_ Functionality increases Viability}

The initial approach to this design research was to discard functional aspects and just look at the other less tangible aspect of transport infrastructure. Through talking to ferry owners and operators it became clear that this just wasn't possible. The technical aspect of transport infrastructure is paramount to attracting people to use the system. Functionality in the transport system isn't mutually exclusive of public life, but rather enhances it. By increasing the people using the system purely as a mode of transport the pulse of movement increases and offers other opportunities. Circular Quay provided an example of this in the case studies. The public transport system there works very well from a technical point of view and that affects the atmosphere of the public space. The public space itself isn't the only important part of the site. If the transport system wasn't so efficient the public life would be affected.

This finding really affected the design process as it changed the scope of the project. Functionality in the transport system was used as a tool for increasing public life. Often a transport system is designed in a technical manner and then that is the end of the design process. This thesis argues that once the design of the system is understood then the design of the public life can be enhanced. The quantitive and qualitive aspects of the transport system have equal importance in the overall experience of the transport system. 


\section{5_ Harbour relationship}

Wellington is situated in a unique location that has the potential to become part of the identity of the city. The proposed design would increase the connection to the harbour and surrounding context. It would provide an important amenity to the way the city functions, as it has done historically, and could release some of the tension placed on an already struggling transport system. This would allow the ferry infrastructure to become more than just a transport system but a part of the identity of Wellington.

The airport ferry and Wellington Central ferry are the sites that could really influence the way Wellington is perceived. Visitors to Wellington would be introduced to the city from the sea, instantly making a connection between the two. This elevates the transport system from a way of moving people around the system to an important aspect of life in Wellington.

This thesis argued that transport systems can be more than just ways of getting people from one place to another. Through the design process it became clear that this could be more than just a transport system. It could create identity, facilitate development, and enrich public life.

\section{6_ Further research}

There are several branches of research that could further expand upon the work done in this thesis. These were either not investigated because of time restrictions or that they fell outside the scope of this research project.

Public interaction with the project could provide feedback on the design from a local point of view. This could allow for further engagement of existing public life and insight into public views of the ferry. Surveys could also help gauge interest in further development. This would allow for a knowledge of numbers of interested people, which could influence ferry numbers, waiting times, and terminal phasing.

There was limited research into the cost of this project. Analysis of construction costs would allow for feasibility studies that focus on the economic viability of the design. 
_11 Conclusion 
In conclusion, this research has explored ways in which the design of transport infrastructure can enhance public life in Wellington. The test site was Wellington harbour and the surrounding harbour edge. This research is specific to the development of ferry infrastructure, although a similar approach could be taken with other modes of transport. The design method that generated this research could provide a process for the design of other ferry systems in harbour side cities globally.

This design research has investigated landscape architectural approaches to the design of transport infrastructure and has attempted to shift the way it is designed to focus on its public life generating abilities. This research has established discipline tendencies through the review of relevant theory and case studies. Design strategies have been developed from fieldwork that indicates ways of designing that will manipulate public life. The method chosen for this research was developed to engage with public life that is associated with transport infrastructure. Through the design of the system, and the design of individual sites this thesis has developed a technically functional transport system that affects the public life on the harbour edge. Whilst the discipline tendency seems to focus on technical aspects of transport infrastructure, this project addresses quantitive and qualitive aspects associated with the implementation of a ferry network.

This ferry system and associated spaces are designed specifically for Wellington Harbour. Fieldwork was undertaken on existing Wellington sites so the findings from that also have a degree of site specificity. This project adds to the discipline knowledge as the method that produced the design results could be utilised in the design of a ferry network globally. This is a field that has traditionally been dominated by other disciplines yet recently landscape architecture has gained more authority over the design of this infrastructure.

As a whole this thesis has developed and refined an approach to the design of ferry infrastructure that gives importance to the public life and place making ability associated with that infrastructure. This allows the transport system to move past the functionality of moving people around the system and gives it the power to change the way the city operates and functions in a qualitive manner. 


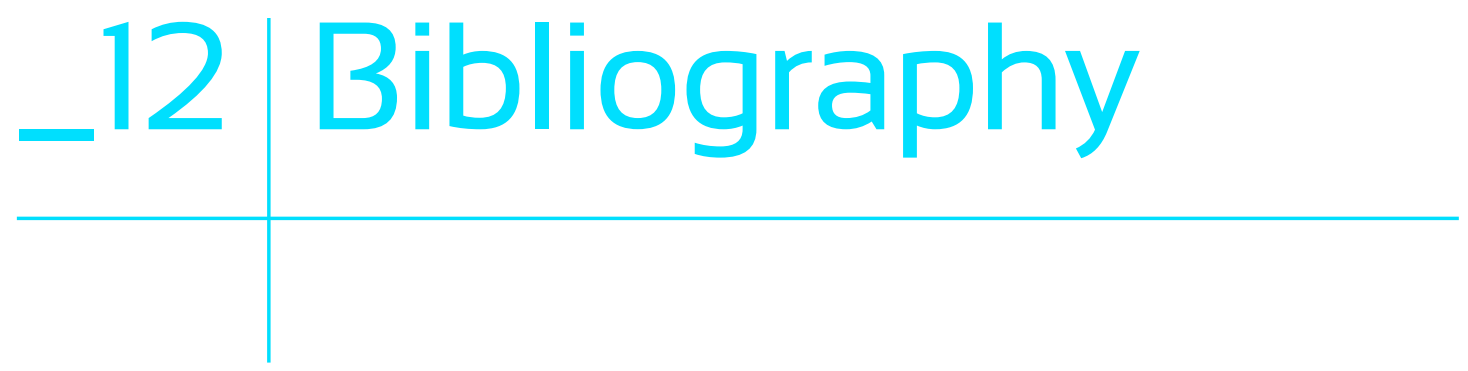

Anonymous. (1999). Integrated Sydney Ferry Services. International Cruise \& Ferry Review.

Beardsley, J. (2008). Urban Acupuncture Caracas. Harvard Design Magazine', 38

Department of Transportation. (n.d.). Transit-Orientated Development Retrieved 112,2014 from Maryland Department of Transportation: http://www.mdot.maryland.gov/Office_of_Planning_ and_Capital_Programming/TOD/TOD_Homepage.html

Curtis, C (2005). Spatial Planning Urban Form and Sustainable Transport. (K.' Williams, Ed.) Hampshire, England: Ashgate Publishing Limited.

Casagrande, M. (2012). Biourban Acupuncture. (A. Abbate, Ed.) Italy: International Society of Biourbanism.

CentrePort. $(2013,3$ 12). Centreport continues its big ship agenda. Retrieved 12 8, 2013 from CentrePort Wellington: http://www. centreportoperations.co.nz/latest-news/centreport-continues-its-bigship-agenda

Chrofi. (n.d.). Parramatta Road Strategic Plan. Retrieved 1 3, 2014 from Chrofi: http://www.chrofi.com/project/parramatta-road-strategicplan

Corner, J. (2006). Terra Fluxus. In C. Waldheim, The Landscape Urbanism Reader. New York City, USA: Princeton Architectural Press.

Gastil, R. W. (2002). Beyond the edge. (N. Later, Ed.) New York, USA: Princetón Architectural Press. 
Gehl, J. (2004). Public Spaces and Public Life Study 2004. Wellington City Councit.

Greater Wellington Regional Council. (2011, 11 7). Centreport rofit benefits the region. Retrieved 1015,2013 from Creater Wellington Regional Council: http://www.gw.govt.nz/centreport-profit-benefits-theregion/).

Hutt City Council. (2007). Demographic Profile for the city of Lower Hutt. Hutt City Council.

Klumpner, A. B. (n.d.). Build Simply: South of the Border. Retrieved 1 3, 2014 from Más Context: (http://www.mascontext.com/tag/urbanthink-tank/).

Ministry for Culture and Heritage. (2014 122). 1840 First European settlers arrive in Wellington. Retrieved 21,2014 from New Zealand history online: http://www.nzhistory.net.nz/wellington-anniversary-day

NZ Transport Agency. (n.d.). Terrace Tunnel duplication. Retrieved 9 17, 2013 from NZ Transport Ágency: http://www.nzta.govt.nz/network/ projects/project.html?ID=107

NZ Transport Agency. (n.d.). Transmission Gully Project. Retrieved 1 6, 2014 from NZ Transport Ágency: http://www.nzta.govt.nz/network/ projects/project.html?ID=36

Qian, C. S. (2011). Urban Acupuncture Strategy in the Urban Renewal. Wuhan University, Department of architecture. Wuhan: Wuhan University.

Richards, B. (1990). Transport in Cities. London: Architectire Design and Technology Press.

Singer, J. A. (n.d.). Acupuncture, A Brief Introduction. Retrieved 12 15, 2013 from Acupuncture.com: http://acupuncture.com/education/ theory/acuintro.html 
Statistics New Zealand. (2007). Quickstats about Lower Hutt City. Retrieved 1015,2013 from Statistics New Zealand: http://www.stats. govt.nz/Census/20O6CensusHomePage/QuickStats/AboutAPlace/ snapShot.aspx?

Stupar, A. a. (2009). The New Urban Acupuncture: Intermodal Nodes between Theory and Practice. Reviewed paper, Unniversity of Belgrade, Belgrade.

Tourism New Zealand. (n.d.). Wellingtons early maori heritage. Retrieved 11 3, 2013 from Media resources: http://www.newzealand. com/travel/media/features/maori-culture/maori-culture_wellingtonsmaori-history.cfm

Ideas

Urban Taskforce Australia. (2012, June). Urban Ideas. Urban

Urban Think Tank Studio. (n.d.). Metro Cable. Retrieved 1 4, 2014 from Urban-think tank: http://u-tt.com/projects_Metrocable.html

Waldheim, C. (2006). Urbanism, Landscape as. In C. Waldheim, The Landscape Úrbanism Reader. N'ew York City, USA: Princeton Architectural Press.

Wellington Airport. (2010). 2030 The Masterplan. Wellington.

Wellington Airport. (n.d.). Questions on extending the runway. Retrieved 9 12, 2013 from Wellington Airport: http://www. wellingtonairport.co.nz/about/questions-on-extending-the-runway/

Wren, D. M. (1983). Urban Waterfront Development. Washington D.C., USA: the Urban Land Institute. 